\title{
Untersuchung der Pupille und der Irisbewegungen beim Menschen.
}

\author{
Von \\ Karl Weiler. \\ Mit 39 Textfiguren und 3 Tafeln. \\ (Eingegangen am 25. Juni 1910.) \\ Inhaltsübersicht:
}

Einleitung (S. 103).

I. Technik der Pupillenuntersuchung (S. 105).

A. Untersuchung ohne Vergrößerungs- oder Meßapparate (S. 105).

1. Lichtreaktion (S. 106).

2. Hemiopische Lichtreaktion (S. 108).

3. Paradoxe Lichtreaktion (S. 109).

4. Konvergenz- und Akkommodationsreaktion (S. 110).

5. Lidschlußreaktion (S. 110).

B. Untersuchung mit Vergrößerungsapparaten (S. 111).

I. Psychische und sensible Reflexe (S. 111).

2. Der Hirnrindenreflex (S. 112).

C. Untersuchung mit Meßapparaten (S. 112).

1. Apparate zur Bestimmung der Pupillengröße (S. 113).

a) Vergleichspupillometer (S. 114).

b) Tangentiale Pupillometer (S. 114).

c) Pupillometer mit Doppelbilderprinzip (S. 116).

d) Pupillenmessung unter Zuhilfenahme entoptischer Wahrnehmungen (S. 116).

e) Projektionspupillometer (S. 118).

f) Photographie der Pupille (S. 119).

D. Zeitberechnung der Pupillenreaktionen (S. 121).

E. Vorbedingungen einer exakten Pupillenuntersuchung (S. 125).

II. Eigene Methodik (S. 127).

A. Der Beleuchtungsapparat (S. 130).

B. Der Beobachtungs- und Meßapparat (S. 135).

C. Apparat zur Messung der Konvergenzbewegung (S. 137).

D. Apparate zur Messung des zeitlichen Ablaufs der Pupillenbewegungen (S. 138).

E. Apparat zur Photographie der Pupillen (S. 143).

III. Untersuchungen bei Gesunden (S. 147).

A. Physiologische Vorbemerkungen (S. 147).

B. Allgemeine Versuchsanordnung (S. 151).

C. Die Pupillenweite (S. 153).

D. Die Pupille verkleinernde Irisbewegungen (S. 161).

1. Der Lichtreflex (S. 161).

Z. f. d. g. Neur. u. Psych. O. II. 
a) Latenz- und Kontraktionszeit des Sphincter (S. 161).

b) Größe der Reflexbewegung (S. 164.)

c) Verlauf der Reflexbewegung (S. 168).

Anhang: Der galvanische Lichtreflex (S. 169).

1. Die Konvergenzreaktion (S. 170).

3. Die Lidschlußreaktion (S. 172).

E. Die Pupille erweiternde Irisbewegungen (S. 173).

1. Erweiterung der Pupille bei Sympathicuserregung (S. 173).

2. Erweiterung der Pupille, hauptsächlich durch Hemmung des Sphinctertonus veranlaßt (S. 174).

3. Zweck der reflektorischen Pupillenerweiterung (S. 180).

Anhang: Der Hirnrindenreflex (S. 181).

F. Die Pupille des schlafenden Menschen (S. 182).

G. Die Pupille im Tode (S. 186).

IV. Untersuchungen bei Kranken (S. 187).

A. Veränderungen der die Pupille verkleinernden Irisbewegungen (S. 188).

1. Störungen im zentripetalen Abschnitt der Verengerungsbahn (S. 188).

a) Reflextaubheit (S. 188).

b) Hemianopische Reflextaubheit (S. 191).

c) Vorkommen der Reflextaubheit (S. 193).

2. Die reflektorische Pupillenstarre (S. 194).

a) Häufig vorkommende Begleiterscheinungen der reflektorischen Starre (S. 195).

๙) Miosis (S. 195).

"в) Mydriasis (S. 198).

y) Anisokorie (S. 199).

d) Lidschlußreaktion (S. 201).

ह) Störungen der Erweiterungsreaktionen (S. 201).

b) Vorläufer der reflektorischen Starre (S. 202).

๙) Verringerung der Ausgiebigkeit der Irisbewegung bei Belichtung (S. 202).

p) Verlangsamtes Eintreten der Lichtreaktion (S. 204).

r) Schnelles Nachlassen des Iristonus (S. 205).

d) Fehlen der sekundären Reaktion (S. 206).

c) Einseitige reflektorische Starre (S. 207).

d) Das Wesen der reflektorischen Starre (S. 209).

e) Vorkommen der reflektorischen Starre (S. 212).

3. Störungen im zentrifugalen Abschnitt der Verengerungsbahn (S. 215).

a) Absolute Pupillenstarre (S. 217).

๙) Absolute Starre als Lähmungserscheinung (S. 217).

B) Absolute Starre als Reizerscheinung (S. 220).

B. Veränderungen der die Pupille vergrößernden Irisbewegungen (S. 225).

1. Störungen der Sympathicusinnervation (S. 225).

2. Störungen der hauptsächlich durch Hemmung der Sphincterinnervation bedingten Irisbewegungen (S. 226).

a) Fehlen bzw. starke Herabsetzung der Erweiterungsreaktion (S. 227).

b) Verstärkung der Erweiterungsreaktionen (S. 231).

C. Veränderungen der Pupillenweite und Pupillenform (S. 233).

V. Pupillenstörungen bei verschiedenen Giftwirkungen und bei einigen Erkrankungen des Zentralnervensystems (S. 241).

A. Pupillenstörungen bei verschiedenen Giftwirkungen (S. 242).

1. Pupillenreagenzien (S. 242). 
a) Mydriatica (S. 242).

b) Miotica (S. 243).

2. Pupillenveränderungen durch dem Körper zugeführte Gifte (S. 244).

a) Alkohol (S. 244).

b) Nicotin (S. 248).

c) Morphium, Opium (S. 248).

3. Beeinflussung der Pupille durch im menschlichen Organismus erzengte Gifte (S. 249).

B. Veränderungen der Pupille und der Irisbewegungen bei verschiedenen Erkrankungen des Zentralnervensystems (S. 251).

1. Paralyse (S. 251).

2. Syphilis (S. 257).

3. Dementia praecox (S. 260).

4. Manisch-depressives Irresein (S. 267).

5. Psychopathie, Hysterie und Epilepsie (S. 268).

6. Chronischer Alkoholismus (S. 270).

Nach der Anschauung der Alten verließ der Sehstrahl das Auge durch die Pupille, tastete die Gegenstände ab und brachte so dem Menschen Kunde von der Außenwelt. Es kann uns daher nicht wundern, wenn wir schon frühzeitig auf Bemühungen stoßen, die darauf hinzielen, Beziehungen zwischen Sehschärfe und Pupillengröße, zwischen Krankheiten und damit einhergehenden Veränderungen der Iris und des Sehlochs festzustellen. So finden wir bei Hippokrates folgende Stelle $\left.{ }^{1}\right)$ : „Wird die Pupille hellblau oder silbergrau oder dunkelblau, so ist sie nicht mehr brauchbar zum Sehen. Ein wenig besser ist die, welche verkleinert erscheint oder vergrößert oder winklig, sei es aus bestimmter Veranlassung, sei es von selber." Während Hippokrates diese Beobachtungen praktisch nicht weiter verwertete, zog Galen aus ihnen schon die Nutzanwendung. Bei ihm lesen wir: „Darum geschieht es, daß, wenn wir das eine Auge schließen, die Pupille des anderen sich erweitert, da in das eine jetzt allein die Innervation eindringt, welche vorher sich auf beide verteilte. Deshalb erkennt man auch bei den Starkranken, ob sie sehen werden nach dem Stich und dem Niederdrücken des Stars oder nicht, hauptsächlich durch dieses Zeichen. Denn diejenigen, bei denen die Pupille sich erweitert nach Verschluß des anderen Auges, haben Aussicht, nach dem Starstich wieder zu sehen. Aber von denen, bei welchen die genannte Pupillenerweiterung nicht eintritt, hat noch nie einer die Sehkraft wieder erlangt." Diese Bemerkung des Galen legt ein gutes Zeugnis ab für die Beobachtungsgabe der Ärzte des Altertums, denen die äußerst geringe Frweiterung der Pupille eines Auges beim Verschließen des anderen nicht entging. Die Begründung dieser Erweiterung mag zwar auf den ersten Blick unverständlich erscheinen,

1) Hirschberg, J., Geschichte der Augenheilkunde. Graefe-Sämischs Handbuch der gesamten Augenheilkunde XII. 
da nach unserem heutigen Wissen die stärkere Innervation eine stärkere Verengerung der Pupille zur Folge hat; wir dürfen jedoch nicht vergessen, daß zu Zeiten Galens die Verengerung der Pupille auf Lichteinfall noch unbekannt war. An einer anderen Stelle sagt derselbe Autor: „Die Vergrößerung des Sehloches, mag sie angeboren oder später erworben sein, sie schädigt immer die Sehkraft. Die Verkleinerung aber ist, wenn sie angeboren, Bedingung des schärfsten Sehens, des schlechten, wenn erworben." Die anderen Veränderungen der Pupille, wie Verengerung und Zerreißung, hält er für belanglos. Auch diese Beobachtungen sind im großen und ganzen richtig, wenn man sich vergegenwärtigt, daß einerseits die Myopen durchschnittlich erweiterte Pupillen haben, andererseits Pupillenvergrößerung sich bei Amaurose und sonstigen schweren Schädigungen des Sehnerven einzustellen pflegt. Denkt man bei der erworbenen Verengerung an den presbyopischen Greis, so ist auch hier die Beobachtung zutreffend; die Pupillenverengerung ist zwar nicht Ursache des schlechteren Sehens, geht aber doch mit den Linsenveränderungen Hand in Hand.

Die ersten Angaben über die Pupillenverengerung bei Lichteinfall ins Auge machte ar-Razì, ein arabischer Arzt, der vom Jahre 850-92.3 unserer Zeitrechnung lebte und in seinem Kitāb al-hāwì eine Realenzyklopädie der Heilkunde schrieb. Er verfaßte eine besondere Abhandlung darüber, ,weshalb die Pupillen im Licht sich verengern und in der Dunkelheit sich erweitern". Die Tatsache also, daß das Menschenauge auf Lichteinfall durch Veränderung der Pupille sichtbar reagiert, blieb jahrhundertelang unbeachtet, und doch hätte sie, wie Hirsch berg treffend sagt, der erste denkende Mensch bei jeder Abenddämmerung am Auge seiner Gefährtin entdecken müssen.

Die Kenntnis von der Verengerung der Pupillen bei Lichteinfall fand bei den Arabern bald praktische Verwertung. A mmas, ein arabischer Augenarzt, der um das Jahr 1000 unserer Zeitrechnung lebte, sagt: ,Siehe, bei dem guten Star sieht der Behaftete den Strahl der Sonne. Siehe, die Pupille erweitert und verengt sich, sie erweitert sich im Finstern und wird eng im Licht." Die Anteilnahme, welche die Alten den Pupillenerscheinungen entgegenbrachten, fand auch im Mittelalter weitere Pflege, jedoch war es erst der jüngeren Zeit vorbehalten, die wichtigsten hierher gehörenden Erscheinungen klar zu erfassen und zu verwerten. Wenn wir heute nie versäumen werden, bei Nerven- und Geisteskranken die Licht- und Konvergenzreaktion der Pupillen zu prïfen und imstande sind, aus dem Ausfall dieser Untersuchung wichtige, manchmal ausschlaggebende Schlüsse auf die Art der Erkrankung zu ziehen, so ist es das große Verdienst eines Argyll Robertson, Erb u. a., gezeigt zu haben, von welch hoher Bedeutung diese Prüfung ist. Später lernten wir noch die Pupille als ein äußerst feines 
Reagens auf alle psychischen und-sensiblen Vorgänge im Körper kennen, und in der allerneuesten Zeit gelang es, diese Reaktionen zur Differentialdiagnose bei Geisteskrankheiten zu verwerten.

Die Beobachtung der groben V.eränderungen und Reaktionen der Pupille stellt nun an den Untersucher und seine Technik keine allzu großen Anforderungen; gewaltig wachsen jedoch die Schwierigkeiten, wenn wir versuchen, die Pupillenerscheinungen einer genauen, exakten Beobachtung und Messung zu unterwerfen, wie wir sie sonst in der Physiologie anzuwenden gewohnt sind. Einerseits erschweren die Kleinheit des Objektes, noch mehr aber die leichte Beweglichkeit des Augapfels die Untersuchung, während andererseits die Pupille, versteckt im Bulbus, für Meßinstrumente nicht direkt zugänglich ist und solche dem Auge, wegen seiner allzu großen Empfindlichkeit gegen jeden Reiz, nicht eng genähert werden können.

Mit mehr oder weniger gutem Frfolg haben sich Forscher aller Zeiten bemüht, Methoden und Apparate zu ersinnen, um dem Problem der exakten Pupillenbeobachtung und -messung gerecht zu werden, und es soll der Zweck der folgenden Zeilen sein, zunächst eine gedrängte Ủbersicht der wichtigsten, bisher angewandten Untersuchungsarten zu geben und dann den Leser mit einer neven Methode und damit gewonnenen Untersuchungsresultaten bekannt zu machen.

\section{Technik der Pupillennntersuchung.}

\section{Untersuchung ohne Vergrößerungs- oder Meßapparate.}

Gröbcre Differenzen in der Weite der beiden Pupillen werden wir schon bei der einfachen Betrachtung feststellen können. Während früher dem Bestehen einer Anisokorie großer diagnostischer Wert beigelegt wurde, hat sich bei umfangreichen, statistischen Untersuchungen gezeigt, dal3 Pupillendifferenz auch bei gesunden Personen ein nicht sehr seltenes Vorkommnis ist. Wenn demnach diese Erscheinung für uns keine diagnostische Bedeutung mehr haben kann, so wird sie doch immerhin den Verdacht auf das Bestehen einer Nervenkrankheit erregen.

Die wertrollsten diagnostischen Aufschlüsse gibt uns bekanntlich die Untersuchung der Lichtreaktion der Pupillen, sowohl der direkten wie der konsensuellen. Gelingt es, das Vorhandensein der hemiopischen Lichtreaktion bzw. hemianopischen Lichtstarre nachzuweisen, so erhalten wir genaueren Aufschluß über den Sitz der Leitungsunterbrechung. Wie wir bei allen Pupillenuntersuchungen mit größtmöglicher Sorgsamkeit alle bekannten und denkbaren Fehlerquellen auszuschließen uns bemühen müssen, so ist ganz besondere Vorsicht bei der Feststellung einer paradoxen Lichtreaktion am Platze. Hier liegen die Verhältnisse 
noch schwieriger als sonst, wie weiter unten näher auseinandergesetzt werden soll. Wir dürfen in keinem Falle unterlassen, die Veränderungen der Pupille bei der Konvergenzbewegung und der Akkommodation zu prüfen, sollen unsere Untersuchungen überhaupt Wert haben. Achten wir dann noch auf den Lidschlußreflex, so können wir unsere Untersuchung für beendet ansehen, falls wir nicht besondere Hilfsapparate zur Verfügung haben.

Lichtreaktion. Zur Untersuchung der Lichtreaktion steht uns eine ganze Reihe von Methoden zu Gebote, die mehr oder weniger gleichwertig sind. Falls es möglich ist, die Untersuchung bei Tageslicht vorzunehmen, so können wir folgendermaßen verfahren. Wir stellen die Versuchsperson so, daß sie zum Fenster hinaus ins Freie blicken kann, und bedecken ihire beiden Augen mit den Händen. Durch Wegnehmen der einen oder andern Hand verschaffen wir dem Lichte Zutritt zur Retina und lösen den Lichtreflex aus. So bequem und einfach diese Methode ist, so leicht kann sie zu Fehlschlüssen führen, wenn wir nicht gewisse Vorsichtsmaßregeln anwenden. Die Untersuchungen Schirmers und seiner Nachfolger haben gezeigt, daß eine kurz dauernde Beschattung des Auges nicht genügt, um unter allen Umständen eine wesentliche Erweiterung der Pupillen hervorzurufen. Befand sich die Versuchsperson vorher längere Zeit im hellbeleuchteten Raume, so tritt bei Verdunkelung der I'upille die Erweiterung nur langsam ein und wird erst nach Minuten ausgiebiger. Wir kommen also bei Prüfung der Lichtreaktion nach kurz dauerndem Bedecken des Auges in die Gefahr, eine Pupille für lichtstarr zu halten, die nach längerer Verdunkelung eine Reaktion zeigt. Sicherer und schneller gelingt die Prüfung des Lichtreflexes, wenn man beide Augen frei läßt und nun in das zu untersuchende ein Mehr von Licht einfallen läßt. Hat man Tageslicht zur Verfügung, so kann man sich vorteilhaft eines Konkavspiegels bedienen, wie er zu Augenhintergrund- und Ohruntersuchungen angewendet wird, indem man mit seiner Hilfe reflektiertes Licht ins Auge der Versuchsperson bringt, die man mit dem Rücken gegen das Fenster gestellt hat. Statt des Tageslichtes kann man natürlich auch Kerzen-, Gas- oder clektrisches Licht benutzen. Untersuchungen mit künstlichem Licht macht man womöglich im Dunkelzimmer und verfährt dann am besten so, daß man die Lichtquelle, wie beim Augenspiegeln, neben und etwas hinter dem Kopf der Versuchsperson aufstellt. Bei dieser Methode läßt sich die Stärke des ins Auge geschickten Lichtes beliebig verändern, je nachdem man den Spiegel näher zum Auge und der Lichtquelle bringt oder davon entfernt. Will man die Retina mit möglichst starkem Licht treffen, so bedient man sich einer Konvexlinse, mit deren Hilfe man ein Büschel konzentrierter Strahlen ins Auge fallen läßt. Zu bemerken ist noch, daß man bei der Spiegelmethode sehr viel leichter die konsensuelle Reaktion

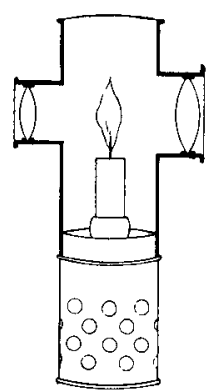

Fig. 1. prüfen kann als mit der erstbeschriebenen, da man beide Pupillen vor sich sieht und sowohl die direkte wie die konsensuelle Reaktion nebeneinander beobachten kann.

Noch bequemer und sicherer gestaltet sich die Untersuchung der Lichtreaktion, wenn man dazu eigens konstruierte Lampen benutzt. Eine brauchbare Pupillenuntersuchungslampe muß gestatten, ein nicht allzu breites Lichtbündel schnell ins Auge zu bringen. Die nebenan abgebildete Pristley-Smithsche Lampe (Fig. 1) wurde bisher viel verwendet. Man kann sie sowohl für Kerzen- wie für elektrisches Licht einrichten. Die beiderseits angebrachten Konvexlinsen haben verschiedenen Krümmungsradius und entsenden daher ein mehr oder weniger stark konvergieren- 
des Strahlenbündel. Falls die Lampe mit einer Glühbirne versehen ist, läßt sich die Lichtstärke leicht dadurch veränderbar machen, daß man einen Rheostaten in die Leitung einschaltet, ein Prinzip, das bekanntlich Sommer bei seinem Pupillenmeßapparat anwandte. Bequem und für die Prüfung der Reaktion in nicht allzu hellen Räumen genügend sind die einfachen, elektrischen Taschen. lampen, bei denen allerdings die Punktform des Lichtes insofern störend ist, als die Untersuchten zu gern darauf akkommodieren.

Wenn auch die Pristley-Lampe im allgemeinen gute Dienste tut, so birgt sie doch einige Ubelstände in sich, vor allem den, daß der Raum in der Nähe des Pat. durch sie erhellt wird, da sie dauernd brennt und das Licht an drei Stellen ungehindert austritt, ferner, daß man gewisse Vorsicht anwenden muß, damit man bei dem Belichten des einen Auges, was nur durch Drehen der Lampe geschehen kann, nicht auch das andere Auge mitbelichtet. Um diesen Utbelständen abzuhelfen, habe ich versucht,. eine bequeme Handlampe ${ }^{1}$ ) zu konstruieren. Die Fig. 2 zeigt schematisch ihre Einrichtung. Auf einem hölzernen sechseckigen Handgriff $a$ ist ein Metalltubus $b$ aufgesteckt, der eine kleine Glühlampe $c$ (10-Meterkerzen 110-220 Volt) birgt. Bei $d$ wird die Lampe mittels einer Leitungsschnur an den elektrischen Strom angeschlossen. Der Stromkreis wird durch Druck auf den Knopf $e$ geschlossen und so die Lampe zum Glühen gebracht. In der Höhe des Glühfadens ist eine Öffnung in den Tubus geschnitten, die durch die Mattscheibe $f$ ausgefüllt wird. Vor dieser steht eine plankonvexe Linse $g$, um die Länge ihrer Brennweite von der Scheibe entfernt. Glüht die Lampe, so wird die Mattscheibe erleuchtet, ihr Licht wird von der Linse aufgenommen und verläßt, da die Strahlen aus dem Brennpunkte der Linse kommen, diese als paralleles Strahlenbündel. Damit kein weiteres Licht aus der Lampe austreten kann,

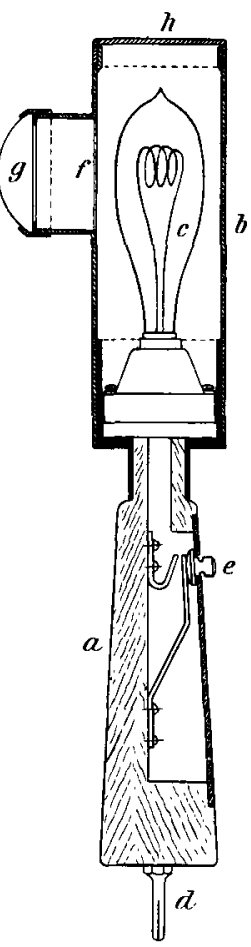

Fig. 2. ist die obere Öffnung des Tubus durch den Deckel $h$ verschlossen. Die Lampe entsendet, so lange der Druck auf den Knopf $e$ anhält, ein ca. $3 \mathrm{~cm}$ breites Bündel homogenen Lichtes, in dem keine störenden Glühfäden bemerkbar sind. Um dieses angenehme Licht auch zu anderen Zwecken nutzbar zu machen, ist noch folgende Einrichtung getroffen. Der Knopf $e$ kann durch eine leichte Schiebung festgeklemmt werden, so daß die Lampe dauernd brennt. Dabei würde die Metallhülse allerdings in kurzer Zeit glühend hei $\beta$ werden, was man jedoch durch Abnahme des Deckels $h$ vermeidet. Nun kann die Lampe sehr

1) Fabrikant: C. Stiefenhofer, München, Karlsplatz 6 . 
bequem zur Augenhintergrund- und Ohruntersuchung, besonders bei bettlägerigen Kranken, verwendet werden, indem man sie brennend auf das Kopfkissen, neben den Kopf des Kranken legt. Sie wird seit 6 Jahren in der Psych. Klinik in München zu der einfachen Pupillenuntersuchung ausschließlich verwendet und hat sich als sehr brauchbar erwiesen.

Für die Erhebung eines verwertbaren Pupillenbefundes ist es endlich noch notwendig, zu wissen, wie sich die Reaktionen bei gleich starker Belichtung verschiedener Abschnitte der Netzhaut verhalten. Exakte Untersuchungen haben gezeigt $\left.\left.{ }^{1}\right)^{2}\right), d a B$ die Erregbarkeit von der Mitte nach der Peripherie zu stetig abnimmt, so daß wir bei der Prüfung möglichst dafür sorgen müssen, daß das Zentrum der Retina von dem eindringenden Licht getroffen wird.

Hemiopische Lichtreaktion. Bedeutend schwieriger als die Untersuchung der Lichtreaktion im gewöhnlichen Sinne gestaltet sich die Untersuchung der hemiopischen Lichtreaktion bezw. die Feststellung der hemianopischen Lichtstarre. Bedingung für das Gelingen dieser Ontersuchung ist es, $\mathrm{da} B$ man über ein möglichst feines, parallelstrahliges Lichtbündel verfügt. Der Apparat von Fragstein und Kempner ${ }^{3}$ ), den die Fig. 3 wiedergibt, ermöglicht die Erzeugung eines derartigen Strahlenbündels. Das Instrument birgt in seinem Innern ein kleines Glühlämpchen, das, gespeist von einer Taschenbatterie, durch Druck auf einen Knopf zum Glühen gebracht wird. Sein Licht wird durch Linsenkombinationen in ein paralleles Strahlenbündel konzentriert, dessen Durchmesser durch mehrfach zwischengeschaltete, immer kleiner werdende Blenden auf ea. $1 \mathrm{~mm}$ reduziert ist. Das Instrumentchen ist sehr leicht und handlich, und man kann mit dem feinen Lichtstrahl die Netzhaut in jedem Bezirk abtasten. Einerseits bleibt dabei allerdings zu bedenken, daß die Medien, die der Strahl im Auge vor seinem Auf. treffen auf die Retina passieren muß, bei seinem Durchgang selbstleuchtend werden und diffuses, wenn auch sehr schwaches Licht aussenden, wodurch eine Lichtreaktion der Pupille ausgelöst werden kann. Andererseits kann man aber aus dem starken Unterschied in der Ausschlagsbreite der Pupille, je nachdem man die reflextaube oder reflexempfindliche Hälfte der Retina beleuchtet, auf das Vorhandensein hemianopischer Lichtstarre schließen.

Viel primitiver als dieser Apparat ist die von Veraguth zu demFig. 3. selben $Z_{\text {wecke angegebene Lampe }}^{4}$ ) (Fig. 4). Ihre Konstruktion ist ohne
weiteres klar. Das von ihr entsandte Strahlenbündel ist zwar bei weitem
nicht so fein und sicher begrenzt, wie bei dem vorher beschriebenen Instrumente, Fig. 3. selben $Z_{\text {wecke angegebene Lampe }}^{4}$ ) (Fig. 4). Ihre Konstruktion ist ohne
weiteres klar. Das von ihr entsandte Strahlenbündel ist zwar bei weitem
nicht so fein und sicher begrenzt, wie bei dem vorher beschriebenen Instrumente,

1) Wolff, H., Úber die Abnahme der Pupillarreflexempfindlichkeit vom Zentrum nach der Peripherie. Zeitschr. f. Augenheilk. 12, 644. 1904.

2) Hess, C., Untersuchungen über die Ausdehnung des pupillomotorisch wirksamen Bezirkes der Netzhaut und über die pupillomotorischen Aufnahmeorgane. Arch. f. Augenheilk. 58. 1907.

3) Fragstein \& Kempner, Pupillenreaktionsprüfer. Klin. Monatsbl. f. Augenheilk. 37, 243.1899.

Fabrikant: Reiniger, Gebert \& Schall, Erlangen.

4) Veraguth, O., Zur Prüfung der Lichtreaktion der Pupillen. Neurol. Centralbl. 338. 1905.

Lieferant: Zulauf \& Co., Zürich. 
jedoch bleibt nach Abnahme des konischen Tubus eine einfache Taschenlampe übrig, die zur Untersuchung der Lichtreaktion genügt, und bei der die Stärke des austretenden Lichtes durch eine zwischengeschaltete Irisblende regulierbar ist.

Paradoxe Lichtreaktion. In der Literatur finden wir eine Anzahl von Fällen beschrieben, die das höchst eigentümliche und wunderbare Phänomen der sog. paradoxen Lichtreaktion gezeigt haben sollen, d. h., die Pupillen wurden hier bei Lichteinfall weiter als zuvor, statt enger. Soviel ich sehen konnte, ist unter allen diesen Fällen kein einziger, bei dem neben der Störung der normalen Lichtreaktion (im pupillenverengernden Sinne) auch eine solche der Akkommodationsreaktion bestanden hätte, was nicht unwichtig sein dürfte. Bei der Feststellung einer wirklich paradoxen Lichtreaktion ist es jedenfalls unerläßliche Bedingung, jeglichen Reiz, von dem wir wissen, daß er die Pupille beeinflussen kann, mit absoluter Sicherheit auszuschließen; vor allem werden wir Veränderungen der Akkommodation verhindern müssen. Bekanntlich ist die Akkommodationsreaktion bei lichtstarren Pupillen vielfach viel deutlicher zu sehen als bei solchen, die normal reagieren. Während bei letzteren geringe Akkommodationsveränderungen den Eintritt und $\mathrm{Ab}$ lauf der Lichtreaktion nicht wesentlich stören, kann bei lichtstarren Pupillen auch

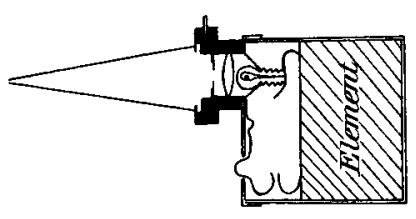

Fig. 4 . durch weniger starke Akkommodationsbewegungen eine Verengerung auf LichteinfluB vorgetäuscht werden, wie auch eine Erweiterung. Ich möchte daher nicht verfehlen, hier auf eine einfache Methode, sich vor einer Täuschung durch unbemerkt eintretende Akkommodationsänderung zu schützen, aufmerksam machen. Vor Jahren fiel mir bei der Untersuchung eines Paralytikers auf, daß bei Lichteinfall eine Erweiterung der Pupille eintrat (ich hatte damals keine Kenntnis davon, daß eine paradoxe Lichtreaktion beschrieben sei). Die Akkommodationsund Konvergenzreaktion waren gut. Als auch hinzugeholte Kollegen bestätigten, daß die Pupillen sich tatsächlich erweiterten, sobald intensives Licht ins Auge geworfen wurde, suchte ich mir das Phänomen zu erklären und vor allem eine etwa in Frage kommende Akkommodationsänderung aufzudecken und kam zu folgendem Verfahren. Ich forderte den Kranken, der ungefähr normale Sehschärfe hatte, auf, von einer mit großen Buchstaben bedruckten Tafel, die in etwa 1/2 m Entfernung aufgehängt war, den Inhalt abzulesen. Er las fließend, bis ich plötzlich das eine seiner Augen mit einer Pristley-Lampe stark belichtete. Die Pupille erweiterte sich; zugleich stockte der Kranke und las nicht mehr weiter, trotzdem er andauernd nach dem Blatte hinsah. Gefragt, warum er nicht weiterlese, sagte er, es sei ihm plötzlich alles vor den Augen verschwommen. Die Wiederholung des Experimentes hatte jedes- 
mal denselben Erfolg. Folgende Erklärung des Vorganges dürfte wohl gerechtfertigt sein. Der Kranke akkommodierte zunächst energisch auf die in nur $1 / 2 \mathrm{~m}$ Entfernung aufgehängte Tafel; als das Licht in sein Auge fiel, wurde er auf der einen Seite geblendet und stellte sein Auge unwillkürlich auf ,Unendlich“ ein, das andere folgte bei dieser Akkommodationsbewegung; die Pupillen erweiterten sich und die Buchstaben erschienen dem Pat. verschwommen. Hier täuschte offenbar die Akkommodationsreaktion eine paradoxe Lichtreaktion vor. Es bot sich mir in der Folgezeit noch dreimal die Gelegenheit, eine scheinbar paradoxe Lichtreaktion zu sehen; auch in allen diesen Fällen hatte die Anwendung der obigen Methode denselben Erfolg.

Konvergenz- und Akkommodationsreaktion. Nachdem wir die Lichtreaktion untersucht haben, prüfen wir die Konvergenz- und Akkommodationsreaktion. Bei der Aufstellung eines brauchbaren Pupillenbefundes darf diese Untersuchung nie fehlen, da wir sonst $z$. B. nie wissen können, ob eine bei Lichteinfall unbewegliche Pupille reflektorisch oder absolut starr ist. Die Fragen, ob es sich bei diesen Mitbewegungen der Pupille um die Erregung eines und desselben Zentrums handelt, ob die Pupillenbewegung mit der Akkommodation oder mit der Konvergenz einhergeht, sind zurzeit noch unentschieden und kaum von praktischem Interesse. Dagegen ist die Tatsache, daß die Konvergenzreaktion beim normal reagierenden Auge ausgiebiger ist als die Lichtreaktion, wie auch Bumke betont, von großer praktischer Bedeutung, indem man eine träge Lichtreaktion am besten durch Vergleich mit der Konvergenzreaktion feststellen kann. Man prüft letztere bekanntlich am einfachsten dadurch, daß man die Versuchsperson auffordert, einen Bleistift oder dergleichen, den man langsam aus ca. $1 \mathrm{~m}$ Entfernung ihrer Nase nähert, mit beiden Augen zu fixieren.

Lidschlußreaktion. Schließen wir das Auge durch festes Zusammenkneifen der Lider, so verengert sich die Pupille; das Phänomen tritt auch dann ein, wenn der Lidschlu $B$ nur intendiert, a ber mechanisch verhindert wird. Bei der letzteren Versuchsanordnung wird die Verengerung direkt sichtbar, während man auf sie sonst nur aus der beim Öffnen der Lider eintretenden Erweiterung schließen kann. Dieser Vorgang ist leicht bei lichtstarren Pupillen sichtbar zu machen; bei solchen, die gute Lichtreaktion zeigen, nur unter Zuhilfenahme eines Kunstgriffes, da sonst der beim Öffnen eintretende Lichtreflex die Erweiterung verdeckt resp. überlagert. Zum Nachweis des Lidschlußreflexes, der auch Orbicularisphänomen genannt wird, bei gesunden Personen, wandte $\mathrm{Bu} \mathrm{mke}^{1}$ ) folgende Methoden an, die mit des Autors eigenen Worten beschrieben werden mögen; er sagt: „Wird während des Lidschlusses die Helligkeit von 60-70 Meterkerzen auf 7-10 vermindert, so wird eine nach dem Offnen des Auges eintretende Erweiterung an Stelle der gewöhnlichen Verengerung auch bei Personen beobachtet, bei denen der Versuch ohne diese Maßnahme, bei der man gewissermaßen der Adaptation der Retina zuvorkommt, negativ ausgefallen wäre. Ebenso ist es mir zuweilen gelungen, durch länger dauernde, intensive Belichtung des Auges (50-70 Meterkerzen) die Lidschlußreaktion sichtbar zu machen; es werden dann die den Lichtreflex vermittelnden Retinaelemente für eine hinreichend lange Zeit derart erschöpft, daß geringe Lichtmengen (10-20 Meterkerzen) eine verhältnismäßig unerhebliche Sphincterkontraktion auslösen." Wenn auch das Orbicularisphä-

1) Bumke, Die Pupillenstörungen bei Geistes- und Nervenkrankheiten. Jena 1904. 
nomen, eine Mitbewegung der Iris, entstanden durch Miterregung des Oculomotorius mit dem Facialis, bisher keine besondere praktische Bedeutung gewonnen hat, so dürfen wir nicht übersehen, daß es zur Fehlerquelle bei der Pupillenbeobachtung werden kann. Hält man einen widerstrebenden Kranken bei der Untersuchung der Lichtreaktion die Augenlider mit der Hand auseinander, so kann durch den Lidschlußreflex ein Lichtreflex vorgetäuscht werden bzw. eine schlechte, minimale Reaktion ausgiebiger erscheinen und zu Irrtümern Veranlassung geben.

\section{Untersuchung mit Vergrößerungsapparaten.}

Mit den bisher angeführten Methoden können wir nur gröbere, ausgiebige Bewegungen der Iris feststellen. Sobald es sich um feine, allerfeinste Veränderungen handelt, sind wir auf die Hilfe des Vergrößerungsglases angewiesen. Wollen wir uns vergewissern, ob die normalerweise nie fehlende Pupillenunruhe vorhanden ist, ob eine Pupille auf sensible oder psychische Reize reagiert, oder handelt es sich um die Prüfung des Hirnrindenreflexes, so bedürfen wir dazu optischer Hilfsmittel, die es uns gestatten, die Iris aus einiger Entfernung in allen ihren Einzelheiten deutlich, hell und groß zu sehen.

Psychische und sensible Reflexe. Wir wissen, daß die Pupille ein äußerst feines Reagens für alle psychischen und sensiblen Reize ist, die das Individuum treffen, da sie darauf mit Größenveränderungen antwortet. Die Folge davon ist, daß die menschliche Iris nie stillsteht, sondern immerzu feine, oszillierende Bewegungen macht. Zur Beobachtung dieser feinen Ausschläge kann man sich einer einfachen Lupe mit langer Brennweite bedienen, die man an einem kleinen Holzgestell befestigt. Ungleich bequemer und sicherer wird die Untersuchung jedoch mit Hilfe des Zehender-Westienschen binokularen Cornealmikroskops ${ }^{1}$ ). Dieses gibt uns ein stark vergrößertes, plastisches Bild der Iris, so daß auch die geringfügigsten Bewegungen des Pupillensaumes uns nicht entgehen. Fig. 5 zeigt das Instrument. Die Lupe ist auf einem soliden, schweren Eisenfuß befestigt; mittels Zahntrieben kann die Höhen- und Tiefeneinstellung auf das Auge des gegenübersitzenden Kranken, dessen Kopf auf einem Kinnhalter aufgestützt ist, besorgt werden. So angenehm dieser Apparat ist, einen unvermeidlichen Fehler birgt er in sich, nämlich den, daß er sehr nahe an das Auge der Versuchsperson herangebracht werden muß, wodurch diese leicht gestört werden kann. Das Gesichtsfeld des Instrumentes reicht nicht viel über den äußeren Irisrand hinaus, ist aber sehr hell, so daß man bei ganz geringer Beleuchtung (7-10 Meterkerzen) Beobachtungen anstellen kann.

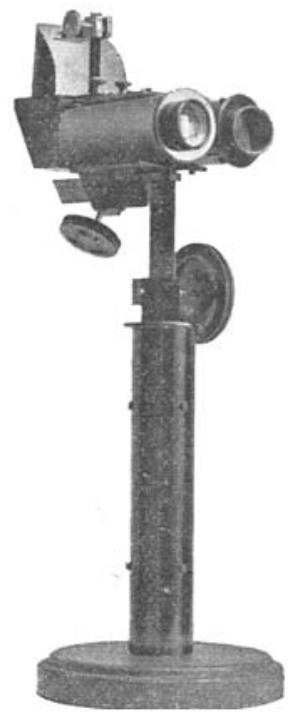

Fig. 5.

1) Axenfeld, Th., Mitteilung: Eine neue Westiensche binokulare Handlupe (Brillenlupe) zum Präparieren und für klinjsche Zwecke mit veränderlicher $\mathrm{Pu}$ pillendistanz und verstellbarem Kopfhalter. Klin. Monatsbl. f. Augenheilk. 28, 20. 1900 .

Fabrikant: Westien, Rostock. 
Es mag hier gleich erwähnt werden, daß die Untersuchung der psychischen und sensiblen Reflexe am besten bei einem mittelstarken Licht geschieht, nehmen wir zu grelles Licht, so kommen wir in Gefahr, daß ein Spasmus der Irismuskulatur ein Fehlen der Reflexe vortäuscht, abgesehen davon, daß das Auge in heller Umgebung leicht zufällig von einem unbeachteten, optischen Reiz getroffen werden kann, der eine l'upillenveränderung mit nachfolgendem Schwanken hervorrufen und zu Fehlschlüssen führen kann. Nehmen wir andererseits zu schwaches Licht, so erweitert sich unter Umständen nach einiger Zeit die Pupille so stark, daß die Iris nur noch als ganz schmaler Ring erscheint. Da nun bekanntlich die psychischen und sensiblen Reflexe in einer Erweiterung der Pupille sich kundtun, so ist es ohne weiteres klar, daß sie bei maximal erweiterter Pupille unsichtbar oder wenigstens undeutlich werden müssen. Ein Licht von 20-30 Meterkerzen Stärke ist nach meinen Beobachtungen als das günstigste anzusehen.

Wenn wir uns vergegenwärtigen. daß jede kleinste, psychische Regung sich in einer Veränderung der Pupillenweite kennzeichnet, so verbietet es sich von selbst, bei der Untersuchung dieser Reflexe ungewollte Reize durch geräuschvolles Herumhantieren auszulösen, ebenso selbstverständlich ist es, daß das Auge gut an das Licht des Untersuchungszimmers adaptiert sein und jede Veränderung der Augenstellung vermieden resp. kontrolliert werden muß. Hier wird es sogar wesentlich, daß man darauf achtet, ob nicht die Augen mehr oder weniger weit geöffnet werden, weil durch die dadurch bedingten Intensitätsschwankungen des die Retina treffenden Lichtes Veränderungen der Pupillenweite hervorgerufen werden können. die dann eine psychische Reaktion vortäuschen.

Der Hirnrindenreflex. Als Hirnrindenreflex wurde die Beobachtung beschrieben ${ }^{1}$ ), daß die Pupillen bei lebhafter Vorstellung schwarzer Gegenstände weit. bei Vorstellung helleuchtender Objekte eng werden. ohne daß das Auge dabei mehr oder weniger stark belichtet wird. Der erste Teil der Beobachtung zeigt nichts von den psychischen Reflexen Verschiedenes, da er ebensogut durch die blohe Anspannung der Aufmerksamkeit ausgelöst sein kann, gleichviel, ob diese sich auf einen dunklen oder hellen Gegenstand richtet; anders wäre es bei dem zweiten Teil der Beobachtung, wonach die Pupillen ohne Lichtzufuhr oder Akkommodation eng werden, bei Vorstellung heller Dinge. Will man sich bei der Untersuchung vor groben Irrtümern schützen, so wird man zweckmäßig die Versuchsperson durch ein Signal - eine Marke auf einer rotierenden Trommel etwa - angeben lassen, ob sie an dunkle oder helle Gegenstände dachte, und seine eigenen Beobachtungen, ob Frweiterung oder Verengerung der l'upille erfolgte, ebenfalls auf demselben Zylinder mittels Schreiber notieren. Die Schwankungen selbst würden sich recht gut mit der Westienschen Lupe beobachten lassen. Ich möchte hierbei nur darauf hinweisen, daß die auf eine Pupillenerweiterung folgende Verengerung in sehr unregelmäßigen Zeitabschnitten nach Beginn der Erweiterung eintritt, und daß es sehr schwer ist, in einer Versuchsreihe, bei der an die Versuchsperson die Aufgabe gestellt wird, sich, während sie gegen eine schwarze Wand sieht, abwechselnd dunkle oder helle Gegenstände lebhaft vorzustellen, die einfache Ersohlaffung der psychischen Reaktion und den etwa eintretenden Hirnrindenreflex bei Vorstellung heller Gegenstände auseinander zu halten.

\section{Untersuchung mit Meßapparaten.}

Bei den bisher angeführten Untersuchungen handelt es sich nur darum, Veränderungen der Pupillengröße, Folgeerscheinungen der dem 1903.

1) Haab, O., Der Hirnrindenreflex der Pupille. Arch. f. Augenheilk. 46, 1. 
Untersuchten zugefügten Reize, als solche festzustellen; die Größe und Geschwindigkeit der Irisbewegungen wurde dabei nicht berücksichtigt. Diese Art der Untersuchung mag wohl für den praktischen Gebrauch genügen. Wollen wir aber tiefer in das Wesen der Pupillenerscheinungen eindringen, so bedürfen wir zur Beobachtung exakter Meßapparate; einerseits solcher, die uns über die Größenveränderungen der Pupille zahlenmäßig genauen Aufschluß geben, andererseits Zeitmeßinstrumente, die uns auch über den zeitlichen Ablauf dieser Bewegungen Klarheit verschaffen. Betrachten wir znächst die Apparate, welche gestatten, die Größe der Pupille genau festzustellen.

Apparate zur Bestimmung der Pupillengröße. In den Jahrbüchern für Psychiatrie vom Jahre 1903 hat Fuchs1) eine ziemlich umfassende Darstellung dieser Instrumente gegeben, so daß ich mich kurz fassen werde, doch scheint es mir zweckmäßig, hier im Zusammenhang eine kurze Aufzählung und Beschreibung dieser Apparate zu geben und den Wert der einzelnen kritisch zu beleuchten. Dabei erscheint es nicht angebracht, die Methoden in der Reihenfolge, wie sie erdacht wurden, aufzuzählen, da dann Wiederholungen derselben Auseinandersetzungen notwendig würden. Ich folge daher dem Vorgange von Fuchs, sie nach den Prinzipien, welche die einzelnen Forscher bei der Angabe ihrer Instrumente im Auge hatten, zusammenzustellen.

Ehe wir zu den eigentlichen Pupillenmeßapparaten kommen, wollen wir noch einer Methode gedenken, die ohne Zuhilfenahme eines eigens zu dem Zwecke konstruierten Instrumentes von einigen zur Messung der Pupillengröße angewandt wurde. Sie kann allerdings nur historisches Interesse beanspruchen, da sie so voller Fehlerquellen steckt, daß sie als praktisch unverwertbar bezeichnet werden muß.

Nach unseren bisherigen Kenntnissen machte Lambert ${ }^{2}$ ) als erster im Jahre 1760 den Versuch, die Pupillengröße zahlenmäßig festzulegen. Vor einem Spiegel sitzend suchte er das Bild seiner Pupille zwischen zwei an die Spiegelplatte angelegten Zirkelspitzen zu fassen, wonach er die Entfernung dieser abmaß und als Pupillenweite annahm. Er ging dann noch weiter, indem er den Blick gegen das helle Himmelslicht wandte, wieder schnell in den Spiegel schaute, abmaß und nun die Abweichung der jetzt gewonnenen Zahl von der früher bestimmten als Ausschlagsweite der Pupille nach Belichtung aufschrieb. Es erübrigt sich, die dabei mitspielenden Fehlerquellen näher zu betrachten.

$\mathrm{KuBmaul}^{3}$ ) maß mittels eines Zirkels die Pupillen bej Tieren. Heddae us ${ }^{\mathbf{1}}$ ) endlich versuchte die Pupillengröße beim Menschen dadurch festzustellen, daß er einen Zirkel mit abgerundeten Spitzen in größtmöglichste Nähe des Auges brachte und die Spitzenentfernung ablas. Ihm sowohl wie $\mathrm{KuBmaul}$ war als hauptsächlichste Fehlerquelle bei der Methode aufgefallen, daß psychische und

1) Fuchs, A., Die Messung der Pupillengröße und Zeitbestimmung der Lichtreaktion der Pupillen bei einzelnen Psychosen und Krankheiten. Jahrbücher f. Psychiatrie 24, 326. 1903.

2) Lambert, J. H., Photometria sive de mensura et gradibus luminis colorum et umbrae 1760, 368 .

3) Kußmaul, Untersuchungen über den Einfluß, welchen die Blutströmung auf die Bewegungen der Iris ausübt. J. D. Würzburg 1855.

4) Heddaeus, E., Die Pupillarreaktion auf Licht, ihre Prüfung, Messung und klinische Bedeutung. Wiesbaden 1886. 
Konvergenzreize die Richtigkeit der Messung problematisch machten. Wenden wir uns nun den eigentlichen Pupillenmeßapparaten zu, und zwar zunächst der Gruppe der

Vergleichspupillometer. Hierhin gehört eine ganze Anzahl von Apparaten, deren Prinzip darin besteht, daß der Pupille eine Reihe von kreisförmigen schwarzen Scheiben oder kreisrunden Ausschnitten in Metallplatten oder endlich Glasplatten mit eingeritzten Kreisen verschiedenster Größe genähert wird, worauf man durch Vergleich dieser mit der Pupille den ihr in der Größe am nächsten stehenden Kreis aussucht und seinen Durchmesser als Pupillenweite aufschreibt.

Fig. 6 zeigt das von $\mathrm{Haab}^{1}$ ) angegebene Pupillometer; auf einem Papierstreifen sind in einer Reihe schwarze, runde Punkte von 1,5-8 mm Größe, an-

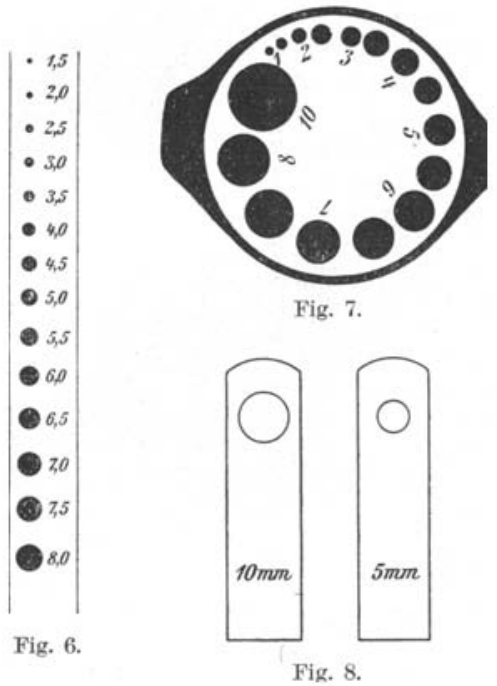
wachsend um je $0,5 \mathrm{~mm}$, aufgedruckt. Fig. 7 führt den an dem Augenspiegel von Weeks') angebrachten Pupillenmesser vor, der die gleiche Anordnung zeigt, während Fig. 8 dem von Schnabl ${ }^{3}$ ) konstruierten entspricht, bestehend aus einer Serie dünner Glasplättchen, auf die Kreise verschiedener Größe eingraviert sind.

Derartige Vorrichtungen sind leicht zu handhaben und gestatten bei einiger Übung ziemlich genaue Ablesungen. Die beste ist wohl die $\mathrm{Haabsche}$ resp. Weekssche, da hier nichts vor das Auge der Versuchsperson gebracht wird, wodurch, wie bei dem Pupillometer von Schnabl, leicht ungewollte störende Reize ausgeübt werden.

Weitere Vergleichspupillometer wurden von Follin ${ }^{4}$ ), Jessop ${ }^{5}$ ), Paster natzky ${ }^{6}$ ) und $G u i l l o z^{7}$ ) angegeben, die zu beschreiben zu weit führen würde, da sie nichts wesentlich Neues bieten.

Tangentiale Pupillometer. Eine weitere Möglichkeit, die Pupillengröße zu bestimmen, besteht darin, daß Apparate zwischen das Auge des Untersuchten und den Beobachter gebracht werden, auf denen Linien oder dgl. angebracht sind, die in tangentiale Berührung mit dem Pupillenrande an den zwei Endpunkten seines Durchmessers gebracht werden können, wonach ihr Abstand die Größe des Pupillendiameters angibt.

Als solchen Apparat kann man das Strabometer von Laurence ${ }^{8}$ ) (Fig. 9)

1) Haab, Atlas der Ophthalmoskopie. Lehmanns med. Atlanten. 1900.

2) Weeks, J. E., Retinoscope, pupillometer and strabometer combined. Med. Rec. York 36, 167. 1889.

3) Bezugsquelle: Optiker Schwarz, Wien.

4) Follin, Traité d'ophthalmol. de Wecker et Landolt, 1, 942.

5) Jessop, W., A new pupillometer. Ophthalm. Review 5, 320. 1886.

6) Pasternatzky, Utber die Ungleichheit der Pupillen. Wratsch. 9, 896.

7) Guilloz, Procédé pour la mesure rapide de la dimension des petits objets, independamment de leur distance. Application à la pupillométrie. Acad. de Sciences. Recueil d'ophthalmol., 372. 1899.

8) Laurence, Traité d'ophthalmol. de Wecker et Landolt 1, 493. 
benutzen. Das bei weitem einfachste, handlichste und für genauere Messungen geeignete Instrument ist das von Schloesser ${ }^{1}$ ) angegebene (Fig. 10). Auf einer Glasplatte sind zwei Linien eingeritzt, die sich unter einem Winkel von ca. $8^{\circ}$ schneiden. In Abständen von je $1 \mathrm{~mm}$ resp. $0,5 \mathrm{~mm}$ sind Querstriche angebracht. Man verschiebt die Platte so lange vor dem Auge der Versuchsperson hin und her, bis die Endpunkte einer solchen Querlinie mit dem Pupillenrande zusammenfallen, und liest die Weite direkt ab. Auch dieses Instrument hat den Fehler, daß durch seine Handhabung vor dem Auge störende Reize ausgeübt werden können. Diese gefährden jedoch bei einiger Vorsicht und Geduld nicht allzusehr den Wert der Untersuchung, besonders deshalb nicht, weil eine Einstellung auf die Striche

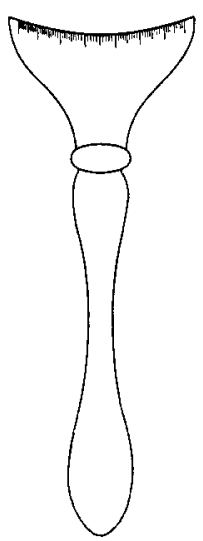

Fig. 9.

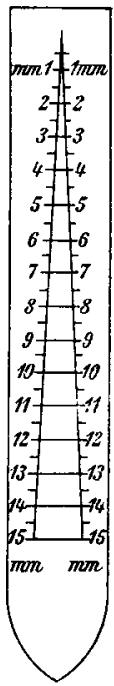

Fig. 10.

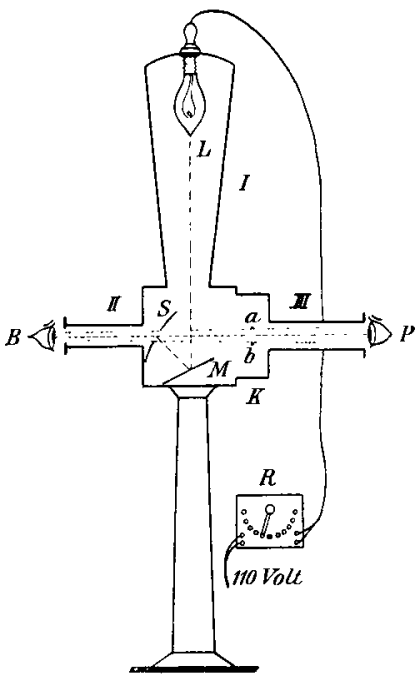

Fig. 11 .

wegen ihrer großen Nähe nicht möglich ist. $\mathrm{Zu}$ den tangentialen Pupillometern gehört auch der Pupillenmeßapparat von So $\left.m \mathrm{mer}^{2}\right)^{3}$ ), der den Vorzug hat, daß man eine beliebig veränderbare Lichtmenge ins Auge der Versuchsperson schicken kann. Die Fig. 11 zeigt schematisch die Einrichtung des Apparates. Auf einem festen Metallfuß ist ein Kasten $k$ angebracht, an dem 3 Tuben I, II und III, befestigt sind. Am oberen Ende des Tubus I finden wir eine Glühlampe von ca. 50 Meterkerzen Lichtstärke. Das von ihr ausgesandte Licht wird von einer Mattscheibe $M$ auf einen in der Mitte durchbohrten Hohlspiegel $S$ reflektiert, von dem es ins Auge der Versuchsperson gelangt. In Tubus II ist ein Vergrößerungssystem eingebaut, durch das der Beobachter schaut. Bei $a$ und $b$ sind zwei Fäden parallel

1) Schloesser, Demonstration eines Pupillometers. 23. Vers. d. Ophthalmol. Gesellschaft. Heidelberg 1893. 234.

Fabrikant: Optiker Buchner, München, Domplatz.

2) So m mer, R., Lehrbuch der psychopathologischen Untersuchungsmethoden. Wien-Berlin 1899.

3) Derselbe, Demonstration des verbesserten Pupillenmeßapparates mit Messung von Reiz und Wirkung. Vers. d. südwestdeutsch. Nervenärzte in Frankfurt a. M. 12. Nov. 1899.

Fabrikant: Zimmermann in Leipzig. 
zueinander gespannt, ihre beiderseitige Entfermung ist von außen veränderbar. Das zu untersuchende Auge wird in die Öffnung des Tubus III eingestellt und von $B$ aus betrachtet. Bringt man nun die Fäden $a$ und $b$ durch Verschieben so zusammen, daß sie dem Beobachter an den Rändern der Pupille der Versuchsperson zu liegen scheinen, so haben wir die Verhältnisse, wie sie in der Zeichnung angenommen sind. An dem Apparat ist außen eine empirisch festgestellte Teilung angebracht, die nach der jeweiligen Stellung der Fäden den Durchmesser der Pupille abzulesen gestattet. Ein Rheostat $(R)$ dient dazu, die Lichtstärke der Lampe $L$ beliebig zu variieren. Der Apparat bedeutet in der Technik der Pupillen. messung einen wesentlichen Fortschritt, weil die Versuchsperson, wenn ihr Auge einmal eingestellt ist, nicht mehr durch die Messung, die ihr unbemerkbar bleibt, gestört wird und die Lichtzufuhr zum Auge (der Reiz) variierbar ist. Leider hat auch dieses Instrument Fehler, dje seine Handhabung sehr erschweren; vor allem ist es schwer, das Auge einzustellen, wie Sommer selbst hervorhebt, ferner ist die Einstellung der Fäden nicht leicht, da kleine Abweichungen relativ große Fehler bedingen, wie aus dem Schema leicht ersichtlich ist. Im übrigen sei auf Sommers eigene Darstellung in seinem Lehrbuch der psychopathologischen Untersuchungsmethoden verwiesen.

Pupillometer mit Doppelbilderprinzip. Ein solches wurde unter anderen von Landolt1) angegeben. Die Fig. 12 zeigt seine Einrichtung. An

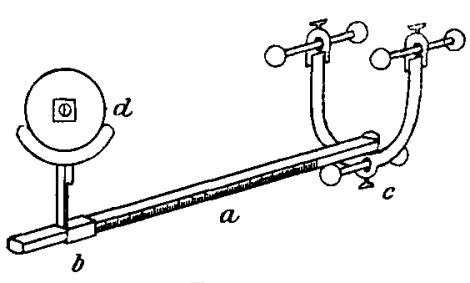

Fig. 12. einem Stab $a$ ist ein verschieblicher Teil $b$ angebracht; an dem entgegengesetzten Ende sehen wir eine Vorrichtung $c$, die das Instrument auf dem Rande der Orbita festzustellen gestattet. Der Teil $b$ trägt bei $d$ eine runde Platte mit einer Prismeneinlage. Zwei Prismen von gleichem Winkel sind so nebeneinander befestigt, daß ihre Kanten einander gegenüberstehen. Betrachtet man mit einem Auge durch die Prismen hindurch einen Gegenstand, so sieht man ihn demnach doppelt. Der Abstand der Doppelbilder nimmt mit zunehmender oder abnehmender Entfernung zwischen Objekt und Prismen ebenfalls zu oder ab. Setzt man den Apparat vor das Auge der Versuchsperson, so wird man durch Verschieben des Teiles $b$ auf $a$ einen Punkt finden, bei dem sich die Ränder der Doppelbilder der Pupille gerade berühren. Eine auf dem Stab a angebrachte Teilung gibt dann, abgelesen an der Stelle, wo Teil $b$ steht, die Pupillengröße in Millimetern an.

Pupillenmessung unter Zuhilfenahme entoptischer Wahrnehmungen. Bringt man, während das Auge für die Ferne eingestellt ist, zwei leuchtende Punkte nahe an dasselbe heran, so entstehen davon auf der Retina zwei Zerstreuungskreise, die voneinander abweichen oder sich nähern, je nachdem die Leuchtpunkte voneinander entfernt oder näher zusammengebracht werden. Diesen Umstand benutzte zuerst Fick ${ }^{2}$ ) im Jahre 1855 zur Pupillenmessung: Fig. 13 mag zur Erläuterung seines Apparates dienen. Er besteht aus zwei Metallplatten, die gegeneinander verschieblich zusammengefïgt sind. Die eine hat einen senkrechten Schlitz $a$, die andere zwei Fugen $b$ und $c$, die schräg gegeneinander laufen. Es ist klar, daß, wenn die Platten in eine Lage gebracht sind, bei der die Schlitze übereinander stehen, wie in der Figur angenommen ist, bei $\alpha$ und $\beta$ zwei

1) Landolt, Ein Pupillometer. Centralbl. f. d. medizin. Wissenschaften 1875,563 .

2) Fick, A., Einige Versuche über die chrom. Abweichung des menschlichen Auges. Arch. f. Ophthalmologie 2, 76. 1855. 
kleine Öffnungen entstehen, durch die das Licht hindurchdringen kann. Durch Verschieben des Schlitzes $a$ kann der Abstand der Löcher verändert werden. Hält man die Platten vor ein Ange, während man mit dem anderen in die Ferne blickt, so bilden sich von den Lichtpunkten $\alpha$ und $\beta$ zwei Zerstreuungskreise auf der Retina $a b$; bringt man nun die Platten in eine Lage, daß die Zerstreuungskreise sich eben berühren, so gibt die Entfernung der beiden Punkte den Durchmesser der Pupille an. Daß es dabei ziemlich gleichguiltig ist, wie weit die Platten vom Auge entfernt sind, zeigte $\mathrm{Badal}^{1}$ ). Das nebenstehende Schema (Fig. 14) mag dies erläutern. $A$ und $A^{\prime}$ seien zwei leuchtende Punkte, die vor dem auf $\infty$ eingestellten Auge stehen. Die Punkte werden sich nicht scharf auf der Retina abbilden, da Strahlen von Gegenständen, die nahe am Auge liegen, bei der Einstellung auf $\infty$ erst hinter der Retina sich vereinigen können, man sieht also in Zerstreuungskreisen. Nehmen wir an, die Punkte $A$ und $A^{\prime}$ seien um den Diameter der Pupille $p p^{\prime}$ von einander entfernt und die Linie $K^{\prime} K^{\prime \prime}$ stelle eine durch den Knotenpunkt $K$ gelegte Senkrechte dar, so wird ein Strahl von $A$ parallel zur Richtungslinie $r r^{\prime}$ am Rande der Pupille vorbei bei $b$ gebrochen werden und, weil das Auge auf $\infty$

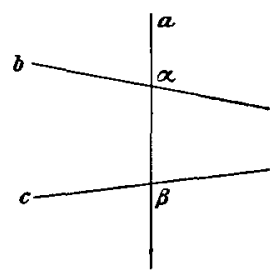

Fig. 13.

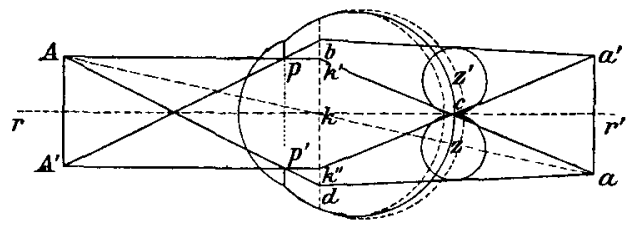

Fig. 14.

eingestellt ist, bei $c$ die Retina treffen. Ein weiterer Strahl von $a$ wird bei $d$ gebrochen werden. Ziehen wir durch den Knotenpunkt $K$ von $A$ aus die optische Axe, verlängern $b c$ über $c$ hinaus, so werden sich in dem Schnittpunkte $a$ die Strahlen treffen und hier der Bildpunkt für $A$ liegen; dieselbe Utberlegung und Zeichnung kann man für $A^{\prime}$ machen. Als Zerstreuungskreise ergeben sich dann $Z$ und $Z^{\prime}$, deren Rënder sich berühren müssen. Umgekehrt kann man nun sagen, daß, wenn die Ränder der Zerstreuungskreise $Z$ und $Z^{\prime}$ sich berühren, die Fintfernung der Punkte $A A^{\prime}$ gleich dem Durchmesser der Pupille ist.

Bringt man die Punkte $A$ und $A^{\prime}$ weiter vom Auge fort, so ändert das nichts an den Verhältnissen, nur werden die Zerstreuungskreise kleiner, bis sie beim Emmetropen theoretisch in einer Entfernung von $30 \mathrm{~m}$ völlig verschwinden, da dieser alle Gegenstände zwischen $30 \mathrm{~m}$ und $\infty$ bei einer Einstellung des Auges gleichmäßig scharf sieht. Diese Tatsachen gelten natürlich nur für das emmetropische Auge. Beim Myopen oder Hypermetropen würden die Kreise sich nicht ganz berühren, wie aus den eingezeichneten Linien ersichtlich ist, da im einen Falle der Augapfel zu kurz, im anderen zu lang ist und sich dann die Strahlen aus $\infty$ entweder vor oder hinter der Retina vereinigen und so unsere Überlegungen stören. Abgesehen von diesem Fehler der Methode, ergibt sich vor allem noch die Schwierigkeit, daß man bei ihrer Anwendung auf die Zuverlässigkeit der Beobachtung des Untersuchten angewiesen ist, während man den Umstand, daß die Strahlen schon vor der Cornea, bevor sie noch zur Iris gelangen, leicht gebrochen werden, vernachlässigen kann. Geradezu problematisch drohen aber derartige Messungen zu werden, wenn wir bedenken, daß durch die Spannung der Aufmerksamkeit die Pupillenweite wesentlich verändert werden kann.

1) Badal, Mesure du Diamètre de la pupille et des cercles de diffusion. Annales d'oculistique $\% 5,290.1876$.

Z. f. d. g. Neur. u. Psych. O. II. 
Projektionspu pillometer. Bei fast allen bisher beschriebenen Pupillenmeßapparaten ist eine starke Annäherung des Instrumentes ans Auge notwendig, die leicht zur Fehlerquelle wird. Versuche, den Maßstab von dem Auge wegzubringen, führten zur Konstruktion von Projektionspupillometern, bei denen eine Teilung ins Auge gespiegelt wird, ohne daß der Untersuchte etwas davon merkt

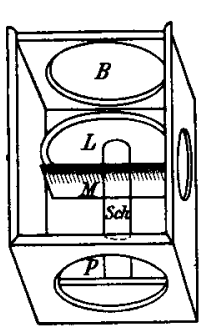

Fig. 15. oder dadurch gestört wird. Die Fig. 15 zeigt das von - Coccius ${ }^{1}$ ) angegebene Instrument. In einem rechteckigen Kasten von $60 \mathrm{~mm}$ Länge, $40 \mathrm{~mm}$ Breite und Höhe ist eine Linse $L$ von $74 \mathrm{~mm}$ Brennweite angebracht. Bei $B$ ist eine $3 \mathrm{~cm}$ breite Öffnung, durch die der Beobachter das vergrößerte Bild der gegenüber eingestellten Pupille betrachtet. Die Öffnung $P$ ist durch einen Spiegel, dessen spiegelnde Fläche dem Innern des Kastens zugewandt ist, zur Hälfte vordeckt. In ihm bildet sich die Teilung $M$ ab. Rückt man die Linse so lange auf dem Schieber Sch hin und her, bis die Pupille und die Teilung im Spiegel scharf erscheinen, so hat man ein vergrößertes Bild der Pupille mit darunterliegendem Tangentialpupillometer vor sich, an dem man die Pupillenweite abliest.

Hess ${ }^{2}$ ) projiziert mittels eines vertikal unter einem Winkel von $45^{\circ}$ aufge. stellten Deckglases eine Millimeterskala in die Pupille, ein Verfahren, das später von $B$ umke angewandt wurde, ohne daß dieser den Apparat von Hess vorher kannte. Den handlich konstruierten Apparat von $\mathrm{Bumke}^{3}$ ) zeigt die Fig. 16 halbschematisch. An einem Holzstiel

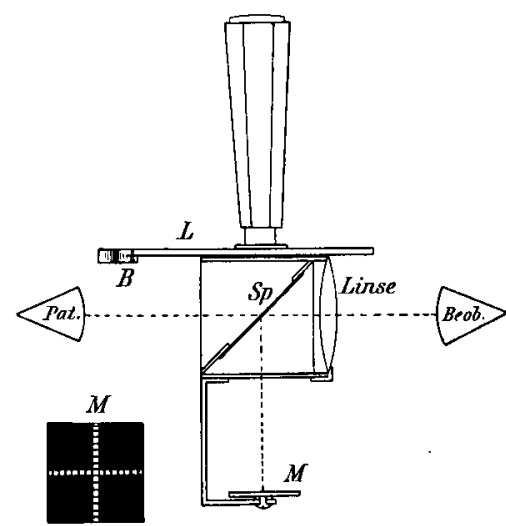

Fig. 16. sitzt ein Tubus, in dem ein dünnes Deckglas $S p$, unter einem Winkel von $45^{\circ}$ geneigt, festgemacht ist. Das eine Ende des Tubus ist durch eine Bikonvexlinse verschlossen. Bei $M$ ist eine schwarze Tafel mit weißen, je um $1 \mathrm{~mm}$ von einander abgetrennten Punkten angebracht. Zwischen ihr und der spiegelnden Fläche des Deckglases ist der Tubus durchbrochen, so daß ein Spiegelbild der Teilung entsteht, das natürlich so weit hinter der Fläche des Deckglases zu liegen scheint, wie die Scheibe $M$ vor ihr steht. Dem Beobachter erscheint beim Blick durch die Linse nach dem Deckglas ein vergrößertes Bild der Teilung $M$. Hält man den Apparat so vor das Auge des Patienten, daß die Entfernung von seiner Pupille zur Mitte des Deckglases gleich ist der von dieser zur Platte $M$, so sieht man das scharfe, vergrößerte Bild der Pupille, in der das ebenfails

1) Coccius, Ein neues Instrument zur Bestimmung der Hornhautbasis und der Pupillenweite. Leipzig 1873.

2) Hess, C., Demonstration eines Instrumentes zur Messung von Pupillendurchmesser und Pupillendistanz. 23. Vers. der ophthalmol. Gesellschaft. Heidelberg $1893,235$.

3) Bu mke, Fin neues Pupillometer. Münch. med. Wochenschr. 1903, 1343.

Fabrikant: Elbs, Freiburg i. B., Friedrichstraße. 
scharfe Bild der gleichmäßig vergrößerten Teilung $M$ zu liegen scheint, und kann nun die Pupillenweite ablesen. Zur leichteren Einstellung des Instrumentes wird der Riegel $B$ mittels der Leitstange $L$ gegen die Stirn der Versuchsperson angedrückt. Die Ablesung wird besonders dadurch erleichtert, daß die Teilung auf schwarzem Grunde in der dunklen Pupille erscheint, von der sie sich sehr gut abhebt. Durch die Anlegung des Apparates wird die Versuchsperson nur wenig gestört, so daß er zu Untersuchungen am Krankenbett wohl geeignet erscheint. Dasselbe Instrument brachte B u m ke in etwas veränderter Form an der Westienschen Lupe an, wie es Fig. 6 zeigte.

Die Reihe der Projektionspupillometer abschließend, sei die äußerst sinnreiche Methode von Schirmer ${ }^{1}$ ) noch besonders hervorgehoben. Fig. 17 mag zur Erläuterung seines Apparates dienen. Die eine Kathetenfläche $(b)$ eines Glasprismas ist mit Quecksilber belegt. Der Hypothenusenfläche gegenüber steht vertikal ein Maßstab $(m)$, eine auf eine matt geschwärzte Metallplatte eingeritzte Millimeterskala. Richtet der Beobachter $(B)$ seinen Blick, wie in der Figur angedeutet, gegen die andere Kathetenfläche $(a)$, so sieht er zugleich mit der in $P$ befindlichen Pupille das durch den Spiegel $(b)$ entworfene Bild der Skala. Diese und die $\mathrm{Pu}$ pille werden theoretisch gleich deutlich, scharf und in ihrer richtigen Größe sichtbar sein, wenn die Entfernung vom Auge des Beobachters zur Skala ebenso groß ist,

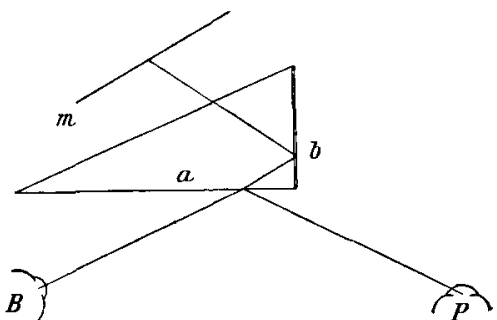

Fig. 17. wie die zur Pupille bəi $P$. Betrachten wir aber zwei Objekte, von denen das eine nur wenig hinter dem anderen steht, so sehen wir beide scharf, auch wenn sie sich ziemlich nahe vor unseren Augen befinden; mit anderen Worten, wir können wegen der Tiefenschärfe des optischen Apparates unseres' Auges nicht schließen, daß zwei Objekte, die uns gleich scharf erscheinen, auch gleich weit von uns entfernt sind. Um nun die richtige Einstellung bei seinem Apparat dennoch zu ermöglichen, geht Schirmer so vor, daß er seinem Auge bei der Beobachtung eine Konvexlinse von 10 Dioptrien vorsetzt, wodurch er einerseits eine starke Vergrößerung des Maßstabes und der Pupille erreicht, andererseits die Tiefenschärfe seines Auges sehr vermindert. Fr berechnet die Genauigkeit seiner so erhaltenen Meßresultate auf $1 / 4 \mathrm{~mm}$. Diese dürfte für praktische Zwecke vollauf genügen, wenn man bedenkt, daß die dauernde Pupillenunruhe exaktere Messungen überhaupt unsicher erscheinen läßt. Das von Schirmer angewandte Prinzip der Pupillenmessung ist vor allem deshalb besonders günstig, weil hier vor dem Auge des Untersuchten nichts aufgestellt wird, was akkommodative oder sonstwie störende Reize ausüben könnte. Leider ist aber für das Gelingen des Versuchs Bedingung, daß das Auge ruhig an seinem Platze bleibt, da die kleinste Bewegung jede Messung unmöglich bzw. ein Nachfolgen des ganzen Apparates nötig macht.

\section{Photographie der Pupille.}

Wie die medizinische Wissenschaft im allgemeinen jeden Fortschritt der Technik beobachtet und für ihre besonderen Zwecke nutzbar zu machen sucht, so auch die Pupillenforschung.

1) Schirmer, O., Demonstration eines Pupillometers. Ber. über die 24. Vers. d. Ophthalmol. Gesellschaft zu Heidelberg, 242. 
Als man daran ging, Momentaufnahmen von Personen bei künstlichem Lichte (Blitzlicht) zu machen, versuchte (l. du Bois - Reymond ${ }^{1}$ ) alsbald (1888), diese neue technische Errungenschaft bei der Pupillenmessung anzuwenden. Er ging so vor, daß er das Auge einem bestimmten Lichtreiz aussetzte und dann durch eine Blitzlichtaufnahme die Pupille auf die Platte zu bannen suchte. Auf den ersten Blick scheint diese Methode einwandsfrei zu sein, und man könnte erwarten, von $\mathrm{ihr}$ genaueste Aufschlüsse über die Pupillengröße und -form bei verschiedenster Belichtung zu erhalten, doch gelingt dies nicht ohne gewisse Vorsichtsmaßregeln. Untersuchungen ${ }^{2}$ ) haben gezeigt, daß noch während der kurz dauernden Einwirkung des Magnesiumblitzlichtes eine Pupillenverengerung eintritt. Wollen wir daher die Größe der Pupille, die vor der Blitzlichtwirkung bestand, feststellen, so müssen wir den Versuch so einrichten, daß die Dauer der Abbrennzeit des Magnesiumpulvers nicht länger ist als die Latenzzeit der Pupillenreaktion, da wir sonst zu kleine Werte bei der Ausmessung des Photogrammes erhalten würden. Wenn auch die kurzdauernde Blendung bei der Blitzlichtaufnahme ohne Schaden für das belichtete Auge vorbeigeht, so ist doch äußerste Vorsicht bei dem Versuch am Platze, um das Auge vor umherspritzenden glühenden Magnesiumteilchen zu schützen. Am besten geschieht dies durch Vorsetzen von Glasplatten, wodurch dann auch Wärmereize ausgeschaltet werden.

Fuchs ${ }^{3}$ ) benutzte statt des Magnesiumlichtes den Funken eines Rumkorffschen Apparates als Lichtquelle für die Momentaufnahme der Pupille. Er stabilisierte den Funken (Schlagweite $20 \mathrm{~cm}$ ), indem er ihn zwischen zwei zugespitzten Aluminiumbändern durch eine dünne Ölschicht leitete. Auch dieser ganz kurz dauernde Lichtreiz bewirkt, wie Versuche (Vintschgau s. u.) zeigten, eine Pupillenverengerung, doch liegt hier die Belichtungszeit innerhalb der Latenzzeit des Lichtreflexes der Pupille.

Um sich Aufschluß ïber den Ablauf der Pupillenerweiterung nach Verdunkelung zu verschaffen, photographierte Garte ${ }^{4}$ ) die Pupille unter Zuhilfenahme von ultravioletten Strahlen, erzeugt durch ein Quarzprisma. Zur Aufnahme selbst verwandte er eine Quarzlinse.

$\mathrm{Ob}$ der Versuch, eine Pupille zu photographieren, gelingt, hängt vor allem sehr von der Farbe der sie begrenzenden Iris ab. Ist die Iris blau oder grau, so werden die Bilder schön und klar, ist sie aber mehr braun oder gelb, so hebt sich die Regenbogenhaut meist so wenig von der Pupille ab, daß die Grenze nur schwer, vielfach gar nicht $\mathrm{zu}$ entdecken ist. Ein weiterer Utbelstand, der sehr leicht zur Fehlerquelle bei der Ausmessung von Pupillenphotogrammen werden kann, wird dadurch bedingt, daß der die Pupille direkt umgrenzende Teil der Iris vielfach dunkler gefärbt ist als die übrige Regenbogenhaut und deshalb leicht mit zur Pupille gerechnet wird, so daß deren ausgerechnete Weite zu groß ausfällt.

Sehen wir von diesen Mängeln und Schwierigkeiten der photographischen Methode der Pupillenmessung ab, so ist sie doch die bei weitem objektivste und besonders, wie wir weiter unten sehen werden, für die exakte Messung der $\mathrm{Pu}$ pillenbewegung fast unentbehrlich.

1) Du Bois - Reymond, Cl., Úber das Photographieren der Augen bei Magnesiumblitzlicht. Centralbl. f. prakt. Augenheilk. 12, 68. 1888.

2) Magnus, R., Die Pupillarreaktion der Octopoden. Archiv f. d. ges. Physiol. 92, 623. 1902.

3) Fuchs, A., Die Messung der Pupillengröße und Zeitbestimmung der Lichtreaktion der Pupillen bei einzelnen Psychosen und Krankheiten. Jahrb. f. Psychiatrie 1903.

4) Garten, S., Beiträge zur Kenntnis des zeitlichen Ablaufs der Pupillenreaktion nach Verdunkelung. Archiv f. d. ges. Physiol. 68, 68. 1897. 


\section{Zeitberechnung der Pupillenreaktionen.}

Wir bemühen uns bekanntlich bei der einfachen klinischen Untersuchung der Pupillenreaktion auf Lichteinfall, die Geschwindigkeit, mit der die Sphincterkontraktion vor sich geht, einigermaßen zu kennzeichnen, indem wir sie als rasch oder langsam (träge) benennen. Es hat nun nicht an Versuchen gefehlt, die Schnelligkeit der Reaktion exakter zu messen und auch ein Urteil über die Latenzzeit der Bewegung zu gewinnen, wobei es wohl keinem der Experimentierenden verborgen blieb, daß sich diesen Feststellungen große Schwierigkeiten entgegenstellen.

Stehen nur wenig Hilfsmittel $\mathrm{zu}$ Gebote, so kann man auf folgende ziemlich einfache Art annähernde Werte für die Größe der Kontraktionszeit des Irisschließmuskels gewinnen. Fig. $18 \mathrm{mag}$ die Versuchs-

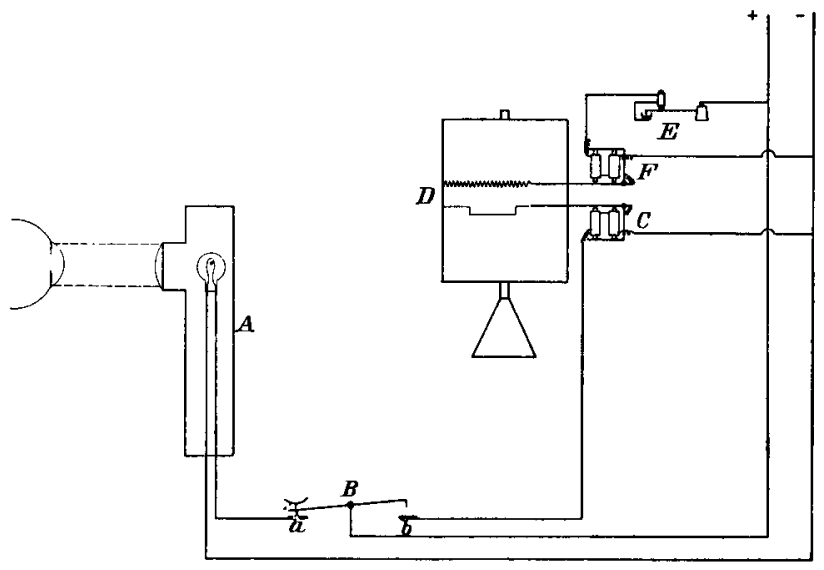

Fig. 18 .

anordnung erläutern. Vor dem Auge der Versuchsperson ist bei $A$ eine Lampe aufgestellt, wie ich sie zur gewöhnlichen Pupillenuntersuchung verwende. In deren Stromkreis ist bei $B$ ein Taster eingeschaltet, der, auf $a$ niedergedrückt, die Glühlampe erstrahlen läßt. Beim Aufhören des Druckes schnellt der eine Tasterarm zurück und der andere liegt nun bei $b$ auf. Dadurch wird ein elektrischer Stromkreis geschlossen, der durch den Elektromagneten $C$ geht und die mit diesem verbundene Schreibfeder in Bewegung setzt. Letztere ist an einem Kymographion $D$ angelegt und zeichnet auf dem berußten Papier eine Linie. Die bei $E$ gezeichnete elektromagnetische Stimmgabel schreibt durch den Elektromagneten $F^{1} /{ }_{100}$ Sekundenmarken auf. Zur Messung der Kontraktionszeit der Iris bei Lichteinfall ins Auge geht man nun folgendermaßen vor. Durch Niederdrücken des Hebels $B$ bringt man die Lampe zum Aufleuchten und läßt den Hebel in dem Moment, wo die Irisbewegung zum Stillstand kommt, los. Die Zeit, während der der Stromkreis, welcher don 
Magneten $C$ versorgt, unterbrochen war, zeichnet sich dann auf dem Kymographion auf, und wir haben in ihr die Kontraktionszeit der Iris einschl. der Latenzzeit dieser Bewegung und der eigenen Reaktionszeit des Experimentierenden, d. h. der Zeit, die verfließt, bis er nach Erkennung des Abschlusses der Iriskontraktion den Hebel $B$ zurückschnellen läßt. Zieht man diese persönliche Reaktionszeit ab, so kann man, wenn auch nicht exakte, doch annähernde Werte für die Dauer der Iriskontraktion gewinnen, deren Genauigkeit man durch wiederholte Versuche steigert.

Auf ähnliche Weise suchte Vintschga $\left.\mathbf{u}^{1}\right)^{2}$ ) die Kontraktionszeit der eigenen Iris unter Zuhilfenahme des entoptischen Gesichtsfeldes zu messen; zugleich bestimmte er die Latenzzeit der Bewegung. Seinen Untersuchungen voraus gingen ähnliche Versuche von Donders ${ }^{3}$ ) und F. Arlt jun. ${ }^{4}$ ).

Zur Bestimmung der Latenzzeit der Erweiterung der Pupillen auf psychische oder sensible Reize kann man in derselben Weise vorgehen, wenn man dafür sorgt,

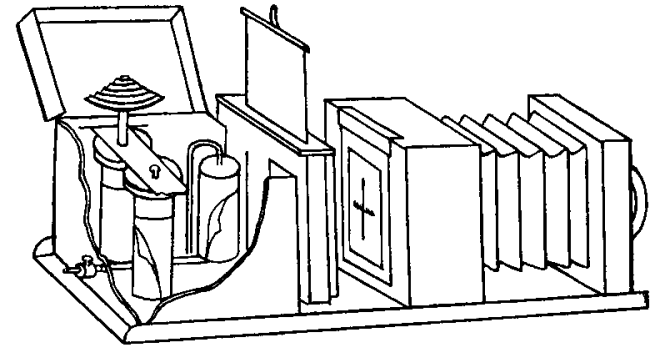

Fig. 19. daß der Moment des Reizes auf der Registriertrommel verzeichnet wird, eine Methode, die Buccolas) anwandte. Steht ein Chronoskop zur Verfügung, so erübrigt sich die graphische Registrierung. Da diese Methoden natürlich nur annähernde Werte für die Kontraktionszeiten der Iirismuskulatur geben können, versuchte Bellarminof $\left.f^{6}\right)^{7}$ ) als erster, die Veränderungen der Pupillengröße auf photographischem Wege festzustellen. Die Fig. 19 gibt den von ihm konstruierten Aufnahmeapparat wieder, dessen Einrichtung schon aus der Zeichnung ersichtlich sein dürfte. Das Wesentliche desselben besteht darin, daß die Hinterwand einer photographischen Kamera durch eine mit einer senkrechten Spalte versehene Kautschukplatte verschlossen ist, hinter der mittels eines Uhrwerks ein lichtempfindlicher Papierstreifen vorbei-

1) ,Vintschgau, M., Zeitbestimmungen der Bewegungen der eigenen Iris. Archiv f. d. ges. Physiol. 26. 1881.

2) Derselbe, Weitere Beobachtungen über die Bewegungen der eigenen Iris. Archiv f. d. ges. Physiol. 2r. 1882.

3) Donders, Reflexiebeweging der beide Pupillen bij het invallen van licht aan eene Zijde. Nederlandsch Archief voor Genees en Natuurkunde 1865, 106.

4) Arlt, F. jun., Beitrag zur Kenntnis der Zeitverhältnisse bei den Bewegungen der Iris. Arch. f. Ophthalmol. 15, I. 294.1869.

s) Buccola, G., Sul tempo della dilatazione reflessa della pupilla nella paralisi progressiva degli Alienati ed in altre dei malattie centri nervosi. Rivista sper. di freniatria. Reggio Fmilia 9, 98. 1883.

6) Bellarminoff, L., Anwendung der graphischen Methode bei Untersuchung der Pupillenbewegungen. Photocoreograph. Archiv f. d. ges. Physiol. 3\%, 107. 1885.

7) Derselbe, Verbesserter Apparat zur graphischen Untersuchung des intraokulären Druckes und der Pupillenbewegung. Ber. d. 19. Vers. d. Ophthalmol. Gesellschaft Heidelberg 1887, 185. 
gezogen wird. Bellarminoff stellte den Apparat so ein, daß die Pupille des curarisierten Tieres, dessen Lider mit einem Lidhalter zur Seite gezogen waren, sich scharf auf dem photographischen Papier abbildete. Durch Vorbeiziehen des letzteren und gleichzeitige Registrierung von Zeitmarken gewann er ein Abbild der Bewegungen der Iris.

Dieselbe Methode wandte nach ihm Braunstein') an, der ebenfalls nur bei Tieren experimentierte, desgleichen Dogiel2).

In ähnlicher Weise photographierte $\mathrm{Fuchs}^{3}$ ) Bewegungen der Iris. Er verwandte statt des lichtempfindlichen Papiers photographische Platten, die durch ein Uhrwerk hinter einem $1 / 2 \mathrm{~mm}$ breiten Schlitz mit bestimmter Geschwindigkeit vorbeigezogen wurden. Durch ein hochgradig lichtempfindliches Objektiv (Doppelanastigmat von Goerz) wurde die Pupille der Versuchsperson in normaler Größe auf der Platte scharf abgebildet. Fuchs schildert die Technik der Aufnahme in ungefähr folgender Weise. Der Kopf der Versuchsperson wird unter Zuhilfenahme einer Einbeißvorrichtung festgestellt. Soll die Aufnahme gelingen, so ist natürlich vor allen Dingen außer Ruhighaltung des Kopfes absolute Ruhe der Augen notwendig. Ist diese gewährleistet, so wird der größte Durchmesser der Pupille in dem Spalt des Apparates eingestellt. Als Lichtquelle verwendet Fuchs eine Bogenlampe von ca. 800 Meterkerzen Stärke, die in einem Abstand von ca. $10 \mathrm{~cm}$ rom untersuchten Auge aufgestellt ist. Die Wärmestrahlen der Lampe werden durch eine zwischengeschaltete Glasplatte von $0,75 \mathrm{~mm}$ Dicke von dem Auge abgehalten. Zwischen Bogenlampe und Versuchsperson schiebt Fuchs zunächst eine dunkelblaue Glasplatte und adaptiert während der Dauer von 5 Minuten das Auge an dieses blaue Licht. Darauf setzt er den Apparat in Gang. Frst dann läßt er durch plötzliches Wegnehmen der blauen Glasplatte das grelle weiße Bogenlicht ins Auge eintreten. Er
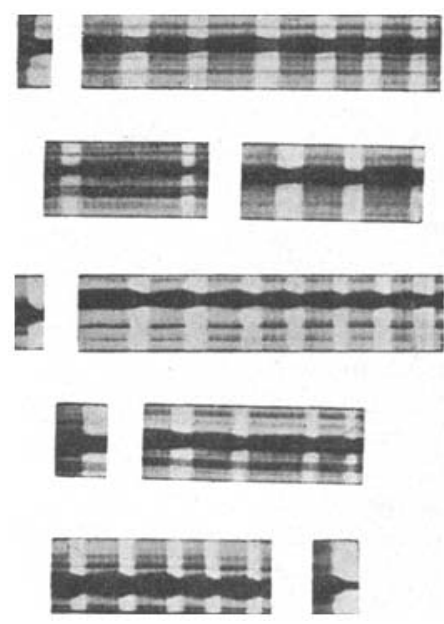

Fig. 20 . gewann auf diese Weise sehr schöne Bilder der Lichtreaktion der Pupille. Fig. 20 gibt einige der von ihm abgebildeten Aufnahmen wieder. Fuchs verhehlte sich nicht, daß die Untersuchungsschwierigkeiten trotz der guten Technik außerordentlich große sind. Nach seinen Darlegungen bestand die hauptsächlichste in der Unsicherheit, ob zur Zeit der Aufnahme der größte Pupillendurchmesser eingestellt geblieben oder nur ein Segment der Pupille getroffen war. Um sich gegen diese bedenkliche Fehlerquelle einigermaßen zu schützen, maß Fuchs die Pupille sowohl bei der Belichtung unter Zwischenschaltung des blauen Glases, als auch nach dessen Wegnahme mittels

1) Braunstein, E., Zur Lehre von der Innervation der Pupillenbewegung. Wiesbaden 1894.

2) Dogiel, J., Die Beteiligung der Nerven an den Schwankungen der Pupillenweite. Archiv f. d. ges. Physiol. 56, 500. 1894.

3) Fuchs, A., Die Messung der Pupillengröße und Zeitbestimmung der Lichtreaktion der Pupille bei einzelnen Psychosen und Krankheiten. Jahrbücher für Psychiatrie 1903, 326. 
eines der gebräuchlichen Pupillometer und verwertete nur solche photographische Aufnahmen, bei denen die Maße mit den auf die vorgenannte Weise gewonnenen übereinstimmten. Bei seinen Versuchen war er bestrebt, nach Möglichkeit störende Geräusche usw. zu vermeiden, die Versuchspersonen wurden genau mit der Methode vertraut gemacht und ihnen, um Schreckeinflüsse zu vermeiden, der Zeitpunkt der Belichtung vorher angegeben. Trotz aller dieser Vorsichtsmaßregeln gelang es ihm bei ganz willigen, ruhigen Personen kaum unter 3-4 Aufnahmen eine für Messungen brauchbare zu erhalten.

Während Fuchs nach alledem seine Methode trotz schöner Resultate nur in beschränktem Maße für anwendbar hält, zeigt sich Piltz ${ }^{1}$ ) bei der Beschreibung eines ähnlichen Apparates, den er mit Hilfe des Ingenieurs P. Lebiedzinski aus Warschau konstruierte, sehr viel hoffnungsfreudiger, obzwar die von ihm wiedergegebene Abbildung von Pupillenreaktionen nicht sehr deutlich ist. Der von Piltz verwendete Apparat (Fig. 21) ist sehr sinnreich. Fr beschreibt ihn folgendermaßen: ,Der Apparat besteht aus dem Objektiv $A$ von Suter in Basel, mit einer wirksamen Öffnung von $\mathrm{F} / 3,12$, welches in dem Rohr $B$ festsitzt. Das

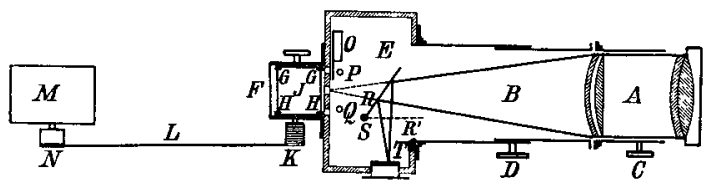

Fig. 21. Hin- und Herschieben des Objektivs mit dem Rohr $B$ wird bewirkt durch die zwei Zahntriebe $C$ und $D$. Das Rohr $B$ ist befestigt an der Kamera $E$, welche hinten eine Filmkassette

besitzt, die man am hellen Tage Iaden und entladen kann. Die Lichtstrahlen vom Auge her, welche das Objektiv verlassen, treffen unterwegs vor dem lichtempfindlichen Papier eine schmale horizontale Spalte, deren Breite man willkürlich regulieren kann. Das lichtempfindliche Papier $G H$ (auf der Fig. 21 sieht man es im Durchschnitt) ist auf den Zylinder $J$ (placiert in der Filmkassette) gewickelt; während der Aufnahme wird dieselbe in vertikaler Richtung in Bewegung gesetzt durch die Bewegung des Zylinders J. Der Zylinder wird von dem Uhrwerk $M$ in Bewegung gesetzt, mit welchem er durch ein leicht biegsames metallisches Seil $L$ verbunden ist. Das Uhrwerk steht auf einer gesonderten Unterlage, um die Erschütterung der Filmkassette möglichst zu verhindern. Die Geschwindigkeit des Uhrwerks $M$ wird mittels eines Windfanges reguliert. In Anbetracht dessen, daß jedes Uhrwerk zur Erreichung einer gegebenen konstanten Geschwindigkeit eine gewisse Zeit in Anspruch nimmt, und andererseits, um dem Beobachter die Möglichkeit zu geben, das lichtempfindliche Papier willkürlich in Bewegung zu setzen, oder es anzuhalten, wurde an dem Uhrwerk $M$ ein besonderes elektromagnetisches System angebracht, das den Zylinder $N$ (des Uhrwerks $M$ ), auf welchen das Seil $L$ gewickelt wird, mit der sich immer in Drehung befindlichen Achse des Uhrwerks $M$ verbindet oder von ihr trennt. Die Geschwindigkeit des lichtempfindlichen Papiers, die Dauer der Beobachtung und die Dauer der Pupillenbewegung gibt an der Chronoskop $O$, welcher im Innern der Kamera $E$ versteckt ist und welcher mit einer Glühlampe $P$ ausgestattet ist. Derselbe gibt uns Teilstriche, welche $1 / 10$ Sekunde entsprechen und welche sich auf dem lichtempfindlichen Papier parallel zu dem Bilde der Pupille photographieren." „Die scharfe Einstellung des Bildes des Auges im Brennpunkte geschieht einerseits mit Hilfe des Spiegels $R$, welcher auf der verti-

1) Piltz, J., Ein neuer Apparat zum Photographieren der Pupillenbewegungen. Neurol. Centralbl. 1904. 
kalen Achse $S$ sich dreht und andererseits mit Hilfe einer mattgeschliffenen Glasscheibe, welche sich an der Seitenwand der Kamera befindet. In der auf der Figur angegebenen Lage verschließt der Spiegel $R$ den Zutritt der Lichtstrahlen zur Filmkassette und reflektiert das Bild des Auges auf die mattgeschliffene Glasscheibe $T$. Nachdem das Bild ganz scharf und deutlich eingestellt wurde, muß der Spiegel $R$ zum Photographieren in die Lage $R^{\prime}$ (eine punktierte Linie) verschoben werden." Piltz beschreibt dann noch einige Vorrichtungen, die eine bequeme Handhabung des Apparates gewährleisten und mit Hilfe deren sonstige Signale mit auf den Papierstreifen photographiert werden können.

Wir sind zu Fnde mit unseren Betrachtungen der älteren Untersuchungsmethoden der Pupille und ihrer Veränderungen, da ich glaube, im vorhergehenden eine allgemeine Übersicht über die hierhin gehörigen Versuchsanordnungen gegeben zu haben, bis zu dem Zeitpunkte, wo ich meine eigene Methodik bekanntgab ${ }^{1}$ ).

\section{Vorbedingungen einer exakten Pupillenuntersuchung.}

Bevor ich zur Darstellung meiner Methode übergehe, wollen wir uns noch einmal vergegenwärtigen, welche Vorbedingungen unerläßlich sind, wenn unsere Untersuchungen den Anspruch auf genaue Registrierung der Pupillenphänomene erheben wollen. Nach den Untersuchungen Schirmers ${ }^{2}$ ) ist es, wie ich oben schon kurz erwähnt habe, zunächst von höchster Wichtigkeit, daß das Auge der Versuchsperson für die Helligkeit, der es ausgesetzt wird, adaptiert ist. Schir mer zeigte, daß die nämliche ins Auge eintretende Lichtstärke sowohl eine Verengerung wie eine Erweiterung der Pupille hervorrufen kann, indem die Art der Bewegung, ob sie in verengerndem oder erweiterndem Sinne an der Pupille sich kundtut, nur von dem Adaptionszustande des Auges abhängig ist. Setzt man das Auge einer bestimmten Helligkeit aus, so dauert es eine längere Zeit, bis dasselbe bzw. die Pupille für diese Beleuchtung eingestellt ist, bis sich die Regina adaptiert hat; kommt die Versuchsperson von einem dunklen in einen helleren Raum, so dauert es ca. 5 Minuten, bis ihre Pupille die dem Licht entsprechende Weite hat, kommt sie dagegen aus einem helleren in einen dunkleren Raum, so erweitert sich die Pupille sehr langsam und erreicht erst nach ca. 15 bis 20 Minuten eine Größe, die von da ab, bei Ausschluß von neuen Reizen, konstant bleibt. Schirmer wies dann ferner nach, daß die Größe der Pupille bei maximaler Adaptation des Auges bei allen Helligkeiten, die in den Grenzen von 100-1100 Meterkerzen liegen, genau die gleiche ist und bezeichnete sie als die physiologische Pupillenweite , $\varkappa \alpha \tau$ '

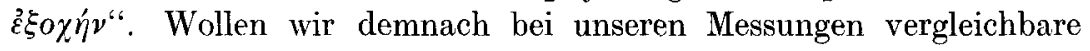
Werte erhalten, so müssen wir zunächst feststellen, bei welcher Hellig-

1) Weiler, K., Demonstration eines neuen Pupillenmeßapparates. Jahresvers. d. Vereins bayer. Psychiater, München, Juni 1905. Neurol. Centralbl. 1905, 682 .

2) Schir mer, O., Untersuchungen zur Physiologie der Pupillen weite. v. Graefes Archiv 40, 5, 8. 1894 . 
keit die Untersuchung vorgenommen wurde, und dann dafür sorgen, daß der Versuchsperson vor Beginn der Versuche genügend Zeit gelassen wird, damit sich ihr Auge an diese Helligkeit adaptieren kann. Die Vernachlässigung dieser Vorbedingung allein macht schon das ganze Ergebnis der Untersuchung problematisch; wir laufen Gefahr, eine Pupillenreaktion auf Licht nur deswegen als gering anzusehen, weil wir, falls die Untersuchung im Dunkelzimmer vorgenommen wird, zu schnell nach Eintritt der Versuchsperson die Reaktion prüften. Das Auge war noch nicht adaptiert, die Nachwirkung der Helligkeit des Raumes, in dem sie sich vorher befand, dauerte noch an und wir konnten deshalb durch Belichtung des Auges mit einem Licht, das vielleicht sogar geringer war als das, dem der Untersuchte sich vorher lange Zeit aussetzte, keine stärkere Iriskontraktion erzielen. Wir werden daher auch unsere Untersuchungen am zweckmäßigsten im Dunkelzimmer vornehmen, da wir sonst jedesmal die Helligkeit des Untersuchungsraumes vorher bestimmen müßten.

Zur Untersuchung werden wir nur solche Apparate verwenden, welche die Versuchsperson möglichst wenig stören, die keine Geräusche machen und die ausschließen, daß während des Versuchs unmerklich Akkommodationsveränderungen eintreten. Die Versuchsperson muß nach Möglichkeit mit der Untersuchungsmethode bekannt gemacht werden, damit sie beim Versuch durch die Handhabung des Apparates nicht in Erstaunen, Angst oder dgl. versetzt wird, da sonst eintretende, psychisch bewirkte Veränderungen der Pupilleninnervation die genaue Untersuchung unmöglich machen. Dieser letzteren Forderung muß natürlich um so mehr Gewicht beigelegt werden, wenn es sich bei der Untersuchung nicht um gesunde Personen, sondern um Nervenleidende oder Geisteskranke handelt.

Wie aus meinen Darlegungen hervorgegangen sein dürfte, steht uns zwar eine ganze Anzahl von Methoden und Apparaten zur Untersuchung der Pupillen zur Verfügung, die zum Teil recht gut sind zur Feststellung der Größe der Pupillen oder einzelner Phänomene, jedoch findet sich darunter kein Instrument, mit dessen Hilfe man alle bei der Pupillenuntersuchung in Betracht kommenden Vorgänge exakt messen kann. Dies zu erreichen war mein Ziel, als ich daran ging, selbst einen der Pupillenmessung dienenden Apparatenkomplex zusammenzustellen und eine Methode auszubauen. Ich stellte mir dabei folgende Aufgabe:

1. Der Apparat sollte gestatten, ein beliebig starkes, veränderbares Licht in das eine oder andere Auge oder in beide gleichzeitig so zu projizieren, daß möglichst der zentrale Teil der Retina von ihm getroffen würde.

2. Die Pupillengröße sollte unter Ausschluß von akkommodativen Veränderungen bei jeder beliebigen Beleuchtungsstärke bis auf 
$1 / 10 \mathrm{~mm}$ meßbar sein, und zwar sollte der Meßapparat so eingerichtet sein, daß die Richtigkeit der Messung durch eine zweite Person außer dem Versuchsleiter kontrolliert werden könnte.

3. Der Apparat sollte eine Vorrichtung enthalten, die gestattete, ein Auge oder beide sowohl momentan als auch für längere Zeit zu belichten.

4. Die Zeit zwischen Reiz und Bewegung der Iris, wie auch die Kontraktionszeit der Schließmuskeln sollte auf graphischem Wege bestimmbar sein.

5. Der Apparat sollte photographische Aufnahmen der Pupille bzw. der Bewegungen der Irismuskulatur ermöglichen, und zwar unter Verwendung der bei der gewöhnlichen Untersuchung benutzten Lichtquelle.

6. Die Größe der Konvergenzreaktion sollte bestimmbar sein.

7. Die Pupille sollte derartig vergrößert sichtbar sein, daß die Einflüsse von psychischen Reizen usw. gut studierbar wären.

8. Der zeitliche Ablauf dieser Bewegungen sollte feststellbar sein.

9. Die Handhabung des Apparates sollte möglichst einfach und ohne jedes Geräusch vor sich gehen können.

Inwieweit ich dieser Aufgabe gerecht werden konnte, mögen die folgenden Ausführungen zeigen.

\section{Eigene Methodik.}

Nach jahrelangen Versuchen erhielt mein Apparat ${ }^{1}$ ) die in Fig. 22 schematisch dargestellte Anlage. Fig. 23 zeigt ihn seitlich geöffnet -die Seitenwände wurden, soweit möglich, abgeschraubt - und Fig. 24 läßt einen Blick in sein Inneres tun, nachdem die ihn verschließenden Türen geöffnet wurden. Die Maße des aus Metall gearbeiteten Instrumentes sind so gehalten, daß die Augen der bequem am Tisch sitzenden Versuchsperson in annähernd gleicher Höhe stehen mit den zur Beobachtung der Pupillen im Apparat eingeschnittenen Offnungen. Dieser besteht im wesentlichen aus 3 Teilen, die in Fig. 22 mit I, II und III gekennzeichnet sind.

In dem Kasten I ist die Beleuchtungsvorrichtung untergebracht. Nach vielen Vorversuchen entschied ich mich, als Lichtquelle Nernstlampen zu verwenden, hauptsächlich deshalb, weil sie ein annähernd punktförmiges und dabei fast weißes Licht geben, das sich neben dem Bogenlicht sehr gut für photographische Zwecke eignet. Wie aus der Fig. 24 deutlich ersichtlich ist, sind 2 Nernstlampen, für jedes Auge eine, eingebaut. Das Licht der Lampen (Fig. 22,a) wird durch einen kompli-

1) Der Apparat wird hergestellt durch die Firma M. Sendtner-München, Schillerstr. 22. 
zierten Kondensator $(b, c)$, auf dessen Einrichtung ich später zurückkomme, an einem Punkte vereinigt, der in der oberen Platte des Kastens I liegt. Hier ist in diesen ein kleines, rundes Loch von $1 \mathrm{~cm}$ Durchmesser eingebohrt $(d)$. Durch diese Öffnung kann nun das Lichtbündel in den dem ersten aufgebauten Kasten II gelangen. Dabei muß es zunächst

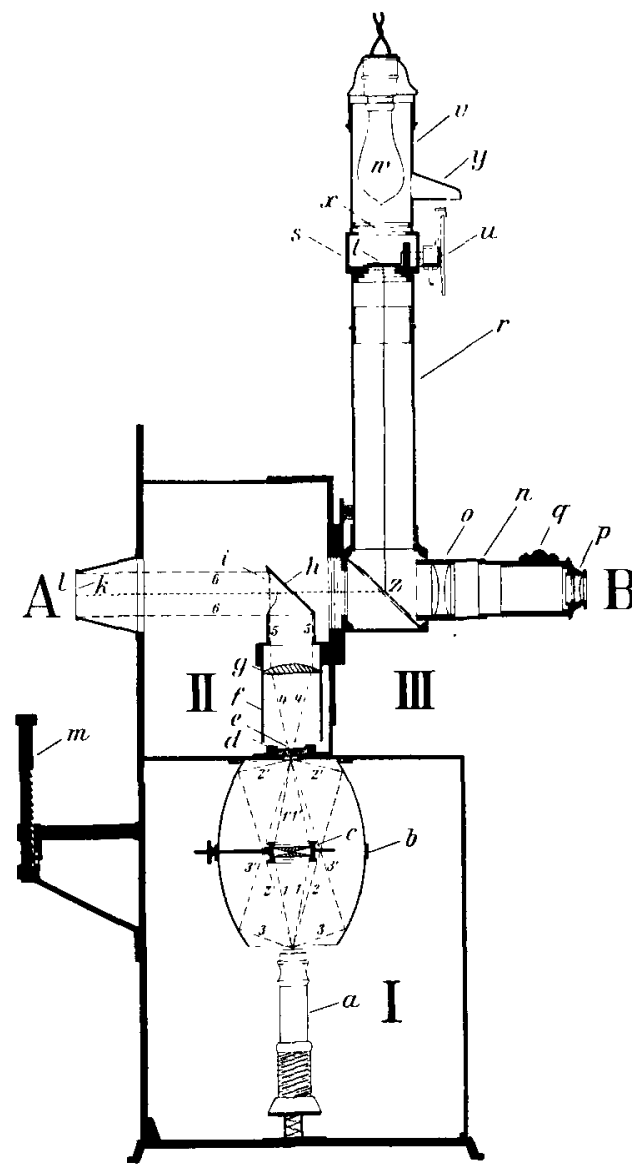

Fig. 22. noch ein Filter $(e)$ durchdringen, dessen Bedeutung weiter unten beschrieben werden soll. Das austretende Licht wird, wie deutlich aus den Fig. 22 und 23 hervorgeht, von Metallhülsen $(f)$ umschlossen und dann von einer plankonvexen Linse $(g)$ aufgefangen, wodurch die Strahlen zu einem parallelen Bündel zusammengefaßt werden. Nach dem Durchgang durch die Linse trifft das Strahlenbündel unter einem Winkel von $45^{\circ}$ auf einen Spiegel $(h)$, der die Metallhülse nach oben abschließt, verläßt diese darauf durch die Öffnung $(i)$ und tritt bei $k$ aus dem Apparat aus. Das Auge der Versuchsperson befindet sich bei $A$, die Pupille in der Ebene von $l$. Der Kopf der Versuchsperson wird durch eine verstellbare Kinnstütze $(m)$ und durch Anlegen der Orbitalränder an die aus der Wand des Apparates vorstehenden, in der Zeichnung deutlichen Metalldüsen gehalten. Das Lichtbündel fällt, wie aus Fig. 24 ersichtlich, etwas schräg ins Auge (unter einem Winkel von ca. $10^{\circ}$ ). Damit dürfte die Forderung, daß möglichst der zentrale Retinateil von dem Licht getroffen werden soll, in hinreichender Weise erfüllt sein. Während die Lichtquellen im unteren Kasten nur durch die Kondensorrorrichtung abgeschlossen sind, ist der obere Kasten durch eine Scheidewand in zwei Hälften lichtdicht getrennt.

Der dritte Teil des Apparates (III) dient zur Beobachtung der 
Pupille. Der Beobachter schaut bei $B$ durch einen Vergrößerungsapparat, der ähnlich wie die Brückesche Lupe konstruiert wurde, $d . h$. wie eine Lupe mit sehr langer Brennweite. In dem Rohr $u$ zeigt Fig. 22 das Objektiv $o$; bei $p$ ist das Okular eingesteckt, das durch einen Zahntrieb $(q u)$ gegen das Objektiv verschoben werden kann. Diese Lupe steckt in einem kleinen viereckigen Kästchen, auf dem sich in einem rechten Winkel ein zweites Rohr $(r)$ erhebt. Auf dieses ist ein kleines Kästchen $(s)$ aufgesteckt (drehbar um die vertikale Axe), in dem ein Meßapparat $(t)$ untergebracht ist, der weiter unten genauer beschrieben werden soll. An der Außenseite des Kästchens befindet sich eine eingeteilte Scheibe $(u)$, auf welcher der jeweilige Stand des Meßapparates abgelesen werden kann (siehe unten). Uber dem Kästchen erhebt sich nochmals ein Rohr $(v)$, in dem eine kleine Glühlampe $(w)$ (10 Kerzen, 110-220 Volt) untergebracht ist. Deren Licht fällt auf eine Mattscheibe $(x)$, die in der Decke des Kästchens $s$ befestigt ist. Das Licht der Glühlampe wird durch eine Spiegelvorrichtung $(y)$ zugleich zur Beleuchtung der Skala $(u)$ benutzt. Der Meßapparat $(t)$ ist durchscheinend, sein Bild wird von einer unter einem Winkel von $45^{\circ}$ gestellten planparallelen Glasplatte $(z)$, die in

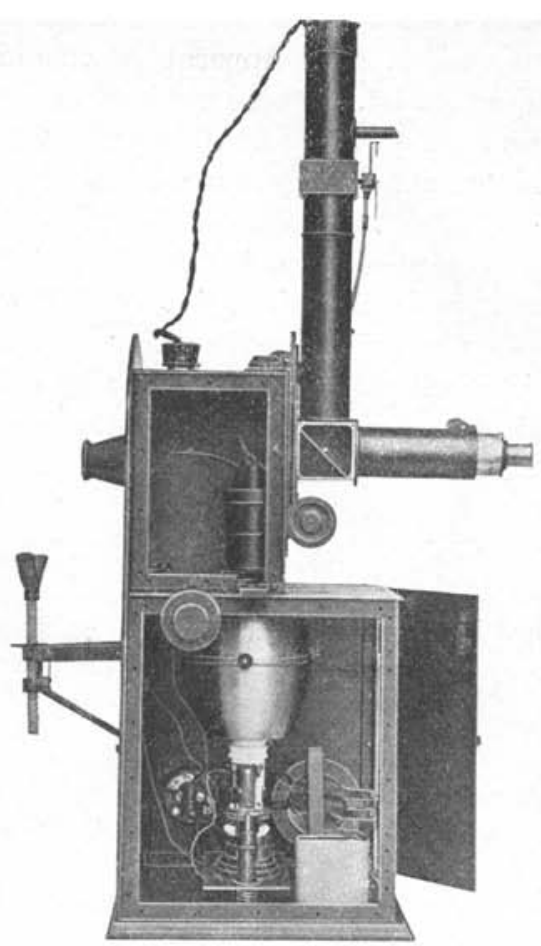

Fig. 23.

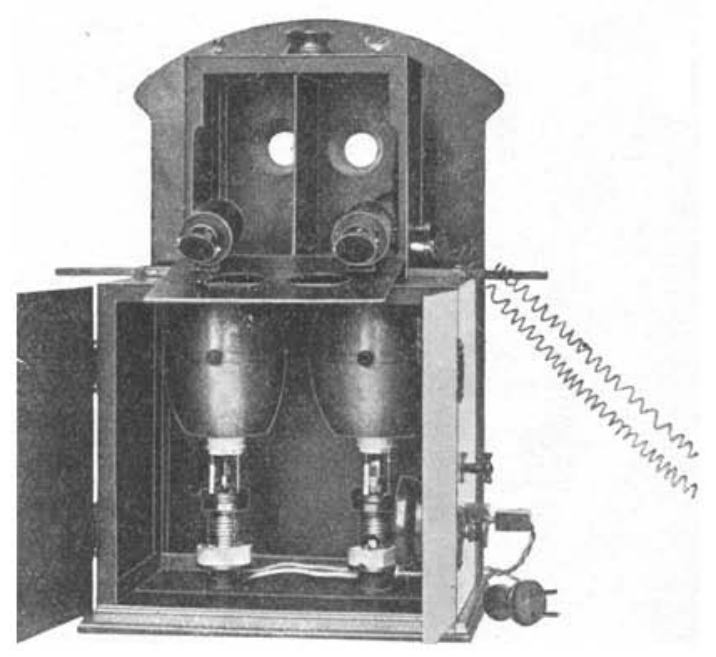

Fig. 24. 
dem Verbindungskasten der Lupe und des Rohres $v$ untergebracht ist, reflektiert. Der Apparat ist so eingerichtet, daß die Entfernung $A z$ gleich $l z$ ist. Nach den Gesetzen der Reflexion erscheint demnach das Bild des Meßapparates $A$ am Pupillenort $l$, da es um die gleiche Strecke hinter der spiegelnden Glasplatte zu liegen scheint, wie es tatsächlich davorsteht. Der Beobachter $(B)$ sieht also die Pupille und den scheinbar darin liegenden Meßapparat in vergrößertem Maßstab. Die Vergrößerung ist veränderbar, sie schwankt zwischen 3- bis 9 maliger, je nachdem bei $p$ schwächere oder stärkere Okulare eingeschoben werden.

Nachdem wir damit eine allgemeine UUbersicht über die größeren Einrichtungen des Apparates gewonnen haben, wollen wir seine einzelnen Teile und noch unbesprochene, kleinere Vorrichtungen eingehender erläutern.

\section{Der Beleuchtungsapparat.}

Die Fig. 25 zeigt uns schematisch den Strahlengang des von

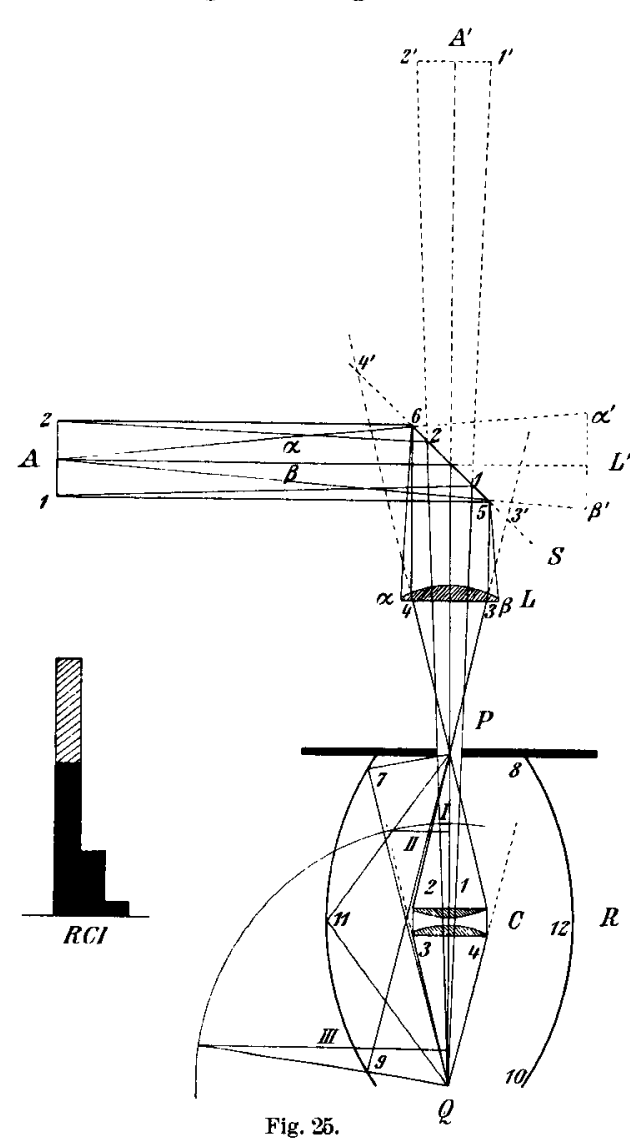
der Nernstlampe entsendeten Lichtes. Der Punkt $Q$ bezeichnet die Lage des Glühstäbchens der Lampe. Die zu beleuchtende Fläche am Augenort $A$ hat einen Durchmesser von ca. $30 \mathrm{~mm}$. Das Licht des Nernstbrenners würde ohne besondere Vorrichtungen nur in sehr geringem Grade ausgenützt werden, und zwar nur ein schmaler Lichtkegel, dessen Spitze bei $Q$ liegen und dessen Basis durch den Kreis $A$ 1-2 gebildet würde. Bei $\mathrm{P}$ tritt das Licht aus dem unteren in den oberen Kasten und passiert dabei ein Filter, das wir weiter unten besprechen werden und das allgemeinhin als eine mattgeschliffene Glasplatte hetrachtet werden kann. Um in der Ausnützung des Lichtes weiter zu gehen, schalten wir zunächst in der Mitte $\mathrm{z}$ wischen Lichtquelle und 
dem genannten Filter Kondensorlinsen $(C)$ ein, die von $Q$ in $P$ ein gleichgroßes Bild entwerfen. Eine weitere, plankonvexe Linse $L$ macht die von $P$ kommenden Strahlen über die Öffnung $L$ 3-4, welche die gleiche Größe wie $A$ 1--2 hat, parallel, so daß der Spiegel $S$ nicht viel größer als der Linsendurchmesser zu sein braucht. Es wird nun alles zwischen $C$ 3-4 ausstrahlende Licht in $A 1-2$ vereinigt. Man gelangt bei dieser Anordnung an die Grenze der Leistungsfähigkeit, wenn der Durchmesser C 3-4 der zwei Kondensorlinsen, welche die plane Seite nach außen, die konvexe einander zukehren, höchstens etwa $1 / 2$ ihrer kombinierten Brennweite, also $1 / 4$ der Entfernung $C Q-C P$ beträgt.

Ein Blick auf die Fig. 25 zeigt, daß die benützte Lichtmenge zur erzeugten noch in sehr ungünstigem Verhältnis steht. Die Nutzwirkung läßt sich aufs äußerste treiben, wenn wir um $P$ und $Q$ als Brennpunkte einen elliptisch gekrümmten Reflektor anbringen, welcher der bekannten Eigenschaft der Ellipse zufolge alle von $Q$ ausgehenden Strahlen in $R$ 5-10 nach $P$ reflektiert. Die zur Beleuchtung des Auges verwendete Lichtmenge wird dadurch erheblich gesteigert, allerdings gelangt sie durch den hohen Reflexionsverlust nur mit etwa $60 \%$ zur Ausnützung.

In der Ausführung würde sich die elliptische Form nur schwer genau erzielen lassen. Da also Fehler unvermeidlich und in der Strahlenvereinigung der Kondensoren auch schon vorhanden sind, wurde der Schnitt durch den Reflektor nicht elliptisch, sondern sphärisch geformt, wodurch sich die genaue Ausführung erheblich vereinfacht. Der Radius des Kreisbogens $R 5-7-9$ ist dann etwa gleich der Distanz $P Q$. Würde man die Kondensorlinsen kleiner im Durchmesser machen, so würde auch der Durchmesser $R$ 7-8 abnehmen, jedoch scheinen die verwendeten Maßverhältnisse ein Maximum der Leistung zu verbürgen, und die Reflektoren ließen sich noch gut nebeneinander in dem Kasten I des Apparates unterbringen.

Man könnte den Einwand machen, daß die durch den Reflektor gewonnene Lichtmenge infolge der großen Neigung der Strahlen zu der Mattscheibe bei $P$ nicht mehr durch die Linse $L$ gehen könne, demnach zwecklos sei. Dabei ist jedoch zu bedenken, daß die Strahlen die Mattscheibe ja nicht durchdringen, sondern sie nur helleuchtend machen, indem jedes Teilchen derselben das empfangene Licht weiterstrahlt. Es kommt daher nur darauf an, daß möglichst viel Licht zu ihnen gelangt.

Dem Mathematiker unter den Lesern ist hekannt, daß die Intensität des Lichtes proportional der Oberfläche der ausstrahlenden Calotte, und diese proportional der Höhe der Kugelhaube ist. Berücksichtigt man dies und die Tatsache, daß in der Praxis Strahlen von mehr als $80^{\circ}$ Neigung nicht mehr zur Geltung kommen, so ergibt sich der Effekt des Beleuchtungsapparates ohne Kondensoren und Spiegel zu I, mit den 
Kondensoren zu $C$ und mit dem Reflektor zu $R$. Auf diese Art dürfte das Nernstlampenlicht in möglichst ausgiebiger Weise ausgenützt $\operatorname{sein}^{1}$ ).

Fig. 26 zeigt noch die Einrichtung der Kondensoren und der Spiegel. Der ganze Apparat kann leicht aus dem Kasten I herausgenommen

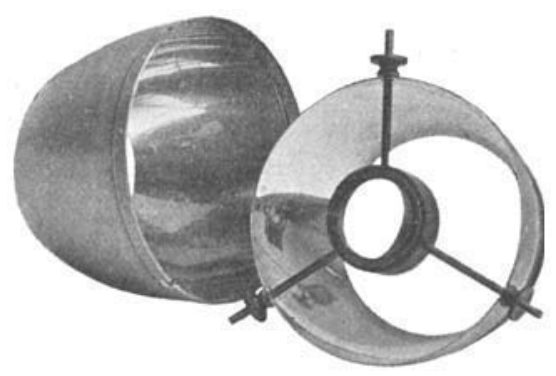

Fig. 26. werden. Dies ist deshalb notwendig, weil die Lichtquelle doch mit der Zeit die über ihr hängenden Teile berußt, so daß sie gereinigt werden müssen. $\mathrm{Zu}$ dem Zwecke sind die Spiegelkalotten aus einem polierten Weißmetall, in der Mitte auseinandernehmbar, hergestellt, wie es die Fig. 26 zeigt. In ihnen ist der Kondensor an 3 Stäben, durch Schrauben einstellbar, aufgehängt.

Die Fig. 27 soll die Einrichtung der bei $P$ eingefügten Lichtfilter und ihren Zweck erläutern. Zugleich zeigt sie die Vorrichtung zur Belichtung des Auges. Der Grundriß der Zeichnung stellt die obere Platte des Kastens I dar; über ihr ist der Kasten II im Querschnitt angegeben. An der rechten Seitenwand dieses Kastens stehen 3 Druckknöpfe (I, II

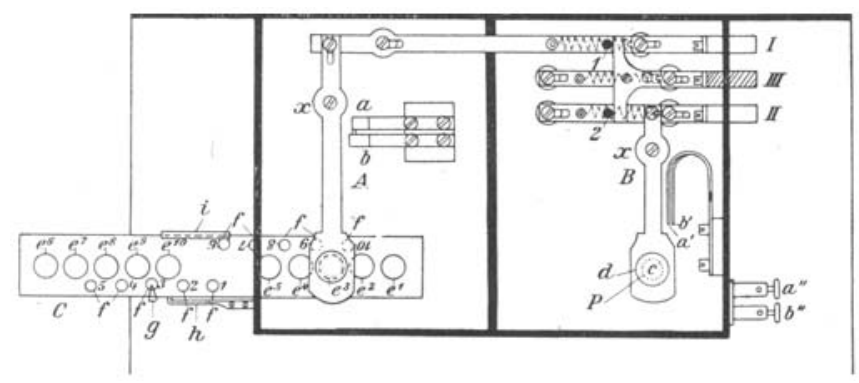

Fig. 27.

und III) vor. Durch Druck gegen diese werden die Hebel $A$ und $B$ um ihre Achsen $x$ gedreht, und zwar steht der Knopf bzw. die Stange I mit dem Hebel $A$, der Knopf II mit dem Hebel $B$ in Verbindung. Sollen beide Hebel zugleich bewegt werden, so genügt ein Druck auf den Knopf III, wodurch die Schieber I und II mit Hilfe der Zapfen 1 und 2 mitgenommen werden. An dem Apparat ist noch eine Vorrichtung (in der Figur nicht gezeichnet) angebracht, durch welche die Hebel nach der

1) Ich will nicht verfehlen, auch an dieser Stelle Herrn Joh. Kaiser, Rechner bei C. Zeiß, Jena, für die Berechnung der im Apparat verwendeten Linsensysteme und der Spiegelkalotten meinen Dank auszusprechen. 
Bewegung in der veränderten Stellung festgehalten werden können, während sie ohne Einschaltung dieser Hemmung durch Federzug nach Aufhören des Druckes in ihre alte Lage zurückschnellen. Werden die Hebel $A$ und $B$ in Bewegung gesetzt, so treffen sie auf die Federn $a$ und $b$ und $a^{\prime}$ und $b^{\prime}$, wodurch diese gegeneinander angepreßt werden. Führt man bei $a^{\prime \prime}$ und $b^{\prime \prime}$ einen elektrischen Strom in den Apparat, so wird dieser in dem Moment, wo sich die Federn $a$ und $b$ oder $a^{\prime}$ und $b^{\prime}$ berühren, geschlossen.

Die Endscheiben der Hebel befinden sich in der Ruhelage gerade über der in der Fig. 25 mit $P$, hier mit $P$ und $c$ bezeichneten Öffnung. Wären sie undurchlässig für Licht, so würden sie also in ihrer Ruhelage die Lichtzufuhr zu dem oberen Kasten und dem Auge der Versuchsperson abschließen, während bei Druck auf die Knöpfe I, II oder III das Licht ungestört durchfallen könnte. Auf diese Art würden wir das Auge, welches vorher in voller Dunkelheit war, mit dem hellen Licht unseres Beleuchtungsapparates belichten können, ähnlich wie wir es mit einer einfachen Pupillenlampe erreichen, bei der das Licht durch Druck auf einen Kontaktknopf entsteht.

Wie aus unserer Aufgabestellung ersichtlich ist, sollte das Licht in beliebiger, veränderbarer Stärke zur Verfügung stehen und es sollten Messungen der Pupille bei jeder beliebigen Lichtstärke möglich sein. Dieses Ziel wurde durch zwei Vorrichtungen erreicht. Die Öffnung $P$ wurde verdeckt durch ein für Licht durchgängiges Filter, das in der Figur mit $C$ bezeichnet ist. Es besteht aus einem kleinen flachen Metallkästchen, in dessen beide Wände 10 größere $(e 1-10)$ und 10 kleinere ( $f$ 1-10) Löcher gebohrt sind. In dem Kästchen liegt zunächst eine feingeschliffene Mattscheibe. An der Stelle des Loches $e^{1}$ befindet sich außer dieser Scheibe kein weiteres Hindernis für das durchfallende Licht, während bei $e^{2}$ noch ein Pflanzenpapierblättchen, wie sie zu den bekannten, zu photographischen Zwecken benutzten Photometern verwendet werden, aufgelegt ist. Bei $e^{3}$ befinden sich 2 solche Blättchen, bei $e^{4}$ sind 3 mit vorgeschaltet usf. Es ist klar, daß das durchfallende Licht um so schwächer wird, je mehr Blättchen zwischengeschaltet werden. Das Filterkästchen kann nun in dem Apparat beliebig verschoben werden, und der Zeiger S gibt außen an, welches Loch des Filters gerade über der Durchfallsöffnung des Lichtes steht, wie dies die Figur deutlich zeigen dürfte. In den kleineren Löchern (f $1-10)$ sind Nummern eingeschrieben, die mit den Nummern der größeren Löcher $(e$ l-10) in dem Sinne korrespondieren, daß sich z. B. das mit 3 bezeichnete kleine Loch gerade unter dem Zeiger $g$ befindet, wenn das dritte große Loch über der Lichtöffnung steht. Eine Einschnappvorrichtung $(h)$ sorgt dafür, daß die Finstellung der Öffnungen nur genau übereinander geschehen kann. Auf diese Art erreichen wir, daß 
das Licht der Nernstlampe in 10 verschiedenen Stärken in den oberen Kasten eintreten kann, ohne daß sich seine Farbe ändert. Die Einlage der Mattscheibe bietet noch verschiedene, nicht unwesentliche Vorteile. Zunächst wird dadurch das Licht gemildert, so daß eine allzu grelle, blendende Beleuchtung der Augen der Versuchsperson ausgeschlossen ist, zugleich werden die Wärmestrahlen fast völlig abgefangen, so daß nach genauen Messungen die Erwärmung am Ort der Pupille ganz gering ist (nach 10 Minuten langer Belichtung betrug sie noch nicht ganz $1^{\circ} \mathrm{C}$ ). Das in den Glasplatten fortgeleitete Licht ist eben genügend, um die Nummern der Schieber, die ja außerhalb des Kastens II ablesbar sein sollen, zu erhellen, so daß die Orientierung auch im Dunkelzimmer leicht möglich ist. Wären die Endplatten der Schieber $A$ und $B$ vollständig massiv, so könnten wir also jetzt durch ihre Fortbewegung von der Öffnung $P$ und dem darübergelegten Filter die Retina unserer Versuchsperson mit einem Licht von veränderbarer Stärke treffen. Über die Form der Pupille vor Belichtung des Auges könnten wir so jedoch kein Urteil gewinnen, da dieses ja zunächst in vollkommenem Dunkel ist. Da es uns aber darauf ankommt, die Größe der Pupille auch vor dem Einfall stärkeren Lichtes zu messen, mußte eine Dauerbelichtung des Auges ermöglicht werden, die allerdings nur von sehr geringer Intensität sein durfte. Zu dem Zwecke wurden die Endplatten der Hebel $A$ und $B$ durchbohrt. Das entstandene Loch $(d)$ wurde darauf durch eine Anzahl von Pflanzenpapierblättchen verschlossen, so daß nur mehr gerade so viel Licht durchtreten konnte, als zur Belichtung des Auges notwendig war, wollte man noch genau die Grenzen der Pupille sehen. Das auf diese Art mit minimalstem Licht erhellte Auge kann dann durch Wegschieben der Hebel mit beliebig starkem Licht bestrahlt werden.

In der Zeichnung ist das Filterkästchen nur einseitig eingefügt, selbstverständlich findet sich am Apparat auch an der gegenüberliegenden Seite ein ganz gleich gearbeitetes Filter.

\section{Der Beobachtungs- und Meßapparat.}

In Fig. 28a ist der Teil des Apparates dargestellt, der die Vergrößerungs- und Meßeinrichtungen enthält. Durch zwei Klemmschrauben (Fig. 24) wird er an dem oberen Kasten (II) befestigt. Seine Einstellung auf das zu untersuchende Auge geschieht durch zwei Zahntriebe in vertikaler und horizontaler Richtung. Dabei ist Vorsorge getroffen, daß der Kasten, in den die Versuchsperson schaut, bei den Bewegungen des Beobachtungsapparates völlig lichtdicht abgeschlossen bleibt. Die Glühlampe, welche den Meßapparat beleuchtet, wird durch Stöpselung in einem an der obersten Platte des Apparates angebrachten Steckkontakt mit dem elektrischen Strom in Verbindung gebracht. 
Nun noch einige Worte über den Meßapparat. In der kleinen schematischen Zeichnung (Fig. 28b) wird seine Anordnung gezeigt. Utber einer mattgrauen Glasplatte (photographische Platte) können zwei parallel gestellte Metallstäbe durch einen Zahnradmechanismus gegeneinander bewegt werden. Die Glasplatte liegt flach auf dem Boden des kleinen Kästchens, das in Fig. 22 mit s bezeichnet wurde und über ihr gleiten die parallel gerichteten Stäbe. Deren Bewegung zeigt sich in einer Drehung der außen am Apparat sichtbaren runden Scheibe, die mit einer Einteilung versehen ist, auf welcher der jeweilige Abstand der beiden Stäbe in $1 / 10 \mathrm{~mm}$ abgelesen werden kann. Die Bewegung der Stäbe kann durch Drehen an dieser Scheibe bewerkstelligt werden. Da diese jedoch sehr hoch am Apparat angebracht ist, ermüdet dabei, wie die Erfahrung zeigte, die Hand des Versuchsleiters bei längeren Versuchen sehr stark. Es wurde deshalb die Bewegung der Stäbe durch eine biegsame Welle und einen Zahntrieb ermöglicht, der an dem das Beobachtungsrohr mit dem senkrecht stehenden Rohr verbindenden Kasten angebracht ist. Von hier aus kann die Stellung der Stäbe ohne jede Schwierigkeit verändert werden.

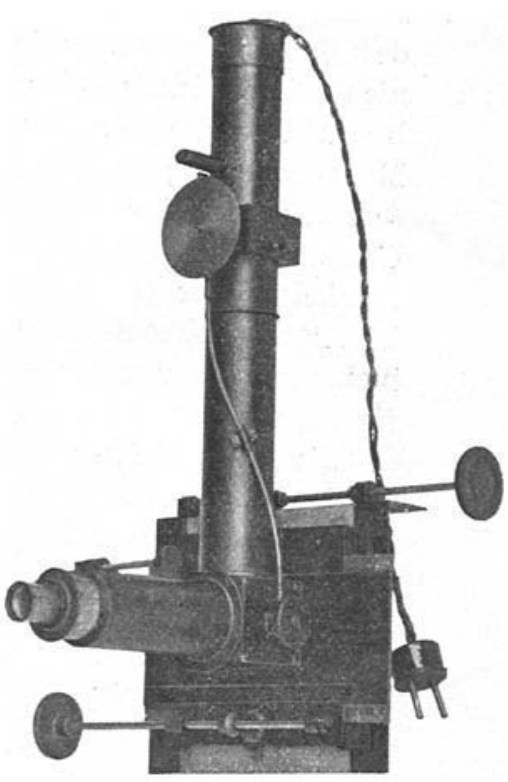

Fig. 28a. In der Mitte der Glasplatte, an der Stelle, bei der die Distanz der Stäbe gleich Null ist, befindet sich eine weiße Linie, d. h. hier ist die Platte ganz ungefärbt.

Die Messung der Pupillengröße geht nun folgendermaßen vor sich. Der Meßapparat wird an den Apparat angeschraubt, seine Lampe durch Anstöpseln der Leitung zum Erglühen gebracht. Dadurch wird die

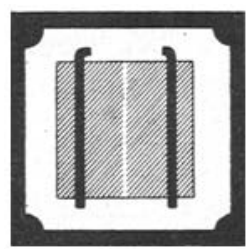

Fig. $28 \mathrm{~b}$. Platte mit den Stäben beleuchtet, und wir sehen infolge der Spiegelung im Apparat (nach unseren obigen Auseinandersetzungen) das Bild der Platte und der darüberliegenden Stäbe am Pupillenort, d. h. es erscheint dort eine senkrechte weiße Linie, von der beiderseits gleich weit entfernt zwei schwarze Stäbe stehen. Mit Hilfe der den Meßapparat verschiebenden Zahntriebe, stelle ich diesen nun zunächst so ein, daß die weiße Linie die Pupille der Versuchsperson in der Mitte schneidet, was sehr leicht zu bewerkstelligen ist. Darauf schiebe ich die Stäbe so lange durch Drehen an dem mit ihnen verbundenen Triebapparat hin und her, 
bis ihre Bilder als Tangenten an den Rändern der Pupille stehen, und lese an der graduierten Scheibe ihre Distanz bzw. die Größe der Pupille direkt in $1 / 10 \mathrm{~mm}$ ab.

Hierbei ist noch einem Umstande Rechnung zu tragen. Ist das Auge der Versuchsperson nur ganz gering beleuchtet, der Meßapparat jedoch stark (die Glühlampe brenne mit voller Stärke), so sieht man das Bild des Meßapparates sehr deutlich, das des Auges jedoch kaum oder gar nicht. Die Lichtstrahlen des Spiegelbildes überdecken die des direkt betrachteten Auges. Ist umgekehrt das Auge stark belichtet und die Meßvorrichtung verhältnismäßig schwach, so sieht man das Auge scharf, während von den Maßstäben nichts zu sehen ist. Um diesem Ubelstand zu begegnen, wurde in den Stromkreis der Glühlampe ein Dunkelschalter (Regulierwiderstand) eingeschaltet (man sieht ihn in Fig. 24 unten rechts im Kasten I), mit Hilfe dessen die Beleuchtung des Meßapparates der der Augen jeweils angepaßt werden kann, so daß man Maßstäbe und Pupille gleichmäßig deutlich sieht.

Diese Art der Messung hat, abgesehen von dem Umstand, daß die Versuchsperson nichts von ihr bemerkt, den Vorteil, daß nach Einstellung der Stäbe die Richtigkeit der Messung sowohl von dem Versuchsleiter wie auch von dritten Personen nachgeprüft bzw. ein Fehler korrigiert werden kann.

Da es häufig von Interesse sein kann, nicht nur den senkrechten Durchmesser der Pupille zu messen, wurde der Apparat so eingerichtet, daß der die Maßstäbe bergende Teil um seine vertikale Achse gedreht werden kann. Dadurch dreht sich das Bild der Stäbe in der Pupille, und nun kann man an ihr jeden beliebigen Diameter messen.

Die Stärke des am Pupillenort aus dem Apparat tretenden Lichtes läßt sich leicht photometrisch bestimmen. Da es jedoch für den gewöhnlichen Gebrauch weniger darauf ankommt, zu wissen, wie stark das benutzte Licht ist, als vielmehr, ob es beiderseits gleich stark ist, will ich nicht verfehlen, eine Methode anzugeben, mittels der man sich hierüber schnell ein objektives Urteil verschaffen kann. Man nimmt ein weißes Blatt Papier und zieht darauf einige schwarze Linien von ca. $10 \mathrm{~cm}$ Länge in einem Abstand von einigen Millimetern. Dieses Blatt befestigt man so an dem Apparat, daß es die beiden Eingucköffnungen überdeckt und die schwarzen Linien am Pupillenort sichtbar sind; darauf beleuchtet man es mit dem Licht des Apparates. Nachdem dies geschehen, stellt man den Beobachtungsapparat auf der einen Seite so ein, da $\boldsymbol{B}$ die Linien auf dem Blatt gut und die Stäbchen des Meßapparates eben noch sichtbar sind. Führt man nun den Beobachtungsapparat, ohne an dessen Beleuchtung etwas zu ändern, zur anderen Seite hinüber, so müssen auch hier die schwarzen Linien gut und die Meßstäbchen eben noch sichtbar sein. Ist dies der Fall, so hat man die Gewißheit, daß die Licht- 
stärke am Pupillenort beiderseits gleichgroß ist. Verschwinden dagegen die Meßstäbchen, so ist das Licht auf der zuletzt beobachteten Seite stärker, verschwinden die Linien auf dem Blatt oder werden sie undeutlich, so ist es schwächer. Die ev. nötige Regulierung bewerkstelligt man dann entweder mit Hilfe der Lichtfilter oder durch Einsetzen neuer Nernstbrenner.

\section{Apparat zur Messung der Konvergenzbewegung.}

Um zu verhüten, daß die Versuchsperson während der Untersuchung Akkommodationsveränderungen vornimmt, wurde der obere Kasten, in den sie schaut, durch eine mittlere Scheidewand getrennt, so daß sich kein für beide Augen gleichzeitig fixierbarer Punkt ergibt. Ich be- $P$ merke hier, daß der ganze Apparat innen und außen völlig geschwärzt ist. Die Versuchsperson wird zu Beginn der Messung aufgefordert, ruhig geradeaus gegen die schwarze Wand des Kastens zu blicken.

Wir hatten in unserer Aufgabe auch die Forderung aufgenommen, die Konvergenzreaktion meßbar zu machen. Um dies bewerkstelligen zu können, mußte der Versuchsperson ein Fixierpunkt gegeben werden, der in enge Nähe zwischen ihre Augen gebracht werden kann. Als Maximum der Annäherung dürften $7 \mathrm{~cm}$ Entfernung vom Auge genügen. Man hätte nun einfach so vorgehen können, an einem bestimmten Punkt in der Scheidewand des oberen Kastens ein helles Objekt an-

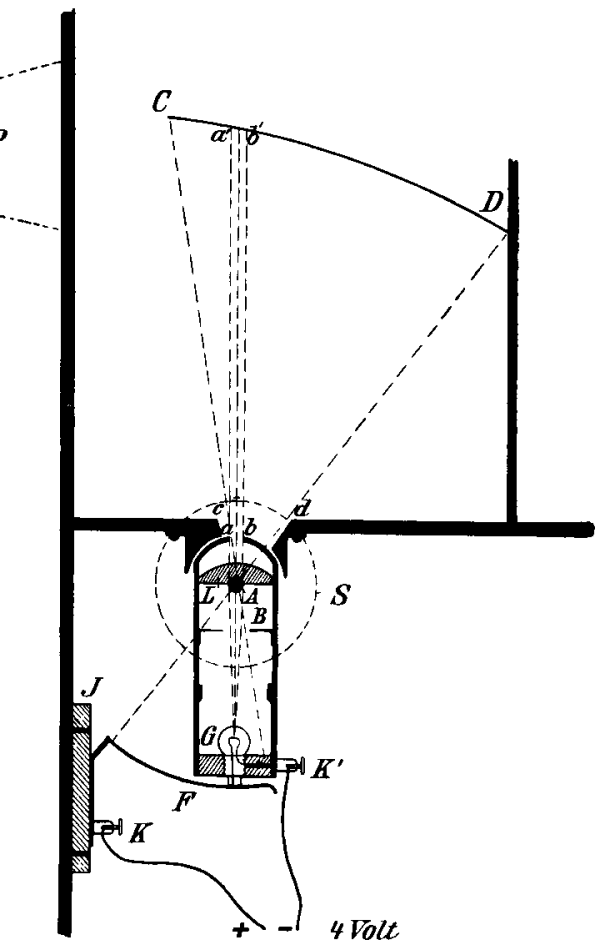

Fig. 2\%. zubringen, das die Versuchsperson nach Aufforderung zu fixieren hätte. Bei dahingehenden Versuchen stellte sich jedoch heraus, daß es ihr nur selten gelang, das zu sehende Objekt zu finden. Ich baute daher meinem Apparat eine Vorrichtung ein, die Fig. 29 zeigt. Ausgehend von der Erfahrung, daß man die Konvergenzreaktion am besten prüft, indem man dem Auge einen kleinen Gegenstand langsam nähert und die Versuchsperson auffordert, ihn zu fixieren, traf ich folgende Vorkehrungen. In die Decke des Kastens I wurde in einer Entfernung von $3 \mathrm{~cm}$ von der 
Wand, bei der die Versuchsperson einblickt, ein Loch von $1 \mathrm{~cm}$ Durchmesser geschnitten, gerade unterhalb der den oberen Kasten trennenden Scheidewand, so daß das Loch zu beiden Seiten derselben halbmondförmig vorstand. Unterhalb dieser Öffnung wurde der in der Zeichnung abgebildete Apparat an der dort im Querschnitt getroffenen Achse $(A)$ aufgehängt. Er besteht aus einem allseits bis auf eine runde Öffnung $(a b)$ geschlossenen Metalltubus, der an seinem unteren Ende eine kleine, bei einer Stromstärke von 4 Volt brennende Glühlampe $(G)$ trägt. Das von ihr ausgehende Licht wird zunächst durch die Blende $B$ eingeengt, dann von der Linse $L$ aufgefangen und zu einem schmalen, parallelstrahligen Bündel vereinigt, das bei $a b$ den 'Tubus verläßt und in den oberen Kasten austritt. An der Scheidewand des letzteren ist auf jeder Seite, in der Höhe der Blicklinie der Versuchsperson, ein schmaler Metallstreifen aufgenietet, der um $1 / 2 \mathrm{~cm}$ aus der Wand vorsteht und auf der der Versuchsperson zugekehrten Seite vernickelt ist $(C D)$. Leuchtet das kleine Glühlämpchen, so bildet sich bei einer Stellung des Apparates, wie sie in der Figur angenommen ist, bei $a^{\prime} b^{\prime}$ eine halbmondförmige, helle Scheibe $a b$, desgleichen auf der gegenüberliegenden Seite der Scheidewand. Der Apparat ist von außen durch Drehen einer Scheibe $S$ beweglich und wird bei der Konvergenzprüfung zunächst so eingestellt, daß das Lichtbündel in der Richtung der Linie $d$ austritt. Es erscheint dann am Ende des Streifens $C D$ zu beiden Seiten der Scheidewand ein hell leuchtender Halbmond, der bei seiner großen Entfernung $-18 \mathrm{~cm}$ vom Auge der Versuchsperson - von dieser bald entdeckt wird. Dabei verschmelzen die beiden Halbmonde zu dem Bilde einer kleinen, runden, hellen Scheibe. Nachdem die Versuchsperson diesen Punkt fixiert hat, führt man ihn durch Drehen des Konvergenzapparates längs des Streifens $C D$ nach vorn, bis er $7 \mathrm{~cm}$ vor dem Auge der Versuchsperson steht. Man kann so die Größe der Pupille bei jeder beliebig starken Konvergenzstellung des Auges messen, da die außen angebrachte Drehscheibe $(S)$ graduiert ist. Die Stromzuführung zu dem Glühlämpchen (G) geschieht mittels der Klemmen $K$ und $K^{\prime}$. Mit der letzteren ist die Lampe direkt verbunden, während die Stromübertragung von der anderen erst durch einen Schleifkontakt $F$ geschieht, der an der Vorderwand des Kastens auf der Isolierschicht $J$ befestigt ist. Will man den Konvergenzapparat außer Tätigkeit setzen, so dreht man ihn so lange, bis die Verbindung der Lampe mit dem Schleifkontakt unterbrochen ist.

\section{Apparate zur Messung des zeitlichen Ablaufs der Pupillenbewegungen.}

Bei der Beschreibung des Beleuchtungsapparates machte ich schon darauf aufmerksam, daß beim Wegdrücken der die Lichtzufuhr zum Auge absperrenden Schieber zugleich ein elektrischer Stromkreis ge- 
schlossen werden kann. Schalten wir in diesen einen Elektromagneter mit Schreibstift ein, so können wir auf einer berußten Trommel der Zeitpunkt, in dem das Licht ins Auge der Versuchsperson eindringt festlegen. Wenn wir bei der Prüfung der Lichtreaktion die Iris genav beobachten, so ist es nicht allzu schwer, den Zeitpunkt zu bestimmen in dem diese das Maximum der durch den Lichteinfall bewirkten Kon traktion erreicht hat. Wir können demnach zur Messung der Kontrak tionszeit der Irismuskulatur so vorgehen, da $B$ wir nach geschehener Belichtung den Schieber nur so lange festhalten, bis die Pupille das Maximum der Verengerung erreicht hat. Lassen wir ihn jetzt zurückschnellen, so wird der durch den elektromagnetischen Registrierapparat gehende Strom unterbrochen, und wir können unter Zuhilfenahme der Aufzeichnung von Stimmgabelschwingungen die Zeit, die zwischen Beginn der Belichtung und Ende der Kontraktion der Iris verflossen, bestimmen, d. h. einschließlich unserer persönlichen Reaktionszeit; berechnen wir diese und ziehen sie von dem gefundenen Werte ab, so bleibt nur die Kontraktionszeit der Iris auf Lichteinfall übrig. Durch Häufung der Versuche können wir auf diese Weise ein annähernd genaues Urteil hierüber gewinnen. Sehr viel bequemer gestalten sich diese Bestimmungen, wenn ein Chronoskop zur Verfügung steht, da man dann nur dies in den Stromkreis einzuschalten braucht und die Zeiten direkt ablesen kann. Ich benutzte zu meinen Untersuchungen ausschließlich ein Chronoskop, wodurch eine große Häufung der Versuche und damit eine höchstmögliche Genauigkeit der Resultate erzielt werden konnte.

Sehr viel schwieriger als die Bestimmung der Lichtreaktionszeit, eigentlich Kontraktionszeit der Iris nach Lichteinfall, ist die Feststellung der Reflexzeit bzw. der Latenzzeit dieser Bewegung. Diese ist, wie wir später sehen werden, sehr kurz, und wenn man bei ihrer Bestimmung nicht äußerst sorgfältig und vor allem auch geübt ist, erhält man nur sehr grobe, fehlerhafte Resultate. Zu ihrer Feststellung ist es natürlich notwendig, den Hebel schon bei Beginn der Kontraktionsbewegung loszulassen.

Aus meinen früheren Darlegungen dürfte ohne weiteres klar sein, daß die Einrichtungen des Apparates diese Bestimmungen sowohl für die direkte, wie für die konsensuelle Reaktion zulassen.

Es erschien nicht allein notwendig, die Messung der Lichtreaktionszeit zu ermöglichen, vielmehr mußte es auch von Interesse sein, genaue Zeitbestimmungen für den Ablauf der auf psychische und sensible Reize eintretenden Pupillenveränderungen anstellen zu können. Die Fig. 30 zeigt einen kleinen, eigens zu diesem Zwecke konstruierten Apparat. Er dient gleichzeitig als reizauslösendes Instrument und zur Zeitmessung. Ein zum größten Teil aus Metall gearbeiteter Hebel $\boldsymbol{A}$ ist durch Druck auf den Knopf $C$ um die Achse $B$ drehbar. Das diesem entgegen- 
gesetzte Ende des Hebels besteht aus einem Hartgummistück $(D)$, auf dem an der oberen Seite wieder ein Metallplättchen $(E)$ befestigt ist. Die Feder $F$ läßt den Hebel beim Aufhören des Druckes auf $C$ wieder emporschnellen. Beim Niederdrücken des Hebels gerät der Metallstift $g$ in Berührung mit der Feder $H$. An der gegenüberliegenden Seite ist ein rechtwinklig abgebogenes Metallplättchen $(J)$, um die Achse $k$ drehbar, aufgehängt. Mit ihm fest verbunden sehen wir eine auf einem Draht aufgesteckte Metallkugel $(L)$. Die Einstellung des Apparates ist nun so getroffen, daß das Metallstück $E$ des Hebels $A$, wenn dieser in der Ruhelage ist, nicht mit dem rechtwinklig abgebogenen, drehbaren Metallplättchen in Verbindung steht. Wird dagegen der Hebel niedergedrückt, so kommen beide Metallstücke in Kontakt. Dies dauert jedoch nur einen kurzen Moment, da die Kugel $L$ infolge ihrer schrägen Stellung und der Schwerewirkung den ganzen kleinen Apparat bald zum

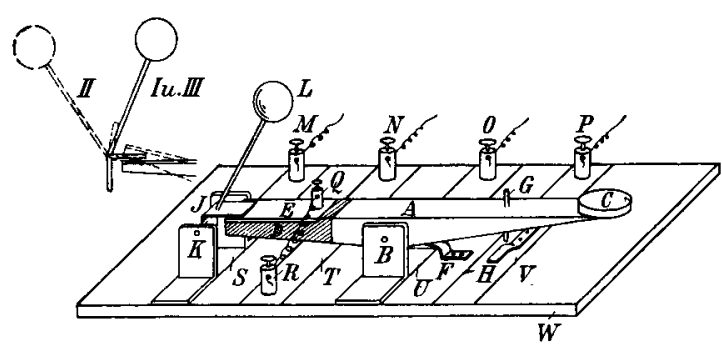

Fig. 30. Umkippen bringt. Das völlige Umfallen hindert dann der gegen den Kautschukteil des Hebels anstoßende, nach unten abgebogene Teil des Metallplättchens $J$. Die kleine Nebenzeichnung zeigt die Stellung des Appa-

rates vor dem Niederdrücken des Hebels bei I. Bei II ist der Hebel heruntergedrückt und der kleine Apparat völlig umgekippt. Läßt man den Hebel wieder zurückschnellen, so nimmt er durch Druck gegen den unten anliegenden Teil des Stückes $J$ auch dieses mit, und der Apparat rückt sich selbsttätig wieder in die Stellung von I ein. Wir bemerken außerdem noch 4 Metallstreifen $S, T, U, V$, die auf einer Kautschukplatte $W$ befestigt und zu denen durch die Klemmen $M, N, O, P$ Stromzuleitungen möglich sind. Während die Streifen $S, U$ und $V$ direkt mit den Metallteilen des Apparates verbunden sind, ist diese Verbindung bei dem Streifen $T$ durch die Klemmen $Q$ und $R$ hergestellt.

Dieser kleine Apparat gestattet nun zunächst, kurz dauernde Reize auszulösen, und ich benutze ihn zur Hervorbringung bzw. Vermittlung akustischer und sensibler Reize, wie folgt. Führe ich durch die Klemmen $M$ und $N$ einen mit einem elektrischen Rasselwerk verbundenen Strom in den Apparat ein, so wird dieser beim Niederdrücken des Hebels $A$ durch Berühren der Platten $J$ und $E$ für einen kurzen Moment geschlossen, darauf kippt der kleine Apparat um, der Strom ist unterbrochen. Er wird auch beim Loslassen des Hebels nicht wieder geschlossen, da das Plättchen $J$ infolge der Trägheit der Kugel $L$ erst dann wieder in 
die Anfangsstellung zurückschwingt, wenn der Hebel schon wieder zurückgeschnellt ist. Auf diese Art löse ich einen kurz dauernden, man kann sagen momentanen, akustischen Reiz (Schreckreiz) aus. Zur Erzeugung eines Schmerzreizes bediene ich mich desselben Apparates, nur schalte ich statt des Rasselwerkes einen faradischen Apparat ein und benutze zwei ganz kleine Elektroden, die in Gestalt von federnden Zwingen um zwei Fingerbeeren der Hand der Versuchsperson befestigt werden. Während die eine Elektrode mit Stoff überzogen und befeuch-

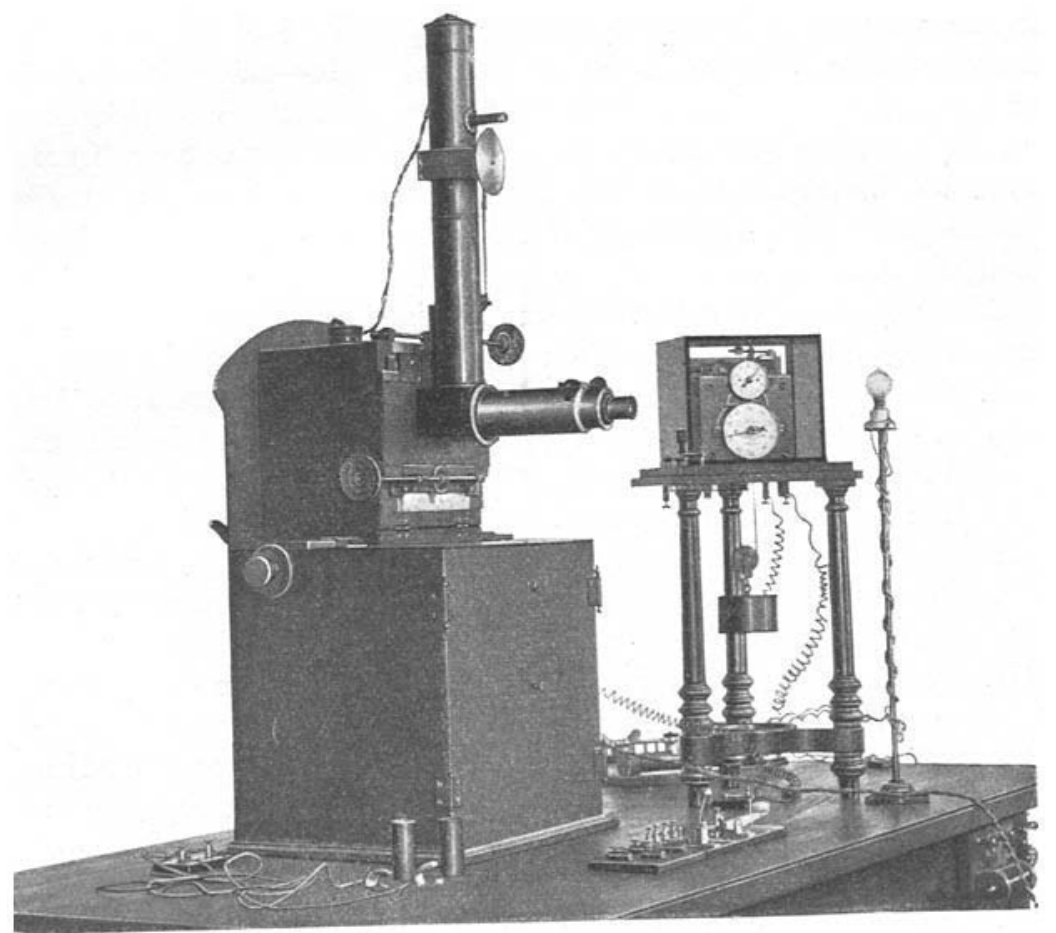

Fig. 31 .

tet ist, besteht der wirksame Teil der anderen in einer zwischen Lederstreifen verborgenen, die Haut eben berührenden Metallspitze. Bei Stromschluß entsteht dann ein stichartiger Schmerz in der von ihr umfaßten Fingerbeere. In das zweite Klemmenpaar $O P$ führe ich den durch das Chronoskop gehenden Strom, der beim Niederdrücken des Hebels geschlossen wird.

Füge ich nun der Versuchsperson einen Schreck- oder Schmerzreiz zu, während ich deren Pupille beobachte, und lasse den Hebel in dem Moment los, wo ich eine Bewegung derselben sehe, so kann ich auf die 
nämliche Weise, wie oben bei der Lichtreaktion, die Latenzzeit dieser Bewegung bestimmen.

Die Fig. 31 endlich mag die gesamte, von mir benutzte Versuchsanordnung übersichtlich zeigen. Neben dem Untersuchungsapparat ist das Chronoskop aufgestellt, dessen Skalen durch eine kleine Glühlampe erhellt werden. Vor dem Versuchsleiter ist auf dem Tisch der vorhin beschriebene Reizapparat befestigt. Das Rasselwerk und der Faradisierapparat sind unter dem Tisch angebracht, auf dem ganz vorne noch die besprochenen Reizelektroden liegen. Zur Inbetriebsetzung dieses Apparatenkomplexes müssen uns zwei elektrische Stromkreise zur Verfügung stehen; zunächst ein Starkstrom von 110-220 Volt Spannung zur Speisung der Nernstlampen und der Glühlampe im Meßapparat, dann ferner ein Schwachstrom für den Konvergenzapparat, das Chronoskop, den faradischen Apparat und die Lampe zur Beleuchtung des Chronoskops. Die Aufstellung des Apparatenkomplexes geschieht in einem Dunkelzimmer.

Sehen wir zu, inwieweit wir unsere Aufgabe bisher erfüllt haben. Wir können folgende Sätze aufstellen:

I. Der Apparat gestattet, in das eine oder andere Auge einer Versuchsperson oder in beide zugleich entweder dauernd oder nur momentan ein beliebig starkes Licht zu schicken.

II. Dabei werden die zentralen Teile der Retina von dem Licht getroffen. Das Auge wird nicht geblendet und nicht wesentlich erwärmt.

III. Die Akkommodation ist so weit wie denkbar ausgeschaltet.

IV. Wir können die Größe der Pupille in verschiedenen Durchmessern bei jeder beliebigen Beleuchtung messen, und zwar mit einer Genauigkeit von $1 / 10 \mathrm{~mm}$.

V. Unsere Resultate können sofort von anderen Personen nachgeprüft werden, da das Meßergebnis sichtbar eingestellt bleibt.

VI. Die Größe der Iriskontraktion a uf Lichteinfall wie die bei der Konvergenzbewegung ist meßbar.

VII. Wir können den zeitlichen Ablauf der Lichtreaktion der Pupille feststellen, sowohl der direkten, wie der konsensuellen, desgleichen die Reflex-bzw. Latenzzeiten.

VIII. Wir sind imstande, momentan akustische und sensible Reize auszü̈ben und die Dauer der Latenzzeit der ihnen folgenden Pupillenbewegungen $z u$ bestimmen. 


\section{Apparat zur Photographie der Pupillen.}

Wie aus unseren früheren Darlegungen hervorgeht, empfanden die Autoren, welche sich bisher mit der Photographie der Pupille bzw. der Pupillenbewegungen beschäftigten, vor allem den Umstand sehr störend, $\mathrm{da} ß$ aus dem gewonnenen Photogramm nicht mit Sicherheit geschlossen werden konnte, ob der größte Durchmesser der Pupille bei der Aufnahme getroffen war. Ich suchte daher auf anderem Wege als diese, photographische Aufnahmen der Irisbewegungen zu erhalten und erhoffte mir mehr von der kinematographischen Methode.

Bei der von Bellarminoff, Fuchs und Piltz angewandten Technik war es unmöglich, einen Utberblick über einen breiteren Pupillenbezirk zu erhalten, aus dessen Berandung man die Lage des photographierten Teiles hätte schließen können, da ja durch das unaufhaltsame Vorbeiziehen der photographischen Aufnahmefläche die aufeinander folgenden Bildstreifen übereinander geschoben werden mußten. Bei der kinematographischen Methode dagegen erhalten wir, da der Aufnahmefilm ruckweise vorgeschoben wird und zur Zeit der Aufnahme stillsteht, scharfe, nebeneinander stehende Bilder. Die exponierte Stelle wird beim Kinematographen bekanntlich nach geschehener Belichtung sofort weitergeschoben, und das folgende Bild kommt hinter das vorhergehende zu stehen, ohne dies teilweise zu überdecken.

$\mathrm{Zu}$ meinen Versuchen benutzte ich zunächst einen gewöhnlichen kinematographischen Aufnahmeapparat von Meester, der mit einer Planarlinse von Zeiß $(1: 3,6 . F=60 \mathrm{~mm})$ ausgerüstet war. Dieser wurde nach Wegnahme der Beobachtungs- und Meßvorrichtung an den Pupillenuntersuchungsapparat herangeschoben, bis sich auf der Einstellscheibe ein scharfes Bild des Auges der Versuchsperson abbildete. Dann wurde in der üblichen Weise unter Verwendung eines Elektromotors eine Aufnahme der Irisbewegung nach Lichteinfall gemacht. Die Fig. 32 (Tafel VI) gibt ein so gewonnenes Kinematogramm wieder, auf dem das Auge in verkleinertem Maßstab erscheint. Die Größen der Bilder verhalten sich zur Wirklichkeit wie $0,4: 1,0$. Die Bildreihen sind von oben nach unten zu betrachten. Durch eine Zeitschreiberorrichtung wurde die Dauer der Aufnahme bestimmt. Es läßt sich an dem Kinematogramm leicht ausmessen, wann die Bewegung der Pupille nach Lichteinfall (hier entstand das erste Bild, da das Auge vorher völlig verdunkelt war) anfing (bei a) und wann sie beendet war (bei b). Dabei konnten Veränderungen der Lage des Augapfels nicht unbemerkt bleiben, da das Bild des ganzen Auges festgehalten wurde. Wie die Abbildung zeigt, konnte ich mit dieser Darstellung insofern zufrieden sein, als Schärfe des Bildes und Sicherheit der Aufnahme nichts zu wünschen übrig ließen; nur einen Utbelstand hatte die Methode, sie war sehr kost- 
spielig. Der Kinematograph mußte eine Zeitlang vor Beginn der Aufnahme in Bewegung gesetzt werden, nicht nur, um einen gleichmäßigen Gang desselben zu erzielen, sondern vor allem deshalb, weil durch seine Tätigkeit ein starkes Geräusch, das bekannte, klappernde Kinematographengeräusch, entstand und die Versuchsperson zunächst daran gewöhnt werden mußte. Dadurch ging natürlich schon ein großer Filmstreifen verloren. Dieser und der zu der Aufnahme benötigte hatten zum mindesten eine Länge von $11 / 2-2 \mathrm{~m}$, kosteten mithin $1,35-1,90 \mathrm{M}$. Da nun außerdem manche Aufnahme durch zufälligen Lidschlag der Versuchsperson oder durch eine grobe Bewegung ihres Augapfels unbrauchbar wurde, stellten sich die durchschnittlichen Kosten eines guten brauchbaren Pupillenkinematogrammes auf ca. 5 M., so daß von einer systematischen Anwendung dieser Methode kaum die Rede sein konnte.

Mein Bestreben ging deshalb dahin, einen kinematographischen Aufnahmeapparat zu konstruieren, bei dem die einzelne Aufnahme möglichst billig werden sollte. Dabei mußte natürlich Film gespart werden. So schön Aufnahmen, wie die oben abgebildete, für Projektionszwecke sich eignen, da man das ganze Bild des Auges vor sich sieht, in dem sich das Pupillenspiel vollzieht, ebensowenig notwendig erschien es für Messungen der Irisbewegungen, das ganze Auge bzw. die ganze Pupille zu photographieren. Es genügt offenbar, wenn ein 3-4 mm breiter Streifen der Pupille im Bilde festgehalten wird, da man aus den Rändern desselben mit Sicherheit entnehmen kann, ob ihr größter Durchmesser mitgetroffen ist.

Bei der Konstrultion des Pupillenkinematographen, den Fig. 33 zeigt, griff ich wieder auf das Plattensystem zurück, da es mir bequemer schien und auch wohl die Schärfe der Bilder erhöhen konnte. Auf eine genaue, ins einzelne gehende Beschreibung dieses Instrumentes will ich aus zwei Gründen hier nicht eingehen. Erstens würde eine derartige Auseinandersetzung zu viel Raum einnehmen, und zweitens halte ich den abgebildeten Apparat noch nicht für geeignet, als endgültige Lösung des Problems der kinematographischen Pupillenaufnahme zu gelten. Im wesentlichen besteht der Kinematograph aus einem Objektiv, das an der Aufnahmefläche ein auf die halbe Größe reduziertes Pupillenbild entwirft, ferner aus einer eigens konstruierten, fast ganz geräuschlos arbeitenden Fortschaltungsvorrichtung, die eine Platte $(5 \mathrm{~cm}$ breit, $26 \mathrm{~cm}$ lang) ruckweise um je $4 \mathrm{~mm}$ weiter schiebt, und aus einer Registriertrommel, auf der die Zeitverhältnisse aufgezeichnet werden können. Der ganze Apparat wird an den Klemmschrauben, die für gewöhnlich den Meßapparat halten, an dem oberen Kasten unseres Hauptapparates befestigt, wie es die Fig. 33 zeigt. Durch einen Trieb kann er so verschoben werden, $d a B$ von seiner Linse entweder ein Bild des rechten 
oder des linken Auges der Versuchsperson entworfen wird. Die Bildstrahlen werden vor der Platte durch eine bis auf einen $3 \mathrm{~mm}$ breiten, senkrecht stehenden Schlitz verschlossene Metallwand abgefangen. Der Apparat wird so eingestellt, daß in diesem Spalt das Bild des mittleren Teiles der Pupille erscheint. Darauf wird die Platte eingeschoben, der Apparat geschlossen und nun durch Gewichtszug in Bewegung gesetzt. Dabei wird die Platte ruckweise fortgeschaltet und zugleich der Spalt nur dann durch eine mit einem Ausschnitt versehene, vor ihm rotierende Scheibe geöffnet, wenn die Platte stillsteht. Während ihrer Bewegung bleibt der Schlitz verschlossen. Dadurch erhalten wir nebeneinander eine Reihe von Abbildungen des mittelsten Teiles der Pupille, Iris und Sclera,

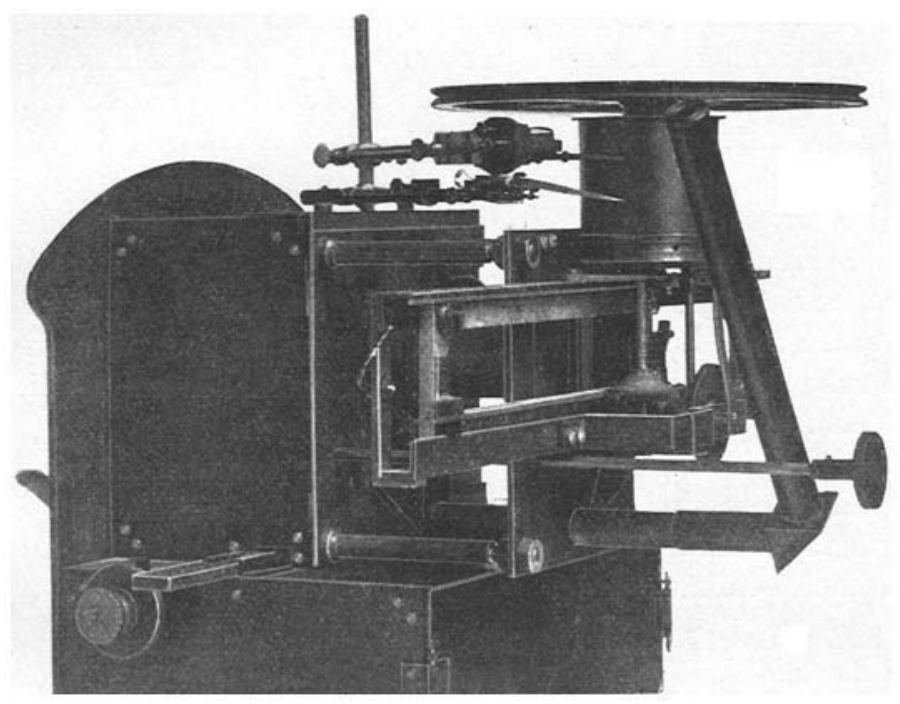

Fig. 33.

wie man aus den beigedruckten Kinematogrammen, aufderen Besprechung ich noch zurückkomme, ersehen kann (Tafel VII, Fig. 34). Wegen der ruckweisen Fortbewegung der Aufnahmeplatte war es natürlich undenkbar, auf ihr Zeitmarken anzubringen; die Zeitschreibung mußte daher auf einen Teil des Apparates, der während der Aufnahme in gleichmäßiger Bewegung war, vor sich gehen. Die oben auf dem Apparat sichtbare Trommel entspricht diesen Bedingungen. Auf ihr geschieht die Zeitmarkierung durch einen mit dem das Licht freigebenden Schieber unseres Apparates verbundenen Elektromagneten, der den Beginn der Belichtung markiert und durch einen, Stimmgabelschwingungen von $1 / 100$ Sekunden aufzeichnenden, kleineren Elektromagneten. Eine Spiegelvorrichtung endlich gestattet, das Auge, während es photographiert 
wird, dauernd $\mathrm{zu}$ beobachten; bemerkt man dann grobe Stellungsveränderungen, Lidschlag oder dgl. während des Ablaufens des Kinematographen, so kann man sich das Entwickeln der Platte ersparen. Läßt man den Apparat ganz ablaufen, so bekommt man 60 nebeneinanderstehende Bildstreifen. Die Ablaufzeit ist durch schwächeren oder stärkeren Gewichtszug regulierbar. Ich benutzte im allgemeinen eine Geschwindigkeit, bei der die Dauer der Einzelaufnahme ca. 0,08 Sekunden beträgt. Auch bei dieser ganz kurzen Belichtungszeit genügt das Nernstlampenlicht zur Aufnahme.

Die Fig. 34 (Tafel VII) zeigt bei a die Aufnahme der Irisbewegung bei direktem Lichteinfall in das photographierte Auge, bei b ist derselbe Vorgang festgehalten, den störenden Einfluß eines Iidschlags zu Anfang der Belichtung zeigend. Die Abbildung c zeigt, daß man Schiefstellung des Auges (zum Schlitz) sofort entdeckt und so vor Fehlschlüssen gesichert ist. Ich glaube mit diesen Abbildungen deutlich dargetan zu haben, daß der Weg der kinematographischen Pupillenaufnahme gangbar und aussichtsvoll ist, da auch die Kosten der Aufnahme nur unwesentliche sind. (Bei der Verwendung von Platten $5 \times 26 \mathrm{~cm}$ kostet die Aufnahme ca. 30 Pf.) Zurzeit bin ich mit der Vereinfachung des Pupillenkinematographen beschäftigt, wodurch ein ganz geräuschloses Arbeiten ermöglicht werden soll. Zugleich wird die Plattengröße noch mehr reduziert werden, und dann dürfte es ohne großen Kostenaufwand möglich sein, lange Versuchsserien anzufertigen.

Damit haben wir auch den letzten Teil der Aufgabe, die wir uns eingangs stellten, erfüllt. Ich bemerke noch ausdrücklich, daß bei den kinematographischen Aufnahmen zur Beleuchtung nur das Licht der Nernstlampe benutzt wurde.

Anhang. Im Mai des Jahres 1905 demonstrierte ich zuerst diesen Pupillenmeßapparat und zeigte die damit gewonnenen Kinematogramme; seitdem vorgenommene Verbesserungen und Vereinfachungen hielten mich ab, früher eine genaue Beschreibung desselben zu veröffentlichen. Inzwischen wurden von $\mathrm{Oh} \mathrm{m}^{\mathbf{1}}$ ), Hübner ${ }^{2}$ und Krusius $\left.{ }^{3}\right)^{4}$ ) binokulare Pupillenmeßapparate angegeben, die einerseits nicht als Universalinstrumente betrachtet werden können, andererseits abgesehen von dem Ohmschen, bei dem Prismenbilder verwendet werden, nichts wesentlich Neues bieten, so daß ich auf eine genauere Beschreibung derselben nicht eingehe.

1) $\mathrm{Oh} \mathrm{m}$, Ein binokulares Pupillometer. Centralbl. f. prakt. Augenheilk. 1906.

2) Hübner, Demonstration eines Apparates zur Untersuchung der Pupillen. 78. ord. Generalvers. des Psych. Vereins der Rheinprovinz zu Bonn 1906. Ref. Centralbl. f. Nervenheilk. u. Psych. 30, 102. 1907.

3) Krusius, Fr. Fl., Demonstration zweier Apparate für die Praxis. Ber.

d. 34. Vers. d. Ophthalmol. Gesellschaft in Heidelberg 1907.

4) Derselbe, Ửber ein Binokular-Pupillometer. Neurol. Centralbl. 1908, 154. 


\section{Untersuchungen bei Gesunden.}

\section{Physiologische Vorbemerkungen.}

Die Regenbogenhaut dient bekanntlich einerseits zur Abblendung der zur Netzhaut strebenden Randstrahlen, zur Verschärfung des Bildes, und andererseits zur Abstufung der Größe des Lichteinfalles ins Auge.

Diese Regulierbewegungen der Iris werden ermöglicht durch zwei in ihr liegende Muskelsysteme. Wir unterscheiden einen Ring von zirkulär gerichteten, glatten Muskelfasern am Rande der Pupille, den wir Musc. sphincter pupillae nennen und einen in den Fasern der hinteren Grenzschicht der Iris verborgenen Muskel, den wir als Musc. dilatator pupillae bezeichnen. Lange Zeit erschien es zwar zweifelhaft, ob ein pupillenerweiternder Muskel überhaupt bestände, doch haben die Untersuchungen von Langley und Anderson ${ }^{1}$, Heerfordt2) u. a. unzweifelhaft dargetan, daß ein Antagonist des Sphinkter in der Iris existiert.

Was wissen wir über die Innervation dieser beiden Muskeln?

$\mathrm{Zu}$ dem Musc. sphincter pupillae treten durch die kurzen Ciliarnerven aus dem Ciliarganglion Bahnen, die im Oculomotorius verlaufen, und für die ein Zentrum im Oculomotoriuskern angenommen wird. Utber die genauere Lage dieses Zentrums gehen jedoch die Ansichten der Autoren noch auseinander, und ich verweise, da mir eingehendere anatomische Erörterungen fernliegen, hier auf die Arbeiten von Bernheimer $\left.\left.{ }^{3}\right)^{4}\right)^{5}$ ) und $\left.\left(\mathrm{Bach}^{6}\right)^{7}\right)^{8}$ ).

Die Innervation des Musc. dilatator pupillae geschieht durch den Sympathicus. Pupillenerweiternde Fasern verlassen durch die Rami communicantes des 8. Hals- und 1. Brustnerven das Rückenmark und ziehen zum obersten Brustganglion des Sympathicus. Von dort verlaufen sie zum untersten Halsganglion dieses Nerven, dann zum obersten, worauf sie in das Ganglion Gasseri eintreten. Nach ihrem Austritt aus

1) Langley \& Anderson, On the mechanism of the movement of the iris. Journ. of Physiol. 13, 554.

2) Heerfordt, Ch., Studier over Musc. dilatator pupillae. Inaug. Diss. Kopenhagen 1900.

3) Bernheimer, St., Über die Reflexbahn der Pupillarreaktion. 27. Vers. d. Ophthalmol. Gesellschaft in Heidelberg 1898.

4) Derselbe, Die Reflexbahn der Pupillarreaktion. v. Graefes Archiv 4\%, 1. 1898. 1902.

5) Derselbe, Die Lage des Sphincterenzentrums. v. Graefes Archiv 52, 302.

6) Bach, L., Die Lokalisation des Musc. sphincter pupillae und des Musc. ciliaris im Oculomotoriuskerngebiete. v. Graefes Archiv 49, 519. 1899.

7) Derselbe, Was wissen wir über Pupillenreflexzentren und Pupillarreflexbahnen? Berlin 1904.

8) Derselbe, Pupillenlehre. Berlin 1908. 
diesem Ganglion legen sie sich an den ersten Trigeminusast an, begleiten ihn und treten schließlich durch die langen Ciliarnerven ins Auge. Als Pupillenerweiterungszentrum nehmen wir das Budgesche Centrum ciliospinale ${ }^{1}$ ) an, das im Bereich des ersten bis dritten Brustwirbels liegt.

Da nach Durchschneiden des Oculomotorius Pupillenerweiterung eintritt und bei Durchschneidung des Sympathicus die Pupillen sich verengern, schließen wir, daß beide Zentren tonisch innerviert sind. Der "Tonus des Erweiterungszentrums scheint nach unseren bisherigen Kenntnissen wesentlich automatischer Natur zu sein, während der Tonus des Verengerungszentrums hauptsächlich reflektorisch erhalten wird, da er nach Opticusdurchschneidung wegfällt.

Wir kommen hiermit zu den Einflüssen, welche auf die Pupillenzentren bzw. Irismuskelzentren wirksam werden können und damit zur Betrachtung der zentripetalen, für die Pupillenveränderungen wesentlichen Bahnen.

Die bekannteste Äußerung einer reflektorischen Erregung des Sphincterzentrums stellt die Pupillenverengerung bei Lichteinfall ins Auge dar. Nach den neuesten Untersuchungen von $\mathrm{Hess}^{2}$ ) hat der pupillomotorisch wirksame, zentrale Teil der Netzhaut einen Radius von höchstens $3 \mathrm{~mm}$, und dieser Forscher hält es nicht für ausgeschlossen, daß noch ein wesentlich kleinerer Bezirk der Retina, vielleicht nur der der Fovea entsprechende Teil, mit pupillomotorisch wirksamen Elementen ausgestattet ist. Jedenfalls hat Belichtung der Peripherie der Netzhaut kaum einen Pupillen verengernden Erfolg. Da eine vollständig isolierte Belichtung der zentralen oder der peripheren Retinateile, wie wir schon oben bei der Besprechung der Untersuchungsmethoden (hemiopische Lichtreaktion) sahen, nicht möglich, ist demnach eine exakte Entscheidung der vorliegenden Frage nicht ausführbar.

Während Schirmer ${ }^{3}$ ) annehmen zu müssen glaubte, daß der Lichtreflex in den amacrinen Zellen der Netzhaut seinen Anfang nehme, gehen die Ansichten anderer Autoren dahin, daß als Aufnahmeapparate für den pupillomotorisch wirksamen Lichtreiz die Stäbchen und Zapfen der Netzhaut zu betrachten sind, eine Annahme, die durch die Untersuchungen von Abelsdorff $\left.{ }^{4}\right)^{5}$ ) und Hess ${ }^{6}$ ) sehr an Sicherheit gewann.

1) Budge, J., U̇ber die Bewegungen der Iris. Braunschweig 1855.

2) Hess, C., Untersuchungen über die Ausdehnung des pupillomotorisch wirksamen Bezirkes der Netzhaut und über die pupillomotorischen Aufnahmeorgane. Arch. f. Augenheilk. 58. 1907.

3) Schirmer, O., Die Funktion der sog. pararetikulären oder amacrinen Zellen in der Retina. Ber. üb. die 26. Vers. d. Ophthalmol. Gesellschaft in Heidelberg $1897,146$.

4) Abelsdorff, G., Die Änderung der Pupillenweite bei verschiedenfarbiger Belichtung. Zeitschr. f. Psychol. u. Physiol. der Sinnesorgane 22, 81 u. 451. 1899.

5) Abelsdorff, G., und Feilchenfeld, U., Über die Abhängigkeit der Pu- 
Die Erregung verläuft dann im Opticus, und zwar sollen die stärkeren Fasern dieses Nerven den Lichtreiz weiterleiten. Im Chiasma findet eine partielle Kreuzung dieser Fasern statt, wobei nur wenige ungekreuzt auf derselben Körperseite weiterlaufen. Die gekreuzten und ungekreuzten Fasern treten dann in den vorderen Vierbügel ein. Von hier aus nimmt man eine Verbindung der den pupillenverengernden Reiz tragenden Elemente mit dem Oculomotoriuskern an, deren Verlauf noch nicht bekannt ist. Die Annahme, daß die Pupillarfasern sich vor ihrem Eintritt in den Oculomotoriuskern nochmals kreuzen, hat viel Wahrscheinlichkeit für sich, doch liegen zwingende Beweise hierfür zurzeit noch nicht vor. Ob die beiderseitigen Sphincterkerne unter sich innig verbunden sind, ist bisher ebenfalls noch unbekannt.

Außer bei Lichteinfall sehen wir eine Innervation des M. sphincter pupillae eintreten, wenn das Auge sich für die Nähe einstellt oder wenn die Augen eine Konvergenzbewegung ausführen. $\mathrm{Ob}$ es sich bei diesen Bewegungen um einheitliche Erscheinungen handelt, ob die Verengerung der Pupille mit der Akkommodation oder mit der Konvergenz einhergeht, ist zurzeit nicht mit Sicherheit entschieden. Ich verweise hier auf die Arbeiten von Scheiner ${ }^{1}$ ), v. Graefe ${ }^{2}$ ), le Conte ${ }^{3}$ ), Marina $\left.{ }^{4}\right)^{5}$ ), Adamück and Woinow ${ }^{6}$, Vervoort $\left.{ }^{7}\right), \mathrm{Bach}^{8}$ ) und die in diesen Arbeiten angeführten Literaturangaben. Nach diesen ist mit größerer Wahrscheinlichkeit die Verengerung beim Blick in die Nähe an die Konvergenzbewegung der Bulbi geknüpft. Wir haben es dabei mit einer

pillarreaktion von Ort und Ausdehnung der gereizten Netzhautoberfläche. Zeitschr. f. Psychol. u. Physiol. der Sinnesorgane 34, 111. 1904.

6) Hess, C., 1. Úber Dunkeladaptation und Sehpurpur bei Hühnern und Tauben. 2. Untersuchungen über Lichtsinn und Farbensinn der Tagvögel. Arch. f. Augenheilk. 5\%. 1907.

1) Scheiner, Ch., Oculus hoe est fundamentum opticum. Lit. I pars II Exp. III p. 31 Oeniponti 1619 cit. nach Bach. Pupillenlehre. 1908.

2) Graefe, A. v., Das Akkommodationsverhalten der Pupille beim Hunde nach einer Mitteilung von Dr. A. Müller. v. Graefes Archiv 1, 440. 1854.

3) le Conte, Adjustements of the eye. Amer. Journ. of Sciences et Arts. 47, 68.1869.

4) Marina, A., Ưber die Pupillenreaktion bei der Konvergenz. 47. Vers. deutsch. Naturforscher u. Ärzte. Karlsbad, Sept. 1902.

5) Marina, A., und Cofler, A., Utber die Kontraktion des Sphincter iridis bei der Konvergenz und über die Konvergenz und Seitenbewegungen der Bulbi. Deutsche Zeitschr. f. Nervenheilk. 24, 274. 1903.

6) Adamück und Woinow, Utber die Pupillenveränderung bei der Akkommodation. v. Graefes Archiv 1\%, 158. 1871.

7) Vervoort, Die Reaktion der Pupille bei der Akkommodation und Konvergenz und bei der Beleuchtung verschieden großer Flächen der Retina mit einer konstanten Lichtmenge. v. Graefes Archiv 49, 348. 1900.

8) Bach, L., Das Verhalten der Pupille bei der Konvergenz und Akkom. modation. Zeitschr. f. Augenheilk. v. Kuhnts und v. Michel 12, 725. 1905. 
Mitbewegung der Iris zu tun; die Bahn, in welcher der sie veranlassende Reiz verläuft, ist noch unbekannt, während ihr Beginn in der Hirnrinde zu suchen ist.

Ebensowenig sicher ist der genauere Verlauf der die sog. Lidschluß-. reaktion vermittelnden Bahn bekannt. Am ehesten dürfte noch die von dem Entdecker dieser Reaktion, A. v. Graefe ${ }^{1}$ ) gegebene Erklärung

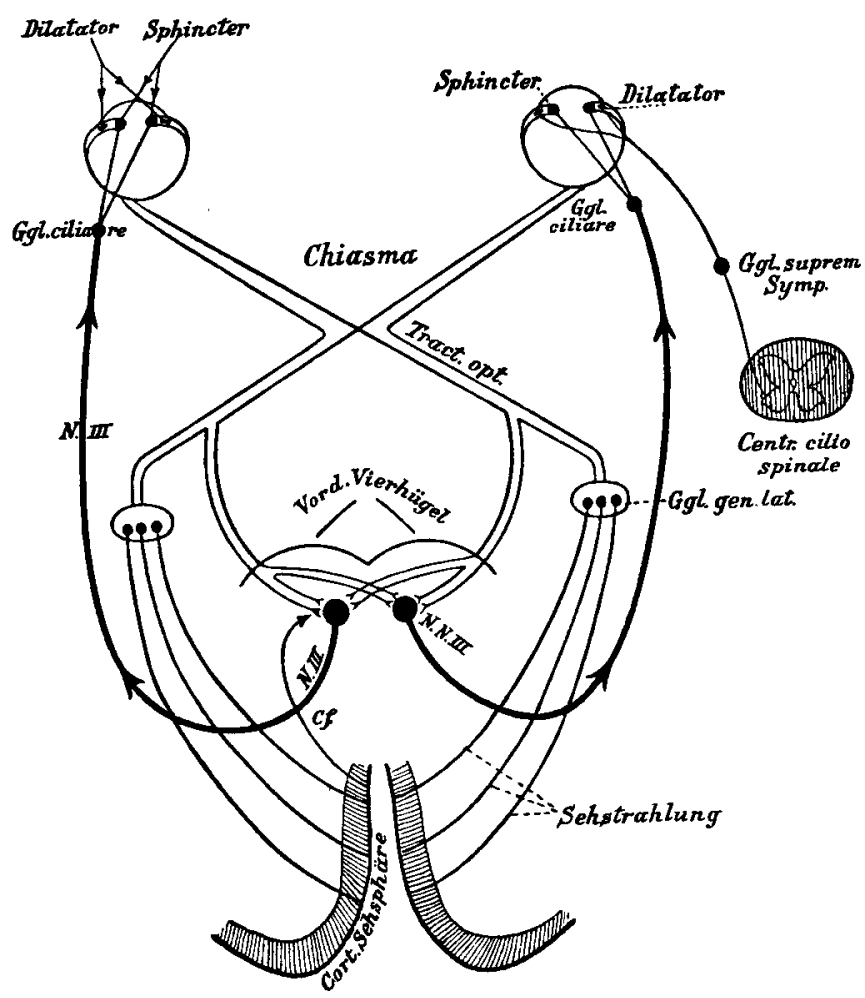

Fig. 35.

Cf.: Vermutete zentrifugale Bahn vom Cortex zum Sphincterzentrum. Ggl. gen. lat. = Ganglion geniculatum laterale.

N. . III = Nucleus N. oculomot.

N. III $=$ Nervus oculomot.

$\mathrm{zu}$ Recht bestehen, die dahin ging, daß die beim Lidschluß eintretende Verengerung der Pupille durch eine Mitbewegung der Iris veranlaßt sei, indem der Oculomotorius mit dem Facialis erregt wird.

Außer diesen Verengerungsreaktionen kennen wir auch noch Erweiterungsreaktionen der Pupille, die hauptsächlich durch reflektorische

I) Graefe, A. v., Notiz über die Behandlung der Mydriasis. v. Graefes Archiv 1, 315. 1854. 
Beeinflussung des Sphincterzentrums rustande kommen. Hierhin gehört die Pupillenerweiterung, die wir in der Pupillenunruhe erkennen, und die wir auf sensible, sensorische und psychische Reize hin auttreten sehen. Es handelt sich dabei offenbar im wesentlichen um eine Hemmung des Sphinctertonus, welche hauptsächlich wohl durch Reize, die auf einer Bahn von der Hirnrinde aus auf das Sphincterzentrum wirken, ausgelöst wird, während nicht mit Bestimmtheit die Möglichkeit, daß eine Pupillenerweiterung allein durch Innervation des Dilatator durch den Sympathicus zustande kommen kann, abgelehnt werden darf. Der Verlauf der vermittelnden Bahnen ist noch unbekannt. Wir werden auf diese Erweiterungsreaktionen der Pupille weiter unten noch in ausführlicher Weise zurückkommen.

Die Bedeutung des Muse. dilatator für die Irisbewegungen wurde früher sehr überschätzt, indem man alle Erweiterungsreaktionen durch Erregung des ihn versorgenden Sympathicus veranlaßt glaubte. Heute können wir ihm diese Rolle nicht mehr zuteilen, wir müssen ihn vielmehr im wesentlichen als einen die Irisbewegungen durch Gegenzug zum Sphincter regulierenden Muskel auffassen, der in automatisch erhaltenem Tonus die durch die Sphincterreaktion veranlaßten Bewegungen der Regenbogenhaut dämpft. Nach unseren allgemeinen Kenntnissen über die Innervation von antagonistischen Muskeln erscheint es außerdem wahrscheinlich, daß eine Verstärkung der Erregung des Sphincterzentrums mit einer Hemmung des Dilatatorzentrums einhergeht und umgekehrt.

Nach dem bisher Ausgeführten entspricht das von Liepmann ${ }^{1}$ ) dargestellte ,,vereinfachte Schema der Pupillenreflexe" am meisten den tatsächlich bekannten oder mit Wahrscheinlichkeit vermuteten, die Pupillenbewegungen vermittelnden Bahnen; ich gebe es daher in Fig. 35 wieder.

\section{Allgemeine Versuchsanordnung.}

Im nachfolgenden sollen die Ergebnisse einer Anzahl von Messungen der Pupille und der Irisbewegungen, die ich teils beim Gesunden, teils bei Nerven- und Geisteskranken unter Zuhilfenahme meines Meßapparates vorgenommen habe, mitgeteilt werden. Zuvor sei noch kurz der Hergang der Untersuchung skizziert. Der Apparat war in einem geräumigen, schallsicheren Dunkelzimmer aufgestellt, in dem zur Beleuchtung nur eine kleine Glühlampe ( 6 Volt) brannte; dabei war dafür Sorge getragen, daß ihr Licht nicht direkt zu dem Platz, den die Versuchsperson einnehmen sollte, vordrang. Diese wurde zunächst an den

1) Liepmann, H., Normale und pathologische Physiologie des Gehirns. In Curschmanns Lehrbuch der Nervenkrankheiten. Berlin 1909. S. 433. 
Apparat gesetzt und mit dem Zweck der Untersuchung, soweit möglich, vertraut gemacht. Nachdem der Drehstuhl, auf dem sie Platz genommen, so gestellt war, daß sie ihr Kinn bequem auf die am Apparat befestigte Kinnstütze auflegen konnte und letztere selbst so eingestellt war, daß die Pupillen in der Mitte der Eingucköffnungen standen, wurde der Raum verdunkelt und der Versuchsperson nunmehr 10 Minuten Zeit zur Adaptation der Netzhaut an die fast völlige Dunkelheit gelassen. Dann wurden die Nernstlampen eingeschaltet, nachdem die Schieber und Lichtfilter so gestellt waren, daß die Umgrenzung der Pupille noch gerade deutlich und scharf zu sehen war. Zur Adaptation an dieses geringe licht (ca. 6 MK.) wurden der Versuchsperson nochmals 1-2 Minuten Zeit gelassen und dann mit der Messung begonnen.

Die Versuchsperson wurde zunächst aufgefordert, geradeaus ,,ins Schwarze" zu sehen. Erst, wenn ich mich von der Befolgung dieses Auftrages überzeugt hatte, nahm ich die Messung der Pupillenweite bei der vorhin bezeichneten, minimalen Belichtung auf der rechten Seite vor, dann auf der linken. War der Meßapparat so eingestellt, daß die schwarzen Stäbe als Tangenten am Rande der Pupille zu stehen schienen, so wartete ich noch einige Zeit ab, um mich zu überzeugen, ob die Messung stimmte, oder ob etwa noch Veränderungen der Pupillenweite zu beobachten waren. Darauf stellte ich den Meßapparat wieder auf das rechte Auge ein, schickte nun in dieses durch Wegdrücken der Schieber ein weit stärkeres Licht (270 MK.) und maß nun wieder die Pupillengröße. Der Vorgang wurde bei jeder Versuchsperson mehrmals wiederholt.

Der Meßapparat blieb nun auf das linke Auge eingestellt; beide Schieber wurden zunächst wieder geschlossen. Darauf wurde das rechte Auge mit dem starken Licht beleuchtet und die Weite der linken Pupille festgestellt. Darnach wurden beide Augen wieder der anfänglichen Minimalbeleuchtung ausgesetzt und nach $1 / 2-1$ Minute dieselbe Messung am rechten, bei belichtetem linken Auge gemacht. Endlich wurden beide Schieber zusammen weggedrückt, so daß in beide Augen gleichzeitig das starke Licht einfiel und nun rechts und links nochmals die Pupillengröße bestimmt. Damit war die Messung der Pupillengröße vor und nach Belichtung, d. h. bei minimaler und sehr starker Belichtung, beendet. Die Konvergenzreaktion wurde meist nur auf dem gewöhnlichen Wege (dem Auge genäherter Bleistift) festgestellt und nur bei einem kleinen Teil der Fälle mittels des Konvergenzapparates bestimmt, da dieser erst später in den Meßapparat eingebaut wurde.

Darauf wurde durch Wegdrücken der Schieber und Verschieben der Lichtfilter eine mittelstarke Beleuchtung der Augen der Versuchsperson hergestellt (ca. 25 MK.). Nachdem die Retina an dieses Licht adaptiert war (ca. 3 Minuten), wurden Schreck- und Schmerzreize ausgelöst und end- 
lich noch einfache Rechenexempel zur Lösung aufgetragen und die dabei eintretenden Pupillenbewegungen vermerkt. Damit war für gewöhnlich die Untersuchung am Apparat beendet. Bei einer großen Anzahl von Personen wurden noch Zeitmessungen angestellt, doch komme ich darauf weiter unten zurück. Ich betone, daß bei der ganzen Untersuchung der höchste Wert darauf gelegt wurde, daß störende Reize, umständliches Herumhantieren usw. vermieden wurden. Die Ergebnisse der Untersuchung wurden sofort in ein Schema eingetragen, dazu die Irisfarbe und die Art der Patellarsehnenreflexe vermerkt.

Bei gesunden Personen ergaben sich überhaupt keine technischen Schwierigkeiten bei der Vornahme der skizzierten Feststellungen, auch bei Geisteskranken im allgemeinen nicht. Da von dem komplizierten Mechanismus des Apparates außen kaum etwas zu sehen ist und bei seiner Konstruktion von vornherein darauf Bedacht genommen wurde, daß er möglichst harmlos, mehr wie ein Guckkasten aussah, machte auch nur selten einer der Pat. Schwierigkeiten aus Furcht vor dem Ungewohnten oder dgl. Fast alle setzten sich gern an den Apparat, höchstens konnte die Spannung in der Erwartung der Dinge, die es zu sehen gäbe, störend werden. Hie und da wurde allerdings bei Alkoholisten die Untersuchung zeitraubend, indem sie zum Teil anfingen, zu halluzinieren und dann kaum zu bewegen waren, die Augen ruhig zu halten, zum Teil bei stärkerer Belichtung der Augen eine sehr störende profuse Tränensekretion zeigten.

Bei der Schilderung der Versuchsanordnung mag es aufgefallen sein, daß ich nicht erwähnte, wodurch ich mich vergewissere, ob die Versuchsperson ihren Kopf auch wirklich so hält, daß die Ptpille an dem richtigen Ort, soweit es die Entfernung von dem Meßapparat anlangt, hält, da ja sonst die Messung nach unseren bei Besprechung der Methoden ausgeführten Darlegungen fehlerhaft werden müßte. Hier schützt eine einfache Tatsache vor Fehlschlüssen. Die Tiefenschärfe der von mir verwendeten Lupe ist so gering, daß das Bild der Pupille nur dann zugleich mit dem der Meßstäbchen scharf erscheinen kann, wenn Pupille und Meßapparat gleichweite Entfernung von der Linse haben, oder m. E. da $\beta$ es nur so lange gleich scharf erscheint, als durch Abweichung von der verlangten Stellung kein wesentlicher Meßfehler entstehen kann.

Zunächst mag nun über die bei gesunden Personen vorgenommenen Untersuchungen berichtet werden.

\section{Die Pupillenweite.}

Die Weite der Pupille wird bestimmt durch das Zusammenwirken einer ganzen Anzahl von Einflüssen, die auf die beiden Irismuskeln ent- 
weder momentan oder dauernd wirken: Belichtung der Augen, Konvergenzbewegungen, Lidschluß, psychische und sensible Reize u. a. m. Wollen wir die Pupillenweite einzelner Individuen untereinander vergleichen, so müssen wir die Bedingungen, unter denen ihre Messung geschieht, soweit irgend denkbar, gleichmäßig gestalten, da auch geringfügige Unterschiede von großem Einfluß auf die Pupillenweite sein können. Wir müssen uns vor allem vergewissern, ob nicht eine momentane, voraufgegangene Reizwirkung norh ihren Einfluß auf die Irismuskulatur während der Messung ausübt, so daß die beobachtete Weite nicht allein durch die beim Versuch vorausgesetzten Bedingungen veranlaßt ist. Wie ich schon weiter oben erwähnte, ist hier vor allem die Tatsache von weittragender Bedeutung, daß die Pupillenweite nicht allein von der momentan das Auge treffenden Lichtmenge bedingt wird, sondern von dem Adaptationszustande der Netzhaut abhängig ist. Diese Tatsache war schon früher Forschern, die sich mit der Pupillenmessung beschäftigten, aufgefallen und Schirmer stellte hierüber exakte Untersuchungen an. Thm verdanken wir die Feststellung, daß die Pupillen des gesunden Menschen, wenn seine Augen einer Helligkeit von 100 bis 1100 MK. ausgesetzt werden, nach einiger Zeit eine gleichbleibende Weite annehmen, die er als ,physiologische Pupillenweite" bezeichnete. Die Netzhaut adaptiert sich offenbar allmählich an den Lichtreiz, und zwar derart, daß der durch ihn erzeugte Tonus des Sphincter pupillae bei einer Lichtmenge, die im Bereich der unser Auge gewöhnlich treffenden Beleuchtungsverhältnisse liegt, eine konstante mittlere Weite der Pupille entstehen läßt. Wird die Belichtung des Auges geringer als $100 \mathrm{MK}$., so erweitert sich die Pupille und nimmt eine der veränderten Lichtstärke entsprechende Weite an. Auch hierbei dauert es geraume Zeit, bis die Pupille sich im Ruhezustand befindet; die Netzhaut bedarf zur Adaptation an den veränderten Reiz einer gewissen Zeit. Wir haben oben schon hervorgehoben, daß die Adlaptationszeit, verschieden ist, je nachdem die Belichtung des Auges vorher eine stärkere oder schwächere war. Schirmer fand, daß zu diesem Vorgang beim Utbergang vom Hellen ins Dunkle eine Zeit von 10-20 Minuten benötigt wird und beim Utbergang vom Dunkeln ins Helle bis 5 Minuten verstreichen müssen, bis die Netzhaut adaptiert ist, und die Weite der Pupille konstant bleibt. Lans ${ }^{1}$ ) stellte genaue Untersuchungen über den Einfluß verschieden starker Belichtung auf die Pupillengröße an und fand, daß die Weite der Pupillen bei zunehmender Beleuchtungsstärke zunächst sehr rasch, dann immer langsamer abnimmt. Er stellte bei völliger Adaptation der Netzhaut für die jeweilige Belichtung bei zwei Versuchspersonen. folgende Werte fest:

I) Lans, L. J., U̇ber Pupillenweite. Archiv f. Anat. u. Physiol. 1900, 79. 


\begin{tabular}{|c|c|c|c|}
\hline \multicolumn{2}{|c|}{ Weite der Pupille } & \multicolumn{2}{|c|}{ Lichtstärke } \\
\hline Vp. I & Vp. II & & \\
\hline $7,55 \mathrm{~mm}$ & $7,26 \mathrm{~mm}$ & 0 & MK. \\
\hline 6,85, & 6,54, & 0,54 & , \\
\hline 6,38, & 6,31, & 1,6 & , \\
\hline 6,19, & 6,13 & 6 & , \\
\hline 5,84, & 5,71, & 25 &, \\
\hline
\end{tabular}

Bei 11 Personen maß er die Pupillengröße bei Lichtstärken von 25-1000 MK. und fand

$$
\begin{aligned}
& \text { bei } 25-50 \mathrm{MK} \text {. eine Weite von } 4,21 \mathrm{~mm} \\
& \text {, } 50-100 \quad, \quad, \quad, \quad, 3,62 \text {, } \\
& \text {, } 100-500,, \quad, \quad, 3,32 \text {, , } \\
& \text {, 500-1000 ", , , , } 3,25 \text {, }
\end{aligned}
$$

Die Weite nahm also nach diesen Untersuchungen auch zwischen einer Beleuchtung von 100-1000 MK. noch ab, jedoch nur um $0,37 \mathrm{~mm}$, so daß man mit Schirmer, der bei Gesunden eine bei Belichtung von 100-1100 MK. konstant bleibende Weite zwischen 2,75 und $4,75 \mathrm{~mm}$ fand, für eine praktische Betrachtung der Verhältnisse einig gehen kann.

Da die geschilderten Tatsachen von weitgehendstem Interesse sind, versuchte ich, mit meinem Apparat dieselben Messungen anzustellen und die bei verschiedenster Belichtung resultierenden Pupillengrößen photographisch festzuhalten. Von der Beobachtung ausgehend, daß bei den meisten Menschen die konsensuelle Lichtreaktion eine gleichgroße Weite der beiderseitigen Pupillen auch bei einseitiger Belichtung hervorbringt, und in der Erwägung, da $ß$ eine photographische Aufnahme einer bestimmten Pupillengröße nur dann möglich ist, wenn die zur Photographie benötigte Lichtzufuhr zum Auge von kürzerer Dauer ist als die Latenzzeit der auf Lichteinfall eintretenden Irisbewegung, baute ich in meinen Apparat folgende Vorrichtung ein. An Stelle der gewöhnlich zur Beleuchtung des rechten Auges dienenden Nernstlampe setzte ich eine Bogenlampe von 30 Ampere und verschloß die Lichteinfallöffnung zum oberen Kasten unseres Apparates mit einem Momentverschluß aus Metall, der Belichtungen von höchstens $1 / 75$ Sekunden Dauer garantierte. An den Apparat wurde eine photographische Camera, die mit einer Tessarlinse von Zeiß $(1: 6,3 \mathrm{~F}=145 \mathrm{~mm})$ ausgestattet war, angesetzt, so daß auf der Mattscheibe ein auf die Hälfte verkleinertes Bild des rechten Auges der am Apparat sitzenden Versuchsperson entworfen wurde, wenn der Momentversehluß geöffnet war. Meine Versuche, deren Ergebnisse in der Fig. 36 (Tafel VIII) wiedergegeben sind, stellte ich nun folgendermaßen an. Ich ließ die Versuchsperson znächst bei einer minimalsten Belichtung des linken Auges im Dunkelzimmer $1 / 4$ Stunde lang am Apparat sitzen mit dem Auftrage, ,geradeaus" zu schauen. 
Das rechte Auge war dabei völlig unbelichtet. Ich bemerke ausdrücklich, daß ich vorher durch gewöhnliche Messungen mit meinem Apparat feststellte, daß die konsensuelle Lichtreaktion bei meiner Versuchsperson ebenso ausgiebig wie die direkte war und die Pupillen beider Augen dauernd die gleiche Größe behielten. $\mathrm{Zu}$ dem Zwecke belichtete ich $1 / 2$ Stunde lang nur das linke Auge der Versuchsperson und fand, daß nach Ablauf dieser Zeit beide Pupillen noch die gleiche Größe aufwiesen. Es ist auch vielleicht nicht unwichtig, zu erwähnen, daß meine Versuchsperson (ein Pfleger der Klinik) äußerst willig und geduldig, dabei verständig war. Nachdem ich annehmen durfte, daß ihre Netzhaut (nach viertelstündiger gleichmäßiger Belichtung) vollkommen an die minimale Lichtmenge adaptiert sei, wurde jetzt durch Momentbelichtung des rechten Auges eine Photographie gemacht (Fig. 36I, Tafel VIII). Darauf wurde das linke Auge einem verstärkten Licht ausgesetzt, wieder $1 / 4$ Stunde gewartet und dann eine neue Aufnahme des rechten Auges angefertigt (Fig. 36 II, Tafel VIII). Dieses Spiel wiederholte sich noch viermal, indem ich das linke Auge immer stärker belichtete, wobei infolge der optischen Verhältnisse des Apparates die Mehrung der Lichtzufuhr von Versuch zu Versuch immer größer wurde (Fig. 36 III-VI, Tafel VIII). Genaue Messungen der Pupillenweiten am zehnfach vergrößerten Projektionsbild der Negative ergaben folgende Werte:

Adaptation der Netzhaut

$\begin{array}{cr}\text { für Lichtstärke } & \text { Weite der Pup} \\ 1,2 \mathrm{MK} . & 7,0 \mathrm{~mm} \\ 2,6, & 5,8, . \\ 4,8, & 5,2, \\ 11,4, & 4,8, \\ 24,4, & 4,4, \\ 52,2, & 4,1,\end{array}$

Endlich machte ich noch eine Aufnahme der rechtsseitigen Pupille unter Zuhilfenahme eines zweiten, am photographischen Apparat befindlichen Momentverschlusses, während der das Bogenlicht abblendende Momentverschlu $\beta$ geöffnet war, so da $\beta$ dieses dauernd Zutritt zum Auge hatte, und stellte so die Pupillenweite des Auges bei einer Lichtstärke von ca. $5200 \mathrm{MK}$. fest. Dieser Versuch unterscheidet sich nicht allein dadurch von den vorhergehenden, daß jetzt das photographierte Auge durch das zur Messung verwendete Licht getroffen war, sondern auch dadurch, daß dem Auge keine Zeit zur Adaptation gelassen werden konnte, da das grelle Licht bei länger danerndem Einfall ins Auge zu schmerzhaft geworden wäre. Als Größe des Pupillendurchmessers stellte ich hierbei $3,0 \mathrm{~mm}$ fest. 
Die Fig. 38 zeigt den pupillomotorischen Effekt der Zufuhr der immer größer werdenden Lichtreize bei vorheriger Adaptation der Netzhaut an verschieden große Lichtstärken. Nach unseren Berechnungen verengerte sich die Pupille bei Adaptation der Netzhaut an minimalstes Licht um 1,2 $\mathrm{mm}$ (I) bei Zufuhr eines Lichtreizes von 1,4 MK., bei Adaptation an dieses Licht und neuerlicher Mehrung des Lichteinfalles um 2,2 MK. nur mehr um 0,6 mm (II), dann zweimal um je $0,4 \mathrm{~mm}$ (III, IV) bei Lichtzuwachs von 6,6 bzw. 13,0 MK. und schließlich noch um $0,3 \mathrm{~mm}$ (V) nach Verstärkung des Lichtes um 27,8 MK. Diese Feststellungen und die Tatsache, daß bei einer Verstärkung der Beleuchtung von $52 \mathrm{MK}$. auf ca. $5200 \mathrm{MK}$. nur noch eine Verengerung der Pupille um $0,9 \mathrm{~mm}$ stattfand, geben uns für die praktische Handhabung einer zweckmäßigen Prüfung der Lichtreaktion wertvolle Aufschlüsse. Wie es uns bei der Untersuchung des Kniesehnenreflexes sehr daran gelegen ist, die Spannungen der Beinmuskulatur möglichst zu vermindern, so ist es offenbar am zweckmäßigsten, wenn man bei der Untersuchung des Lichtreflexes der Pupillen auch hier dafür sorgt, daß der Sphinctertonus zunächst möglichst gering ist. Wir erreichen mit kleinem Reiz bei möglichst geringem Tonus des Verengerers sehr viel mehr,

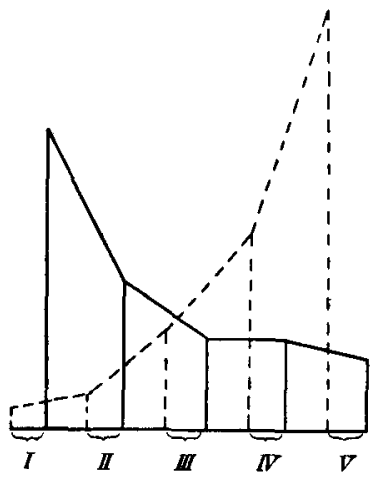

Fig. 38.

Die punktierten Ordinaten stellen die Größe des jeweiligen Lichtzuwachses dar. Die ausgezogenen Ordinaten bezeichnen die Größe der darauf erfolgenden Irisbewegung. die Pupille antwortet auf den Reiz mit einem viel größeren Ausschlag, als wenn wir bei schon starker Sphincterinnervation sehr starke Lichtzufuhr zum Auge veranlassen. Nicht unwichtig ist hier auch der Úbelstand, daß eine grelle Belichtung für die Versuchsperson sehr unangenehm ist und länger dauernde Untersuchungen sehr erschwert oder unmöglich macht. Auf Grund dieser Ubberlegungen und Versuchstatsachen stellte ich für meine Pupillenuntersuchungen das oben schon skizzierte Schema auf.

Greifen wir wieder auf unser eigentliches Thema, die Besprechung der Pupillenweite, zurück. Ich machte noch den umgekehrten Versuch und stellte die Größen der Pupille fest, wenn ich zunächst starkes Licht (52,2 MK.) ins Auge projizierte, dann immer schwächeres und nach jedesmaliger $1 / 4$ Stunde dauernder Adaptation eine photographische Aufnabme machte, wie es oben geschildert wurde. Die Untersuchungen wurden an derselben Versuchsperson gemacht, und zwar 2 Tage nach den oben besprochenen. Ich fand folgende Werte. 


$\begin{array}{cc}\text { Adaptation der Netzhaut } & \text { Weite der Pupille } \\ \text { für Lichtstärke } & \\ 52,2 \text { MK. } & 3,7 \\ 24,4 \text { ", } & 4,0 \\ 11,4 \text { ", } & 4,6 \\ 4,8 \text { ", } & 5,1 \\ 2,6 \text { ", } & 5,8 \\ 1,2, & 7,2\end{array}$

Wir sehen hier (m. E.) dasselbe Resultat wie bei unserem ersten Versuch, jedenfalls denselben Verlauf der Kurve des pupillomotorischen Effektes gleichstarker Lichtzufuhr bei verschiedener Adaptation der Netzhaut.

Nach einer Bemerkung, die ich in Bachs Pupillenlehre fand, hat Ovio (Italienische Ophthalmol. Vers. 1907) das Verhältnis der Einheit der Pupillenerweiterung und der Einheit der Lichtveränderung dahin bestimmt, da $\beta$ der Pupillenerweiterungskoeffizient der Lichtintensität umgekehrt proportinal ist, indem die Pupille sich bei gleichförmiger Veränderung des Lichtes zuerst langsam, dann immer rascher erweitert (die Abhandlung darüber war mir nicht zugänglich).

Wie meine Befunde bei Vermehrung der Lichtzufuhr mit denen von Lans übereinstimmen und nicht wesentlich von denen Schirmers abweichen, so würden sie auch die Feststellungen von Ovio bestätigen.

Die Netzhaut bedarf, wie ich schon oft erwähnt habe, zur Adaptation an einen bestimmten Lichtreiz einer mehr oder weniger langen Zeit. Die Zeit ist länger, wenn das vorher stark belichtete Auge an eine geringere Lichtmenge adaptiert werden soll, als umgekehrt. Es war nun von besonderem Interesse, zu erfahren, wie diese Adaptation vor sich geht, wenn das Auge verdunkelt wird. Garten ${ }^{1}$ ) hat hierüber sehr exakte Untersuchungen angestellt, indem er Pupillenaufnahmen mit Blitzlicht machte. Seine Untersuchungsergebnisse illustriert folgende Tabelle.

$\begin{array}{cc}\text { Dauer des Aufenthaltes } & \text { Pupillenweite } \\ \text { im Dunkeln } & \\ 0 \text { Sekunden } & 4,76 \mathrm{~mm} \\ 5 \quad " & 7,36 \quad " \\ 30 \text { ", } & 7,30, " \\ 15 \text { Minuten } & 7,59, " \\ 30 \text { ", } & 7,53, " \\ 1 \text { Stunde } & 7,48, " \\ 8 \text { Stunden } & 7,99,\end{array}$

1) Garten, S., Beiträge zur Kenntnis des zeitlichen Ablaufs der Pupillar. reaktion nach Verdunkelung. Archiv f. d. ges. Physiol. 68, 68. 1897. 
Mit meiner oben geschilderten Methodik fertigte ich ebenfalls Pupillenphotogramme in verschiedenen Zeitabständen nach totaler Verdunklung beider Augen an. Das Resultat meiner Bemühungen zeigt Fig. 37 (Tafel VIII), die berechneten Werte folgende Tabelle.

Dauer des Aufenthaltes

$\begin{array}{cc}\text { im Dunkeln } & \text { Pupillenweite } \\ 0 \text { Sek. } & 3,8 \mathrm{~mm} \\ 5 \text { ", } & 5,8, " \\ 30 \text {," } & 6,4 \text { ", } \\ 5 \text { Min. } & 6,6 \text { ", } \\ 10 \text { ", } & 7,0, " \\ 15 \text {," } & 7,4, "\end{array}$

Die Kurve des Eintritts der Adaptation der Netzhaut nach Verdunklung, ausgedrückt durch die dabei sich ergebenden Veränderungen der Pupillenweite, zeigt Fig. 39.

In Übereinstimmung mit Garten fand ich also, daß die Pupille sich sofort nach der Verdunklung sehr rasch erweitert, dann, allerdings sehr langsam, noch weiter wird. Offenbar bleibt zunächst noch trotz Wegfalls des sie veranlassenden Reizes eine erhöhte Empfindlichkeit

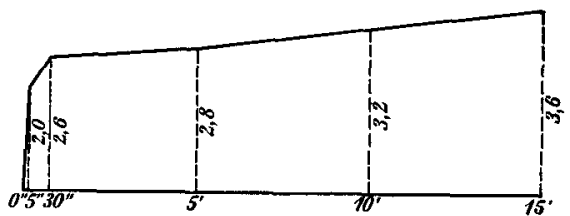

Fig. 39 . der Netzhaut und ein verstärkter Tonus des Sphincterzentrums zurück, der dann langsam abklingt.

Úber den Einfluß der Refraktion auf die Pupillenweite liegen verschiedene Untersuchungsreihen vor. Silberk $\mathrm{uhl}^{1}$ ) fand im allgemeinen keine wesentlichen Größenunterschiede bei Myopen oder Hyperopen, nur schien die Pupillenweite der Myopen in den mittleren Lebensjahren etwas über die der anderen Gruppen zu überwiegen. Tange ${ }^{2}$ ) bestätigte dies letztere Resultat und fand ferner die Pupillenweite der Hyperopen geringer als die der Emmetropen. $\mathrm{Zu}$ denselben Schlüssen führten Untersuchungen von $\mathrm{Körbling}{ }^{3}$ ) und solche von $\mathrm{Bach}$.

Die Pupillenweite ist bei den verschiedenen Altersklassen verschieden, wie Messungen von Tange ${ }^{2}$ ), Pfister $^{4}$ ), Bartels ${ }^{5}$ ) u. a. gezeigt haben.

1) Silberkuhl, W., Untersuchungen über die physiologische Pupillenweite. v. Graefes Archiv 52, III, 179. 1896.

2) Tange, R., Die normalen Pupillenweiten nach Bestimmungen in der Poliklinik. Inaug-Diss. Amsterdam 1901.

3) Körbling, E., Über das Verhalten der Pupillenweite zur Refraktion und zum Alter. Inaug.-Diss. München 1894.

4) Pfister, H., U̇ber das Verhalten der Pupille und einiger Reflexe am Auge im Säuglings. und frühen Kindesalter. Arch. f. Kinderheilk. 24. 1899.

5) Bartels, M., Pupillenverhältnisse bei Neugeborenen. Zeitschr. f. Augenheilk. 12, 638. 1904. 
Pfister und Bartels fanden, daß die Pupillenweite der Neugeborenen kleiner ist als die jugendlicher Personen, die Pupillengröße nimmt nach ihnen im Verlauf der ersten 6 Lebensjahre allmählich zu. Nach den Messungen von Tange bleibt sie dann bis Mitte der zwanziger Jahre konstant und nimmt später langsam ab.

Während Silberkuhl und Tange übereinstimmend keinen Einfluß der Farbe der Regenbogenhaut auf die physiologische Pupillenweite feststellen konnten, glaubten Schadow ${ }^{1}$ ) und andere annehmen zu sollen, daß die pigmentarme Iris mit geringerer Pupillenweite vergesellschaftet sei. Ich konnte bei meinen Untersuchungen keine eindeutigen Anhaltspunkte dafür finden, daß die Pupillenweite in irgendwelcher Abhängigkeit von der Irisfarbe steht.

Meine Untersuchungen am Gesunden erstreckten sich über 84 Personen, die in einem Alter von 14-56 Jahren standen. Die für die Weite ihrer Pupillen festgestellten Werte gibt folgende Tabelle wieder.

Weite der Pupille bei beiderseitigem

Lichteinfall von 5,88 MK.

$$
\begin{array}{ll}
3,6-4,0 & \mathrm{~mm} \\
4,1-4,5 & , \\
4,6-5,0 & , \\
5,1-5,5 & , \\
5,6-6,0 & , \\
6,1-6,5 & ,
\end{array}
$$

Weite der Pupille bei beiderseitigem

Lichteinfall von $276 \mathrm{MK}$.

$$
\begin{array}{ll}
2,1-2,5 & \mathrm{~mm} \\
2,6-3,0 & , \\
3,1-3,5 & , \\
3,6-4,0 & , \\
4,1-4,5 & ,
\end{array}
$$

Anfallende gesunde Versuchspersonen (in Prozenten)

16

16

22

23

17

6

Anfallende gesunde Versuchspersonen (in Prozenten)

14

34

18

4

Während demnach die größte Mehrzahl der Versuchspersonen bei minimalster Beleuchtung der Augen mit einer Lichtstärke von ca. 6 MK. eine Weite von 4-6 mm aufwies, fanden sich bei beiderseitigem Lichteinfall von $276 \mathrm{MK}$. meist Pupillendurchmesser von 2,6-3,5 mm. Wir können also beim Gesunden eine durchschnittliche Pupillenweite von ca. $5 \mathrm{~mm}$ bei beiderseitiger geringer Belichtung der Augen erwarten, die sich um ca. $2 \mathrm{~mm}$ verringert, wenn das Einfallslicht auf eine Stärke von $270 \mathrm{MK}$. erhöht wird.

Auf Unterschiede der Pupillenweite bei Belichtung nur eines Auges werde ich weiter unten noch ausführlich zu sprechen kommen.

Wir sehen, daß die Pupillengröße beim Gesunden in ziemlich weiten

1) Schadow, Beiträge zur Physiologie der Irisbewegung. Arch. f. Ophthalmologie. 28, III, 183. 1882. 
Grenzen schwankt, eine Feststellung, die uns nicht sehr wundern kann, wenn wir bedenken, daß die Irisbewegungen, die Spannungen der Irismuskulatur von sehr vielen Bedingungen abhängig sind, die zum Teil von außerhalb an die Versuchspersonen herantreten, zum Teil wohl auch in ihrem Organismus, in ihrer persönlichen Anlage begründet sind. Hier können Nahrungsaufnahme, vorausgegangene Ermüdung, fortwirkende psychische Erregungen, endlich momentane Beunruhigung durch den Versuch sowohl, wie allgemeine psychische Empfindlichkeitsunterschiede eine große Rolle spielen. Immerhin zeigen die gemessenen Werte doch bei der größten Anzahl der Versuchspersonen eine gute t'bereinstimmung, und wir werden später sehen, daß die für die Pupillenweite gefundenen Mittelwerte bei einzelnen Erkrankungen des Nervensystems doch weit von denen der Gesunden abweichen, wenn auch die Grenzwerte bei Gesunden und Kranken ineinander übergehen. Die Feststellung der Pupillenweite müssen wir daher doch als wertvoll bei der Beurteilung des nervösen Zustandes der Versuchsperson betrachten, trotz der beim Gesunden schon bestehenden Breite ihrer Norm.

\section{Die Pupille verkleinernde Irisbewegungen.}

\section{Der Lichtreflex.}

Lassen wir in ein, an eine bestimmte Helligkeit adaptiertes Auge ein stärkeres Licht einfallen, so antwortet die Iris beim Gesunden darauf mit einer Kontraktion. Diesen Vorgang nennen wir den Lichtreflex der Pupille. Die zentralen Teile der Netzhaut nehmen den durch das Licht gesetzten, sensiblen Reiz auf, der, in der Opticusbahn weitergeleitet, zum Oculomotoriuskern übergeht und dann als motorische Erregung im Oculomotorius zum Sphincter iridis verläuft, dessen Kontraktion er veranlaßt.

Zur Zurücklegung dieses Weges und zur Umsetzung der sensiblen in die motorische Erregung wird eine Zeit verbraucht, die wir als Latenzzeit zwischen Reizmoment und sichtbarer Irisbewegung verstreichen sehen. Bestimmungen dieser Zeit wurden vielfach versucht. Arlt ${ }^{1}$ ) berechnete sie zu 0,49 Sek. im Mittel, Vintschga ${ }^{2}$ ) zu 0,55 Sek. Da diese Messungen unter Zuhilfenahme entoptischer Wahrnehmungen gemacht wurden, können sie wegen der vielen Fehlerquellen dieser Methode keinen allzugroßen Anspruch auf Sicherheit und Genauigkeit machen.

Latenz- und Kontraktionszeit des Sphincter. Ich versuchte zunächst, die Latenzzeit der Lichtreaktion mittels der Zeitschreibemethode bzw. durch Ablesen der am Chronoskop angezeigten Zeit zu

1) 2) Zitiert bei Technik der Zeitbestimmung der Pupillenbewegungen. 
messen, doch mußte ich bald einsehen, daß eine solche Bestimmung unmöglich war. Die Latenzzeit war offenbar sehr kurz, und ihr Beginn nach Öffnen des dem Licht Zutritt verschaffenden Schiebers wurde zumeist übersehen. Mit sehr vieler Ưbung gelang es mir wohl allmählich, zu Beginn der sichtbar werdenden Kontraktion den Hebel loszulassen und so die Zeit zwischen Reiz und Bewegungsbeginn am Chronoskop zu bestimmen, doch stellte sich bei fortlaufenden Messungen heraus, daß die gefundenen Werte sehr wechselten, so daß ich zu dieser Methode kein Vertrauen mehr hatte. Hier konnte nur die Photographie helfen. Bei der Berechnung von nunmehr aufgenommenen Kinematogrammen stellte sich zweierlei heraus. Zunächst bestätigte sich meine Vermutung, daß die Latenzzeit sehr kurz sein müsse, ich fand im Mittel eine solche von 0,20 Sek., manchmal sank die Zeit gar auf 0,15 Sek., manchmal fanden sich höhere Werte bis zu 0,28 Sek. Des weiteren wurde mir klar, warum es so schwer fiel, den Anfang der Irisbewegung zu beobachten. Die Kinematogramme zeigten, daß die Verengerung der Pupille nicht rasch, sondern im Verhältnis zur Kürze der Latenzzeit und zur Ausschlaggröße der Bewegung sehr langsam vor sich geht; daher die Schwierigkeit, ihren Anfang zu erkennen.

Sehr viel leichter gelang die Bestimmung der Kontraktionszeit, einschließlich der Latenzzeit. Bei 23 gesunden Personen stellte ich ihre Messung in folgender Weise an. Ich bestimmte zunächst die Kontraktionszeit, wenn ich das Auge direkt belichtete, indem ich das Chronoskop, wie oben geschildert, mit meinem Apparat verband und sein Zeigerwerk bei der Belichtung des Auges durch Wegdrücken des Schiebers in Gang setzte. Sobald ich den Stillstand der Iris nach der Kontraktionsbewegung beobachtete, hielt ich das Uhrwerk durch Loslassen des Schiebers wieder an. Diese Messung gelang nach einiger Ưbung leicht, und der Moment des Stillstandes der Iris war unschwer zu beobachten. Die Messung wurde hintereinander, unter Wahrung einer jedesmaligen, kleinen Erholungspause für das Auge des Untersuchten, mindestens $30 \mathrm{mal}$ wiederholt. Als Kontraktionszeit wurde das Stellungsmittel aller Beobachtungen angenommen, d. h. nach Abzug des persönlichen Fehlers, meiner eigenen Reaktionszeit. Diese bestimmte ich ebenfalls an meinem Apparat. Ich brachte am Pupillenort eine schwarze Scheibe an, die in der Mitte ein Loch von $5 \mathrm{~mm}$ Durchmesser hatte. Hinter ihr war ein kleiner Fallapparat aufgestellt, in dem eine weiße Scheibe hin und her gleiten konnte, und der so eingestellt war, daß ein elektrischer Stromkreis geschlossen wurde, wenn die Scheibe im Loch des schwarzen Diaphragmas sichtbar wurde. Ein Stromkreis lief durch diesen Fallapparat und den Meßapparat zum Chronoskop, in dem Sinne, daß dessen Zeigerwerk in Bewegung geriet, wenn die weiße Scheibe von mir gesehen werden konnte, während es sofort zum Stillstand kam, 
wenn ich den Schieber losließ. Ich wartete also, indem ich den Schieber festhielt, bis das weiße Objekt erschien und ließ ihn dann zurückschnellen. Auf diese Weise erhielt ich am Chronoskop offenbar die Zeit, die verfloß, bis ich auf die Erkennung des weißen Objektes mit der Loslassung des Schiebers reagierte, meine Reaktionszeit auf einen optischen Eindruck, erzeugt am Pupillenorte. Daß bei diesen Versuchen Vexierversuche (schwarze oder farbige Scheibe) eingeschoben wurden, und daß die Scheiben geräuschlos erschienen, versteht sich von selbst. Ich berechnete vor und nach jeder Versuchsreihe meine Reaktionszeit, die im Mittel 0,18 Sek. betrug und zog sie von den bei der Pupillenbeobachtung gefundenen Werten ab.

Auf diese Weise konnte ich die Reaktionszeit der Pupille bei direkter Belichtung des untersuchten Auges berechnen und fand im Mittel als Zeit für die Kontraktion des Irismuskels einschließlich der Latenzzeit dieser Bewegung 0,92 Sek. Die Werte schwankten zwischen 0,70 und 1,20 Sek.

Ich konnte mich durch Kontrollversuche mittels kinematographischer Aufnahmen überzeugen, daß die so gefundenen Werte den tatsächlichen Verhältnissen sehr nahe kamen, so daß die genannte Methode für die praktische Feststellung der Zeit genügt, die nach Lichteinfall verfließt, bis die Iris in stärkster Kontraktion stillsteht.

In einer weiteren Versuchsreihe prüfte ich die Schnelligkeit dieses Vorganges bei indirekter Belichtung, d. h. ich belichtete z. B. das rechte Auge und machte die Messung am linken. Da dieses dabei relativ dunkel war, stellten sich der Messung größere Schwierigkeiten entgegen. Es schien mir wohl in einzelnen Fällen die dabei berechnete Zeit länger zu sein als bei der Messung am direkt belichteten Auge, doch waren die Unterschiede gering und bei der größeren Schwierigkeit des Versuches nicht mit Sicherheit zu verwerten. Bei den meisten Versuchspersonen war die Reaktionszeit bezw. Kontraktionszeit der Iris des indirekt wie des direkt belichteten Auges gleichgroß.

An diese Versuche schloß ich noch eine weitere Untersuchung an, indem ich beide Augen gleichzeitig belichtete und die Zeitbestimmung machte. Auch hierbei fand ich keine wesentlichen Zeitunterschiede gegenüber den bei der einseitrgen Belichtung festgestellten Zahlen.

Die Ausnessung kinematographischer Aufnahmen ergab als Zeit zwischen Reiz und Ende der Sphincterkontraktion im Mittel bei direkter Belichtung 0,87 Sek.; auch hier schwankten die Werte bei den verschiedenen Versuchspersonen ziemlich stark, es fanden sich solche von $0,76-1,08$.

Nach unseren, beim Gesunden vorgenommenen Messungen können wir also sagen: 
I. Die Latenzzeit des Lichtreflexes der Pupille ist sehr kurz, sie beträgt im Mittel 0,20 Sek.

II. Die Zeit, welche zwischen Reiz und völliger Kontraktion des Sphincterverstreicht, beträgt im Mittel 0,87 Sek., die Kontraktionszeit also 0,67 Sek. im Mittel.

III. Auch beim Gesunden finden sich erhebliche Abweichungen von diesen Mittelzahlen.

IV. Wesentliche Unterschiede in den Zeitverhältnissen des Ablaufes der Lichtreaktion, sei es, daß das untersuchte Auge direkt belichtet oder die Kontraktion der Iris durch Belichten des anderen Auges erzielt wurde, sei es, daß beide Augen zugleich dem Lichte ausgesetzt wurden, fanden sich nicht.

Vergleichen wir mit unseren Befunden die von anderen Forschern festgestellten Werte, so können wir die Latenzzeitbestimmung übergehen, da sie schon oben erörtert wurde. Die einzigen vergleichbaren, die Kontraktion betreffenden Messungen liegen von Fuchs vor, der mittels seiner photographischen Methode (siehe bei Technik) bei Kranken und Gesunden Werte von 0,60-1,24 Sek. für die Kontraktionszeit der Iris feststellte. Leider sind unter seinen Fällen nur wenige Gesunde, so daß wir seine Zahlen mit den unseren nicht gut vergleichen können, doch ist wenigstens im allgemeinen eine Utbereinstimmung vorhanden und wir werden bei Besprechung unserer an Kranken gemachten Beobachtungen noch näher auf die von Fuchs aufgestellten Zahlen zurückkommen.

Größe der Reflexbewegung. Bei der gewöhnlichen, klinischen Pupillenuntersuchung sprechen wir von ausgiebiger, mittlerer oder geringer Reaktion der Pupillen bei Lichteinfall, indem wir ein gewisses Urteil über den Grad der auf den Reiz hin eintretenden Bewegung auszudrücken suchen. Die Ausgiebigkeit der Irisbewegung bei der Lichtreaktion hängt, wie wir gesehen haben, wesentlich von dem Adaptationszustand der Netzhaut ab, doch fällt sie auch bei gleicher Adaptation der Retina und bei gleichstarkem Lichtreiz nicht immer gleich groß aus, wie wir weiter unten sehen werden. Daß die Reaktion je nach der Reizgröße eine andere sein wird, war mit Rücksicht auf die allgemeine Physiologie der Reflextätigkeit zu erwarten. Der erste, welcher Beobachtungen über das Verhältnis von Reizintensität und pupillomotorischem Erfolg machte, scheint Lambert ${ }^{1}$ ) gewesen zu sein, der annahm, daß die Pupille um so enger werde, je größer der vom

1) La m bert, J. H., Photometria sive de mensura et gradibus luminis colorum et umbrae 1760,379 . 
Licht getroffene Teil der Netzhaut sei. Henry $\mathrm{y}^{1}$ ) beobachtete, daß bei gleichgroßem, vom Licht getroffenem Netzhautfeld die Pupille bei Lichtzuwachs sich zunächst schnell, dann langsam verengert. Diese Beobachtung stimmt mit unseren bei der Besprechung der Pupillenweite bei verschieden starker Belichtung dargestellten Befunden überein.

Die Größe der auf den Lichtreiz folgenden Bewegung stellte ich zunächst bei direkter Belichtung sowohl am rechten wie am linken Auge fest. Das an ein Licht von 5,88 MK. adaptierte Auge wurde einer Belichtung von 276 Meterkerzenstärken ausgesetzt und nun die Pupillenweite bestimmt. Die Differenz der Pupillendurchmesser vor und nach der Belichtung betrug bei den gesunden Versuchspersonen 0,8-2,7 $\mathrm{mm}$. Auf die einzelnen Personen verteilten sich die Werte wie folgt:

$\begin{array}{cc}\text { Ausschlagsgröße } & \text { Anfallende Personen (in \%) } \\ 0,8-1,0 \mathrm{~mm} & 34 \% \\ 1,1-1,5, & 40, \\ 1,6-2,0, & 18, \\ 2,1-2,5, & 6, \\ 2,5-2,7,, & 2,\end{array}$

Bei der größeren Mehrzahl der Gesunden trat also bei einseitiger Belichtung eine Verengerung der Iris um $1-1 \frac{1}{1} / 2 \mathrm{~mm}$ ein.

Bei diesen Untersuchungen fiel es auf, daß die Reaktionsbreite bei derselben Person unter den gleichen Verhältnissen nicht immer gleichmäßig groß war, vielmehr schwankten die Werte in mäßigen Grenzen, so daß auf denselben Reiz einmal ein geringerer, ein andres Mal ein größerer Irisausschlag erfolgte. Wir finden demnach hier dieselbe Erscheinung wieder, auf die wir bei Untersuchungen der Funktionen des nervösen Apparates, sei es nun der Reflex- oder auch Willenstätigkeit, immer wieder stoßen, daß nämlich ein und derselbe Reiz verschieden großen Erfolg am gereizten Nervenapparat haben kann, eine Erscheinung, zu deren Erklärung wir ein Schwanken der Reizbarkeit der nervösen Elemente annehmen, die wohl zum Teil durch Bahnung bzw. Hemmung bedingt ist, zum Teil möglicherweise auch in einer Veränderung des Stoffwechsels in den in Betracht kommenden Zentren ihre Ursache hat.

Nach der Prüfung der Größe der direkten Lichtreaktion schritt ich zur Bestimmung des Ausschlags bei der konsensuellen Pupillenverengerung. Bei fast allen meinen gesunden Versuchspersonen fand ich den Erfolg der indirekten Belichtung ebenso groß wie den der indirekten, d. h. bei einseitigem Lichteinfall verengerten sich beide Pupillen gleich-

1) Henry, Ch., Sur les lois nouvelles de la contraction pupillaire. Compt. rend. 109, 353. 1893. 
mäßig. Bei einigen wenigen (ca. 6\% der Fälle) blieb die Pupille des unbelichteten Auges etwas größer als die des anderen.

Ich machte mehrfach den Versuch, bei Leuten, deren Pupillen bei einseitiger Belichtung beide gleichgroß waren, durch lang andauernde $(1 / 4$ bis $1 / 2$ Stunde) Weiterbelichtung nur eines Auges eine Pupillendifferenz zu erzeugen, ohne daß mir dies gelang.

Die Frage, ob die Pupille des belichteten Auges kleiner sei als die des unbelichteten, ist sei langem eine strittige. Während Whytt ${ }^{1}$ ) und Porterfield ${ }^{2}$, die zuerst eine genauere Beschreibung der consensuellen Reaktion gaben, die Ansicht vertraten, daß die Pupille des belichteten Auges enger sei als die des anderen, bestritt E. H. Weber ${ }^{3}$ ) diese Anschauung, indem er behauptete, beide Pupillen seien auch bei einseitiger Beleuchtung gleichgroß. Fuchs fand nur selten ein Überwiegen der Verengerung der Pupille des belichteten Auges gegenüber der anderen. Bach dagegen erzeugte in $80 \%$ der von ihm untersuchten Fälle durch einseitige, stärkere Belichtung eine Pupillendifferenz. Es läßt sich schwer sagen, welche Gründe dieser verschiedenartige Ausfall der Versuche hat. Ob die größere Schwierigkeit, bei der unbelichteten Iris den innersten Saum genau zu beobachten, eventuell die Annahme einer größeren Weite veranlaßt, oder ob in der Verschiedenartigkeit der Versuchsbedingungen die Differenz der Resultate begründet ist, darüber lassen sich nur Vermutungen aufstellen. Jedenfalls konnte ich bei meinen Versuchen nur die Annahme bestätigen, daß einseitige Belichtung bei gesunden Personen mit sehr geringen Ausnahmen beiderseits gleichgroße Pupillen erzeugt.

Nach der Prüfung der direkten und indirekten Lichtreaktion stellte ich noch folgenden Versuch an. Ich belichtete ein Auge, z. B. das rechte; die Pupille verengerte sich beiderseits gleichmäßig; nun belichtete ich auch das linke Auge, und zwar mit genau derselben Lichtstärke, der das rechte schon ausgesetzt war. Darauf verengerten sich die Pupillen beider Augen nochmals um eine gut meßbare Größe und die Verengerung blieb bestehen. Diesen Vorgang, der bei Gesunden immer beobachtet werden konnte, nannte ich ",sekundäre Lichtreaktion". Sie unterscheidet sich wesentlich von der konsensuellen Lichtreaktion. Während diese eine zweckmäßige, reflektorische Schutzbewegung darstellt, indem, entsprechend dem gewohnten Zusammenwirken der beiderseitigen Sehorgane, der infolge künstlicher, einseitiger Abhaltung des Reizes nur eine von beiden treffende Lichtreiz eine Abblendung des Augapfelinnern beider Seiten bewirkt, die durch Verknüpfung der

1) Whytt, R., An essay of the wital and other involountary motions of animals. Edingbourgh 1752, zit. nach Bach: Pupillenlehre.

2) Porterfield, W. A., Treatise on the eye. 1759, zit. nach Bach.

3) Weber, E. H., De motu iridis. Lipsiae 1852. 
beiderseitigen, den Lichtreflex vermittelnden Bahnen gewährleistet wird, müssen wir das Wesen der sekundären Reaktion ganz anders auffassen. Sie stellt meines Erachtens nichts weiter dar als den Ausdruck einer Reizsummationswirkung im Zentrum des Lichtreflexes. Eine besondere biologische Bedeutung kann ihr nicht zukommen, da ja das anfangs belichtete Auge für den dasselbe treffenden Lichtreiz schon abgeblendet war und trotzdem seine Iris sich bei Belichtung des anderen Auges noch weiter zusammenzieht, eine Utberlegung, die ebenso für das vorher unbelichtete Auge gilt. Auch hier mußte die durch die konsensuelle Reaktion veranlaßte Verengerung der Iris zum Schutze der Retina gegen das nun einfallende Licht genügen, da die Abblendung dessen Stärke offenbar entsprach, wie aus dem Effekt einer einseitigen Belichtung dieses Auges mit der nämlichen Lichtstärke hervorgeht. Die Fig. 40 (Tafel VII) stellt den Vorgang der sekundären Lichtreaktion dar. Die beiden obersten Bilder zeigen die beiden Augen zur Zeit, als nur minimalstes Licht zu ihnen drang, die mittleren Bilder den Zustand nach Belichtung des rechten (im Bilde links) Auges mit starkem Licht. In der untersten Reihe ist der Kontraktionszustand der Iris bei Nachbelichtung des linken Auges mit dem nämlichen starken Licht dargestellt, während die Belichtung des rechten Auges unverändert fortbestand. Wir sehen, daß der Ausschlag bei der sekundären Reaktion ziemlich groß ist.

Die Bedeutung der sekundären Reaktion liegt offenbar darin, daß sie, aufgefaßt als Summationserscheinung, nur durch Vermittelung zentraler Vorgänge in dem beim Lichtreflex tätigen Nervenapparat zustande kommen kann; sie wird demnach auf die Empfindlichkeit dieser zentralen Apparate rückschließen lassen und kann somit bei der Bestimning des Sitzes der Ursache einer Pupillenstörung von Wert sein. Wo dies der Fall ist, werden wir weiter unten sehen. Die Größe dieser sekundären Reaktion schwankt bei den Gesunden zwischen 0,2 und $0,8 \mathrm{~mm}$. Die Werte verteilen sich wie folgt:

$\begin{array}{cc}\text { Ausschlagsgröße } & \text { Anfallende Personen } \\ 0,2 \mathrm{~mm} & 12 \% \\ 0,3, & 14 \% \\ 0,4, & 26 \% \\ 0,5, & 24 \% \\ 0,6, & 10 \% \\ 0,7, & 6 \% \\ 0,8, & 8 \%\end{array}$

Am häufigsten fand sich demnach ein Ausschlag von $0,4-0,5 \mathrm{~mm}$ als Ausdruck der sekundären Reaktion.

Der umgekehrte Vorgang, Erweiterung der Pupille des unverdeckt 
bleibenden Auges beim Bedecken des anderen, war, wie ich schon eingangs erwähnte, bereits Galen bekannt, als er sagte: „Darum geschieht es, daß, wenn wir das eine Auge schließen, die Pupille des anderen sich erweitert, da in das eine jetzt allein die Innervation eindringt, welche vorher sich auf beide verteilte." Die sekundäre Reaktion gibt uns auch eine Erklärung für die Tatsache, daß die Pupille eines Auges bei verdecktem zweiten Auge größer ist, als wenn dieses unbeschattet bleibt. Silberkuhl (siehe bei Weite der Pupillen) maß diese Differenz und stellte fest, daß sie $1 / 4-3 / 4 \mathrm{~mm}$ beträgt, $\mathrm{Bach}$ bestätigte diese Befunde.

Die Reaktionsbewegung der Iris war dementsprechend größer bei Belichtung beider Augen, als bei der Auslösung der direkten Lichtreaktion auf einem Auge. Bei meinen Untersuchungen fand ich folgende Werte.

$\begin{array}{cc}\text { Ausschlagsgröße } & \text { Anfallende Personen } \\ 1,2-1,5 \mathrm{~mm} & 40 \% \\ 1,6-2,0, & 42 \% \\ 2,1-2,5, & 14 \% \\ 2,6-3,0, & 4 \%\end{array}$

Während nach unseren oben mitgeteilten Befunden die Pupillenverengerung bei einseitiger Belichtung meist $1-11 / 2 \mathrm{~mm}$ betrug, berechnete sich der Effekt der beiderseitigen Belichtung in der Mehrzahl der Fälle auf 1,2-2,0 mm.

Verlauf der Reflexbewegung. Aus den kinematographischen Aufnahmen läßt sich leicht ein Urteil über den Ablauf der durch den Licht-

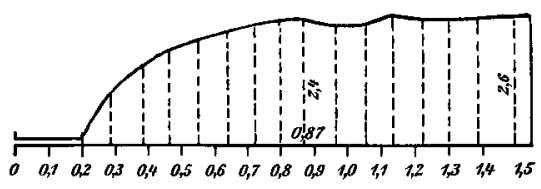

Fig. 41 . reiz veranlaßten Irisbewegung gewinnen. In Fig. 41 ist dieser Vorgang graphisch dargestellt, und zwar so, daß die Kontraktion des Sphincter, ausgedrückt durch die in den einzelnen Zeitabschnitten nach dem erfolgten

Lichteinfall ins Auge gemessene Verengerung der Pupille, als eine Erhebung der Kurvenlinie deutlich wird. Während auf der Abscissenlinie die Zeitverhältnisse aufgetragen sind, bezeichnen die auf ihr errichteten Ordinaten die Größe der jeweiligen Pupillenverengerung. Nach einer Latenzzeit, im gezeichneten Falle 0,2 Sek., verengert sich die Pupille zunächst rasch, wie aus dem schnellen Anstieg der Kurve hervorgeht, dann langsamer und erreicht 0,87 Sek. nach der Belichtung einen Höhepunkt. Darauf sehen wir eine kleine Erweiterung der Pupille eintreten, die sich in einem Abfall der Kurve kundtut. Nach kurzer Zeit steigt diese wieder an, und die Verengerung der Pupille 
wird noch etwas stärker. Diese letztgenannte Erscheinung, die stärkere Kontraktion des Sphincter nach der kurz dauernden Erweiterung, fand sich häufig, jedoch nicht regelmäßig. Die geringe Erweiterung der Pupille nach der anfänglichen starken Verengerung wurde dagegen nie vermißt und stellt die bekannte als ,,sekundäre Erweiterung" benannte, Erscheinung dar. Wodurch sie veranlaßt wird, läßt sich nicht sicher sagen, möglich wäre es, daß sie einem Gegenzug des Dilatator ihren Ursprung verdankt oder aber einer auf das Sphincterzentrum von der Hirnrinde her wirkenden Hemmung als Antwort auf die Lichtempfindung. Die letztere Erklärung hat meines Erachtens die meiste Wahrscheinlichkeit für sich, wie ich weiter unten bei Besprechung der Pupillenerweiterungsreaktionen noch ausführen werde.

Hiermit sind wir am Ende der Besprechung des Lichtreflexes der Pupille angelangt und wir können als durch unsere Untersuchungen festgestellte, bzw. bestätigte Tatsachen den bei der Zeitmessung genannten, nachfolgende hinzufügen.

I. Die nach einseitiger Belichtung erfolgende Pupillenverengerung beträgt meist $1,0-1,5 \mathrm{~mm}$.

II. Die konsensuelle Reaktion ist meist ebenso groß wie die direkte, doch gibt es hiervon Ausnahmen.

III. Wird das zweite Auge, nachdem eines schon mit einem bestimmten starken Licht bestrahlt war, einem Licht von gleicher Stärke ausgesetzt, so verengern sich nochmals beide Pupillen. Diese Bewegung, die ich als ,,sekundäre Reaktion" bezeichnete, veranlaßt eine weitere Verengerung der Pupille um 0,2-0,8 $\mathrm{mm}$ und stellt den Ausdruck einer Reizsummationswirkung dar.

IV. Bei beiderseitiger Belichtung verengtensich die Pupillen bei der gröbten Mehrzahl der Versuchspersonen um $1,2-2,0 \mathrm{~mm}$.

V. Die Pupillenverengerung auf Lichteinfall geht zunächst rasch, dann langsamer vor sich und ist von einer kleinen sekundären Erweiterung gefolgt.

Anhang. Der galvanische Lichtreflex. Die Pupille verengert sich nicht nur, wenn wir die Retina durch optische Reize erregen, sondern auch dann, wenn wir sie elektrisch reizen. Bumke ${ }^{1}$ ) stellte exakte Untersuchungen über die Einwirkung galvanischer Ströme auf die pupillenbewegenden Elemente an. Lassen wir schwache elektrische Ströme aufs Auge wirken, so bekommen wir eine Lichtempfindung, bei Verwendung stärkerer Ströme tritt eine Bewegung der Iris in pupillenverengerndem Sinne hinzu. Daß bei schwachen Strömen eine Lichtempfindung stattfindet, war schon seit Helmholtz²) bekannt. Bumke stellte

1) B u m ke, Der galvanische Lichtreflex. Centralbl. f. Nervenheilk, 1903, 487.

2) Helmholtz, H. v., Handbuch der physiologischen Optik. 1896. 
die pupillomotorische Wirkung stärkerer Ströme fest, die mit Hilfe von Vergrößerungsapparaten z. B. der Westienschen Lupe gut beobachtet werden kann.

Die Darstellung der Methode gebe ich mit Bumkes Worten wieder. Er schreibt: ,Am besten wird nun eine (ca. $80 \mathrm{qcm}$ ) große Elektrode auf dem Sternum befestigt oder der Versuchsperson in die Hand gegeben, die kleinere Reizelektrode dagegen (ich benutze eine mit $10 \mathrm{~cm}$ Durchmesser) dicht neben dem Auge auf die Schläfe gesetzt oder, wenn nur die konsensuelle Reaktion geprüft werden soll, direkt über dem geschlossenen, durch eine Watteschicht vor jedem Druck geschützten Auge mittels eines um den Kopf gelegten Gummibandes befestigt. Dieser Unterschied in der Versuchsanordnung macht es ohne weiteres begreiflich, daß die absolut kleinsten wirksamen Reize bei der konsensuellen, nicht bei der direkten Reaktion festzustellen sind."

Bei Verwendung dieser Methode traten zunächst bei Anodenschluß sichtbare Veränderungen der Pupillengröße auf. Der Wirkung der Anodenschließung am nä.chsten stand die der Kathodenöffnung, während Anodenöffnung und Kathodenschluß sich erst bei Anwendung viel stärkerer Ströme wirksam erwiesen.

Bumke stellte mit seiner Methode umfangreiche Untersuchungen bei Gesunden und Kranken an und fand, daß bei Durchleitung des Stromes durch die Schläfe Stromstärken von 2,4 Milliampere erforderlich waren, um eine Verengerung der gleichseitigen und der kontralateralen Pupille zu erzielen, während bei Befestigung der Elektrode direkt über dem Auge 0,3 Milliampere Stromstärke zur Kontraktion des Sphincter genügten.

Die Hoffnung Bumkes, mit Hilfe des galvanischen Lichtreflexes die Frage, ob ein Unterschied zwischen der Kontraktionsbewegung der Iris am direkt gereizten Auge und der am kontralateralen besteht, durch Vergleich der Reizschwellen zu lösen, erfüllte sich leider nicht. Er sagt: „Es gibt Individuen, bei denen der Reflex an dem direkt gereizten Auge früher eintritt, als an dem anderen. bei einer etwas größeren Anzahl ist'ein solcher Unterschied, auch mit dieser Methode, nicht festzustellen."

Ich selbst habe den galvanischen Reiz bei meinen Untersuchungen nicht angewendet; doch glaubte ich hier näher auf die Besprechung des galvanischen Lichtreflexes eingehen zu sollen, indem die bei meinen Untersuchungen festgestellte Tatsache auch bei den Untersuchungen Bumkes zutage trat, daß nämlich ungleiche Belichtung auch beim Gesunden Pupillendifferenz hervorrufen kann, meist jedoch nicht erzeugt.

\section{Die Konvergenzreaktion.}

Nächst dem Lichtreflex der Pupille ist deren Veränderung bei der Konvergenzbewegung bzw. der Akkommodation des Auges von praktischer Wichtigkeit. Wir haben oben gesehen, daß die Verengerung der Pupille bei der Naheeinstellung des Auges als eine Mitbewegung der Iris aufzufassen ist, indem der Sphincter pupillae zugleich mit den Innenwendern des Auges und dem Ciliarmuskel durch einen gemeinsamen, zentralen Impuls kontrahiert wird.

$\mathrm{Da}$, wie ich schon bemerkte, der Konvergenzapparat erst später in meinen Apparat eingebaut wurde, nahm ich nur bei einer geringeren Anzahl (18) meiner gesunden Versuchspersonen Messungen der Verengerung der Pupillen bei der Konvergenzbewegung vor. Ich ließ die 
Versuchspersonen zunächst unter Beleuchtung mit dem minimalsten, eine Messung der Pupille noch erlaubenden Licht $1 / 4$ Stunde lang geradeaus in den Apparat schauen, worauf ich die dann bestehende Pupillenweite beiderseits feststellte. Jetzt wurde der Konvergenzapparat in Bewegung gesetzt und die Versuchsperson aufgefordert, auf den kleinen, ganz gering leuchtenden Kreis (siehe Methodik) zu konvergieren. Dieses Fixationsobjekt stand zunächst in einer Entfernung von $18 \mathrm{~cm}$ vom Auge der Versuchsperson, so $\mathrm{da} ß$ bei einer Pupillendistanz von $6 \mathrm{~cm}$ jedes Auge eine Drehung von ca. $10^{\circ}$ machen mußte. Hierauf wurden wiederum beide Pupillen gemessen, dann der Konvergenzapparat weiterbewegt, bis der durch ihn erzeugte, mattschimmernde Lichtkreis in einer Entfernung von $7 \mathrm{~cm}$ vor den Augen der Versuchsperson angelangt war, und nun wurden beide Pupillen nochmals gemessen.

An diese Messung, die mehrmals wiederholt wurde, schloß ich die Untersuchung der Lichtreaktion, indem ich die Pupillenweite zunächst bei dem minimalsten, bisher verwandten Licht feststellte und dann bei starker Belichtung des einen oder anderen Auges oder beider Augen zugleich.

Dabei stellte sich folgendes heraus. Die Pupillen verengerten sich bei der Konvergenzbewegung der Bulbi beiderseits gleichmäßig, und es zeigte sich bei der Innenwendung um $10^{\circ}$ aus der Einstellung auf Unendlich ein wesentlich größerer Ausschlag als bei der darauffolgenden weiteren Drehung zur Beobachtung des in $7 \mathrm{~cm}$ Entfernung stehenden Fixationspunktes, die eine Innenwendung jedes Bulbus um weitere $15^{\circ}$ nötig machte.

Dieses Resultat scheint den von anderen Autoren (E. H. Weber ${ }^{1}$, Adam ück und Woinow ${ }^{2}$ ), Vervoort $\left.{ }^{3}\right)$ ) gemachten Angaben, daß die Sphincterkontraktion bei Fixierung eines dem Auge genäherten Objektes proportional dem Grade der Konvergenz einhergehe, zu widersprechen, doch dürfen wir einen Umstand nicht außer acht lassen. Während beim geradeaus gerichteten Blick die zentralen Teile der Retinafläche von dem Licht meines Apparates getroffen werden, ist deren Beleuchtung bei der Innenwendung der Bulbi eine geringere, so daß die infolge des vęrminderten Lichtreizes entstehende Pupillenerweiterung in gewissem Sinne der Verengerung bei der Konvergenz entgegenwirkt, bzw. deren Erfolg allmählich scheinbar geringer werden läßt. Allerdings $m u ß$ andererseits betont werden, da $\beta$ die Lichtwirkung bei unserem

1) Weber, E. H., De motu iridis. Lipsiae 1852.

2) Adamück und Woinow, Über die Pupillenveränderung bei der Akkommodation. v. Graefes Arch. 1\%, 158. 1871.

3) Vervoort, Die Reaktion der Pupille bei der Akkommodation und Konvergenz usw. v. Graefes Arch. 49, 388. 1900. 
Versuch keine besonders große sein kann, da bei minimalster Beleuchtung untersucht wurde.

Die absoluten Werte waren bei den einzelnen Versuchspersonen entsprechend der Ausgangsweite der Pupillen (beim geradeaus gerichteten Blick) verschieden, indem ein geringerer Ausschlag erfolgte, wenn die Anfangsgröße der Pupillen kleiner war. Die geringe Anzahl meiner Versuchspersonen gestattet nicht, Durchschnittswerte aufzustellen. Ich gebe daher nur die bei zwei Versuchspersonen gewonnenen Resultate wieder.

Einstellung auf $\infty \quad 0^{\circ}$ Drehung I Vp. 6,5 II Vp. 6,0

$\begin{array}{llllll}" & \quad 18 \mathrm{~cm} 10^{\circ} & & & 4,5 & 3,8 \\ " & \quad 7 \quad, 25^{\circ} & , & 3,7 & 3,2\end{array}$

Weite der Pupillen:

bei minimalster Belichtung (ca. 6 MK.) Vp. I: 6,5 II : 6,0 ", beiderseitiger, starker " $\quad$ (ca. $270 \quad$ ") $\quad 3,6 \quad 3,0$

In ähnlicher Weise verhielten sich auch die übrigen gesunden Versuchspersonen. Interessant und wichtig scheint mir, abgesehen von dem allmählich geringer werdenden Einfluß gleichgroßer Konvergenzbewegungen, wenn die Augen sich schon vorher in starker Konvergenzstellung befinden, die Tatsache, daß die Größe der Pupillen bei maximalster Konvergenzstellung der bei Belichtung beider Augen mit starkem Licht entspricht, daß, mit anderen Worten, die Konvergenzbewegung beim Gesunden die gleichgroße oder annähernd gleichgroße Irisbewegung zur Folge hat wie die beiderseitige starke Belichtung. Diese Tatsache dürfte für die Bewertung von Pupillenstörungen, bei denen Konvergenzreaktion und Lichtreflex nicht gleichmäßig betroffen zu werden pflegen, von weitgehendster Bedeutung sein; ich komme darauf bei der Besprechung der an Kranken gemachten Messungen noch eingehend zurück.

Der Versuch, die Geschwindigkeit, mit der die Konvergenzreaktion der Pupillen vor sich geht, zu messen, ersehien mir müssig, da ja zur Konvergenzbewegung der Augen eine vollständig von der Versuchsperson abhängige Zeit verbraucht wird. Die Konvergenz ist der Willkür unterworfen, und ein durch Willkürbewegungen veranlaßter unwillkürlicher Vorgang kann keiner exakten Zeitmessung zugänglich sein. Die Annahme mancher Autoren, daß die Verengerung bei der Konvergenz langsamer vor sich gehe als bei der Lichtreaktion, läßt sich daher weder bezweifeln noch experimentell beweisen.

Die Lidschlußreaktion (Orbicularisphänomen).

Seit A. v. Graefe war es bekannt, daß eine mydriatische Pupille durch energischen Augenschluß verengert werden kann. Man kann diese Reaktion natürlich nicht direkt beobachten, sondern nur aus der beim 
Öffnen des Lides eintretenden Erweiterung der Pupille schließen. In neuerer Zeit wurde dieses Phänomen genauer untersucht, so von Westphal $\left.{ }^{1}\right)^{2}$ ), Piltz ${ }^{3}$, Bumke ${ }^{4}$ ) u. a.

Diese Untersuchungen haben zunächst ergeben, daß das Orbicularisphänomen auch beim ganz gesunden Menschen zur Darstellung gebracht werden kann, wenn man die Versuche so anstellt, daß die den Erfolg des Zusammenkneifens der Augenlider darstellende Pupillenverengerung nicht durch den beim Öffnen der Augen entstehenden Lichtreflex überdeckt wird. Bumke schildert eine derartige Versuchsanordnung wie folgt: „Wird nämlich, um ein Beispiel zu wählen, während des Lidschlusses die Helligkeit von $60-70 \mathrm{MK}$. auf $7-10$ vermindert, so wird eine nach dem Öfnen des Auges eintretende Erweiterung an Stelle der gewöhnlichen Verengerung auch bei Personen beobachtet, bei denen der Versuch ohne diese Maßnahme, bei der man gewissermaßen der Adaptation der Retina zuvorkommt, negativ ausgefallen wäre."

Ich stellte gleichartige Experimente an und fand die Angaben der Autoren bestätigt, daß das Orbicularisphänomen beim gesunden Menschen unter Benutzung der genannten Vorsichtsmaßregel beobachtet werden kann, mithin als eine physiologische Erscheinung aufzufassen ist.

Von nicht zu unterschätzender Bedeutung ist hierbei, daß die Lidschlußreaktion auch dann eintritt, wenn der Augenschluß zwar gewollt, aber seine Ausführung mechanisch, durch Spreizen der Lider mit der Hand, gehindert wird, im Zusammenhalt mit der Tatsache, daß das Orbicularisphänomen am deutlichsten bei lichtstarren Pupillen zu beobachten ist. Prüft man daher bei einem widerstrebenden Kranken die Reaktion der Pupille auf Licht, indem man seine Augenlider mit den Fingern gewaltsam spreizt, so läuft man Gefahr, eine Lichtreaktion anzunehmen, während die eintretende Kontraktionsbewegung der Iris der Ausdruck der Lidschlußreaktion war.

\section{Die Pupille erweiternde Irisbewegungen.}

\section{Erweiterung der Pupille bei Sympathicuserregung.}

Reizt man den Halssympathicus mit stärkeren elektrischen Strömen oder auch mechanisch oder chemisch, so tritt bei Tieren eine maximale Mydriasis auf, zugleich erlischt die Lichtreaktion ${ }^{5}$ ). Werden weniger

1) Westphal, A., Über ein bisher nicht beschriebenes Pupillenphänomen. Neurol. Centralbl. 1899, 161.

2) Derselbe, U̇ber das Westphal-Piltzsche Pupillenphänomen. Berl. klin. Wochenschr. 1901, 1226.

3) Piltz, J.. Über neue Pupillenphänomene. Neurol. Centralbl. 1899.

4) Bumke, Das Orbicularisphänomen. Zentralbl. f. Nervenheilk. 1904, 89.

5) Bach, L., Pupillenlehre. Berlin 1908, 70. 
starke Reize in Anwendung gebracht, so zeigt sich eine Verstärkung der auf psychische, sensible und sensorische Reize eintretenden Pupillenbewegungen, während die Lichtreaktion herabgesetzt wird.

Die Latenzzeit der bei Reizung des Halssympathicus eintretenden Pupillenerweiterung betrug nach an der Katze angestellten Messungen 0,292 Sek. ${ }^{1}$ ).

Die Frage, ob diese Wirkung der Sympathicusreizung ihre Ursache in einer Innervation des von diesem Nerven versorgten Dilatator iridis hat oder vielmehr als eine durch Vermittelung des Sympathicus veranlaßte Hemmung des Sphincterzentrums aufzufassen ist, darf zurzeit noch nicht als sicher geklärt betrachtet werden. Nach Beobachtungen, auf die ich bei der Besprechung der durch Vermittelung dieses Nerven stattfindenden Erweiterungsreaktionen der Pupille näher eingehen werde, scheint es mir nicht ausgeschlossen, daß wenigstens eine die Erweiterung unterstützende aktive Mitwirkung des Dilatator bei der Reaktion der Pupille auf sensible Reize anzunehmen ist.

\section{Erweiterung der Pupille, hauptsächlich durch Hemmung des Sphincter- tonus veranlaßt}

Soviel ich der Literatur entnehmen konnte, war Gratiolet²) der erste, welcher beobachtete, daß die Pupillen sich bei starken Gemütsbewegungen erweitern. Darwi ${ }^{3}$ ) suchte vergeblich nach bestätigenden Belegen der Angaben dieses Forschers, indem er nur bei einer geisteskranken Frau, welche an großer Furcht litt, feststellen konnte, daß ihre Pupillen sehr weit waren. Heute wissen wir, daß bei jeder Gemütsbewegung eine Erweiterung der Pupillen eintritt, die allerdings nur unter Berücksichtigung von Vorsichtsmaßregeln und mit Zuhilfenahme von Vergrößerungsapparaten beobachtet werden kann. Interessant ist die Erklärung, welche Darwin für das von Gratiolet beschriebene Phänomen gibt, indem er sagt: „Angenommen, daß Gratiolets Angabe korrekt ist, scheint es wahrscheinlicher zu sein, daß das Gehirn direkt durch die gewaltige Erregung der Furcht affiziert wird und auf die Pupillen zurückwirkt."

Die erste Beobachtung über eine durch sensible Reize ausgelöste Irisbewegung machte C. Westphal $1^{4}$ ) bei einem chloroformierten Patienten.

1) Braunstein, Zur Lehre von der Innervation der Pupillenbewegung. Wiesbaden 1894.

2) Gratiolet, De la physiognomie et des mouvements d'expression S. 51, 256 und 346. Paris 1855. Zit. nach Bumke, Pupillenstörungen.

3) Darwin, Ch., Der Ausdruck der Gemütsbewegungen bei den Menschen und Tieren. Übersetzt von J. V. Carus. Stuttgart 1901, 266.

4) Westphal, C., Aus Virchows Archiv 1861. 27. Bd. in C. Westphals ges. Abh. II, 98. Berlin 1892. Úber ein Pupillenphänomen in der Chloroformnarkose. 
Inzwischen mehrten sich unsere Kenntnisse der eine Pupillenerweiterung auslösenden Vorgänge bedeutend, und wir wissen heute, daß jedes psychische Geschehen eine mehr oder weniger starke pupillenerweiternde Irisbewegung zur Folge hat. Daher kommt es, daß die Regenbogenhaut des Menschen, außer im tiefsten Schlaf, fortdauernd kleinste Bewegungen macht, die wir nach Laque ur $\left.{ }^{1}\right)^{2}$ ) als Pupillenunruhe benennen. Schiff ${ }^{3}$ ) bezeichnet schon die Pupille als das feinste Ästhesiometer, und wir haben in neuester Zeit gelernt, in der Pupillenunruhe und den Erweiterungsreaktionen der Iris für die seelischen Vorgänge bedeutsame Ausdrucksbewegungen zu erkennen. Seit den verdienstvollen Arbeiten Sommers ${ }^{4}$ ) wissen wir den Wert der Ausdrucksbewegungen für die Erkennung und Analyse psychischer Vorgänge zu schätzen, und es kann uns daher nicht wundern, wenn das Studium der psychischen Reaktionen der Pupille in neuerer Zeit eifrig betrieben wurde. Es würde zu weit führen, hier die Ergebnisse dieser Studien im einzelnen zu betrachten, ich verweise daher auf die besonders bei $\mathrm{B} \mathrm{u} \mathrm{m} \mathrm{ke}$ (Pupillenstörungen) und $\mathrm{Bach}$ (Pupillenlehre) vermerkten Literaturangaben. Ein übereinstimmendes Resultat dieser Arbeiten, von denen die bedeutendsten wohl die von Laqueur, Schadow ${ }^{5}$ ), Rieger und Forster ${ }^{6}$, v. Forster ${ }^{7}$ ), Roubinowitsch $\left.{ }^{8}\right)^{9}$ ), Bumke und Hübner $\left.{ }^{10}\right)$ sind, war die Feststellung der Tatsache, daß die Pupillenunruhe beim gesunden Menschen nie fehlt und die Pupille, vorausgesetzt, daß die Retina an das bei der Beobachtung zur Verwendung kommende Licht völlig adaptiert war, auf den Versuchspersonen zugeführte Reize, seien sie nun sensorischer, sensibler oder rein psychischer Art, immer

1) Laq ue ur, Ủber Beobachtungen mittels der Zehender-Westienschen binokularen Corneallupe. Klin. Monatsbl. f. Augenheilk. 1887, 463.

$\left.{ }^{2}\right)$ Derselbe, Beiträge zur Lehre von der Pupillenbewegung. Arch. f. Augenheilk. 38, 135. 1899.

3) Schiff, M. et Foa, P., La pupilla come estesiometro. Imparziale 1874, Nr. 7 (Nagels Jahrbericht).

4) Sommer, R., Lehrbuch der psycho-pathologischen Untersuchungsmethoden. Berlin 1899.

5) Schadow, Beiträge zur Physiologie der Irisbewegungen. Arch. f. Ophthal. mol. 28, 183. 1882 .

6) Rieger und Forster, Auge und Rückenmark. Arch. f. Ophthalmol. 2y, 109. 1881 .

7) Forster, v., Ứber feinere Störungen der Pupillenbewegungen. Deutsche med. Wochenschr. 1893.

8) Roubinovitsch, Du reflexe ideo - moteur de la pupille. Centralbl. f Nervenheilk. u. Psychiatrie 1900.

9) Derselbe, Des variations du diamètre pupillaire en rapport avec l'effet intellectuel. Congr. de Psychologie. Paris 1900.

10) Hübner, A. H., Untersuchungen über die Erweiterung der Pupillen auf psychische und sensible Reize nebst einigen allgemeinen Bemerkungen über $\mathrm{Pu}$ pillenreaktionen. Arch. f. Psychiatrie 41. 
mit einer Erweiterung antwortet. Nur bei Neugeborenen wurde nach den Beobachtungen Pfisters ${ }^{1}$ ) die Pupillenerweiterung auf sensible Reize in den ersten 4 Wochen vermißt, während sie vom 6 . Lebensmonat an regelmäßig, nach Bartels ${ }^{2}$ ) sogar vom 3 . Monat an zu beobachten war.

Ich untersuchte bei meinen gesunden Versuchspersonen die auf sensorische, sensible und psychische Einwirkungen erfolgenden Irisbewegungen, indem ich mittels meines Rasselwerkes oder durch Händeklatschen Gehörsreize ausübte, dann durch Nadelstiche, Kneifen ins Ohrläppchen oder mittels des faradischen Apparates sensible Reize applizierte und endlich die Aufmerksamkeit und intellektuelle Tätigkeit der Versuchsperson durch Aufforderung zur Lösung von Rechenexempeln oder Ähnliches anregte. Dabei fand ich, daß es nicht günstig ist, wenn das zur Beleuchtung des Auges bei diesen Beobachtungen verwendete Licht gar zu gering ist, eine Lichtstärke von ca. 25 Meterkerzen scheint nach meinen Erfahrungen die besten Versuchsbedingungen abzugeben. In Ubereinstimmung mit den bisher von den oben genannten Autoren u. a. erhobenen Befunden konnte ich feststellen, daß auch bei meinen Versuchspersonen weder die Pupillenunruhe noch die Erweiterung der Pupille nach den genannten Reizen ausblieb.

Die Stärke der Irisbewegungen war dabei allerdings sehr verschieden, bei manchen überschritten die Oscillationen des Irissaumes kaum die Breite von $1 \mathrm{~mm}$, bei anderen wieder erweiterte sich die Pupille um $2-21 / 2 \mathrm{~mm}$; bestätigen kann ich, daß die Ausschläge bei Frauen meist größer sind als bei Männern.

Die Reaktion der Iris auf die sensorischen Reize tat sich im allgemeinen in einer nach einer längeren Latenzzeit deutlich werdenden, ziemlich raschen Erweiterung der Pupille kund, die allmählich, in ganz unregelmäßigen Zeiten, wieder ihre frühere Weite annahm.

Lenkte die Versuchsperson ihre Aufmerksamkeit auf die gestellte Aufgabe, so wurde gewissermaßen die dauernd zur Beobachtung kommende Pupillenunruhe größer, die Ausschläge schienen sich zu mehren und das Wogen des Pupillensaumes wurde stärker.

Der Erfolg des sensiblen Reizes stellte sich als eine rasch eintretende, nur langsam größer werdende, dabei aber sehr starke Erweiterung der Pupille dar, die nach Aufhören des Reizes ganz allmählich wieder, gefolgt von einigen gröberen Schwankungen des Irissaumes, verschwand und der gewöhnlichen Pupillenunruhe Platz machte. Eine genaue Messung der Ausschlaggröße der Pupille bei den genannten Reaktionen

1) Pfister, H., Utber das Verhalten der Pupille und einiger Reflexe am Auge im Säuglings- und frühen Kindesalter. Arch. f. Kinderheilk. 26. 1898.

2) Bartels, M., Pupillenverhältnisse bei Neugeborenen. Zeitschr. f. Augenheilk. 12, 638 . 
ließ sich nicht gut durchführen, da das Auge dabei nicht immer ganz stillgehalten wurde und zudem die Intensität der Bewegungen wechselte, doch halte ich einen Umstand für wichtig und leicht zu bemerken, daß nämlich die Erweiterung auf sensible Reize die anderen Bewegungen durchgehends übertrifft.

Diese letztere Tatsache dürfte nicht ganz unwichtig bei der Frage nach dem Wesen des pupillenerweiternden Vorganges sein. Hier stehen sich zwei Anschauungen gegenüber; nach der einen wird die Pupillenerweiterung auf sensible Reize durch Innervation des Dilatator veranlaßt, nach der anderen durch Hemmung des Sphinctertonus. Bechterew vertritt die letztgenannte Auffassung, da er beobachtete, daß bei einem Kranken, bei dem auf der einen Seite die Opticusleitung unterbrochen war, die Erweiterungsreaktion ausblieb, wenn er das andere Auge bedeckte, während sie an beiden Pupillen gut zu sehen war, wenn in das reflexempfindliche Auge Licht hineinfiel. Diese Befunde konnte $\mathrm{Bach}$ bestätigen, ich selbst konnte ebenfalls derartige Beobachtungen machen. Um die Ursache der Erweiterung der Pupillen bei sensiblen Reizen aufzudecken, stellte Braunstein ${ }^{1}$ ) experimentelle Untersuchungen an Katzen an, bei denen er die Pupillenbewegungen mittels der photographischen Methode registrierte. Er durchschnitt einmal den Sphincter, ein andermal den Ischiadicus, reizte die zentralen Enden dieser Nerven und fand dabei folgendes. Nach Reizung des zentralen Stumpfes des Sympathicus trat nach kurzer Latenz eine schnell erfolgende Pupillenerweiterung ein, die bald wieder zurückging. Reizte er dagegen das zentrale Ende des Ischiadicus, so fand er, $\mathrm{da}$ nach einer längeren Latenzzeit eine kleinere Erweiterung der $\mathrm{Pu}$ pille erfolgte, die bald nachließ, um einer nun eintretenden stärkeren, langsam anwachsenden und langsam abklingenden Erweiterung Platz zu machen. Braunstein schließt aus dem verschiedenen Ausfall der Experimente, daß die Erweiterung auf sensible Reize nicht durch Innervation des Dilatators zustande komme, sondern durch Hemmung des Sphinctertonus. Eine Stiitze seiner Ansicht fand er noch darin, daß nach Durchschneidung des Oculomotorius jede Pupillenerweiterung auf sensible Reize ausblieb.

Andere Autoren machten die Beobachtung, daß nach Durchschneidung des Halssympathicus die auf sensible Reize eintretende Pupillenerweiterung einen geringeren Ausschlag zeigte und langsamer ablief als zuvor.

Vulpian²) fand zuerst, daß die Erweiterung auf sensible Reize

1) Braunstein, E., Zur Lehre von der Innervation der Pupillenbewegung. Wiesbaden 1894.

2) Vulpian, A., Maladie du système nerveux. Paris 1879. Zit. nach B u mke, Pupillenstörungen. 
auch nach Sympathicusdurchschneidung noch möglich ist. Bu mke ${ }^{1}$ ) hatte Gelegenheit, bei Leuten mit totaler Sympathicuslähmung oder exstirpiertem Sympathicus die sensiblen und psychisch bedingten Reaktionen der Pupillen zu prüfen und fand dieselben stets erhalten, nur mit dem Unterschied, daß der Ausschlag bei sensibler Reizung geringer war als in der Norm, während die Schwankungen nach psychischen Reizen auch quantitativ nicht verändert waren.

Braunstein lehnt jede aktive Beteiligung des Sympathicus bei dem Zustandekommen der Pupillenerweiterung auf sensiblem Wege ab und schreibt ferner: „Wenn sich der Charakter der reflektorischen Pupillenerweiterung nach Durchschneidung des Nervus sympathicus ändert, indem die Erweiterung einen besonderen Typus mit langdauernder Latenzperiode und langsamem Ansteigen der Erweiterung zeigt, so beruht das darauf, daß durch die Unterbrechung der Rückenmarksdilatatoren, welche stets im Zustande der tonischen Erregung sich befinden, ein gewisser Bruchteil der die Erweiterung unterstützenden Kraft verloren geht. Infolgedessen gewinnen die pupillenverengernden Apparate die Oberhand über die dilatierenden Apparate, denn die der Erweiterung antagonistische Kraft ist relativ höher geworden. Das gestörte Gleichgewicht ist die Ursache der langsamer eintretenden Pupillenerweiterung. "

Der Annahme Braunsteins, daß die sensible Pupillenerweiterung durch alleinige Hemmung der Sphincterinnervation zustande komme, treten Tschirkowsky ${ }^{2}$ ), Anderson ${ }^{3}$ ) und Hirschl ${ }^{4}$ ) entgegen, während die Untersuchungen Bochefontaines ${ }^{5}$ ), Mislawskis ${ }^{6}$ ) und Parsons ${ }^{7}$ ) die Erklärung Braunsteins stützten, indem sie fanden, da $\beta$ von Rindenbezirken aus durch Reizung Pupillenerweiterung hervorgerufen werden kann, die sich von der durch Sympathicusreizung veranlaßten in charakteristischer Weise unterscheidet und nach Oculomotoriusdurchschneidung nicht mehr auslösbar ist. Allerdings wird sie geringer, wenn man den Sympathicus vorher durchschneidet.

1) Bumke, Die Pupillenstörungen bei Geistes- und Nervenkrankheiten. Jena 1904.

2) Tschirkowsky, Die Bewegungen der Pupille nach Opticusdurchschneidung. Arch. f. Augenheilk. 55, 119. 1906.

3) Anderson, Reflex pupill-dilatation by way of the cervical sympathetic nerve. Journ. of Physiol. 30, 15. 1904.

4) Hirschl, Ủber die sympathische Pupillenreaktion und die paradoxe Lichtreaktion der Pupillen bei progressiver Paralyse. Wien. klin. Wochenschr. 1899, 592.

5) Bochefontaine, Etude expérim. de l'influence exercée par la faradisation de l'ecorce grise du cerveau sur quelques fonctions de la vie organique. Arch. de physiol. 1876, 140.

6) Mislawski, Utber den Einfluß der Hirnrinde auf die Pupillendilatatoren. Ref. Centralbl. f. Nervenheilk. 1888, 30.

7) Parsons, H., On Dilatation of the pupil from Stimulation of the cortex cerebri. Journ. of Physiol. 26, 366. 1901. 
Auf Grund aller dieser Untersuchungen und Frwägungen können wir zurzeit nicht behaupten, daß die Frage nach dem Wesen der $\mathrm{Pu}$ pillenerweiterung auf sensible und psychische Reize gelöst sei. Ich möchte nach den in der Literatur niedergelegten Befunden und meinen eigenen Beobachtungen der Vermutung Raum geben, daß 3 wir bei diesen Bewegungen unterscheiden müssen zwischen den auf sensible Reize erfolgenden und den anderen. Fis liegt zunächst bei den auf sensorische und psychische Reize eintretenden Pupillenbewegungen keine Veranlassung vor, der Ansicht Bechterews und Braunsteins entgegenzutreten, indem keine zwingenden Beweisgründe gegen die Annahme, daß es sich hier um eine primäre, rein reflektorische Hemmung des Sphinctertonus handelt. Daß mit dieser Hemmung eine Frregung des Dilatatorzentrums einhergehen wird, müssen wir nach unseren durch Sherringto $\mathbf{n}^{1}$ ) erheblich geförderten Kenntnissen der Innervationsvorgänge in antagonistisch wirkenden Muskelgruppen wohl annehmen.

Anders liegen die Verhältnisse bei der sensiblen Reizung. Bumke sah den Ausschlag der Iris auf sensible Reize nach Sympathicusdurchschneidung kleiner werden, ich konnte feststellen, daß die Pupillenverengerung auf Schmerzreize unter normalen Bedingungen stärker ausfiel als bei anderen Reizen. Auf Grund dieser Tatsachen möchte ich doch annehmen, daß hier eine aktive Mitwirkung des Sympathicus nicht auszuschließen ist. Diese Annahme stütze ich ferner noch, indem ich meinen späteren Ausführungen vorgreife, auf die Tatsache, daß bei einzelnen Kranken, bei denen die Lichtreaktion aufgehoben war, die Erweiterung auf psychische und sensorische Reize fehlte und die gewöhnliche Pupillenunruhe nicht mehr zu beobachten war, auf starke Schmerzreize noch eine Erweiterung der Pupillen eintrat; ferner auf die Beobachtung, daß bei an Dementia praecox leidenden Kranken die Reaktion auf sensible Reize häufiger erhalten war, als die auf rein psychische und sensorische.

Für diese Auffassung spricht auch die von Bumke betonte Tatsache, daß die auf sensible Einwirkungen erfolgende Irisbewegung weniger ausgiebig erfolgt, wenn der Sympathicus entfernt ist, während die anderen auf psychische und sensorische Reize erfolgenden Pupillenveränderungen dadurch unbeeinflußt bleiben. Hier trifft die Erklärung Braunsteins, der für die Verminderung der Ausschläge bei der sensiblen Reaktion nach Sympathicusausschaltung den Wegfall des von diesem Nerven unterhaltenen Tonus des Dilatators verantwortlich macht, nicht mehr zu, da die anderen Pupillenerweiterungsreaktionen dann doch ebenfalls beeinträchtigt werden müßten.

Ich versuchte die Latenzzeit der Erweiterungsreaktionen mittels

1) Sherrington, Ch. S., The integrative action of the nervous system. London 1908. 
meines Reizapparates festzustellen. Dies gelang mir jedoch nur in wenigen Fällen. Die Bewegungen waren offenbar zu Beginn der Reaktion meist sehr wenig ausgiebig, man hatte den Eindruck, als schliche sich der Reiz erst ein und seine Summierungswirkung werde erst deutlich sichtbar. Die gefundenen Zeiten schwankten beim Gesunden schon sehr stark, ich konnte als Latenzzeit bei der sensiblen Reizung (Farad.Strom) als niedrigsten Wert 0,44 Sek. feststellen, bei Schreckreiz (Rasselwerk) schien die Bewegung nach den Messungen, die Werte bis auf 0,36 Sek. herunter ergaben, rascher einzutreten. Leider muß ich jedoch gestehen, daß ich diesen Feststellungen keinen großen Wert beilegen kann, da die Schwankungen zu groß waren. Hier kann meines Erachtens ebenfalls nur die Photographie helfen. Ich bemühe mich zurzeit noch, meinem Kinematographen einen völlig geräuschlosen Gang zu erteilen, da er bisher noch zu starke Geräusche erzeugte, die eine exakte Registrierung der psychisch ausgelösten Pupillenphänomene verhindern, bzw. zu starke Additionsreize notwendig machen.

Nach dem vorhin Ausgeführten können wir folgende Sätze aufstellen:

I. Die Pupillenunruhe und die Erweiterungsreaktion der Pupille bei dem Organismus zugeleiteten sensiblen, sensorischen und psychischen Reizen fehlen beim Gesunden nie.

II. Die Erweiterungsbewegung auf sensible Reize ist größer als die auf sensorische und psychische Einwirkungen.

III. Es ist wahrscheinlich, daß die Pupillenreaktionen a uf sensorische und psychische Einflüsse ihren Ursprung einer von der Hirnrinde ausgehenden Hemmung des Sphinctertonus verdanken, während bei der sensiblen Erweiterung eine aktive Mitwirkung des Dilatator infolge einer Sympathicusinnervation nicht auszuschließen ist.

\section{Zweck der reflektorischen Pupillenerweiterung.}

Nachdem wir in diesen Erweiterungsreaktionen der Pupille offenbar Reflexerscheinungen erkennen, müssen wir uns auch die Frage nach dem Zweck dieser Bewegungen vorlegen.

Nach den Untersuchungen von Exner ${ }^{1}$ ) und A u bert $\mathbf{t}^{2}$ ) wissen wir, daß die Wahrnehmung von Bewegungen an der Netzhautperipherie

1) Ex ner, S., Über das Sehen von Bewegungen und die Theorie des zusammen. gesetzten Auges. Sitzungsbericht der Wiener Akademie, mathem.-naturw. Kl. I2, 156. 1875 .

2) A ubert, H., Die Bewegungsempfindung. Arch. f. d. ges. Physiol. 39, 347. $1886 ; 40,459$. 1887. 
viel feiner ist als das Distinktionsvermögen daselbst, so daß die peripher gelegenen Netzhautteile hauptsächlich die Aufgabe haben, Bewegungen wahrzunehmen, auf die dann zur scharfen Erkennung des bewegten Gegenstandes der Blick gerichtet wird. Diese Tatsache dürfte uns als Fingerzeig gelten, wenn wir nach dem Zweck der Erweiterungsreflexe suchen. Wie der Mensch beim Erstaunen und beim Erschrecken unwillkürlich die Lidspalte weit öffnet, um den Blick möglichst freizugeben zur Erkennung der drohenden Gefahr, so öfnen sich auch seine Pupillen, wenn unvorhergesehene Reize ihn stören. Die reflektorisch erfolgende Erweiterung des Sehlochs gestattet ihm, im weiten Umkreis Bewegungen zu sehen, indem jetzt auch Eindrücke zu den beim scharfen Sehen ausgeschalteten peripher gelegenen Netzhautpartien gelangen können. Die Pupillenerweiterung hilft dem Organismus bei der Suche nach dem ihn reizenden, ihn bedrohendem Unbekannten. Dabei kommt es ja zunächst nicht darauf an, daß das Reizobjekt scharf gesehen wird, sondern es genügt, wenn es möglichst rasch überhaupt nur entdeckt wird, und diese Aufgabe erfüllt die Tätigkeit der peripheren Netzhautpartien vollkommen. Damit dürfte eine genügende Erklärung des Zweckes der Pupillenerweiterung auf das Individuum bedrohende Reize hin gegeben sein.

Wie sind nun die Reaktionen bei Anspannung der Aufmerksamkeit zu erklären? Wir wissen, daß wir die Gegenstände undeutlicher erkennen, wenn unsere Pupille z. B. durch Atropineinfluß erweitert ist; wir wissen ferner, daß unsere Aufmerksamkeit dann am besten in einer bestimmten Richtung angespannt ist, wenn wir die Fähigkeit unserer Sinnesorgane bis auf die derjenigen, in deren Bereich die Qualitäten des Objekts unserer Aufmerksamkeit liegen, ausgeschaltet haben. Es ist demnach für die Anspannung unserer Aufmerksamkeit, wenn sie sich nur auf gedankliche Vorstellungen konzentrieren soll, von höchstem Wert, wenn die starke Einstellung unserer Sinnesorgane dabei nachläßt. In der Tat überhören wir ja laute Gehörreize, die wir für gewöhnlich sicher wahrnehmen, dann, wenn unsere Aufmerksamkeit auf ein anderes Sinnesgebiet konzentriert ist. Ebenso läßt die Schärfe unseres Sehens nach, wenn wir nicht genötigt sind, unsere Aufmerksamkeit auf Gesichtsbilder zu richten; wir kennen alle den scheinbar in unendliche Fernen gerichteten Blick des tiefnachdenklichen Menschen. Ich möchte daher die Erweiterung der Pupillen bei Anspannung der Aufmerksamkeit in dem Sinne als zweckmäßige Reflexbewegung-deuten, daß durch sie die Schärfe der Gesichtseindrücke vermindert wird, so daß die das Sehorgan treffenden Reize weniger imstande sind, unsere Aufmerksamkeit abzulenken.

Anhang. Der Hirnrindenreflex. Wenn ich den als Hirnrindenreflex von $\mathrm{Ha}$ a beschriebenen Vorgang, daB die Pupille sich erweitert, wenn die Versuchs- 
person ihre Aufmerksamkeit auf die Vorstellung eines dunkeln Gegenstandes richtet, daß sie sich dagegen verengt, wenn die Vorstellung eines hell leuchtenden Objekts gelingt, nur anhangsweise bespreche, so tue ich dies deshalb, weil es mir nicht sicher bewiesen scheint, daß ein derartiger Reflex, also ein normal physiologischer Vorgang, der sich von den gewöbnlichen Pupillenbewegungen bei Anspannung der Aufmerksamkeit wesentlich unterscheiden würde, existiert. Ich habe mir immer und immer wieder Mühe gegeben, eine derartige Erscheinung nachzuweisen und hatte immer nur den einseitigen Erfolg, daß die Pupillen bei Anspannung der Aufmerksamkeit sich erweiterten. Allerdings gibt es Individuen, bei denen die zunächst eintretende Pupillenerweiterung äußerst rasch verschwindet und einer nun folgenden Verengerung Platz macht. Ich sah diese Erscheinung bei Leuten, deren Retina offenbar für Lichteinfall sehr reizbar war, indem bei ihnen auch der kleinste, durch eine geringe Erweiterung der Iris stattfindende Lichtreiz am dunkel adaptierten Auge einen deutlichen Ausschlag im Sinne einer Verengerung der Pupille erzeugte, der leicht beim U̇bersehen der anfänglichen Erweiterung für eine Reaktion auf die Vorstellung eines hellen Gegenstandes gehalten werden konnte. Diesen Vorgang beobachtete ich nicht nur bei den Versuchen, das Haabsche Phänomen zu sehen, sondern auch bei der Prüfung der Reaktion auf psychische Reize. Es stellte sich mir seinerzeit ein Mann vor (den Namen habe ich leider nicht notiert), der an allen Universitäten herumreiste und sich produzierte, da er eine außergewöhnliche Fähigkeit in der Beherrschung der einzelnen Körpermuskeln eingeübt hatte und erklärte, es sei ihm nun auch gelungen, seine Pupillen willkürlich zu bewegen, zu erweitern und zu verengern, ohne Benutzung der Convergenzbewegung der Bulbi. Ich untersuchte ihn am Apparat und fand seine Angabe insoweit richtig, als er imstande war, auf Befehl die Pupillen zu erweitern. Offenbar hatte er gelernt, durch Anspannung der Aufmerksamkeit die Erschlaffung des Sphinctermuskels hervorzurufen, bzw. trat bei ihm, weil er sich Mühe gab, die Pupillen zu bewegen, die bekannte Reaktion ein. Eine Verengerung der Iris war er jedoch ebensowenig imstande, herbeizuführen, wie meine übrigen Versuchspersonen. Auch als ich ihn belehrte, daß es vielleicht dann möglich sei, wenn er versuche, sich einen hellen Gegenstand vorzustellen, gelang es ihm nicht, eine Verstärkung des Sphinctertonus herbeizuführen.

Nach meinen Untersuchungen, die mit den Erfahrungen Bumkes übereinstimmen, stehe ich dem Hirnrindenreflex im Sinne Ha abs daher skeptisch gegenüber, wobei ich besonders mit Rücksicht auf Beobachtungen Bachs nicht bestreiten will, $\mathrm{da} \beta$ vielleicht unter ganz besonderen Bedingungen als Rarität und Anomalie eine derartige Erscheinung beobachtet werden kann, jedenfalls ist sie nicht ohne weiteres unter die physiologischen, in den Bewegungen der Irismuskulatur sich kennzeichnenden Vorgänge einzureihen.

\section{Die Pupille des schlafenden Menschen.}

Bedecken wir unsere Augen mit den Lidern, ohne sie krampfhaft zu schließen, so erweitern sich die Pupillen, da der Lichtreiz fortfällt. Der Sphincter erschlafft, bzw. der Dilatator gewinnt das Ubergewicht trotz seiner geringen Zugkraft, was sich aus einer beim Öffnen der Augen eintretenden Kontraktionsbewegung der Iris schließen läßt. Die Erwartung, daß die Pupille des schlafenden Menschen ebenfalls infolge Lichtabschlusses weit sein würde, bestätigt sich bei daraufhin gerichteten Untersuchungen keineswegs. Öffnet man unter genügenden 
Vorsichtsmaßregeln - man vermeide besonders eine Berührung der Augenbrauen - einem Menschen, der im tiefen Schlaf liegt, die Augen durch Heben des Oberlides, so trifft man die Bulbi vielfach nach oben, innen gerollt an, ebenso häufig jedoch geradeaus stehend, wie beim Blick in die Ferne, und die Pupillen sind sehr eng. Nimmt man den Versuch unter starker Lampenbeleuchtung des Auges vor, so kann man beobachten, daß die schon stark verengte Pupille sich bei der intensiven Beleuchtung noch weiter verkleinert. Ich habe häufig derartige Versuche angestellt und konnte fast immer das Vorhandensein der Lichtreaktion der Pupille im Schlaf feststellen, wonach ich mich den Angaben anderer Autoren, die fanden, daß die Lichtreaktion höchstens im tiefsten Schlaf aufgehoben sei und deutlicher ausfalle, wenn der Schlaf flacher geworden, in bezug auf die letztere Beobachtung anschließe. Eine vollständige reflektorische Lichtstarre fand ich allerdings nie. Beobachtet man die Pupille weiter, so tritt plötzlich nach mehr oder weniger langer Zeit eine sehr starke Erweiterung der Pupille ein und die Versuchsperson macht zweckmäßige koordinierte Bewegungen, sie erwacht. Läßt man während dieser Vorgänge das starke Licht andauernd aufs Auge wirken, so verändert dies an der Erweiterung der Pupillen zunächst nichts, und man kann eine bald dem Erwachen folgende, starke Lichtreaktion leicht wahrnehmen. Uberhaupt ist es bei einiger Utbung nicht schwer, die geschilderten Tatsachen zu beobachten, da sich ihre Folge gar nicht sehr rasch abspielt.

Die Enge der Pupillen scheint mit Zunahme der Schlaftiefe zu wachsen. Unter besonders günstigen Bedingungen (sehr große Schlaftiefe) kann man sich leicht davon überzeugen, daß die Reaktion der Iris auf sensible und sensorische Reize beim Schlafenden erhalten ist; durch leichte Nadelstiche oder Geräusche kann man eine Erweiterung der Pupillen im Schlaf hervorrufen. Auch diese Reaktionen schienen mir um so stärker auszufallen, je geringer die Schlaftiefe wurde, d. h. beim oberflächlichen Schlaf genügten kleinere Reize, um große Ausschläge der Irisbewegungen zu erzielen, während beim tiefschlafenden Menschen schon ziemlich bedeutende Reize angewandt werden mußten, sollten sich deutliche Reaktionen zeigen. Ein Erwachen aus dem Schlaf trat dabei nicht immer ein, oder vielfach erst geraume Zeit nachher, und dann konnte man eine neuerliche, noch stärkere Erweiterung der Pupillen beobachten.

Einen Einfluß von Augenbewegungen auf die Pupillenweite während der Untersuchung am Schlafenden konnte ich nie bemerken.

Der erste, welcher genaue Beobachtungen über das Verhalten der Pupillen im Schlaf anstellte, scheint Fontanal) gewesen zu sein: be-

1) Fontana, F., Dei unoti dell' iride. Lucca 1765. 
sonders umfangreiche Untersuchungen stellten darüber Raehl $\operatorname{man} n^{1}$ ), Witkowski $)^{2}$ ), Sander ${ }^{4}$ ), Plotke ${ }^{5}$ ), Schmeichler ${ }^{6}$ ) und in nenester Zeit Gudde $n^{7}$ ) an. Alle Forscher, die sich mit den Pupillenerscheinungen im Schlaf beschäftigten, interessierte naturgemäß am meisten die Frage nach dem Zustandekommen der Miosis im Schlaf, eine Frage, die noch immer ihrer einwandfreien Lösung harrt.

J. Müller ${ }^{8}$ ) machte die Konvergenzbewegung der Augen im Schlaf dafür verantwortlich und erklärte die Miosis als Folge eines Mitbewegungsvorganges. Diese Anschauung stellte sich als irrig heraus, als man erkannte, daß die Annahme, die Augen ständen im Schlafe immer nach innen gedreht, falsch ist.

Andere, besonders Weber ${ }^{9}$ ), machten einen Reizzustand des Oculomotorius dafür verantwortlich, während Fontana die Miosis als Folge einer Sympathicuslähmung auffaßte.

Raehlmann und Witkowski endlich suchten die Erscheinung dahin zu deuten, daß der Wegfall der Aufnahme aller psychischen und sensiblen Reize, die bekanntermaßen einer Verengerung der Pupille entgegenwirken, Schuld sei an dem Znstandekommen der Miosis.

Bumke schreibt hierzu: ,So viel Bestechendes die Theorie von Raehlmann und Witkowski auch hat - und sie ist in der Tat bis heute die einzig annehmbare - so ist doch nicht zu leugnen, daß ihre Voraussetzung, der Wegfall der sensiblen Reize allein könne das ebenso vollständige Fehlen jeder Lichtwirkung derart überkompensieren, daß statt einer Erweiterung auf 8 bis $10 \mathrm{~mm}$ eine maximale Miosis einträte, etwas Uberraschendes und schwer Einzusehendes enthält. Daß mit ihr die Bechterewsche Ansicht, die sensiblen Reize wirkten über-

1) Raehlmann, E., u. Witkowski, L., Utber das Verhalten der Pupillen während des Schlafes, nebst Bemerkungen zur Innervation der Iris. Arch. f. Anat. u. Physiol, 1878, Phys. Teil, 109.

2) Witkowski, L., Über einige Bewegungserscheinungen an den Augen. Arch. f. Psych. 51, 507. 1881.

3) Sander, W., Ưber das Verhalten der Pupille im Schlaf. Berl. klin. Wochenschrift 1876, 652 .

4) Derselbe, Utber die Beziehungen des Auges zum wachen und schlafenden Zustand des Gehirns und über ihre Veränderungen bei Geisteskranken. Arch. f. Psych. 9, 129. 1879.

5) Plotke, L., Über das Verhalten der Augen im Schlafe. Arch. f. Psych. 10, 205. 1880.

6) Schmeichler, Klinische Pupillenstudien. Wien. med. Wochenschr. 35, 1179. 1885 .

7) Gudden, H., Das Verhalten der Pupillen beim Neugeborenen und im ersten Lebensjahr. Münch. med. Wochenschr. 1910, 405.

8) Müller, Joh., Handbuch der Physiologie 1, 589.

9) Weber, E. H., De motu iridis. Leipzig 1852. 
haupt nur durch Hemmung des Lichtreflexes, nicht gut in Einklang 7u bringen ist, sei hier nur nebenbei erwähnt."

Als ebenfalls gegen diese Theorie sprechend, wurde das Fortbestehen der Atropin-Mydriasis im Schlafe betont, so von Plotke. Letzterem Einwand gegenüber bemerkt $\mathrm{Bach}$, daß in dem Fortbestehen der Atropin-Mydriasis im Schlafe kein Gegenbeweis erblickt werden könne gegen die Anschauung Raehlmanns und Witkowskis, ,denn normalerweise besteht im Schlafe bekanntlich eine Einwirkung der Nerven auf die Muskeln, somit ein gewisser Tonus fort, während durch das Atropin der Muskel dem Nerveneinfluß vollständig entzogen ist".

Dem Bedenken Bumkes möchte ich folgendes entgegenhalten. Es ist ja zweifellos richtig, daß die Pupille nach längerdauernder Verdunkelung weit und weiter wird, da jeder auf das Sphincterzentrum wirkende Lichtreiz fehlt. Die enorme Weite der Pupille dürfte aber nicht nur durch das Fehlen der Sphincterinnervation bedingt sein, sondern auch durch Mitwirkung einer Sympathicuserregung. Wie ich weiter oben ausführte, müssen wir nach unseren neuesten Kenntnissen über die Innervationsbedingungen antagonistischer Muskelgruppen annehmen, daß bei Erregung des Agonisten eine Hemmung des Antagonisten erfolgt und umgekehrt. Demnach dürfte auch bei Hemmung der Sphincterinnervation der Dilatatortonus steigen.

Bedenken wir ferner, daß bei einem Menschen, den wir in einen dunklen Raum setzen, die Hemmung des Sphincters wohl zweckmäßigerweise die denkbar stärkste sein wird, da die Anspannung der Aufmerksamkeit steigt, die sensiblen Gefühle bei W'egfall jeder Ablenkung erheblich anwachsen und die möglichste Freigabe der die Auffassung von Bewegungsvorgängen gut vermittelnden Retinateile zweckmäßig erscheint, während ein Schutz des Auges gegen Lichtwirkungen überflüssig ist, so stehen der Annahme einer mit der Hemmung der Spincterinnervation einhergehenden Erregung des Dilatators keine physiologischen bzw. biologischen Erwägungen entgegen. Dadurch wird der sonst beständig unterhaltene, auch ohne Lichtreiz bestehende Tonus des Sphincters ebenfalls herabgesetzt, so daß die verstärkte Dilatatorspannung trotz ihrer geringen Kraft die maximale Erweiterung der Pupille veranlassen kann.

Will man diesen Ausführungen sich anschließen, so widerspricht die Theorie Raehlmanns nicht der Bechterewschen.

Betrachten wir das Verhalten der Pupille im Schlaf unter diesen Gesichtspunkten, so erklärt sich die Pupillenenge physiologisch aus dem Fortfall der Sympathicusinnervation, durch die der auch ohne Lichtreiz bestehende Tonus im Sphincter verstärkt wird. Im Schlaf fällt die Wirkung der gewöhnlichen sensiblen Reize fort, die psychischen Apparate stellen ihre Tätigkeit größtenteils ein, so daß weder cine direkte Erregung 
des Sympathicus zustande kommt, noch eine Verstärkung seines Tonus infolge Hemmung des Sphincterzentrums. Es erfolgt auf diese Weise die zweckmäßigste Einstellung der Iris, indem sie das Innere des Auges, das schon gegen Lichteinfluß durch Lidschluß geschützt ist, völlig gegen etwa durchschimmernde Reize abdeckt. Dieser Schutzvorgang wird zu Beginn des Schlafes noch durch eine Einwärtsdrehung der Augen unterstützt, da zunächst bei der weniger großen Schlaftiefe die Pupillenverengerung noch nicht so hochgradig ist wie im tiefsten Schlaf, in dem dann erst die Augäpfel eine mehr dem Blick in die Ferne entsprechende Lage annehmen. Die weniger starke Verengerung der Pupillen bei flacherem Schlaf dürfte sich aus einer noch bestehenden Einwirkung sensibler Reize, des Körpergefühls usw., erklären. Die starke Erweiterung der Pupille beim Erwachen trotz Bestrahlung des Auges mit hellem Licht würde als zweckmäßiger Vorgang in dem Sinne zu deuten sein, daß das Individuum sich schnell orientieren soll, woher der ungewohnte Reiz kommt. Damit würde auch die Beobachtung stimmen, daß mit der Wiederkehr des Bewußtseins die Erweiterung verschwindet und der Einfluß des Lichtes zur Geltung kommt.

Nach alledem möchte ich mich der Ansicht der Autoren anschließen, welche die Miosis im Schlaf als Zeichen des Wegfalls jeder Wirkung sensibler und psychişcher Einflüsse auf die Irisinnervation ansehen und noch besonders darauf hinweisen, daß durch die Verminderung des Sympathicustonus eine Verstärkung des ohne Lichteinfluß bestehenden Sphinctertonus zustande kommt, wodurch ein zweckmäßiger Abschluß des Auges gegen Lichtwirkungen und sonstige Gewalten bewirkt wird.

\section{Die Pupille im Tode.}

In der Literatur ist eine Reihe von Beobachtungen niedergelegt über die Veränderungen der Pupille vor, in und nach dem Tode. Besonders eingehend wurden die Verhältnisse von Albrand und Schroederl) und von Placzeck ${ }^{2}$ ) studiert. Das Ergebnis der Beobachtungen war, daß die Pupille beim Menschen vor dem Tode in der Agone meist enger ist als zuvor, während sich in einer wenig großen Anzahl von Fällen eine Erweiterung fand. Im Moment des Todes oder ganz kurz vorher pflegt die Pupille sich stark zu erweitern, worauf sie nach eingetretenem Tode ganz allmählich unter Verlust ihrer Rundung enger wird. Die Verengerung in der Agone müssen wir wohl auf eine Steige-

1) Albrand, W. u. Schroeder, H., Die Pupille im Tode. Halle a. S. 1905.

2) Placzeck, Utber Pupillenveränderungen nach dem Tode. Virchows Arch. 173, 172. 1903 . 
rung des Sphinctertonus zurückführen, die vielleicht als Folge des Wegfalles sensibler und psychischer Reizerscheinungen eintritt, ähnlich wie im Schlafe. Die Erweiterung im Moment des Todes läßt sich aus einem frühzeitigen Nachlassen des Sphinctertonus bzw. der Lichtreaktion gegenüber der Sympathicuswirkung erklären, vielleicht auch aus dem gleichzeitigen Fortfall beider Innervationen. Die Verengerung der Pupille nach dem Tode kommt, wie dies Placzeck und Albrand betonen. infolge der eintretenden Totenstarre zustande, die mit Rücksicht auf die Stärkeverhältnisse von Sphincter und Dilatator zur Verengerung der Pupille führen muß.

Interessant ist die von Albrand und Schroeder festgestellte Tatsache, daß der Ablauf der Pupillenveränderungen im Tode beim Tier sich um so mehr dem beim Menschen beobachteten nähert, je höher das Tier steht, indem bei den niederen Tieren Abweichungen von den beim Menschen beobachteten postmortalen Pupillenveränderungen in um so stärkerem Grade beobachtet werden, je tiefer das Tier in der Reihe der Wirbeltiere steht.

Bei Beobachtungen, die ich an den Pupillen von kurz vorher Verstorbenen anstellte, fiel mir ein Umstand auf, nämlich der, daß einzelne Individuen, die im Leben absolut starre, dabei mydriatische Pupillen aufwiesen, sofort nach dem Tode wesentlich verkleinerte Pupillen zeigten, eine Tatsache, auf deren Bedeutung ich weiter unten noch zurückkomme.

\section{Untersuchungen bei Kranken.}

Nachdem wir im vorhergehenden einen Überblick über die unter physiologischen Bedingungen sich abspielenden Pupillenerscheinungen gewonnen haben, gehen wir dazu über, die unter krankhaften Verhältnissen zur Beobachtung kommenden Störungen der Irisinnervation zu betrachten. Dabei kann uns die Frage, welche Pupillenstörungen bei bestimmten Erkrankungen vorkommen, zunächst nicht wesentlich interessieren, wir werden vielmehr nach dem Sitz der Erkrankung bei bestimmten Veränderungen der Reaktionen der Iris auf sonst in ganz gesetzmäßiger Weise wirkende Reize forschen und unsere Besprechung daher so einteilen, daß wir dem Gang der Reizwirkung folgen und demnach zwischen Störungen, die entweder in dem zentripetalen oder dem zentrifugalen Teil der Reflexbahnen oder endlich in dem Reflexzentrum selbst ihren Sitz haben, unterscheiden. Wie weit eine derartige Unterscheidung überhaupt möglich ist, wird sich bei der Darstellung der verschiedenartigen Störungen ergeben. Auch jetzt wollen wir die Veränderungen der die Pupille verkleinernden und der sie vergrößjernden Irisbewegungen getrennt besprechen. 


\section{Veränderungen der die Pupille verkleinernden Irisbewegungen.}

\section{Störungen im zentripetalen Abschnitt der Verengerungsbahn.}

Wie wir weiter oben gesehen haben, nimmt der das Auge treffende sensible Lichtreiz, bis es zu einer Umsetzung in einen motorischen Reiz kommt, folgenden Verlauf. Die Retina, d. h. in ihrem zentralen Teile gelegene nervöse Elemente, nehmen den Lichtreiz auf, der im Opticus zu den vorderen Vierhügeln und dann zum Oculomotoriuskern verläuft. Ob wir die zuletzt von dem Lichtreiz zurückgelegte Strecke, vom Vierhügel zum Oculomotoriuskern, noch, streng genommen, als zentripetale Bahn anschauen können, d. h., ob wir annehmen dürfen, daß die Erregung in dieser Strecke noch rein sensibler Natur ist, mag fraglich erscheinen, jedoch besitzen wir bisher keine klinischen oder anatomischen sicher verwertbaren Anhaltspunkte, durch die eine gegenteilige Annahme bedingt bzw. der Nachweis des Pupillenreflexzentrums erbracht wäre.

\section{Reflextaubheit.}

Sind nun die nervösen, den Lichtreiz aufnehmenden Netzhautelemente erkrankt, oder ist die Leitung im Sehnerven unterbrochen, so tritt eine ganz bestimmte Störung der Lichtreaktion der Pupillen ein, für die Bach die Bezeichnung ,amaurotische Starre“ vorschlug, während Heddaeu $\left.\left.\mathrm{s}^{1}\right)^{2}\right)^{3}$ ) sie als "Reflextaubheit" benannte. Ich halte den von Heddaeus gewählten Namen für kennzeichnender, weil es einerseits feststeht, daß die gemeinte Störung bei Amaurose nicht immer vorzukommen braucht und andererseits die Bezeichnung "Reflextaubheit" schon sagt, daß es sich hier um eine Unempfindlichkeit der den Reflex vermittelnden sensiblen Bahnen handelt.

Wir stellen die Diagnose „Reflextaubheit", wenn wir finden, daß bei Belichtung eines Auges weder die Pupille desselben noch die des anderen Auges sich verändert, dagegen bei Lichteinfall in das andere Auge beide Pupillen sich verengern, und wenn zugleich die Konvergenzreaktion an beiden Augen erhalten ist.

Zur Registrierung der an meinem Apparat festgestellten Pupillenbeobachtungen bediene ich mich eines Schemas, in das die bei der Messung der Pupillenweite unter den verschiedenen Lichteinwirkungen gefundenen Werte eingetragen werden. Ich gebe die Einteilung des

I) Heddaeus, Reflexempfindlichkeit, Reflextaubheit und reflektorische Pupillenstarre. Berl. klin. Wochenschr. 25, 332 und 353. 1888.

2) Derselbe, Die zentripetalen Pupillenfasern und ihre Funktion. Zeitschr. z. Feier d. 50 jähr. Jubiläums d. Ärzte. Düsseldorf 1894.

3) Derselbe, Klinisehe Studien über die Beziehungen zwischen Pupillenreaktion und Sehvermögen. Inaug.-Diss. Halle 1880. 
Schemas hier wieder und bemerke, daß unter I die Werte vermerkt werden, die sich als Pupillenweite bei beiderseitiger minimalster Beleuchtung (ca. $6 \mathrm{MK}$.) des an dieses Licht adaptierten Auges finden. Jie unter II eingezeichnete Zahl gibt die Pupillenweite des mit starkem Licht (ca. 270 MK.) bestrahlten Auges an. Der bei Belichtung beider Augen mit starkem Licht (ca. 270 MK.) gefundene Pupillendurchmesser wird unter III eingetragen, während die unter IV stehende Zahl die Weite der Pupille des unbelichteten Auges anzeigt, wenn das contralaterale Auge starkem Lichte (ca. 270 MK.) ausgesetzt ist. Demnach würde beim Erhaltensein aller physiologischen Pupillenerscheinungen unser Schema folgende Eintragungen aufweisen:

Pupillenuntersuchung.

\begin{tabular}{|c|c|c|c|c|c|c|c|c|c|c|c|}
\hline Name & Alt: & Datum & $\mathrm{R} \quad \mathrm{I}$ & II & III & IV & L I & II & III & IV & Eonvergenzr. \\
\hline Georg Ambach & 34 & 16.X.08 & 5,2 & 3,6 & 3,2 & 3,6 & 5,2 & 3,6 & $3,2 \mid$ & 3,6 & $\mathrm{R}+\mathrm{L}+$ \\
\hline Psych. Reaktion & $\operatorname{Seh}$ & imerz $\mathrm{R}+$ & $\mathrm{I}$ & ; & Sab & $P$ & $+\mathrm{I}$ & + ; & Geist & 1 & b. $\mathrm{R}+\mathrm{L}+$ \\
\hline
\end{tabular}

Bei einer Kranken mit rechtsseitiger Reflextaubheit würden unsere Eintragungen folgendermaßen aussehen:

Pupillenuntersuchung.

\begin{tabular}{|c|c|c|c|c|c|c|c|c|c|c|c|}
\hline Name & Alt: & Datum & R I & II & III & IV & L I & II & III & IV & Konvergenzr. \\
\hline Anna Gebhardt & 26 & 11.V.06 & 4,6 & 4,6 & 3,4 & 3,4 & 4,6 & 3,4 & 3,4 & 4,6 & $\mathrm{R}+\mathrm{L}+$ \\
\hline Psych. Reaktion & \multicolumn{11}{|c|}{ Schmerz R+L+; Schreck R+L+; Geist. Arb. R+ A+ } \\
\hline Bemerkungen: & \multicolumn{11}{|c|}{$\begin{array}{l}\text { Bei minimalster Belichtung des rechten Auges ist nur noch eine } \\
\text { sehr geringe Reaktion auf Schmerzreiz zu sehen, während die } \\
\text { übrigen psychischen Reaktionen fehlen. }\end{array}$} \\
\hline
\end{tabular}

Bach sagt in seiner Pupillenlehre (S. 101): „Die Pupille des erblindeten Auges ist in der Regel etwas weiter (ca. $1 / 4 \mathrm{~mm}$ ) als die des sehenden Auges. Diese Differenz tritt oft besonders deutlich zu Beginn der Untersuchung im Dunkelzimmer im durchfallenden Licht hervor. Die Behauptung von Heddaeus, daß durch zentripetale Pupillenstörungen niemals Pupillenungleichheit entstehe, ist unrichtig. Nimmt man die Pupillenuntersuchung lediglich bei Tageslicht vor, so kann eine solche irrtümliche Auffassung entstehen, da es bei dieser Untersuchungsmethode wegen der störenden Hornhautreflexe schwer ist, geringe Pupillendifferenzen zu erkennen. Zur Begründung seiner Behauptung zieht Heddaeus eine andere falsche Beobachtung heran, 
daß nämlich beim Gesunden bei Verdunkelung eines Auges und gleichzeitiger greller Belichtung des anderen die Pupillen gleich weit blieben."

Ich hatte selbst nicht häufig Gelegenheit, eine einseitige Reflextaubheit feststellen zu können, was sich aus der Art des von mir untersuchten Krankenmaterials ergibt (Geisteskranke). Im ganzen fand ich diese Pupillenstörung 4 mal und konnte nur in einem Falle, bei welchem zudem die Iris sehr dunkel gefärbt war, nicht mit Sicherheit ausschließen, daß die Pupille des Auges mit reflextauber Retina bei beiderseitiger starker Belichtung bzw. bei Belichtung der reflexempfindlichen Netzhaut doch etwas $(0,2-0,3 \mathrm{~mm})$ größer war als die des anderen Auges. Nach den Erfahrungen, die ich sonst bei der Untersuchung Gesunder und Kranker ohne besondere Störungen des Lichtreflexes machte, kann ich jedoch kaum annehmen, daß sich in einer sehr großen Anzahl der Fälle mit einseitiger Reflextaubheit eine Differenz der Pupillengröße zugunsten der den Lichtzutritt zu der reflextauben Retina gestattenden Pupille finden wird, da hierfür ja Voraussetzung sein müßte, daß einseitige Belichtung meist Pupillenungleichheit zur Folge habe. Ich möchte hier nochmals darauf hinweisen, da $B$ bei geringer Beleuchtung des Auges die Pupille leicht für größer gehalten wird, als sie es wirklich ist, indem man den meist dunkler gefärbten innersten Irissaum nur schwer von der Pupille unterscheiden kann.

So einfach nun die Feststellung einer einseitigen Reflextaubheit ist, so schwierig kann die Diagnose werden, wenn die Störung beiderseits besteht. Die Lichtreaktion ist dann auf beiden Augen aufgehoben, während die Konvergenzreaktion erhalten bleibt. Dieselben Erscheinungen würde nun auch eine beiderseitige, reflektorische Lichtstarre hervorrufen, so da $\beta$ aus der Pupillenstörung allein nicht die Diagnose der Art derselben gestellt werden kann, sondern nur unter Mitberücksichtigung der Untersuchungsergebnisse der Sehprüfung. Bei doppelseitiger Reflextaubheit besteht fast immer Amaurose, während diese mit der reflektorischen Starre nur selten zusammentrifft.

Einigen Anhalt gibt auch die Weite der Pupillen, die bei der Reflextaubheit vergrößert sind, während sie bei der reflektorischen Starre vielfach verkleinert erscheinen.

Bei der Untersuchung meiner Fälle konnte ich mich davon überzeugen, daß bei den vier an einseitiger Reflextaubheit leidenden Individuen die Reaktion auf sensible und psychische Reize erhalten war, wenn ihre beiden Augen, wie ich das für gewöhnlich bei diesem Versuch tue, mit mittelstarkem Licht (ca. $25 \mathrm{MK}$.) belichtet wurden, setzte ich die Beleuchtung der reflextauben Augen bis auf wenige Meterkerzen herab, so konnte ich mit Sicherheit nur noch eine geringe Reaktion auf sen- 
sible Reize feststellen, während auf sensorische and psychische Reize keine Antwort der Iris erfolgte.

Bei doppelseitiger Reflextaubheit (2 Fälle) war ebenfalls nur noch die Reaktion auf sensible Reize in geringem Maße erhalten.

Mit Recht betont Bach, daß die Untersuchung der Pupillenreaktion auf psychische und sensible Reize an Augen mit reflextauber Retina von größter Wichtigkeit für die Entscheidung der Frage ist, ob diese Reaktion durch Hemmung der Sphincterinnervation oder durch Erregung des Dilatators zustande kommt.

Leider konnte ich nur wenige Menschen, bei denen Reflextaubheit bestand, untersuchen und maße mir infolgedessen kein Urteil in dieser Sache an, doch scheinen meine dabei gemachten Beobachtungen die oben schon geäußerte Vermutung, daß wenigstens für das Zustandekommen der Reaktion auf sensible Reize eine Mitwirkung des Sympathicus nicht sicher auszuschließen ist, zu stützen.

Alle Autoren, die sich mit der Reflextaubheit befaßten, stimmen darin überein, daß diese Störung bei Amaurose nicht immer vorhanden sein $m u ß$, daß umgekehrt Reflextaubheit bestehen kann, während die Sehkraft noch nicht verloren ist. Gute Lichtreaktion sah auch ich mehrmals bei völlig erblindeten Leuten.

Reichardt ${ }^{1}$ ) stellte bei der anatomischen Untersuchung eines Falles von linksseitiger Blindheit, in dem die Lichtreaktion an dem erblindeten Auge noch unverändert war, fest, daß im Opticus nur die feinen Fasern ('Träger des pupillomotorischen Reizes?) noch größtenteils normal erschienen. Dieser Fall beweist die Möglichkeit einer elektiven Erkrankung der Seh- bzw. Pupillenfasern im Opticus.

Nach den Beobachtungen der anderen Autoren muß man allerdings doch daran festhalten, daß eine solche elektive Erkrankung der Sehfasern nur als Seltenheit zu betrachten ist und im allgemeinen bei einer Amaurose auch eine Reflextaubheit der betreffenden Retina für den Lichtreiz besteht, und daher bei wirklich Blinden zunächst ein Fehlen der Lichtreaktion erwarten.

Hemianopische Reflextaubheit. In der Annahme, daß in der gesamten Retina den Lichtreflex vermittelnde Elemente verteilt seien, und unter Zugrundelegung einer teilweisen Kreuzung der zentripetalen Bahn dieses Reflexes folgerte $W$ ernicke ${ }^{2}$ ), daß bei Hemianopsie, die durch Zerstörung eines Tractus opticus entstanden sei, nur bei Belichtung der noch Lichteindrücke vermittelnden Retinahälfte eine Iris-

1) Reichardt, U̇ber Pupillenfasern im Sehnerv und ïber reflektorische Pupillenstarre. Deutsche Zeitschr. f. Nervenheilk. 25, 408. 1904.

2) Wernicke, C., Utber hemiopische Pupillenreaktion. In: Gesammelte Aufsätze und kritisohe Referate zur Pathologie des Nervensystems. Berlin 1893, S. 209. 
contraction am belichteten Auge auszulösen sein würde. Er schreibt: „Ist ein Tractus opticus durchtrennt, so bleibt die von ihm versorgte Retina bei der Beleuchtung nicht nur unempfindlich gegen Licht, sondern es bleilbt auch die reflektorische Pupillenverengerung aus, oder sie ist wenigstens viel geringer als die auf Beleuchtung der von dem anderen Tractus versorgten Netzhauthälften erfolgende. (Daß die Pupillenreaktion nicht vollkommen ausbleibt, erklärt sich daraus, daß die Augenmedien nicht vollkommen durchsichtig sind, daher selbst leuchtend werden und diffundiertes Licht auf die normal fungierenden Netzhauthälften gelangen lassen.) “

Vor Wernicke hatte schon Wilbrand ${ }^{1}$ ) darauf hingewiesen, daß bei Tractusläsionen eine gleichmäßige Störung des Sehens, wie eine Herabsetzung der Lichtreflexempfindlichkeit der von ihni versorgten Netzhauthälften eintreten müsse.

Die hemianopische Pupillenstarre (so bezeichnete Wernicke die von ihm deduzierte Pupillenstörung), die wir, um den Begriff der Reflextaubheit nicht zu verwirren, hemianopische Reflextaubheit nennen wollen, fand in der Folgezeit viel Interesse und es entstand darüber eine ganz ansehnliche Literatur; ich verweise auf deren Zusammenstellung bei Bumke und Bach. Heddaeus betonte in einer Kritik der hemiopischen Pupillenreaktion, daß ein vollständiger Parallelismus im Verlauf der Seh- und Pupillenfasern in der Netzhaut, den Sehnerven, dem Chiasma und den Sehstielen noch nicht nachgewiesen sei.

Wenn nun auch die neueren Forschungsresultate den von Heddae us ausgesprochenen Zweifel nicht bestärkten, so verringert die von $\mathrm{He}$ ? festgestellte Tatsache, daß nur ein ganz kleiner, um die Fovea herum liegender Teil der Retina mit pupillomotorisch wirksamen Elementen ausgestattet ist, die Aussicht, eine hemianopische Reflextaubheit sicher feststellen zu können, sehr, indem es äußerst schwer fallen dürfte, diesen kleinen Bezirk nur zur Hälfte zu belichten.

Die Untersuchung mit einer gewöhnlichen Lichtquelle verspricht natürlich gar keinen Erfolg, höchstens könnte die Diagnose mit Hilfe des Fragstein-Kempnerschen Apparates (siehe T'echnik) gestellt werden.

Ich habe im Laufe der Zeit an 3 Fällen Versuche in dieser Richtung anstellen können, zu denen mir die Firma Reiniger in liebenswürdiger Weise den Fragsteinschen Apparat leihweise überließ. Während ich in einem dieser Fälle zu gar keinem Resultat kam, gelang es mir bei den beiden anderen, aus der Differenz des Irisausschlages bei der Belichtung der nasalen bzw. temporalen Netzhautpartie auf die hemianopischen Retinahälften zu schließen. Um sicherzugehen, vermied ich es, mir vorher Kenntnis von dem Ausfall der Gesiehtsfeldprüfung zu verschaffen.

1) Wilbrand, Über Hemianopsie und ihr Verhältnis zur topischen Diagnose der Gehirnkrankheiten. Berlin 1881. 
Ich muß jedoch betonen, da $\beta$ mir eine halbwegs sichere Feststellung, welche Netzhautpartie unempfindlicher für den Lichtreiz war, nur nach langem Versuchen und immer wieder erneutem Vergleich des pupillomotorischen Effektes der verschiedenen Belichtungen möglich war, indem eine geringe Pupillenveränderung immer eintrat, gleichgültig, von welcher Seite das feine Lichtbündel ins Auge fiel, und zudem auch der von der empfindlichen Netzhauthälfte ausgelöste Reizeffekt nicht groß3 war. Die Kranken kamen nicht zur Autopsie.

Nach diesen allerdings geringen Frfahrungen schließe ich mich der Ansicht der Autoren an, die bei Anerkennung des theoretischen Wertes der hemianopischen Pupillenreaktion ihr eine praktische Bedeutung absprechen.

Daß jedoch die scharfsinnige Deduktion Wernickes zu Recht besteht, bewies der oft zitierte Fall, in dem Leyden ${ }^{1}$ ) bei der Sektion bestätigt fand, daß eine am Lebenden festgestellte hemianopische Reflextaubheit mit einer Tractusläsion vergesellschaftet war.

Vorkommen der Reflextaubheit. Aus dem Vorhergehenden dürite deutlich hervorgegangen sein, daß wir dann berechtigt sind, die Diagnose Reflextaubheit zu stellen, wenn wir finden, daß die Pupille eines Auges auf direkten Lichteinfall in dieses weder selbst sich verändert, noch eine Verengerung der Pupille des anderen Auges dabei zu bemerken ist, während bei Lichteinfall in das letztere beide Pupillen sich verengern und außerdem die Konvergenzreaktion an beiden Augen erhalten ist. Fragen wir uns nun, bei welchen Krankheitsprozessen diese Störung vorkommt und welchen lokaldiagnostischen Wert sie besitzt.

Die hauptsächlichste Ursache einer Reflextaubheit stellt die Opticusatrophie dar, ferner Entzündungen der Sehnerven; also im wesentlichen Folgeerscheinungen der Lues und des Alkoholmißbrauches. Eine weit geringere Rolle spiclen andersartige infektiöse Einflüsse und Erkrankungen auf hereditärer Basis. Des weiteren kann eine Reflextaubheit durch direkte Schädigungen des Sehnerven oder des Tractus opticus infolge von Gummiknoten, Tumoren, Blutungen oder Zerreißung des Nervengewebes (Schußverletzungen, Basisfrakturen usw.) veranlaßt sein. Auch bei der Stauungspapille kommt es meist zu einer erheblichen Herabsetzung der Empfindlichkeit der Retina für pupillomotorisch wirksame Reize.

Die lokaldiagnostische Bedeutung der Reflextaubheit im allgemeinen ist nicht von allzu weittragender Bedeutung, da sie einerseits meist mit auch auf anderem Wege (Augenspiegelbefund) feststellbaren Erkrankungen der Sehorgane Hand in Hand zu gehen pflegt, - aller-

1) Leyden, Utber die hemiopische Pupillenreaktion Wernickes. Deutsche med. Wochenschr. 1892, 3. 
dings kann sie Veranlassung geben, bei Nerven- und Geisteskranken das Sehorgan einer genaueren Prüfung zu unterziehen -- und andererseits bei Allgemeinerkrankungen des Gehirns, die mit erhöhtem Hirndruck eiuhergehen, vorkommen kann. Eine größere lokaldiagnostische Bedeutung würde die halbseitige Reflextaubheit haben, doch leider stehen, wie wir gesehen haben, ihrer sicheren Feststellung fast unüberwindliche Schwierigkeiten entgegen.

\section{Die reflektorische Pupillenstarre.}

\section{(Lichtstarre. Argyll Robertsonsches Zeichen.)}

Unter den vielgestaltigen Pupillenstörungen kommt die größte diagnostische Bedeutung bekanntlich der reflektorischen Starre zu. Argyll Robertson $\left.{ }^{1}\right)^{2}$ ) teilte im Jahre 1869 die Beobachtung mit, daß eine Pupille bei Belichtung der Augen unverändert bleiben kann, trotzdem die Iris, wie die bei der Konvergenzbewegung eintretende Reaktion zeigt, beweglich ist. $\mathrm{Erb}^{3}$ ) machte auf die weittragende neuro-pathologische Bedeutung dieser Störung aufmerksam und nannte sie „reflektorische Starre“. Leider wurde die Diagnose „reflektorische Starre" in der Folgezeit in Verkennung ihrer Begriffsbestimmung bei den heterogensten Pupillenstörungen gestellt, ein Fehler, der zu den größten Verwirrungen führen mußte.

Wir dürfen nur dann eine Pupille als ,,reflektorisch starr" bezeichnen, wenn wir bei der Untersuchung finden, daß sie weder bei Belichtung desselben noch des anderen Auges sich verengert, während ihre Reaktion bei der Konvergenzbewegung des Auges in ganz normaler Weise vor sich geht. Besteht die Störung doppelseitig, so müssen wir uns außerdem noch vergewissern, daß wir es nicht mit einer doppelseitigen Reflextaubheit zu tun haben; erst, wenn wir keine Anhaltspunkte für die Annahme finden, dals die Sehnervenleitung gestört ist, dürfen wir die Diagnose der reflektorischen Starre stellen. Wir sehen, daß der Begriff dieser Störung sehr eng und scharf umgrenzt ist, und daß wir besonders darauf achten müssen, daß die Konvergenzreaktion ganz ungestört verläuft und daßs sowohl die direkte, wie die konsensuelle Reaktion nicht auslösbar ist.

So wichtig nun die reflektorische Pupillenstarre in diagnostischer Hinsicht ist, so wenig bekannt ist der Teil der Reflexbahn, in dem die sie veranlassende Störung ihren Sitz hat. Zurzeit gibt es noch keine

1) Argyll Robertson, Four cases of Spinal Miosis, with Remark of the Action of Light on the Pupil. Edinbourgh med. Journ. 1869.

2) Derselbe, On the physiologie of the iris 1, 211. Lancet 1870.

3) Erb, Utber spinale Miosis und reflektorische Pupillenstarre. Universitätsprogramm. Leipzig 1886. 
pathologische Anatomie der reflektorischen Starre, d. h. wir besitzen noch keine eindeutige, durch pathologisch-anatomische Untersuchungsresultate gesicherte Erklärung des Sitzes dieser Pupillenstörung. Bei der Besprechung der die Pupillenbewegungen vermittelnden Bahnen mußten wir eingestehen, daß uns der Verlauf des Abschnittes derselben, welcher vom Vierhügel aus den zentripetalen Teil der Reflexbahn mit dem Oculomotoriuskern verbindet, unbekannt ist. Liegt nun die Störung, deren Resultat eine reflektorische Pupillenstarre ist, auf dieser uns im Verlauf unbekannten Strecke der Reflexbahn, oder verdankt das Argyll Robertsonsche Zeichen der Erkrankung eines Kernabschnittes des Oculomotorius seine Entstehung? Bevor wir uns mit dieser Frage weiter beschäftigen, wollen wir zunächst die Erscheinungen betrachten, welche meist oder wenigstens häufig Begleiterscheinungen der reflektorischen Starre sind.

Häufig vorkommende Begleiterscheinungen der reflektorischen Starre.

Miosis. Unter Miosis verstehen wir gemeinhin eine auffallende Enge der Pupille, es bleibt dabei dem subjektiven Ermessen überlassen, wann eine Pupille als abnorm eng zu betrachten ist. Eine Pupille kann natürlich aus den verschiedensten Gründen eng sein. Das eine Mal kann es ein Utberwiegen des Sphinctertonus, ein anderes Mal ein Nachlassen der Dilatatorspannung sein, deren Resultat uns als Miosis entgegentritt. Von weitgehendster Bedeutung für die Beurteilung einer Miosis ist die Feststellung, unter welchen Beleuchtungsverhältnissen die abnorme Pupillenenge zu beobachten ist. Gesetzt z. B. den Fall, daß eine Schwäche der Dilatatorinnervation unter sonst normalen Bedingungen die Pupille bei gewöhnlicher Tageslichtwirkung besonders eng erscheinen läßt, so kann die Miosis verschwinden, wenn die Lichtwirkung vermindert, der Sphinctertonus herabgesetzt wird. Wann eine Pupille als miotisch zu bezeichnen ist, $d . h$. wie klein der Pupillendurchmesser mindestens sein muß, wenn man von Miosis reden darf, steht nicht fest. Bach glaubt bei einer Pupillenweite von 2,5 $\mathrm{mm}$ und weniger diese Bezeichnung gebrauchen zu sollen. Nach unseren oben mitgeteilten Meßergebnissen bei Gesunden ist die unterste Grenze der Pupillenweite, eine Beleuchtung von ca. 6 MK. vorausgesetzt, bei $3,6 \mathrm{~mm}$ anzunehmen, während beiderseitiger Lichteinfall von ca. 270 MK. Pupillenverengerung bis auf $2,1 \mathrm{~mm}$ erzeugt. Wir sollten meines Erachtens demnach eine Pupille als miotisch bezeichnen, wenn sie bei Tageslichtbeleuchtung die Weite von $2 \mathrm{~mm}$ nicht überschreitet. Unter Berïcksichtigung dieser Voraussetzung fand ich bei meinen an paralytischen Kranken (163 Fälle) angestellten Untersuchungen nur in ca. 4\% der Fälle eine Miosis mit der reflektorischen Starre vergesellschaftet, und zwar handelt es sich in allen diesen Fällen um Tabesparalysen, bei denen zugleich auch die Pupillenerweiterung 
auf psychische und sensible Reize nicht eintrat. Bei den übrigen Kranken mit vollkommener reflektorischer Pupillenstarre schwankte die Pupillenweite zwischen 2,4 und $4,3 \mathrm{~mm}$. War die Lichtreaktion nur noch minimal, $\mathrm{d} . \mathrm{h}$. betrug sie bei beiderseitiger Belichtung von 270 MK. höchstens $0,5 \mathrm{~mm}$, während die Konvergenzreaktion erhalten war, so konnte ich Pupillengrößen von 2,8-5,5 mm feststellen. Bei den Tabesparalysen mit reflektorischer Starre (ca. $8 \%$ der Paralysefälle) schwankten die Pupillenweiten zwischen 2,0 und 4,3 mm.

Leider hatte ich keine Gelegenheit, in größerem Umfange an Tabeskranken Messungen anzustellen und kann daher nur die von anderen Autoren festgestellten Tatsachen wiedergeben. Erb beobachtete eine Miosis in $52 \%$, Berger ${ }^{1}$ ) in $40 \%$ der Tabesfälle, die eine reflektorische Pupillenstarre darboten; Dill man $n^{2}$ ), Voigt ${ }^{3}$ ) und Uhthoff $f^{4}$ ) fanden bei ca. $24 \%$ der Tabiker die reflektorisch starren Pupillen miotisch. Die Angaben Uhthoffs sind besonders wertvoll, weil er nur dann Miosis diagnostizierte, wenn die Pupillen kleiner als $1,5 \mathrm{~mm}$ waren. Demnach kommt die Vereinigung von Miosis und reflektorischer $\mathrm{Pu}-$ pillenstarre bei tabischer Erkrankung ziemlich oft vor, wenn sie auch nicht so häufig ist, wie man im allgemeinen offenbar deshalb anzunehmen geneigt ist, weil die Diagnose Miosis vielfach schon dann gestellt wird, wenn die Weite der Pupillen noch nicht wesentlich von der bei Gesunden vorkommenden abweicht.

Wie ist das Zustandekommen der Miosis bei zugleich bestehender reflektorischer Pupillenstarre zu erklären? Hierfür wurden schon die verschiedenartigsten Ursachen angenommen. Romberg suchte sie auf eine Verminderung der Sympathicusinnervation zurückzuführen. Argyll Robertson, Erb, Leber ${ }^{5}$, Hempel ${ }^{6}$ ) u. a. traten dieser Ansicht im wesentlichen bei und nahmen an, daß die Sympathicusstörung im Halsmark ihren Sitz haben müsse. Erb machte zuerst darauf aufmerksam, daß bei der tabischen Frkrankung der Hinterstrïnge ein großer Ausfall in den unter normalen Bedingungen dem Sphincterzentrum zuströmenden sensiblen Reizen stattfinden müsse, und daß diese Tatsache das Zustandekommen der Miosis bei der Tabes, zum Teil wenigstens, erklären könne.

1) Berger, E., Die Sehstörungen bei Tabes dorsalis. Arch. f. Augenheilkde. 19, 395. 1889 .

2) Dillmann, Utber tabische Augensymptome und ihre diagnostische Bedeutung unter gleichzeitiger Berücksichtigung der Tabes-Syphilisfrage nach dem Material der Schölerschen Augenklinik in Berlin. Inaug.-Diss. Leipzig 1889.

3) Voigt, Syphilis und Tabes dorsalis. Berl. klin. Wochenschr. 1886, 565.

4) Uthhoff, W., Zur diagnostischen Bedeutung der reflektorischen Pupillenstarre. Berl. klin. Wochenschr. 1886, 36.

5) Leber, Spinale Miosis. Virchow-Hirschs Jahresber. 2, 544. 1877.

6) He m pel, U̇ber die Spinalmiosis. v. Graefes Arch. 12, 1. 1876. 
Die heute von den meisten Autoren vertretene Ansicht geht dahin, daß der Fortfall der Wirkung von sensiblen Reizen wohl die Hauptursache der Miosis bei der Tabes sei, daß aber dadurch allein nicht die vielfach beobachtete maximale Miosis erklärt werden könne, daß man hierzu außerdem noch eine sekundäre Contractur des Sphincter annehmen müsse. Diese letztere Annahme stützt sich vor allem darauf, daß bei der experimentell erzeugten Sympathicuslähmung die anfängliche Miosis allmählich geringer wird, und daß bei der Tabes die sonst mit der Sympathicuslähmung einhergehenden Erscheinungen (Verengerung der Lidspalte, Retraktion der Bulbi usw.) trotz bestehender Miosis vielfach fehlen.

Wenn wir uns das bei der Darstellung der Pupillenverhältnisse beim schlafenden Menschen über die Ursachen der Schlafmiosis Gesagte vergegenwärtigen, so kann auch eine maximale Miosis ihre Erklärung wohl in dem Wegfall der Dilatatorinnervation finden, indem der dadurch gesteigerte Tonus des Sphincters eine starke Verengerung der Pupille erzeugt, ohne daß man, wie Heddaeus das tat, gerade einen Sphincterkrampf anzunehmen braucht. Dieser Autor stützte seine Theorie hauptsächlich damit, daß er feststellen zu können glaubte, daß die an der miotischen, reflektorisch starren Pupille eintretende Konvergenzverengerung nicht so schnell beim Aufhören der Innenbewegung der Bulbi zurückgehe wie in der Norm, was auf eine ,Steifigkeit" der Iris im Sinne eines Spasmus des Sphincter schließen lasse. Dieser Annahme dürfte man doch, wenn die Beobachtung, daß die Konvergenzverengerung länger bestehen bleibt als in der Norm, richtig ist, entgegenhalten, daß diese "Steifigkeit" der Iris sich schon allein aus einer fehlenden Funktion des Dilatators erklären läßt. Letztere Annahme würde auch die Beobachtungen Bachs stützen, der fand, daß die Pupillenverengerung bei der Konvergenzbewegung häufig prompter eintrat und ausgiebiger zu sein schien, als unter normalen Bedingungen.

Die Beobachtung, daß die Miosis bei experimentell erzeugter Sympathicuslähmung allmählich zurückgeht, widerspricht auch nicht der Annahme, daß die bei der lichtstarren Pupille beobachtete Enge derselben im wesentlichen durch eine Sympathicuslähmung bedingt sei, da die reflektorisch starre Pupille zugleich dem das Spincterzentrum hemmenden Einflusse der sensorischen und psychischen Reize entzogen zu sein pflegt, die bei der experimentell erzeugten Sympathicuslähmung ihre Wirkung weiter entfalten können.

Will man einen besonderen Reizzustand im Sphincterkern für die Entstehung der Miosis verantwortlich machen, so bleibt dabei zu bedenken, daß motorische Reizzustände gerade bei der Erkrankung, bei der die reflektorische Pupillenstarre mit Miosis am häufigsten vorkommt, der Tabes, sehr selten sind. Der Annahme eines Sphincter- 
krampfes widerspricht auch die schnelle Reaktion der Pupille bei der Konvergenzbewegung, ganz im Gegensatz zu der langsamen Konvergenzverengerung bei einer Eserinmiosis (Bach).

Nach alledem dürfen wir wohl die Frage nach der Ursache der Miosis bei der reflektorischen Pupillenstarre noch nicht als völlig gelöst betrachten, wir werden aber der Wahrheit wohl am nächsten kommen, wenn wir die Pupillenenge im wesentlichen als Folgeerscheinung des Wegfalles der pupillenerweiternden Wirkung psychischer und sensibler Einflüsse auffassen.

Mydriasis. Während die mit der reflektorischen Starre häufig verbundene Miosis der Pupillen, wie wir gesehen haben, vielfach Gegenstand des Interesses der Forscher war, hören wir viel weniger von einer zugleich mit der reflektorischen Starre vorkommenden Mydriasis. Wollen wir diese Frage in Angriff nehmen, so müssen wir wiederum zunächst eine bestimmte Versuchsbedingung schaffen, $d$. $h$. wir müssen festlegen, bei welcher Beleuchtung der Augen wir die Pupillenweite bestimmen. Nachdem wir bei der Miosisdiagnose voraussetzten, da $\beta$ die Augen mit starkem (ca. $270 \mathrm{MK}$.) Licht bestrahlt waren, mit einem Licht, bei dessen Einwirkung die Pupillen ihre physiologische Weite nach Schirmer einnehmen, so können wir von Mydriasis sprechen, wenn die Pupille bei derselben Versuchsbedingung einen größeren Durchmesser behält, als in der Norm vorzukommen pflegt. Unter normalen Verhältnissen fanden sich bei beiderseitigem Lichteinfall dessen Stärke ca. 270 MK. betrug, Pupillengrößen bis $4,5 \mathrm{~mm}$. Als mydriatisch dürfen wir demnach eine Pupille dann bezeichnen, wenn ihr Durchmesser $4,5 \mathrm{~mm}$ überschreitet. Unter den 163 Fällen von Paralyse fand sich bei keinem der Kranken, die vollständige, reflektorische Starre darboten, eine Pupillenweite über 4,3 mm. Bei 45 Kranken, die minimale Lichtreaktion erkennen ließen (die Verengerung der Pupillen betrug bis 0,5 mm), fand sich in 16 Fällen eine Mydriasis von 4,7-6,0 $\mathrm{mm}$. Wie ich weiter unten ausführen werde, müssen wir Pupillen, die sich auf eine Mehrung des Lichteinfalls von ca. $265 \mathrm{MK}$. nur mehr um 0,5 mm verengern, während ihre Konvergenzreaktion gut erhalten ist, ebenfalls den reflektorisch lichtstarren beirechnen, so daß wir eine Mydriasis nicht gerade selten mit der reflektorischen Starre zugleich vorfinden (bei $21,6 \%$ aller Kranken, die eine reflektorische Pupillenstarre im erweiterten Sinne zeigten [74 Fälle]).

Wie kommt diese Mydriasis zustande?

Zunächst sei festgestellt, daß in allen den vorhin genannten Fällen mit Mydriasis, wenn auch weniger deutlich als in der. Norm, die Erweiterungsreaktion auf Schmerzreize erhalten war; bei ganz wenigen Kranken (2) zeigte sich auch noch ein geringer Ausschlag der Iris auf sensorische Reize hin, während bei der verlangten Rechenarbeit keine 
deutlichen Oscillationen der Regenbogenhaut zu sehen waren und die Pupillenunruhe fehlte. Die Ḱniesehnenreflexe waren durchweg erhalten, in 2 Fällen gesteigert.

Nehmen wir die Kranken aus, bei denen mit der reflektorischen Starre (auch die, welche eine Lichtreaktion bis zu 0,5 mm Pupillenverengerung zeigten, sind hier mitgezählt) weder eine Miosis noch eine Mydriasis verbunden war, so bleiben uns 52 Fälle übrig, bei denen die Pupillenweite zwischen 2,0 und 4,5 mm schwankte, wenn beide Augen einem Lichte von ca. 270 MK. Stärke ausgesetzt waren.

Hierunter fanden sich nur 4 Fälle von Tabesparalyse, bei denen Pupillengrößen von 2,3-3,6 $\mathrm{mm}$ gemessen wurden.

15 Kranke ließen keine Besonderheiten der Erregbarkeit der Kniesehnenreflexe erkennen und zeigten Pupillendurchmesser von 3,9 bis $4,5 \mathrm{~mm}$.

Bei 33 Fällen mit gesteigerten Sehnenreflexen fanden sich Pupillengrößen von $2,8-4,5 \mathrm{~mm}$.

Nur bei 12 der Kranken, deren Pupillen weder miotisch noch mydriatisch zu nennen waren, und bei denen sich bei der Belichtung der Augen noch geringe (bis $0.5 \mathrm{~mm}$ ) Ausschläge an der Irismuskulatur erkennen ließen, waren die Erweiterungsreaktionen auf sensible, sensorische und psychische Reize wenigstens andeutungsweise vorhanden, bei 7 weiteren noch in ganz geringem Maße die Erweiterung auf sensible Reize zu sehen, während die Iris bei geistiger Arbeit und auf sensorische Reize unbeweglich blieb.

Wir konnten also feststellen, daß eine Mydriasis bei vollkommener reflektorischer Lichtstarre bei unseren Untersuchungen nicht vorkam, da $\beta$ ferner bei den Fällen mit mydriatischen Pupillen die Reaktion auf sensible Reize zwar verringert, aber vorhanden war, während die anderen Erweiterungsreaktionen fehlten (ausgenommen bei 2 Kranken). Dagegen fehlten die Pupillenbewegungen auf psychische und sensible Reize bei der größten Mehrzahl der Kranken, die engere Pupillen hatten und bei allen, deren Pupillen miotisch zu nennen waren.

Nach alledem scheint mir eine Erklärung des Zustandekommens der Mydriasis bei reflektorisch starren Pupillen in einem Erhaltensein der Dilatatorinnervation, deren Tonus beim Wegfall der Sphinctererregung mit Wahrscheinlichkeit anwächst, zu suchen zu sein. $\mathrm{Ob}$ diese Tätigkeit des Dilatators in den Fällen, bei denen noch eine den Sphincter hemmende Wirkung durch psychische Einflüsse möglich war, noch dadurch unterstützt wird, wage ich nicht zu entscheiden, die Möglichkeit läßt sich jedoch kaum von der Hand weisen.

Anisokorie. Eine weitere, sehr häufig im Verein mit der reflektorischen Pupillenstarre beobachtete Erscheinung ist die Ungleichheit der Pupillen. Es steht zweifellos fest, daß Unterschiede in der Pupillen- 
größe beider Seiten auch beim völlig gesunden Menschen vorkommen können; ich selbst fand sie bei zweien meiner gesunden Versuchspersonen. Die Ungleichheit der Pupillen dürfte hierbei vielleicht nicht anders zu deuten sein als eine Ungleichheit der Gesichtshälften, als Asymmetrien der Ohren usw. Andere Gründe hat jedoch die Anisokorie bei Nervenkrankheiten, indem hier zumeist Innervationsstörungen der Irismuskulatur das veranlassende Moment darstellen werden.

Nachdem wir gesehen haben, daß die verschiedenartige Stärke der Störung der Dilatatorinnervation einerseits und des Sphinctertonus andererseits bei der reflektorischen Pupillenstarre die verschiedensten Grade von Pupillenweite und Pupillenenge erzeugen kann, darf es uns nicht wundern, wenn wir die von allen Autoren betonte 'Tatsache vor uns sehen, daß bei der reflektorischen Starre sehr häufig zugleich Größenverschiedenheiten der Pupillen beobachtet werden.

Ich fand bei meinen Kranken mit reflektorischer Starre $19 \mathrm{mal}$ Pupillenungleichheit, d. h. also in ca. $26 \%$ der Fälle. Dabei ist eine Belichtung der Augen mit starkem Licht (ca. 270 MK.) vorausgesetzt. Bei einer Anzahl der Fälle (11) glich sich die Anisokorie aus, wenn die Augen verdunkelt, d. h. einem Licht von nur ca. $6 \mathrm{MK}$. Stärke ausgesetzt wurden, indem die kleinere Pupille ebenso weit wurde wie die größere. Bei den anderen bestand die Pupillenungleichheit auch bei wechselnder Belichtung fort.

Während demnach bei den erstgenannten Fällen die Anisokorie dadurch bedingt sein dürfte, daß die Störung der Lichtreaktion auf einem Auge weiter fortgeschritten war, als auf dem anderen, läßt sich der Pupillenunterschied bei der anderen Gruppe vielleicht aus einem verschieden starken Tonus der Dilatatorinnervation erklären, indem dieser auf der einen Seite (engere Pupille) nachgelassen hätte. Meine Hoffnung, der Lösung dieser Frage durch Vergleich der Ausschläge an beiden Pupillen bei sensibler Reizung näher zu kommen, erfüllte sich nicht, da es nicht möglich erschien, bei der Geringfügigkeit dieser Bewegungen Größenvergleiche anzustellen. Hier könnte an geeigneten, genau untersuchten Fällen vielleicht die anatomische Untersuchung eine Klärung bringen, doch davon weiter unten.

Auf Tonusänderungen der Irismuskeln dürfte auch der von Levin sohn und Arndt'), Albrand ${ }^{2}$ ) und $\mathrm{Bach}^{3}$ ) beobachtete Vorgang beruhen, daß die Weite der reflektorisch starren Pupillen wechseln

1) Levinsohn und Arndt, Uber die Einwirkung der gebräuchlichen Pupillenreagentien auf pathologische Pupillen. Deutsche Zeitschr. f. Nervenheilk. 20, 397. 1901.

2) Albrand, W., Utber wechselnde Pupillenweite und wechselnde Pupillenungleichheit bei Geisteskranken. Ref. Neurol. Centralbl. 1906, 423.

3) Bach, L., Pupillenlehre S. 121. 
kann, indem an verschiedenen Tagen die Pupillendurchmesser bald größer, bald kleiner gefunden werden. Auch ich konnte bei mehreren Kranken feststellen, daß die lichtstarren Pupillen nicht dauernd dieselbe Weite beibehielten.

Lidschlußseaktion. Bei der reflektorischen Starre kann man vielfach sehr gut die Lidschlußreaktion beobachten, da hier der sonst störende Finfluß der beim Öffnen der Augen das Orbicularisphänomen verdeckenden Lichtreaktion wegfällt. Die Lidschlußreaktion bei reflektorischer Starre ist jedoch keineswegs immer zu beobachten, vielmehr fast nur dann, wenn die Pupillen ziemlich weit sind. Andererseits tritt sie oft in überraschend deutlicher Weise zutage, so daß ein Augenzwinkern genügt, sie auszulösen. In solchen Fällen ist äußerste Vorsicht bei der Untersuchung geboten, da diese Reaktion einen Lichtreflex vortäuschen kann.

Störungen der Erweiterungsreaktionen. Bei der Besprechung des Vorkommens von Miosis und Mydriasis bei reflektorischer $\mathrm{Pu}$ pillenstarre haben wir schon einen Teil der dabei mitspielenden Einwirkungen der Erweiterungsreaktionen kennen gelernt. Es erübrigt hier nur noch eine Zusammenstellung aller Störungen dieser Pupillenbewegungen, die im Zusammenhang mit der reflektorischen Starre vorkommen.

$\operatorname{Er}^{\mathbf{1}}{ }^{1}$ ) stellte zuerst systematische Untersuchungen über die Reaktion reflektorisch starrer Pupillen auf sensible Reize bei Tabeskranken an. Er fand, daß bei diesen Kranken, wenn sie reflektorisch starre Pupillen aufwiesen, selbst bei stärksten faradischen Reizen keine Erweiterung der Pupillen eintrat.

Moeli' ${ }^{2}$ ) bestätigte diese Befunde, indem er bei 10 Tabeskranken auf starke Schmerzreize hin nur einmal die Pupillen sich minimal erweitern sah. Er fand bei paralytischen Männern mit fehlender Lichtreaktion in $65 \%$, bei paralytischen Frauen in $50 \%$ der Fälle keine Erweiterung auf sensible Reize. Leider finden sich in der Arbeit von Moeli keine Angaben über die Pupillenweiten.

Bei meinen Untersuchungen stellte sich, wie zum Teil schon dargelegt wurde, zunächst heraus, daß die sensible Reaktion bei allen Tabesparalysen mit miotischen Pupillen fehlte, daß sie ferner bei 35 paralytischen Kranken, deren Pupillengröße nicht wesentlich von den in der Norm vorkommenden abwich, nicht auszulösen war, dagegen in keinem Falle mit Mydriasis ganz vermißt wurde. Zu betonen ist jedoch, daß auch da, wo die Reaktion noch auslösbar war (ca. $46 \%$ der Fälle) der

1) Erb, W. Über spinale Miosis und reflektorische Pupillenstarre. Universitätsprogramm. Leipzig 1880.

2) Moeli, C., Die Reaktion der Pupillen Geisteskranker bei Reizung sensibler Nerven. Arch. f. Psychiatrie 3, 602. 1882. 
Ausschlag der Irismuskulatur viel geringer war als unter normalen Verhältnissen.

Die Reaktion auf sensorische und psychische Reize wurde bei der größten Mehrzahl der Kranken mit reflektorischer Starre vermißt, sie fand sich nur andeutungsweise bei 1.4 Paralytikern erhalten, $d . i$. in ca. 19\% der Fälle, und zwar nur bei solchen Leuten, deren Pupillen nicht völlig lichtstarr waren, die rielmehr noch geringe Reaktionen, bis zu $0,5 \mathrm{~mm}$ Irisausschlag, erkennen ließen.

Bei völliger reflektorischer Starre fehlte regelmäßig die Erweiterung auf sensorische und psychische Reize und nur bei einigen wenigen Personen war die sensible Reaktion angedeutet.

Wir gehen daher wohl nirht fehl, wenn wir annehmen, daß die Reaktion auf psychische und sensorische Reize bei der reflektorischen Starre nur sehr selten erhalten ist, eine Feststellung, die auch wesentlich zur Stütze der 'Theorie dienen kann, daß die Erweiterung auf sensorische und psychische Reize als Folgeerscheinung einer Hemmung der Sphincterinnervation aufzufassen ist. Ferner zeigte sich, daß die Reaktion auf rein sensible Einwirkungen häufiger erhalten bleibt, was wohl dafür spricht, daß diese Reaktion nicht allein durch Hemmung des Sphinctertonus zustande kommt, sondern in einer Erregung des Dilatators mit ihre Ursache hat. Die Verminderung des Ausschlages dieser Bewegung unter dem Einflusse der reflektorischen Starre weist darauf hin, daß bei der Reaktion unter normalen Verhältnissen eine Hemmung des Sphinctertonus zugleich mit der Dilatatorerregung vor sich gehen muß.

Vorläufer der reflektorischen Starre. Verringerung der Ausgiebigkeit der Irisbewegung bei Belichtung. Stellen wir ausgedehnte Untersuchungen bei Krankheitsformen an, bei denen das Symptom der reflektorischen Starre erfahrungsgemäß häufig vorzukommen pflegt, z. B. bei der Paralyse, so finden wir wohl eine größere Anzahl Kranker, bei denen die reflektorische Pupillenstarre in ausgeprägtester Weise festzustellen ist, daneben aber eine noch größere Gruppe, die zunächst nur eine Einschränkung der Lichtreflexbewegung erkennen ]äßt. Wir sprechen dann von einer wenig ausgiebigen Lichtreaktion. Durch die Erfahrung haben wir gelernt, diese Störung als sehr bedeutsam zu betrachten, da sie oft nur das Vorstadium einer später eintretenden reflektorischen Pupillenstarre darstellt. Allerdings kann auch nicht genug davor gewarnt werden, eine anscheinend schlechte Pupillenreaktion auch dann für bedeutsam zu halten, wenn die Untersuchung nicht unter den nötigen Vorsichtsmaß3regeln vorgenommen wurde. Meines Erachtens sollte man in Fällen, bei denen nach der gewöhnlichen Pupillenuntersuchung eine Einschränkung der Lichtreaktion vorhanden zu sein scheint, nie ein bestimmtes Urteil fällen, bevor der 
Kranke nicht im Dunkelzimmer untersucht ist, nachdem seine Augen an die Dunkelheit adaptiert waren.

Findet man auch dann noch die Lichtreaktionsbewegung nur wenig ausgiebig, d. h. ist die Irisbewegung wesentlich kleiner, als sie unter Berücksichtigung des Alters der Versuchsperson zu erwarten stand, während die Konvergenzreaktion in der ausgiebigsten Weise erfolgt, so darf man annehmen, daß hier die ersten Zeichen einer beginnenden reflektorischen Starre sich darbieten.

Viel sicherer wird natürlich unser Urteil, wenn wir uns bei der Untersuchung eines Meßapparates bedienen, der uns eine objektive Festlegung der Verhältnisse gestattet.

Bei Untersuchungen, welche ich an $\mathbf{5 5 0}$ paralytischen Männern und Frauen unter Benutzung der einfachen elektrischen Handlampe, die ich im technischen Teil darstellte, vornahm, fand ich in ca. $29 \%$ der Fälle vollkommene reflektorische Starre, in weiteren $14 \%$ war die Größe der Reflexbewegung wesentlich eingeschränkt, so daß in $43 \%$ der Fälle entweder eine reflektorische Starre vollständig ausgebildet oder doch in der Entstehung begriffen war. Viele dieser Kranken kamen nach mehr oder weniger langen Z wischenräumen nochmals zur Untersuchung, und dabei fand sich dann oft an der Stelle der früheren unvollkommen reflektorischen Starre, der wenig ausgiebigen Lichtreaktion, ein Fehlen jeglicher Irisbewegung beim Lichteinfall ins Auge. Dadurch bestätigte sich die Richtigkeit unserer Annahme, daß die eingeschränkte Lichtreaktion als Vorläufer der reflektorischen Starre zu betrachten ist. Besonderes Gewicht ist dabei aber immer darauf zu legen, daß die Konvergenzreaktion nichts von ihrer Stärke eingebüßt hat.

Mit Rücksicht auf diese Tatsachen und Erfahrungen stellte ich schon weiter oben die Pupillen, welche nur noch mit einer Verengerung von nicht mehr als $0, \overline{0} \mathrm{~mm}$ auf Lichteinfall reagierten, in eine Reihe mit den völlig reflektorisch starren.

Bei meinen Messungen an paralytischen Kranken fand ich nur in ca. $15 \%$ der Fälle eine vollständige reflektorische Starre, in weiteren $27 \%$ verengerte sich die Pupille bei der Lichtreaktion um nicht mehr als $0,5 \mathrm{~mm}$. Wie ich bei der Besprechung der normalen Verhältnisse darstellte, sank die Ausschlaggröße der Lichtreaktion nach beiderseitiger Bestrahlung mit starkem Licht nicht unter $1,2 \mathrm{~mm}$. Wir dürften demnach berechtigt sein, die Lichtreaktionsbewegung auch dann noch als unausgiebig, d. h. pathologisch verändert in bezug auf ihre Ausschlaggröße zu bezeichnen, wenn diese nicht mindestens $1 \mathrm{~mm}$ beträgt. In 13\% meiner Fälle schwankte die Größe der Verengerungsreaktion zwischen 0,5 und $0,9 \mathrm{~mm}$, so daß wir demnach einerseits bei $15 \%$ der Untersuchten eine vollständige reflektorische Starre feststellen konnten, der andererseits $42 \%$ mit eingeengter Reaktion gegenüberstehen. Wir 
sehen also, daß bei einer relativ großen Anzahl der Fälle die reflektorische Starre erst in ihrem Vorstadium festgestellt werden konnte. Die Untersuchungsresultate bei der einfachen Prüfung der Reaktion mit der Handlampe und bei der genauen Messung weichen insofern voneinander ab, als sich bei der Messung häufiger noch eine kleine Bewegung der Iris feststellen ließ, die der Beobachtung ohne Vergrößerungsinstrument entging. Bei einigen der Kranken ging die anfangs noch vorhandene geringe Lichtreaktion im Verlaufe einiger Wochen verloren, so daß unter unseren Augen aus der schlechten, unausgiebigen Reaktion eine reflektorische Starre entstand. Das Symptom der unausgiebigen Reaktion dürfte daher, wenn bei der Untersuchung die nötigen Vorsichtsmaßregeln angewendet wurden, gleichbedeutend mit der reflektorischen Starre sein.

Verlangsamtes Eintreten der Lichtreaktion. Außer von einer wenig ausgiebigen Reaktion sprechen wir bekanntlich auch von einer ,trägen" Lichtreaktion, und zwar dann, wenn wir bezeichnen wollen, daß die Iriskontraktion langsamer als gewöhnlich vor sich geht. Die Bestimmung, ob die Dauer einer Bewegung größer oder kleiner ist, mag leicht sein, wenn der von dem bewegten Körper zurückgelegte Weg in den zum Vergleich stehenden Fällen wenigstens annähernd gleichgroß ist; es gehört aber eine sehr große Utbung dazu, einigermaßen sichere Schätzungen über die mehr oder weniger lange Dauer von Bewegungsvorgängen anzustellen, wenn die Länge der zurückgelegten Wegstrecken verschieden groß ist. Eine Bewegung, die in derselben Zeit eine kürzere Bahn durchläuft als eine andere, scheint uns zugleich längere Zeit in Anspruch zu nehmen als diese, da wir nicht die absolute Dauer der Bewegung schätzen, sondern die Geschwindigkeit der bewegten Körper miteinander vergleichen. Wenn wir demnach eine Lichtreaktion als träge ansprechen, so sagen wir damit nicht, daß die Kontraktionszeit der Iris länger ist wie sonst, sondern daß der Muskel sich langsamer zusammenzieht, da $\beta$ die Kontraktionsgeschwindigkeit vermindert ist.

Um ein objektives Urteil über die tatsächlichen Verhältnisse zu gewinnen, stellte ich bei einer größeren Anzahl der Fälle von Paralyse (21), die noch eine deutliche, aber träge Lichtreaktion erkennen ließen, Messungen der zur Iriskontraktion verwandten Zeit an und fand die absoluten Zeitwerte nicht wesentlich verlängert gegenüber der Norm. Die Zeit zwischen Reiz und Ende der Verengerungsbewegung schwankte zwischen 0,82 und 1,14 Sek. Während bei der normalen Lichtreaktion die Bestimmung mittels des Chronoskopes recht einheitliche Resultate ergab, indem die bei den einzelnen Messungen gefundenen Werte nicht wesentlich voneinander abwichen, war dies bei der eingeschränkten Bowegung schlecht reagierender Pupillen nicht mehr der Fall. Hier 
war die Fehlerbreite sehr viel größer, was offenbar in der größeren Schwierigkeit, das Ende der kurzwegigen Bewegung zu sehen, begründet war. Es erscheint mir daher unangebracht, diese Meßresultate besonders hoch zu bewerten. Fines jedoch dürfte sicher feststehen, daß die Geschwindigkeit der Iriskontraktion wenigstens in vielen Fällen von Paralyse, die noch einen leidlichen Aussehlag der Pupillen bei der Belichtung erkennen lassen, stark herabgesetzt ist. Es ist nun sehr mißlich, aus den Zahlen, die sich bei der Zeitmessung ergeben, wenn man berechnet, wie lange es dauert, bis die durch den Lichtreiz bewegte Iris wieder zum Stillstand gekommen ist, die Geschwindigkeit der Kontraktion zahlenmäßig zu berechnen, ohne die Latenzzeit dieses Vorganges dabei zu berücksichtigen. Bei der Pupillenbewegung hat eine derartige Bestimmung schon deshalb nur einen sehr zweifelhaften Wert, weil die Latenzzeit unter normalen Verhältnissen schon einen großen Bruchteil (ca. 1/3) der zur Kontraktion verbrauchten Zeit ausmacht. Ich versuchte daher, mir wenigstens bei einigen Fällen ein Urteil über die Dauer der Latenzzeit zu verschaffen, indem ich kinematographische Aufnahmen machte. Bei 5 Paralytikern fand ich in 3 Fällen eine deutliche Verlängerung der Zeit zwischen Belichtung und Beginn der Pupillenverengerung, ich berechnete diese auf $0,36-0,43$ Sek., während bei 2 Kranken nur Zeiten von 0,18 und 0,24 Sek. feststellbar waren.

Danach scheint einerseits in gewissen Fällen die Latenzzeit bei schlecht reagierenden Pupillen verlängert, andererseits aber auch die Geschwindigkeit der Kontraktionsbewegung der Iris verlängert zu sein.

Um hier Klarheit zu schaffen, bedarf es noch einer sehr großen Anzahl von Versuchen, die Bewegungen ,träge" reagierender Pupillen mittels der photographischen Methode zu registrieren. Dabei möchte ich nicht unterlassen zu betonen, daß es auch an den kinematographischen Aufnahmen sehr schwer fällt, den Zeitpunkt zu bestimmen, bei dem die Pupille anfängt kleiner zu werden, da die gesamte Irisbewegung nur sehr gering ist und, soviel ich dies aus den wenigen Aufnahmen beurteilen kann, ganz allmählich, schleichend beginnt.

Wenn wir demnach wohl kaum fehlgehen mit der Annahme, daß bei der sog. ,trägen“ Pupillenreaktion sowohl die Latenzzeit verlängert wird, wie auch die Geschwindigkeit der Irisbewegung vermindert ist, so dürfte doch für den praktischen Gebrauch die Feststellung, daß der Ausschlag der Bewegung geringer ist als in der Norm, viel wichtiger sein als die Schätzung, ob die Bewegung rasch oder langsam abläuft.

Schnelles Nachlassen des Iristonus. Durch die Belichtung der Netzhaut wird, wie wir gesehen haben, eine tonische Kontraktion des Sphincters erzeugt. Unter normalen Verhältnissen geht dieser Tonus allmählich etwas zurück, je nach dem Adaptationszustand der Retina. Bei manchen Fällen von Paralyse kann man jedoch die Beobachtung 
machen, da $\beta$ die auf Lichteinfall eintretende Pupillenverengerung trotz fortdauernder Belichtung nur ganz kurze Zeit bestehen bleibt und einer Érweiterung der Pupille Platz macht. Läßt man das Untersuchungslicht fortwirken, so zieht sich die Iris nach mehr oder weniger langer Zeit wieder zusammen und das Spiel wiederholt sich.

Diese Erscheinung ist nach meinen Beobachtungen nicht sehr häufig, doch konnte ich in zwei Fällen sehen, daß sich nach Monaten an ihrer Stelle eine reflektorische Pupillenstarre entwickelt hatte. Es dürfte sich demnach empfehlen, diesem Phänomen Beachtung zu schenken und seine Weiterentwicklung zu verfolgen.

Die Ursache für diese Erscheinung dürfte wohl in einer gesteigerten Ermüdbarkeit der den Reflex vermittelnden Elemente zu suchen sein, indem der Reiz zwar zunächst einen ausgiebigen Erfolg hat, dagegen nicht imstande ist, für längere Zeit die Tonuserhöhung zu erhalten; die Empfindlichkeit nimmt offenbar sehr rasch ab. Es dauert dann geraume Zeit, bis so weit Erholung eingetreten und die Reizschwelle so stark gesunken ist, daß wieder eine Wirkung des Lichtreizes zustande kommt.

Fehlen der sekundären Reaktion. Zu den Erscheinungen, die als Vorläufer der reflektorischen Starre zu betrachten sind, gehört endlich noch das Fehlen der sekundären Reaktion. Bei meinen an paralytischen Kranken angestellten Messungen fiel mir auf, daß auch dann, wenn noch eine Bewegung der Iris bei Lichteinfall zu sehen war, sehr häufig die sekundäre Reaktion fehlte. Bei einer Zusammenstellung meiner Meßresultate zeigte sich zunächst, daß diese Erscheinung nur bei paralytischen Kranken zur Beobachtung kam, also bei einer Erkrankung, zu deren Symptomenkomplex vornehmlich die reflektorische Pupillenstarre gehört.

Im Laufe der Zeit konnte ich dann auch bei einem Falle in ganz einwandsfreier Weise feststellen, daß die Pupillen, die zunächst in ihren Reaktionen nur dadurch von der Norm abwichen, daß die sekundäre Reaktion ausblieb, innerhalb von 4 Wochen reflektorisch starr wurden. Desgleichen sah ich verschiedene Kranke, die bei der ersten Untersuchung ebenfalls nur ein Fehlen der sekundären Reaktion erkennen ließen, nach längeren Zwischenräumen wieder, und nun waren die $\mathrm{Pu}-$ pillen lichtstarr.

Ich fand dieses Symptom bisher nur bei Kranken, bei denen die Konvergenzreaktion uneingeschränkt auslösbar war und möchte es aus diesem und den oben erwähnten Gründen für einen Vorläufer der reflektorischen Starre halten.

Seine Entstehungsursache liegt offenbar in einer Herabsetzung der Empfindlichkeit des Reflexzentrums, indem die Summierung der Reize bzw. die Verstärkung des Reizes nicht mehr von Erfolg begleitet 
ist, gerade wie ich bei meinen Untersuchungen des Kniereflexes ${ }^{1}$ ) beobachten konnte, daß bei gewissen Kranken mit vermindertem Reflexausschlag eine Verstärkung des Reizes nichts an der Größe der Reflexbewegung änderte.

Die Eintragungen in unser Schema würden bei der fehlenden Sekundärreaktion folgendermaßen aussehen.

\begin{tabular}{c|c|c||c|c|c|c|c|c|c|c|c|c}
\hline Name & Alt: & Datum & R I & II & III & IV & L I & II & III & IV & $\begin{array}{c}\text { Konvergenz- } \\
\text { reaktion }\end{array}$ \\
\hline R. K. & 31 & 14.V.06 & 4,0 & $\mathbf{3}, 3$ & 3,3 & 3,3 & 4,0 & 3,3 & 3,3 & 3,3 & $\mathrm{R}+\mathrm{L}+$ \\
\hline
\end{tabular}

Psych. Reaktion $\mid$ Schmerz R $\varnothing \mathrm{L} \varnothing$; Schreck R0 L0; Geist. Arb. R0 L0.

Bemerkungen: $\varnothing=$ gering.

Einseitige reflektorische Starre. Nachdem wir die Begleiterscheinungen des Robertsonschen Zeichens und seine Vorstadien kennen gelernt haben, bleibt uns nur noch eine besondere Form desselben zu besprechen, die einseitige reflektorische Starre. Wenn auch vielfach die Ausbildung der Lichtstarre an beiden Augen nicht gleichstark erscheint, so gehört es doch zu den größten Seltenheiten, daß die Pupille eines Auges reflektorisch starr ist, während an dem anderen Auge gar keine Störungen der Irisinnervation nachweisbar sind. Daß eine rein einseitige reflektorische Starre vorkommt, wurde erst in den letzten 20 Jahren bekannt $\left(\operatorname{Heddaeus}^{2}\right)$, Seggel $\left.\left.{ }^{3}\right)^{4}\right)$, Schanz $\left.{ }^{5}\right)$ u. a.). Bei dem großen theoretischen Interesse, daß dieser Erscheinung zukommt, will ich nicht verfehlen, über den einzigen Fall, den ich gelegentlich meiner Pupillenstudien fand, zu berichten.

Eine 44jährige Klavierlehrerin wurde anfangs Januar 1907 wegen eines Rauschzustandes in die Klinik verbracht. Bei der am nächsten Tage vorgenormmenen Untersuchung bot sie folgenden Pupillenbefund. Die linke Pupille war größer als die rechte. Sie reagierte weder direkt noch konsensuell auf Lichteinfall. Die Pupille des rechten Auges dagegen zeigte ganz normale Lichtreaktion, sie verengerte sich auch bei Belichtung des linken Auges. Die Konvergenzreaktion war beiderseits gut erhalten. Der Augenhintergrund war normal, das Gesichtsfeld intakt, die zentrale Sehschärfe $=4 / 5$ der normalen. Es bestand kein zentrales Skotom. Die Kniesehnenreflexe waren gesteigert. Druck auf die großen Nervenstämme und die Wadenmuskulatur wurde als schmerzhaft angegeben, die Hände

1) Weiler, K., Untersuchung des Kniesehnenreflexes beim Menschen. Zeitschr. f. d. ges. Neurol. u. Psych. Orig. 1, 157. 1910.

2) Heddaeus, Ủber einseitige reflektorische Pupillenstarre. Arch. f. Augenheilk. 2r, 1.

3) Seggel, Ein Fall einseitiger reflektorischer Pupillenstarre. Arch. f. Augenheilk. 26, 293. 1892.

4) Derselbe, Ein weiterer Fall einseitiger reflektorischer Pupillenstarre. Arch. f. Augenheilk. 31, 63.1895.

5) Schanz, Drei Fälle einseitiger reflektorischer Pupillenstarre. Arch. f. Augenheilk. 31. 259. 1895. 
und die Zunge zitterten beim Vorstrecken. Im übrigen fanden sich auf körperlichem Gebiet keine Abweichungen von der Norm, besonders auch keine Sensibilitätsstörungen. Es wurde eine Lumbalpunktion vorgenommen; der Zellgehalt. der Spinalflüssigkeit war nicht vermehrt.

Die Untersuchte gab noch an, daß sie in ihren zwanziger Jahren öfter an Weinkrämpfen und Ohnmachtsanfällen gelitten und sich luetisch infiziert habe. Seit den dreißiger Jahren habe sie keine Krämpfe mehr gehabt. Durch Verschulden ibres Mannes vermögenslos geworden, spiele sie seit einigen Jahren in Wirtschaften und trinke gelegentlich ziemlich viel.

In psychischer Hinsicht bot die Untersuchte keine Anzeichen dar, die den Verdacht auf Paralyse oder Hirnlues gerechtfertigt hätten. Sie wurde 11 Tage lang in der Klinik verpflegt; bei ihrer Entlassung bestand die einseitige reflektorische Pupillenstarre noch unverändert fort. Die Muskulatur war nicht mehr druckempfindlich, das Zittern der Zunge und der Hände verschwunden.

Ich sah die Untersuchte Anfang Dezember desselben Jahres wieder. Die Pupillenstörung war unverändert geblieben, dagegen fehlten jetzt beide Kniesehnenreflexe. Die serologische Untersuchung des Blutes ergab einen positiven Ausfall der Wassermannschen Luesreaktion (untersucht von Herrn Dr. Plaut).

Ich gebe nun die bei der Messung der Pupillen gefundenen Resultate wieder.

\begin{tabular}{|c|c|c|c|c|c|c|c|c|c|c|c|}
\hline Name & Alt: & Datum & R I & II & III & IV & L I & II & III & IV & $\begin{array}{c}\text { Konvergenz- } \\
\text { reaktion }\end{array}$ \\
\hline \multirow[t]{2}{*}{ A. B. } & 44 & 17. I. 07 & 4,6 & 3,3 & 3,0 & 3,3 & 4,6 & 4,6 & 4,6 & 4,6 & $\mathrm{R}+\mathrm{L}+$ \\
\hline & & 2. XII. 07 & 5,9 & 4,7 & 4,4 & 4,7 & 5,9 & 5,9 & 5,9 & 5,9 & $\mathrm{R}+\mathrm{I}+$ \\
\hline \multirow{2}{*}{\multicolumn{2}{|c|}{ Psych. Reaktion }} & 12. I. 02 & \multicolumn{9}{|c|}{$\begin{array}{c}\text { Schmerz } \mathrm{R}+\mathrm{L} \varnothing ; \text { Schreck } \mathrm{R}+\mathrm{L} 0 ; \\
\text { Geistige Arbeit } \mathrm{R}+\mathrm{L} \varnothing .\end{array}$} \\
\hline & & 2. XI & \multicolumn{9}{|c|}{ 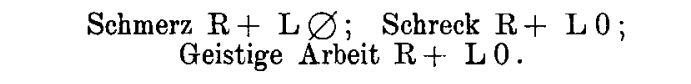 } \\
\hline
\end{tabular}

Aus der Tabelle geht deutlich hervor, daß die linke Pupille sich beim Lichteinfall ins linke oder auch ins rechte Auge nicht veränderte, dagegen gut bei der Konvergenzbewegung. Die Pupille des rechten Auges reagierte sowohl direkt, wie konsensuell und bei der Konvergenz, auch die sekundäre Reaktion fehlte hier nicht. Interessant ist noch die Tatsache, daß die Größe der Pupillen bei den beiden Untersuchungen, die ca. $1 \mathrm{Jahr}$ auseinanderlagen, verschieden war. Die Differenz betrug sogar 1,3 mm. Die Ausschlaggröße der rechten Pupille auf Lichteinfall hatte sich dabei gar nicht verändert. Außerdem sehen wir in dem vorliegenden Fall noch, daß die bei der gewöhnlichen Untersuchung festgestellte Pupillenungleichheit verschwand, wenn die Beleuchtung auf ca. 6 MK. herabgesetzt wurde, wobei die auf Licht reagierende $\mathrm{Pu}-$ pille geradeso weit wurde wie die des anderen Auges. Die Reaktion auf sensible, sensorische und psychische Reize war an der rechten $\mathrm{Pu}$ pille erhalten, links fehlten die Bewegungen bei sensorischen und psy- 
chischen Reizen ganz, bei starken Schmerzreizen zeigte sich noch eine minimale Erweiterung der Pupille.

Das Wesen der reflektorischen Starre. Fassen wir zunächst kurz zusammen, was unsere Untersuchungen an Fällen mit reflektorischer Pupillenstarre ergaben, so können wir folgendes sagen.

Eine Pupille ist als reflektorisch starr zu betrachten, wenn sie auf Belichtung desselben wie auch des anderen Auges entweder gar nicht reagiert, oder aber der Irisausschlag sehr hinter der beim Normalen vorkommenden Größe zurückbleibt, während die Konvergenzreaktion in unveränderter Stärke auslösbar ist. Zeigt sich dieser Symptomkomplex an beiden Augen, so dürfen wir nicht eher von reflektorischer Starre reden, bis wir uns vergewissert haben, daß eine beiderseitige Reflextaubheit nicht besteht. Fast gleichbedeutend mit reflektorischer Starre dürfte auch der Zustand sein, in dem die Pupillenbewegung bei der Lichtreaktion sehr verlangsamt ist, oder wenn sich bei genauen Messungen herausstellt, daß die Latenzzeit wesentlich verlängert ist, oder endlich, wenn die sekundäre Reaktion fehlt, alles natürlich unter der Voraussetzung, daß die Konvergenzreaktion völlig intakt ist. Als Begleiterscheinungen der reflektorischen Starre finden sich häufig Veränderungen der Pupillenweite, Miosis, Mydriasis und Ungleichheit der Pupillen, ferner Störungen der normalerweise auftretenden Pupillenerweiterungsreaktionen. Bestand völlige reflektorische Starre, so fehlten regelmäßig die Reaktionen bei sensorischen und psychischen Reizen, die sensible Erweiterungsreaktion war in einigen Fällen noch andeutungsweise vorhanden. Besser war sie an nicht völlig starren Pupillen zu sehen, die dann auch hie und da noch ein Größerwerden auf sensorische und psychische Reize hin erkennen ließen. Im allgemeinen jedoch war eine Herabsetzung der Erweiterungsreaktionen festzustellen. Besonders bemerkenswert scheint mir der Umstand zu sein, daß bei den reflektorisch starren, miotischen Pupillen der Tabesparalysen die sensible Reaktion immer fehlte, während sie bei der Vereinigung von Mydriasis und Lichtstarre immer, wenn auch nur in geringem Grade, fortbestand. Wir konnten endlich noch bestätigen, daß eine rein einseitige reflektorische Starre vorkommt.

Wie wir bereits weiter oben betont haben, kennen wir zurzeit die pathologisch-anatomischen Ursachen der reflektorischen Starre nicht. Es wurde zwar vielfach nach dem Sitz der sie veranlassenden Veränderungen gesucht, man durchforschte die Gegend der Vierhügel und des Oculomotoriuskerns, man durchsuchte, besonders in neuerer Zeit, das Halsmark, ohne jedoch zu einwandfreien Resultaten zu kommen. Ebensowenig Klarheit brachten experimentelle Untersuchungen.

Da ich mich selbst nicht mit pathologisch-anatomischen Forschungen in dieser Richtung beschäftigt habe, maße ich mir in diesen Dingen kein 
Urteil an und ich verweise hier auf die besonders bei Bumke ${ }^{1}$ ), Tren delenburg $\left.{ }^{2}\right), \mathrm{Bach}^{3}$ ) und $\mathrm{Meyer}^{4}{ }^{5}$ ) gemachten Angaben und Literaturnachweise.

Wir wollen jedoch versuchen, unsere klinischen Erfahrungen in das von Liepmann entworfene Pupillenbahnenschema zu projizieren und sehen, $o b$ unsere Beobachtungen mit dem in diesem angenommenen

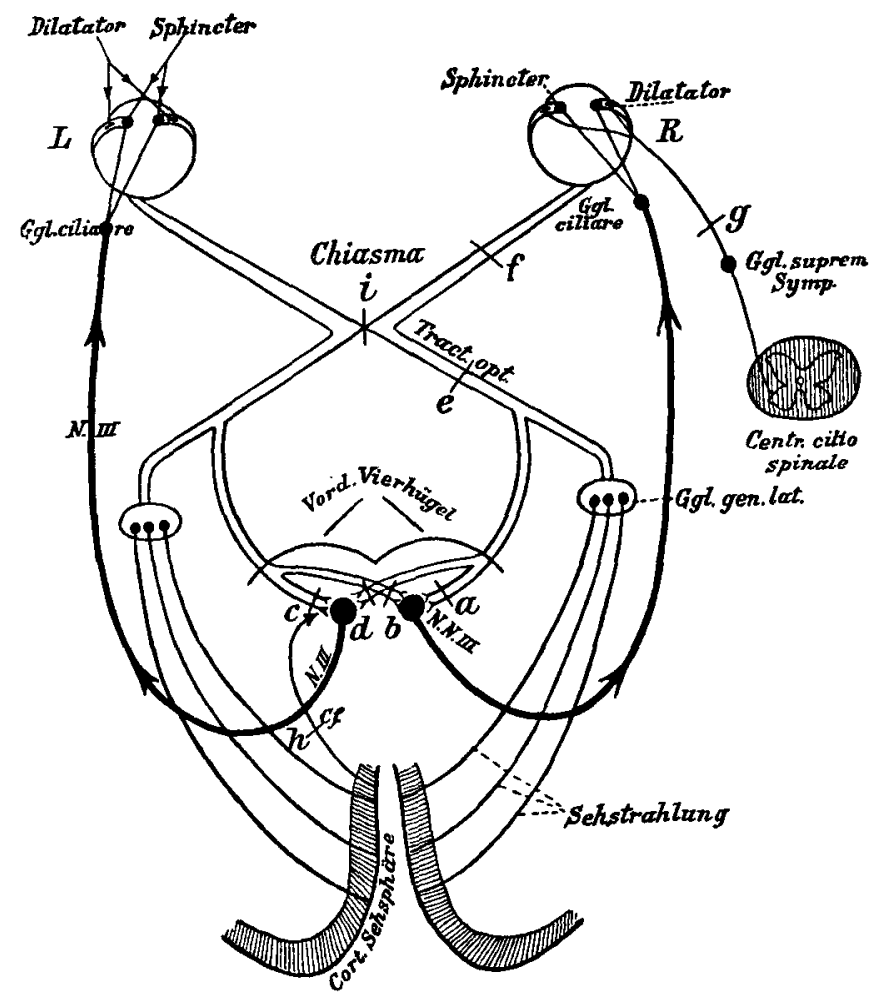

Fig. 42.

Verlauf der Lichtreflexbahn in Ubereinstimmung zu bringen sind. (Fig. 42.)

1) Bumke, Pupillenstörungen, 144.

2) Trendelenburg, W., und Bumke, O., Experimentelle Untersuchungen zur Frage der Bach-Meyerschen Pupillenzentren in der Medulla oblongata. Klin. Monatsblätter f. Augenheilk. 1907, 353.

3) Bach, L., Pupillenlehre, 132.

4) Bach, L. und Meyer, H., I. Experimentelle Untersuchungen über die Abhängigkeit der Pupillenreaktion und Pupillenweite von der Medulla oblongata et spinalis. II. Besprechung und schematische Erläuterung der Pupillenreflexbahn bei mono- und bilateraler Pupillenreaktion. v. Graefes Arch. 55, 414. 1903.

5) Derselbe, Weitere experimentelle Untersuchungen über die Beziehungen der Medulla oblongata zur Pupille. v. Graefes Arch. 56, 297. 1903. 
Am besten gehen wir dabei von der Voraussetzung aus, daß eine einseitige reflektorische Starre bestände. Eine Unterbrechung der Reflexbahn bei $a$ und $b$ würde eine reflektorische Starre der rechtsseitigen Pupille hervorrufen, diese würde weder direkt noch indirekt auf Lichtreiz reagieren, während sämtliche Reaktionen an der linksseitigen Pupille erhalten wären. Eine doppelseitige reflektorische Starre würde entstehen, wenn die Leitung außer bei $a$ und $b$ auch bei $c$ und $d$ unterbrochen ist. Eine Tractusläsion bei $e$ würde hemianopische Reflextaubheit zur Folge haben, eine Leitungsunterbrechung bei $f$ Reflextaubheit der rechtsseitigen Pupille entstehen lassen. Die Kombination einer Unterbrechung der Bahnen bei $a, b$ und der Sympathicusinnervation $(g)$ würde rechtsseitige reflektorische Pupillenstarre, verbunden mit einer Miosis erzeugen, während die Pupille eher mydriatisch erscheinen würde, wenn die Dilatatorinnervation ungestört bleibt.

Bei der völligen reflektorischen Starre würde eine Erregung von der Hirnrinde aus in der angenommenen Bahn $c f$ keinen Erfolg haben, da die Sphinctererregung fehlt, mithin nicht gehemmt werden kann. Ist dagegen die reflektorische Starre nur unvollständig ausgebildet, so wird sich die hemmende Wirkung der Rindenerregung noch zeigen können. Fehlt sie auch dann, so muß man eine Unterbrechung bei $h$ bzw. eine Unempfindlichkeit der Rindenregion für die entsprechenden Reize annehmen.

Demnach würde das gezeichnete Schema allen unseren sichergestellten klinischen Beobachtungen gestörter Pupillenreaktion, deren Ursache in einer Veränderung der zentripetalen Reflexbahn zu suchen ist, und auch der Tatsache, daß die konsensuelle Reaktion nach sagittaler Durchtrennung des Chiasmas (bei i) erhalten bleibt, gerecht werden. Wir müssen uns dabei zunächst damit begnügen, anzunehmen, daß die reflektorische Pupillenstarre in dem letzten Abschnitt des zentripetalen Teiles der Lichtreflexbahn ihren Sitz hat. Unsere klinischen Erfahrungen weisen jedoch darauf hin, daß in den Fällen, in denen die Lichtstarre von einer Miosis der Pupille begleitet ist, vielleicht auch Veränderungen des Halsmarkes eine Rolle spielen.

Es liegt außerhalb des Rahmens meiner Arbeit, die bisher vorliegenden Untersuchungen, die sich mit der Frage der Beteiligung von Veränderungen des Halsmarkes an der reflektorischen Starre beschäftigten, einer kritischen Betrachtung zu unterziehen, doch scheint mir der Hinweis beachtenswert, bei derartigen Untersuchungen, seien sie nun experimenteller Art oder handle es sich dabei um Durchforschung des Gehirns und Rückenmarkes Verstorbener, die reflektorische Pupillenstarre darboten, nicht nur die Pupillenstörung als solche, sondern auch die dabei beobachtete Weite so genau wie möglich festzustellen. Es liegt jedenfalls die Möglichkeit vor, daß da, wo Veränderungen im 
Halsmark nachweisbar sind, diese zwar nicht Ursache der reflektorischen Starre, wohl aber Ursache der Miosis sind. Wir dürfen dann kaum erstaunt sein, bei Rückenmarksuntersuchungen von Paralytikern bei einem Teil der Fälle starke Veränderungen im Halsmark anzutreffen, während ebendort bei anderen trotz früher festgestellter, reflektorischer Pupillenstarre keine anatomische Grundlage hierfür nachweisbar wäre.

Vorkommen der reflektorischen Starre. Mit der Frage, bei welchen Krankheitsformen die reflektorische Starre vorkommt, beschäftigte sich eine Reihe von statistischen Arbeiten. Die bedeutsamsten sind die vielfach zitierten Zusammenstellungen von Uhthoff, Moeli, Siemerling und Thomsen. Ich gebe die Beobachtungen dieser Autoren wieder, indem ich das ganz vereinzelt von ihnen festgestellte Vorkommen der reflektorischen Starre bei Hysterie, Epilepsie, Paranoia usw. unter die Gruppe „Andere“ zusammenfasse.

Uhthoff ${ }^{1}$ ) untersuchte 550 Nervenkranke der Charité und 12000 Augenkranke der Schoelerschen Augenluinik und fand in 137 Fällen „reflektorische Pupillenstarre auf Licht, eventuell auch auf Konvergenz and Akkommodation".

Thomsen ${ }^{2}$ ) stellte bei der Untersuchung von 1697 Geisteskranken in 205 Fällen reflektorische Pupillenstarre fest.

Von Sie merling $\left.{ }^{3}\right)^{4}$ ) liegen zwei Untersuchungsreihen vor, eine betraf 923 geisteskranke Frauen, von denen 79 reflektorische Pupillenstarre zeigten, die andere umfaßt ein Krankenmaterial von 9160 Geisteskranken der Charité, bei denen Si emerling in 1639 Fällen Lichtstarre fand. Ich habe in der folgenden Tabelle die beiden Statistiken in eine Rubrik zusammengezogen.

\begin{tabular}{|c|c|c|c|c|c|c|}
\hline \multirow[b]{2}{*}{ Krank heitsformen } & \multicolumn{2}{|c|}{ Uhthoff } & \multicolumn{2}{|c|}{ Thomsen } & \multicolumn{2}{|c|}{ Siemerling } \\
\hline & $\begin{array}{l}\text { Falle } \\
\text { refl. St. }\end{array}$ & $\%$ & $\begin{array}{l}\text { Falle } \\
\text { refl. St. }\end{array}$ & $\%$ & $\begin{array}{l}\text { Falle } \\
\text { refl. St. }\end{array}$ & $\%$ \\
\hline Paralyse & 12 & 8,8 & 172 & 83,8 & 1587 & 92,3 \\
\hline Tabes & 92 & 67,2 & 4 & 1,9 & 34 & 1,9 \\
\hline Lues & 11 & 8,1 & - & 一 & 19 & 1,1 \\
\hline Alkoholismus . . . . . & - & - & 14 & 6,8 & 17 & 0,9 \\
\hline Senile Demenz . . . & - & - & 4 & 1,9 & 21 & 1,2 \\
\hline $\begin{array}{l}\text { Cerebrale Erkrankungen } \\
\text { (ohne nachweisb. Lues) }\end{array}$ & 8 & 5,8 & 4 & 1,9 & 22 & 1,2 \\
\hline Andere . . . . . & 15 & 10,1 & 7 & 3,4 & 18 & 1,0 \\
\hline Paralyse, Tabes oder Lues & & 84,1 & & 85,5 & & 95,3 \\
\hline
\end{tabular}

1) Uhthoff, W., Zur diagnostischen Bedeutung der reflektorischen Pupillenstarre. Berl. klin. Wochenschr. 1886, 36.

2) Thomsen, Zur diagnostischen Bedeutung der Pupillenphänomene, speziell der reflektorischen Pupillenstarre, bei Geisteskranken. Charité-Annalen 11, 339. 1886. 
Als übereinstimmendes Ergebnis dieser Statistiken sehen wir die Tatsache vor uns, daß die reflektorische Pupillenstarre in $84-95 \%$ der Fälle bei Leuten vorkam, die entweder an Paralyse, Tabes oder Lues erkrankt waren. Bevor wir auf eine Kritik dieser Resultate eingehen, führe ich noch die Beobachtungen Moeli $\left.{ }^{1}\right)^{2}$ ) an, der 500 Paralytiker untersuchte und in $\mathbf{4 7} \%$ der Fälle reflektorische Pupillenstarre fand; bei weiteren $10 \%$ war die Reaktion auf Lichteinfall nur minimal. Derselbe Autor konnte das Symptom der reflektorischen Starre außerdem noch bei 56 Individuen feststellen, bei denen sich zunächst keine Anzeichen darboten, die den Verdacht auf Paralyse oder Tabes gerechtfertigt hätten. Moeli verfolgte diese Fälle weiter und es stellte sich heraus, da $B$ von ihnen innerhalb der nächsten 3-6 Jahre 14 tabisch, 7 paralytisch und 10 von anderen organischen Hirnkrankheiten, die entweder syphilitischen oder alkoholischen Ursprunges waren, befallen wurden.

Diesen statistischen Feststellungen füge ich noch meine eigenen Beobachtungen hinzu. Wie ich weiter oben angab, untersuchte ich die Pupillen von 550 Paralytikern der verschiedensten Stadien mit der gewöhnlichen elektrischen Handlampe und stellte dabei in $29 \%$ der Fälle vollständige reflektorische Starre fest, in weiteren $14 \%$ wesentlich eingeschränkte Reaktion auf Licht, bei erhaltener Konvergenzreaktion, also nach unseren oben gemachten Darlegungen bei $43 \%$ der Kranken einen Zustand, der als reflektorische Pupillenstarre in erweitertem Sinne aufzufassen ist. Bei 163 mittels des Meßapparates untersuchten Paralytikern fand sich bei $57 \%$ der Fälle entweder reflektorische Starre oder stark eingeengte Reaktion. Unter 48 Fällen von Hirnlues fand sich nur bei zweien typische reflektorische Starre. Außerdem konnte ich im Laufe der Zeit noch bei 8 Kranken reflektorische Starre feststellen, die keine für Tabes, Paralyse oder Hirnsyphilis typischen Krankheitssymptome darboten, die aber alle einen positiven Ausfall der Wassermannschen Luesreaktion im Blut (untersucht von Herrn Dr. Plaut) zeigten. Bei zweien von diesen Kranken entwickelten sich im Laufe der Zeit andere tabische bzw. paralytische Symptome. Ich kann über keinen einzigen Fall von typischer reflektorischer Pupillenstarre berichten, bei dem nicht entweder Tabes, Paralyse, Hirnsyphilis vorlag, oder doch zum mindesten feststand, daß er einmal an Lues er-

3) Siemerling, E., Pupillenreaktion und ophthalmoskopische Befunde bei geisteskranken Frauen. Charité-Annalen 11, 363. 1886.

4) Derselbe, Utber die Veränderungen der Pupillenreaktion bei Geisteskranken. Berl. klin. Wochenschr. 1896, 973.

1) Moeli, C., Bemerkungen über die Pupillenreaktion. Neurol. Zentralbl. 1885.

2) Derselbe, Weitere Bemerkungen über die Pupillenreaktion. Berl. klin. Wochenschr. 1897, 573. 
krankt war. Ich will nicht verfehlen zu bemerken, daß die letztgenannten 8 Kranken ganz verschiedenartige Zustände zur Zeit, als die reflektorische Pupillenstarre zuerst festgestellt wurde, darboten; es handelte sich um manische Zustände, Epilepsie, Alkoholismus und in einem Falle war eine psychische Erkrankung nicht nachweisbar; es war ein Unfallkranker, der zur Begutachtung in die Klinik aufgenommen war.

Nun einige Worte zur Kritik der oben mitgeteilten Statistiken. Die von Uhthoff gegebenen Zahlen ließen die Annahme aufkommen, daß sich auch relativ häufig reflektorische Pupillenstarre ohne luetische b\%w. metaluetische Erkrankung entwickeln könne. Leider ist die Statistik Uhthoffs jedoch nicht ganz im Sinne der reinen reflektorischen Starre zu verwerten, da er auch solche Fälle mit anführt, bei denen die Störung sich ,eventuell auch auf Konvergenz und Akkommodation" ausdehnte. Außerdem waren er sowohl wie Thomsen, Siemerling und Moeli für die Feststellung, ob die Untersuchten eine Lues durchmachten, auf die Angaben derselben einerseits und die Möglichkeit der Diagnose einer sicher mit der Lues in Zusammenhang stehenden Krankheit andererseits angewiesen.

Diese Tatsachen erklären wohl zur Genüge die Abweichung der von diesen Forsøhern angeführten Tatsachen von meinen Beobachtungen, bei denen der Ausfall der Wassermannschen Reaktion die Feststellung einer luetischen Erkrankung auch dann ermöglichte, weln Anamnese und Zustandsbild uns im Stich ließen.

Nach alledem glaube ich berechtigt zu sein zur Aufstellung des Satzes: ,Ohne luetische Erkrankung gibt es äußerst selten, wahrscheinlich überhaupt nie eine reflektorische Pupillenstarre."

Eine weitere Frage ist nun die, ob eine reflektorische Pupillenstarre ausschließlich bei Paralytikern oder Tabeskranken vorkommt. Wie wir aus den mitgeteilten Befunden gesehen haben, kommt zweifellos eine rein reflektorische Lichtstarre auch bei Leuten vor, die keine Anzeichen der genannten Krankheiten erkennen lassen. Dabei muß es jedoch zunächst auffallen, wie klein der Prozentsatz der Fälle mit reflektorischer Starre hei Individuen ist, die entweder an Hirnlues leiden oder bei denen nur feststeht, da $\beta$ sie eimal luetisch erkrankt waren. Nun geht einerseits aus der Statistik Moelis sowohl wie aus meinen eigenen Beobachtungen unzweifelhaft hervor, daß sich häufig in derartigen Fällen nachträglich eine Tabes oder Paralyse entwickelt, andererseits wissen wir, daß die reflektorische Pupillenstarre sehr lange Zeit (bis zu 11 Jahren [Thomsen ${ }^{1}$ ) u. a.]), den anderen paralytischen oder tabischen Symptomen vorausgehen kann; liegt es da nicht schon nahe zu vermuten, daß auch die wenigen übrig bleibenden Fälle mit reflek-

1) Thomsen, Über paralytische Frühsymptome, welche dem Ausbruch der Paralyse bis zu 10 Jahren vorangehen. Zeitschr. f. Psychiatrie 52, 889. 1896. 
torischer Pupillenstarre in der Folgezeit ebenfalls noch von einer der genannten Krankheiten befallen werden?

Außerdem wissen wir, daß nicht gar selten Paralyse und luetische Erkrankung des Gehirns nebeneinander bestehen, und es bleibt also auch für die wenigen Fälle von Hirnsyphilis mit reflektorischer Pupillenstarre die Möglichkeit offen, daß sich bei ihnen paralytische Krankheitsprozesse neben den zunächst im Vordergrund stehenden syphilitischen entwickelt haben.

Meiner Meinung nach dürfen wir daher zurzeit zwar nicht mit Sicherheit ausschließen, daß eine reflektorische Starre bestehen kann, ohne daß sich früher oder später eine Tabes oder Paralyse entwickelt, doch dürften derartige Fälle äußerst selten sein.

Dieselbe Ansicht vertraten Moebius, Hoche, Bumke u. a.; andere schränkten sie dahin ein, daß auch die Syphilis sowohl dann, wenn sie eine Hirnerkrankung veranlaßt hat, als auch ihre konstitutionelle Form reflektorische Pupillenstarre zeitigen kann.

Wir haben schon erwähnt, daß diese Störung bis zu 11 Jahren der tabischen bzw. paralytischen Erkrankung vorangehen kann. Daß sie sich unter Umständen auch sehr bald nach der luetischen Infektion entwickelt, stellte Sulzer1) fest, der sie schon 1 Jahr nach der Erwerbung der Syphilis auftreten sah.

Für das Zustandekommen einer dauernden isolierten reflektorischen Starre müssen wir naturgemäß eine anatomische Veränderung im Nervengewebe des Gehirns annehmen, und damit läßt sich die Möglichkeit nicht von der Hand weisen, daß diese Störung auch durch Krankheitsprozesse nicht luetischer Art zustande kommen kann. Nach den in der Literatur niedergelegten Beobachtungen und nach unseren eigenen Erfahrungen dürften jedoch derartige Fälle zu den seltensten Ausnahmeerscheinungen gehören und im allgemeinen der Satz zu Recht bestehen:

Eine dauernde, isolierte reflektorische Starre kommt nur bei Tabes, Paralyse und angeborener oder erworbener Syphilis vor und ist auch in letzterem Falle wohl meist als Frïhsymptom einer Tabes oder Paralyse aufzufassen.

\section{Störungen im zentrifugalen Abschnitt der Verengerungsbahn.}

Die motorische, pupillenverengernde Erregung verläuft vom Sphincterkern im Oculomotorius zum Ganglion ciliare und tritt durch die kurzen Ciliarnerven zum Sphincter iridis. Wie wir wissen, innerviert der Oculomotorius außer dem Sphincter pupillae noch desi Ciliarmuskel und die

1) Sulzer, Des symptomes pupillaires précoces de la syphilis acquise. Annales de Dermat. et de Syphilid. 4, 239. 1901. 
äußeren Augenmuskeln, mit Ausnahme des M. obliquus superior und des M. rectus externus. Ziehen wir ferner noch in Betracht, daß mit Wahrscheinlichkeit für die Innervation des Sphincter und die des Ciliarmuskels versehiedene Kerne bestehen, so können Unterbrechungen des zentrifugalen Abschnittes der Verengerungsbahn verschiedenartige Störungen der Sphincterinnervation erzeugen, die unter Umständen noch von Innervationsveränderungen anderer Augenmuskeln begleitet sind.

Als theoretisch mögliche zentrifugale Pupillenstörungen stellte Bu mke folgende zusammon;

1. Isoliertes Fehlen der Lichtreaktion.

2. Isoliertes Fehlen der Konvergenzreaktion;

3. Isolierte Lähmung der Akkommodation;

4. Fehlen der Konvergenzreaktion und Lähmung der Akkommodation bei erhaltenem Lichtreflex;

5. Fehlen des Lichtreflexes und Lähmung der Akkommodation bei erhaltener Konvergenzreaktion;

6. Fehlen der Licht- und Konvergenzreaktion bei erhaltener Akkommodation (absolute Pupillenstarre);

7. Fehlen der Licht- und Konvergenzreaktion und Lähmung der Akkommodation (Ophthalmoplegia interna);

8. Komplikation einer der unter $1-7$ genænnten Störungen mit der Lähmung eines, mehrerer oder aller vom dritten Hirnnerven innervierten äußeren Augenmuskeln (vollständige oder unvollständige Oculomotoriuslähmung);

9. Komplikation einer der unter 1-8 genannten Störungen mit Trochlearis oder (bzw. und) Abducenslähmung (vollständige oder unvollständige Ophthalmoplegie).

Von all diesen theoretisch möglichen Störungen wurden bisher alle bis auf den unter 5 genannten Symptomenkomplex beschrieben. Da nun die meisten der obengenannten Erscheinungen sehr selten vorkommen, wollen wir uns nur mit den anderen, häufiger zur Beobachtung kommenden beschäftigen.

Die Möglichkeit, daß eine isolierte Lichtstarre auch im zentrifugalen Abschnitt der Lichtreflexbahn lokalisiert sein kann, hat nur theoretisches Interesse, da sie sich in ihrer Erscheinung nicht von der reflektorischen Pupillenstarre unterscheiden lassen wird und auf ihre Art nur daraus geschlossen werden kann, daß sie als Utberbleibsel einer im übrigen abgeheilten Oculomotoriuslähmung fortbesteht. Jedenfalls hat diese Form der isolierten Lichtstarre kein praktisches Interesse, da sie offenbar äußerst selten vorkommt.

Uber Fälle, bei denen nur die Konvergenzreaktion gestört war, während alle anderen Pupillenbewegungen ungestört verliefen, ist zwar 
hie und da in der Literatur berichtet, so ganz stichhaltig sind jedoch alle diese Fälle nicht, indem leichte Störungen anderer Augenmuskelbewegungen damit verbunden waren.

Ebenfalls recht selten dürfte die isolierte Störung der Akkommodation sein. Marina beschrieb sie als postdiphtheritische Lähmung, Thomsen sah sie bei der Paralyse.

\section{Absolute Pupillenstarre.}

Wir bezeichnen eine Pupille als absolut starr, wenn Licht- und Konvergenzreaktion fehlen, während die Akkommodation ungestört ist. Der Ausdruck ,,absolute Starre" besagt jedoch keineswegs, daß die genannten Reaktionen völlig fehlen; wir reden auch dann von absoluter Pupillenstarre, wenn entweder Licht- und Konvergenzreaktion deutlich eingeschränkt sind, oder die Lichtreaktion erloschen und die Konvergenzreaktion verringert ist. Im allgemeinen pflegen absolut starre Pupillen auch insofern unbeweglich zu sein, als die Sympathicuserregung keine sichtbare Wirkung an ihnen entfaltet und die Reaktionen auf psychische und sensorische Reize fehlen. Der Wegfall der Dilatatorwirkung ist jedoch zur Diagnose ,,absolute Starre“ nicht unbedingt erforderlich.

Absolute Starre als Lähmungserseheinung. Diese Pupillenstörung kann nun zunächst als Lähmungserscheinung auftreten, indem entweder Kernläsionen sie verursachen, oder, und dies ist wohl viel seltener der Fall, die den Reflex unterbrechende Störung im peripheren Teil der zentrifugalen Reflexbahn liegt.

Bei meinen Untersuchungen fand ich recht häufig eine absolute Starre der Pupillen, die meist doppelseitig, jedoch auch nicht selten einseitig festzustellen war. So zeigte sich in ca. $14 \%$ der 550 Fälle von Paralyse, die ich mit der Handlampe untersuchte, vollständige absolute Starre, in weiteren $27 \%$ unvollständige, d. h. es waren entweder Lichtund Konvergenzreaktion nur angedeutet vorhanden, oder es fehlte die Lichtreaktion und die Bewegung der Iris bei der Konvergenz war deutlich vermindert. Mithin konnte ich in ca. 41\% der Paralysefälle vollständige bzw. unvollständige absolute Pupillenstarre beobachten.

Die genauen Messungen an 163 Paralytikern ergaben in 16\% vollständige Unbeweglichkeit der Pupille auf Licht und Konvergenz, in $5 \%$ neben völligem Fehlen des Lichtreflexes deutliche Einschränkung der Konvergenzreaktion, in $13 \%$ waren Lichtreaktion und Konvergenzreaktion vermindert, und zwar überschritt hier die Verengerung der Pupille auf Lichteinfall nicht die Größe von $0,8 \mathrm{~mm}$. Eine absolute Pupillenstarre oder eine ihr gleichwertig zu erachtende Störung fand sich also bei $34 \%$ meiner genau untersuchten Paralytiker. Nur in 3 Fällen 
von vollständiger absoluter Starre konnte ich auf starke faradische Reize noch eine geringe Pupillenerweiterung hervorrufen, während die Reaktionen auf psychische und sensorische Reize vollständig fehlten, ebenso die Pupillenunruhe. Bei den übrigen und den Füllen mit fehlender Licht- und minimaler Konvergenzreaktion gelang es nicht, eine Erweiterung auf sensible, sensorische oder psychische Reize auszulösen. Unter den 21 Fällen mit eingeschränkter Licht- und Konvergenzreaktion zeigten 12 deutliche Erweiterung auf sensible und psychische Einwirkungen.

Bei keinem der Kranken mit vollständiger oder unvollständiger absoluter Starre konnte ich eine Miosis beobachten, $d$. h. eine Pupillenweite unter $2,0 \mathrm{~mm}$ bei beiderseitiger Bestrahlung der Augen mit einem Licht von ca. 270 MK.

Bei der vollständigen absoluten Starre schwankten die Pupillengrößen zwischen 3,2 und 6,8 mm. Fine Mydriasis (Weite über 4,5 mm) fand sich unter den 26 Fällen 15mal, also in fast $60 \%$. Die Kranken mit minimaler Konvergenzreaktion und fehlendem Lichtreflex zeigten Pupillenweiten von 2,8-4,0 mm. Bei den Fällen endlich mit eingeschränkter Licht- und Konvergenzreaktion maß3 ich Pupillengrößen von $2,8-5,0 \mathrm{~mm}$. Von den zu der letztgenannten Gruppe gehörigen 21 Kranken zeigten nur 5 eine Mydriasis von 4,7-5,0 mm.

Die Kniesehnenreflexe fehlten bei 11 Kranken, 2 davon zeigten vollständige absolute Starre. Die Pupillenweiten schwankten zwischen 2,8 und $5,0 \mathrm{~mm}$. Bei 7 Fällen waren die Patellarreflexe in normaler Stärke auslösbar, die Pupillengröße betrug 2,8-4,7 mm. In den übrigen 39 Fällen waren die Kniephänomene gesteigert, die Größe der Pupillendurchmesser bestinmte ich zu $3,0-5,0 \mathrm{~mm}$.

Bei der Untersuchung von 48 an Hirnlues Erkrankten zeigten 5 vollständige, 16 weitere unvollständige absolute Starre, mithin fand ich in fast $44 \%$ der Fälle von Hirnlues eine ausgebildete oder beginnende absolute Starre der Pupillen. Bei ungefähr einem Drittel der Kranken zeigte sich die Störung nur einseitig. Auch bei der Hirnlues waren die starren Pupillen vielfach mydriatisch, eine Miosis kam nie zur Beobachtung.

Während wir bei der reflektorischen Pupillenstarre nur in $26 \%$ der Fälle deutliche Anisokorie feststellen konnten, war dies bei der absoluten Starre sehr viel öfter der Fall; Ungleichheit der Pupillen fand sich bei ca. $40 \%$ der Untersuchten.

Nach meinen bisherigen Beobachtungen scheint die sekundäre Reaktion in den Vorstadien der absoluten Starre nicht zu fehlen. Sie war zwar meist nur sehr gering ausgebildet, die Ausschläge standen jedoch in gutem Verhältnis zu der Cesamtreaktion, indem die Verengerung der Pupille bei der sekundären Reaktion meist ungefähr 1/5 der Iris- 
bewegung bei beiderseitigem Lichteinfall ausmachte. Auffallend war, daß in manchen Fällen die sekundäre Reaktion relativ sehr groß war, indem der durch sie erzielte Irisausschlag bis zur Hälfte der Gesamtreaktion in obigem Sinne betrug.

Das Vorkommen einer unvollständigen absolnten Pupillenstarre wurde von anderen Beobachtern auch bei der senilen Demenz festgestellt. Es scheint mir jedoch nicht absolut sicher, ob man dabei eine im zentrifugalen Teil der Reflexbahn liegende Störung annehmen muß, und ich komme darauf noch bei der Besprechung der Veränderungen der pupillenerweiternden Irisbewegungen zurück.

Eine vollständige oder unvollständige absolute Starre wurde gelegentlich auch bei chronischen Alkoholisten bemerkt und häufig die Beobachtung gemacht, daß diese Pupillenstörungen allmählich wieder verschwanden. Häufiger noch wurde eine Pupillenträgheit festgestellt, indem alle Bewegungen der Regenbogenhaut nur langsam vor sich gingen.

Bei der Durchsicht von 900 Krankheitsgeschichten von Personen, die verschiedenartige, infolge Alkoholmißbrauchs entstandene Krankheitsbilder darboten, fand ich in ca. $6 \%$ der Fälle einen auffallend langsamen Ablauf der Pupillenbewegungen bei Lichteinfall und Konvergenz vermerkt. Als verursachendes Moment dürften neuritische Erscheinungen der die Iris innervierenden Nerven einerseits und Kernläsionen infolge von Blutungen in die graue Substanz ihrer Umgebung andererseits in Betracht kommen. Mit dieser Frage werden wir uns weiter unten noch eingehender beschäftigen.

Außer bei der Alkoholintoxikation und den durch sie bewirkten Gehirnveränderungen tritt absolute Pupillenstarre noch bei anderen Vergiftungen auf; sie wurde beschrieben als Begleiterscheinung der Influenza, Diphtherie, als Folge von Fleisch-, Fisch- und Austernvergiftung und soll auch bei der Bleiintoxikation vorkommen.

Um sich vor groben Irrtümern zu schützen, denke man bei der Krankenuntersuchung immer an die Möglichkeit, daß die absolute Pupillenstarre auch nach Anwendung von Atropin, Homatropin, Hyosein, Scopolamin und verwandten Arzneimitteln entsteht.

Tritt zu dem Symptombilde der absoluten Starre noch eine Lähmung der Akkommodation hinzu, so sprechen wir von einer Ophthalmoplegia interna. In den meisten. Fällen, bei denen eine unvollständige absolute Starre vorliegt, wird es schwer, ja unmöglich sein, mit Sicherheit zu unterscheiden, ob es sich nur um eine absolute Starre oder um eine Ophthalmoplegia interna handelt, da man dabei kaum ein sicheres Urteil über das Vorliegen einer Akkommodationsstörung gewinnen kann. Nach den statistischen Zusammenstellungen scheint die absolute Starre ebenso häufig vorzukommen wie die Ophthalmoplegia interna. Letztere 
findet sich nach Bumkes Ansicht überhaupt nie bei Tabes und Paralyse. Ich kann insofern seiner Anschauung beitreten, als ich eine Ophthalmoplegia interna bei meinen 713 Fällen von Paralyse nicht mit Sicherheit beobachten konnte.

Als hauptsächliche Ursache einer Sphincterlähmung ist demnach die Lues zu betrachten. Diese Anschauung vertreten wohl die meisten Autoren, so Erb, Moeli, Heddae us, Uh thoff u. a. Während in dieser Frage im allgemeinen Übereinstimmung herrscht, gehen die Ansichten der Forscher wesentlich auseinander bei der Entscheidung, ob die absolute Pupillenstarre, die Ophthalmoplegia interna und die anderen Pupillenstörungen, die in das Kapitel der als Lähmungserscheinungen infolge Läsion der zentrifugalen Pupillenbahnen zu betrachtenden Innervationsstörungen der Iris gehören, als charakteristisch für die eine oder andere Form luetischer Erkrankung aufzufassen sind. Während die einen die Anschauung vertreten, daß die absolute Pupillenstarre häufig bei Tabes und Paralyse, also bei metasyphilitischen Erkrankungen zu finden ist, halten andere das Vorkommen zentrifugaler Pupillenstörungen bei dieser Form der Lues für selten. Wir können letzteren Standpunkt nicht für richtig balten, da unsere Untersuchungen zeigten, daß absolute Pupillenstarre bei den genannten metasyphilitischen Erkrankungen recht häufig vorkommt. Wie ich mich öfter bei der Untersuchung von Kindern, deren Väter oder Mütter nachweislich syphilitisch oder paralytisch waren, überzeugen konnte, kommt die absolute Pupillenstarre zweifellos auch als einziges oder beinahe alleinstehendes Krankheitssymptom da vor, wo sonstige Zeichen einer luetischen oder sonstigen Erkrankung des Nervensystems fehlen. Im übrigen ist die Tatsache, daß eine absolute Pupillenstarre als einzige nachweisbare Folge einer syphilitischen Infektion vorkommt, wohl allgemein anerkannt. Nach unseren Beobachtungen und auch von anderen Autoren gemachten Feststellungen findet sich die absolute Pupillenstarre besonders häufig bei der Hirnlues, hier auch oft vereint mit einer Lähmung der Akkommodation, während auch wir eine sichere Ophthalmoplegia interna bei keinem unserer paralytischen Kranken feststellten. Nach der Anschauung Uhthoffs dürfen wir bei einer gleichzeitig und doppelseitig auftretenden Ophthalmoplegia interna weniger an Syphilis als Ursache denken als bei einer einseitigen derartigen Affektion. Inwieweit diese Anschauung sicher zu Recht besteht, vermag ich nicht zu beurteilen, da mir fast nur Fälle zur Untersuchung verfügbar waren, die an Erkrankungen des Gehirns litten, während umfassendere Untersuchungen hier nur vom Augenarzt gemacht werden können. Zur sicheren Erkenntnis der Ursache der Pupillenstörungen könnte wohl jetzt die Probe der Wassermannschen Luesreaktion viel beitragen, während, solange wir nur auf die Angaben der Erkrankten angewiesen waren, eine Entschei- 
dung, ob nicht doch eine Luesinfektion schuld an der beobachteten Pupillenstörung war, nicht mit gleicher Sicherheit getroffen werden konnte. Mit Hilfe dieser Untersuchung wird sich wohl voraussichtlich ein Teil der Fälle mit Ophthalmoplegia interna auch noch als syphilitischen Ursprunges herausstellen, während gewiß ein großer Prozensatz als nicht luetischer Natur übrigbleiben wird, da ja eine ganze Reihe anderer Erkrankungen, Blutungen, Tumoren usw. unzweifelhaft Pupillenstörungen durch Läsion der zentrifugalen Reflexbahn hervorrufen kann. Wir müssen daher den von Bumke aufgestellten Satz, , daß die Sphincterlähmnug, soweit sie auf einer Kern-oder a uf einer Stammläsion des Oculomotorius beruht, mit besonderer Häufigkeit bei Syphilis, aber auch bei Tabes, Paralyse, senilerDemenz und anderen organischenGehirnkrankheiten vorkommt, während die Ophthalmoplegia interna niemals bei einer Tabes oder Paralyse, häufig bei Syphilis und selten bei organischen Hirnerkrankungen nicht luetischer Ätiologie beobachtet wird“, als zu Recht bestehend annehmen, vielleicht mit der Einschränkung, daß die Störung bei seniler Demenz nicht mit Sicherheit als Lähmungserscheinung a ufzufassen ist; davon weiter unten.

Absolute Starre als Reizerscheinung. Die Untersuchungen von Hitzig ${ }^{1}$ ), Bechterew $\left.{ }^{2}\right)^{3}$ ), Braunstein ${ }^{4}$ ), Piltz ${ }^{5}$, Parsons ${ }^{6}$ ) u. a. haben uns gezeigt, daß künstliche Reizung bestimmter, eng umschriebener Rindenbezirke beim Tier Verengerung der Pupillen hervorruft, während bei Reizung der übrigen Hirnrinde Erweiterung eintritt. Beim Menschen kennen wir als von der Hirnrinde aus ausgelösten Verengerungsvorgang der Pupille die Sphincterkontraktion bei der Konvergenz und beim Nahesehen. Die Wahrscheinlichkeit, daß beim Menschen ebenso wie beim Tier Reizung der Hirnrinde je nach dem Ort, wo sie geschieht, Verengerung oder Erweiterung der Pupillen bedingen kann, wird zunächst durch die bei der Meningitis beobachteten Pupillenveränderungen sehr nahe gerückt. Wir finden bei dieser Erkrankung häufig,

1) Hitzig, Ed., Physiologische und klinische Untersuchungen über das Gehirn. Gesammelte Abhandlungen. Berlin 1904.

2) Bechterew, v., Über pupillenverengernde und Akkommodationscentra der Gehirnrinde. Neurol. Centralbl. 1900, 386.

3) Derselbe, U̇ber pupillenverengernde und pupillenerweiternde Centra in den hinteren Teilen der Hemisphärenrinde beim Affen. Arch. f. Anat. u. Physiol. 1900, Physiol. Abt., 25.

4) Braunstein, Zur Lehre von der Innervation der Pupillenbewegung. Wiesbaden 1894.

5) Piltz, Utber ein Hirnrindenzentrum für einseitige kontralaterale Pupillenverengerung. Neurol. Centralbl. 1899, 875.

6) Parsons, H., On Dilatation of the pupil from Stimulation of the cortex cerebri. Journ. of Physiol. 26, 38. 1901. 
besonders zu Anfang derselben, miotische, absolut oder fast absolut starre Pupillen, die dann im weiteren Verlauf des Leidens vielfach mydriatisch und absolut starr werden. Diese Erscheinungen lassen sich wohl am ungezwungensten als durch dauernde Rindenreizung verursachte Krampfzustände der Irismuskulatur erklären. Der Wechsel der Pupillenweite würde dann in dem Ubergreifen des anfangs enger begrenzten Entzündungsherdes auf größere Abschnitte der Oberfläche des Gehirns seinen Grund haben.

Eine absolute Starre der Pupillen finden wir bekanntlich auch im epileptischen Anfall. Beobachten wir einen Epileptiker im Krampfzustand, so sehen wir, wie seine vorher auf Lichteinfall und Konvergenz ganz prompt und ausgiebig reagierenden Pupillen im tonischen Stadium des Anfalls plötzlich sehr weit werden und reaktionslos sind. In seltenen Fällen zeigt sich statt einer Mydriasis eine Miosis mit Lichtstarre. Im klonischen Stadium des Anfalls bleiben die Pupillen entweder weit und starr oder es zeigen sich mehr oder weniger starke rhythmische Schwankungen des Irissaumes. Ist der Anfall vorüber, erschlafft die Körpermuskulatur, so verengern sich die Pupillen meist ziemlich stark, reagieren wieder auf Licht, und starke sensible Reize rufen eine Erweiterung derselben hervor. Suchen wir nach einer Erklärung für diesen Ablauf der Erscheinungen, so können wir mit denen des ersten Stadiums, in dem die Pupillen mydriatisch und absolut starr sind, den Erfolg der Reizung größerer Partien der Hirnrinde vergleichen. Offenbar wirken die den epileptischen Anfall veranlassenden Rindenreize auch auf die Pupilleninnervation und erzeugen hier, ebenso wie in der übrigen Körpermuskulatur, einen tonischen Krampfzustand, indem die Hemmung der Sphincterinnervation eine tonische Erregung des Dilatators herbeiführt. Im gleichen Sinne wären auch die häufiger zur Beobachtung kommenden klonischen Irisbewegungen im weiteren Verlauf des Anfalls zu erklären. Die nach dem Anfall eintretende Pupillenenge - die Pupillen sind meist enger als in der anfallsfreien Zeit - würde dann in einer Erschöpfung der pupillenerweiternden Nervenelementeihren Grund haben.

Im epileptischen Dämmerzustande wurden bisweilen ebenfalls weite, absolut starre Pupillen beobachtet. Bei einem Epileptiker, der an häufigen Absensen litt, gelang es mir auch einmal, eine absolute Starre mit Mydriasis in einem derartigen Zustand festzustellen.

Während man früher die Pupillenstarre im Anfall als eines der wichtigsten Unterscheidungsmerkmale der epileptischen und hysterischen Krampfzustände betrachtete, haben die Untersuchungen von Kar$\left.\left.\mathrm{plus}^{1}\right)^{2}\right)$ gezeigt, daß eine absolute Pupillenstarre gelegentlich auch im

1) Karplus, J., Ủber Pupillenstarre im hysterischen Anfall. Wien. klin. Wochenschr. 1896. 1228.

2) Derselbe, U̇ber Pupillenstarre im hysterischen Anfall nebst weiteren Be- 
hysterischen Anfall vorkommt. Die Beobachtungen von Karplus wurden durch Westphal ${ }^{1}$ ) und Hoche ${ }^{2}$ ) bestätigt und es zeigte sich, daß die Pupillen im Anfall sowohl sehr eng wie sehr weit sein können. Auch außerhalb der Anfälle wurde bei Hysterischen vorübergehende, absolute Pupillenstarre festgestellt. Die Tatsache, daß im hysterischen Anfall in einem dem Willen nicht unterworfenen Muskel ein Krampfzustand entsteht, mag zunächst auffallend und schwer erklärlich erscheinen. Wir wissen zwar, daß jede psychische Anstrengung eine Erweiterung der Pupillen hervorruft, wir können uns aber jederzeit leicht davon überzeugen, daß die Iris dadurch nicht reaktionslos bei Lichteinflüssen oder Konvergenzimpulsen wird. Fügen wir der Versuchsperson auch sehr starke sensible Reize zu, so tritt, falls wir zugleich eine Verstärkung des die Augen treffenden Lichtes vornehmen, keine Erweiterung, sondern eine Verengerung der Pupillen ein. Veranlassen wir eine dauernde Erweiterung der Pupillen durch einen anhaltenden, starken, faradischen Schmerzreiz, so bleibt die Pupille doch für Lichtreize reaktionsfähig. Andererseits wissen wir aber, daß die Pupillen Hysterischer auch außerhalb der Anfälle vielfach stark mydriatisch sind. Würden im hysterischen Anfall die absolut starren Pupillen immer mydriatisch gefunden, so könnte die Annahme eines verstärkten Einflusses der auf das Sphincterzentrum wirkenden Hemmungsvorgänge bei vielleicht außerdem anzunehmender Herabsetzung der Reflexempfindlichkeit der Retinaelemente, aber auch ohne diese, zur Erklärung der Pupillenstarre genügen. Nun sind aber auch Fälle beschrieben, bei denen die Pupillen im hysterischen Anfall miotisch waren. Hier müßte man dann ein umgekehrtes Verhalten der Empfindlichkeit der die Irisbewegungen regulierenden Reflexorgane annehmen oder eine Reizung ganz umschriebener Hirnrindenpartien. Die Annahme einer gesteigerten Reflexempfindlichkeit der Retina bei gleichzeitiger Herabsetzung der den Lichtreflex hemmenden Rindenerregung dürfte m. E. mehr Wahrscheinlichkeit für sich haben, wie die Voraussetzung, daß ganz umschriebene Teile der Hirnrinde im hysterischen Anfall in starke Erregung geraten würden. Unsere Untersuchungen bei Hysterischen, auf die ich weiter unten ausführlich zurückkomme, haben uns gezeigt, daß die Pupillenbewegungen bei dieser Krankheit vielfach rascher ablaufen als in der Norm. Aus dieser Tatsache darf man wohl auf eine verstärkte Reizbarkeit der die Reaktionen vermittelnden, nervösen Apparate schließen.

merkungen zur Symptomatologie und Differentialdiagnose hysterischer und epileptischer Anfälle. Jahrb. f. Psych. 6\%. 1898.

1) Westphal, A., Ưber Pupillenerscheinungen bei Hysterie. Berl. klin. Wochenschr. 189\%, 1024 .

2) Hoche, A., Die Differentialdiagnose zwischen Epilepsie und Hysterie. Berlin 1902. 
Stellen sich nun auf der Höhe des hysterischen Anfalles Bewußtseinstrübungen ein, so läßt sich ungezwungen die Annahme machen, daß dann die von der Hirnrinde ausgehenden, das Sphincterzentrum hemmend beeinflussenden Erregungen gering werden oder ganz fortfallen. Die Folge wäre dann bei der gesteigerten Reizbarkeit der den Lichtreflex vermittelnden Elemente ein Krampfzustand des Sphincter iridis, bei dem die Pupille eng erscheinen würde.

Bei der Unsicherheit unserer Erkenntnis über die bei der Hysterie bestehenden Veränderungen des Nervensystems werden wir zunächst kaum über eine theoretische Betrachtung der geschilderten Pupilleninnervationsstörungen hinauskommen. Karplus wirft am Schluß seiner Arbeit über die Pupillenstarre im hysterischen Anfall die Frage auf: "Wie steht es denn überhaupt mit der psychischen Natur des hysterischen Anfalles?" und sagt: „Muß man nicht überhaupt für viele hysterische Anfälle oder für wesentliche Teile derselben annehmen, daß psychische Vorgänge allerdings ursächlich von der größten Bedeutung für dieselben seien, vielleicht aber doch nur in der Weise, daB durch die psychischen Vorgänge ein präformierter Mechanismus ausgelöst würde, der an und für sich mit psychischen Vorgängen gar nichts zu tun hat." Ich möchte dieser Anschauung aus Gründen klinischer Erfahrung beitreten und werde noch eingehend bei der späteren Besprechung der Pupillenerscheinungen bei der Epilepsie und Hysterie darauf zurückkommen.

Zum Schlusse unserer Betrachtung der als Krampfzustand aufzufassenden Pupillenstarre will ich nicht verfehlen, noch zu bemerken, daß auch durch grelle Belichtung der Augen ein Sphincterkrampf hervorgerufen werden kann, der unabhängig von der Rindeninnervation entsteht. Heddaeus macht darauf aufmerksam, indem er sagt: ,Alles, was die Augen blendet, ruft auch gern einen reflektorischen Sphincterkrampf hervor, der bei empfindichen Augen auch nach kurzer Verdunkelung eines oder gar beider Augen noch erhalten sein und reflektorische Starre vortäuschen kann." Diese wohl allgemein anerkannte Tatsache konnte ich bei meinen Untersuchungen auch gelegentlich feststellen und zwar, als ich versuchte, die Pupille unter Zuhilfenahme von Bogenlicht zu kinematographieren. Es zeigte sich, daß die Einwirkung der gewaltigen Lichtstärke (6000 und mehr Kerzen) neben Blendungserscheinungen auch eine ziemlich lang anhaltende Miosis mit fast aufgehobener Licht- und geringer Konvergenzreaktion zeitigte. Diese Beobachtung hat, wie ich schon weiter oben anführte, eine wesentliche praktische Bedeutung, indem sie uns warnen muß, die Lichtreflexprüfung an einem Auge, das vorher einer grellen Belichtung ausgesetzt war, nach nur kurz dauernder Verdunkelung (Beschattung mit der Hand) vorzunehmen, da man dann Gefahr läuft, ohne Berechtigung eine Störung der Pupillenreflexbahn anzunehmen. 


\section{Veränderungen der die Pupille vergrößernden Irisbewegungen.}

\section{Störungen der Sympathicusinnervation.}

Eine Lähmung der oculopupillären Sympathicusfasern kommt ziemlich häufig zur Beobachtung und ist als sog. Hornerscher Symptomkomplex bekannt. Wir verstehen darunter den Zustand, daß eine Pupille miotisch, die Lidspalte verengt - durch Herabsinken des Oberlides und leichten Höherstand des Unterlides - der Augapfel etwas in die Orbita zurückgesunken und weniger gespannt ist. Zugleich ist das Gesicht auf der Seite der Lähmung bei frischen Fällen röter und wärmer, bei alten blässer und kälter, und die Schweißsekretion fällt auf der gelähmten Seite fort. Die Diagnose dieser Sympathicuslähmung ist demnach nicht schwierig.

Die Pupille ist dabei dauernd enger als normal, wodurch, wenn die Störung, und das tut sie zumeist, einseitig ist, eine starke Anisokorie entsteht, die bei weniger starker Belichtung deutlicher wird, als im hellen Tageslicht. Die Reaktionen der Pupille bei Lichteinfall und Konvergenzbewegung der Bulbi sind dabei erhalten, wenn auch, entsprechend der schon bestehenden Verkleinerung des Sehloches, in verminderter Stärke auslösbar. Sehr deutlich ist bei der Sympathicuslähmung die Verlangsamung der Erweiterungsbewegung nach Wegfall starker Belichtung zu sehen, während die Verengerung auf Lichteinfall sehr rasch vor sich zu gehen pflegt. Die reflektorische Erweiterung der Pupille auf sensible Reize ist zwar weniger ausgiebig, aber immer vorhanden, während die Sympathicuslähmung an der Größe der bei psychischen und sensorischen Reizen erfolgenden Pupillenbewegung nichts ändert.

Schwerer kann die Diagnose einer durch Sympathicuslähmung verursachten Innervationsstörung der Iris werden, wenn nur die Pupillenfasern dieses Nerven erkranken. Nach meinen oben mitgeteilten Beobachtungen der Pupillenverhältnisse bei der Tabesparalyse scheint mir die dabei beobachtete Miosis möglicherweise in einer Erkrankung der vom Halsmark zur Pupille strebenden Sympathicusbahn begründet zu sein. In gleichem Sinne dürften wohl auch die Resultate Buccolas'), der bei Paralytikern eine Verlängerung der Latenzzeit der Erweiterungsreaktion auf sensible Reize fand, zu deuten sein.

Bei einem Reizzustand des Sympathicus sehen wir zunächst eine starke Mydriasis auftreten. Die Verengerungsbewegung der Iris bei Lichteinfall ins Auge und Konvergenz ist verlangsamt und weniger ausgiebig. Die Erweiterung auf sensible Reize erfolgt rascher als gewöhnlich und ist bei stärkerer Belichtung des Auges auch ausgiebiger. Unter-

1) Buccola, G., Sull tempo della dilatazione reflessa della pupilla nella paralisi progressiva degli alienati ed in altre malattie dei centri nervosi. Rivista sperimentale di freniatria 9. 1883. 
sucht man jedoch bei sehr schwachem Licht, so vermißt man hie und da diese Erweiterungsbewegung, was darin seinen Grund hat, daß die Pupille auch ohne Einfluß sensibler Reize, schon maximal weit ist; man sieht dann nur noch einen ganz schmalen Streifen des Irisgewebes. Bei diesem Zustande bleiben auch psychische und sensorische Einflüsse ohne Wirkung. Ist die Mydriasis nicht so hochgradig, so zeigen die letztgenannten Reaktionen sich weder qualitativ noch quantitativ verändert.

Die Störungen der Sympathicusinnervation haben für den Psychiater und Neurologen nur ein geringeres Interesse und sind im allgemeinen nicht allzu schwer zu diagnostizieren, besonders wenn man noch auf die Entstehungsursachen derselben Rücksicht nimmt, die meist in mechanischen Einwirkungen auf den Sympathicus durch Strumabildungen und Mediastinaltumoren oder in direkten Verletzungen zu suchen sind.

Zum Schlusse unserer Betrachtungen über die durch Störungen der Sympathicusinnervation veranlaßten Pupillenveränderungen möchte ich noch auf eine Beobachtung zurückkommen, die ich schon im Kapitel „Die Pupille im Tode" erwähnte, daß ich nämlich bei einigen Individuen, die im Leben absolute Pupillenstarre und starke Mydriasis zeigten, kurz nach dem Tode eine Verengerung der Pupillen feststellen konnte, während der umgekehrte Vorgang zu erwarten war. Diese Erscheinung dürfte vielleicht in dem Sinne zu deuten sein, daß sich unter Umständen bei längerem Bestand der Sphincterlähmung eine sekundäre Contractur des Dilatators ausbildet. Die dadurch verursachte, hochgradige Mydriasis verschwindet dann naturgemäß im Tode. Bei den hier in Betracht kommenden Fällen handelte es sich um juvenile Paralytiker, die auch starke Contracturen in der Beinmuskulatur zeigten.

\section{Störungen der hauptsächlich durch Hemmung der Sphincterinnervation bedingten Irisbewegungen.}

Die normalerweise immer eintretenden Erweiterungsreaktionen der Pupille auf sensible, sensorische und psychische Reize können in verschiedener Weise gestört sein. Sie können fehlen oder stark verringert erscheinen, sie können aber auch durch ihr auffallend rasches und ausgiebiges Auftreten von der Norm abweichen. Die Schätzung, ob eine der genannten Reaktionen als gering oder auffallend stark zu bezeichnen ist, muß allerdings, solange unsere photographische Technik noch nicht ganz einwandfrei ist, dem subjektiven Ermessen des Untersuchers überlassen bleiben. Wenn es nun auch alle möglichen UUbergangsformen in quantitativer Hinsicht bei diesen Pupillenbewegungen gibt, so ist es für einen erfahrenen Untersucher doch nicht allzu schwierig, mit einiger 
Sicherheit zu bestimmen, ob eine erhebliche Abweichung der Reaktionsart nach der einen oder anderen Seite von der Norm besteht. Zunächst wollen wir nun sehen, unter welchen Umständen die Erweiterungsreaktionen fehlen oder doch wesentlich herabgesetzt sind.

Fehlen bzw. starke Herabsetzung der Erweiterungsreaktionen. Nach unseren früheren Auseinandersetzungen werden wir gut tun, bei der Betrachtung der Veränderungen der Erweiterungsreaktionen die auf sensible Reize erfolgenden von denen, die sich nach psychischen und sensorischen Einwirkungen zeigen, zu trennen.

Erb suchte zuerst die Tatsache, daß auf sensible Reize unter normalen Verhältnissen eine mehr oder weniger starke Pupillenerweiterung eintritt, für die Pathologie des Nervensystems zu verwerten und fand, daß diese Reaktion bei Tabeskranken mit reflektorisch starren Pupillen ausblieb. Untersuchungen in dem gleichen Sinne wurden dann von Gowers ${ }^{1}$ ) und Moeli $^{2}$ ) gemacht. Sie konnten die Angaben Erbs bestätigen. Diese Frage beschäftigte in der Folgezeit noch häufig die Forscher und es zeigte sich, daß die Pupillenerweiterung auf psychische Reize ausblieb, sobald die Lichtreaktion erloschen war, manchmal jedoch auch schon früher vermißt wurde.

In der neueren Zeit stellte $\mathrm{Bumke}^{3}$ ) fest, daß die Erweiterungsreaktionen auch bei Gehirnkrankheiten, die keine Störungen der Lichtreaktion zu veranlassen pflegen und über deren anatomische Grundlage wir noch kaum etwas wissen, so hauptsächlich bei der Dementia praecox, fehlen können. Die Angaben Bumkes wurden von Hübner $\left.{ }^{4}\right)^{5}$ ) und Verf. $\left.{ }^{6}\right)$ bestätigt.

Nach den übereinstimmenden, klinischen Erfahrungen der Autoren fehlten die Reaktionen auf psychische und sensorische Reize durchwegs bei den Kranken, die keine Lichtreaktion der Pupillen mehr erkennen ließen. Diese Erscheinung hat für den, welcher sich der Ansicht, daß die genannten Reaktionen durch die corticale Hemmung des Sphinctertonus veranlaßt werden, anschließen will, nichts Auffallendes, da eine Hemmung bei fehlender Erregung des Pupillenverengerungszentrums nicht eintreten kann.

1) Gowers, Eye symptomes in diseases of the spinal cord. Lancet 18S3, 1031.

2) Moeli, C., Die Reaktion der Pupillen Geisteskranker bei Reizung sensibler Nerven. Arch. f. Psych. 1882, 602.

3) Bumke, O., Das Verhalten der von psychischen und nervösen Vorgängen abhängigen Irisbewegungen bei Geisteskranken. Centralbl. f. Nervenheilk. 1903, 673.

4) Hübner, A. H., Untersuchungen über die Erweiterung der Pupillen auf psychische und schmerzhafte Reize. Allgem. Zeitschr. f. Psych. 1905, 616.

5) Derselbe, Untersuchungen über die Erweiterung der Pupillen auf psychische und sensible Reize nebst einigen allgemeinen Bemerkungen über Pupillenreaktionen. Arch. f. Psych. 41, 1016. 1906.

$\left.{ }^{6}\right)$ Weiler, K., Pupillenuntersuchungen bei Geisteskranken. Verhandlungen der Jahresversammlung des deutschen Vereins für Psychiatrie 1906. 
Anders liegen die Verhältnisse bei der Erweiterungsreaktion auf sensible Reize. Nach unseren weiter oben gemachten Darlegungen läßt sich bierbei eine Mitwirkung des Sympathicus kaum leugnen, vielmehr sprechen für diese Annahme einerseits sowohl die stärkere Wirkung sensibler Reize, wie auch der veränderte Ablauf der Reaktion bei Störungen der Sympathicusinnervation und andererseits die Beobachtung. daß sich durch sensible Reize noch eine Pupillenerweiterung herbeiführen läßt an Augen, bei denen durch psychische und sensorische Einflüsse keine Bewegungen der Iris mehr erzielt werden können. Wir dürfen uns daher das Zustandekommen der Pupillenerweiterung auf sensible Reize wohl als den Ausdruck zweier Vorgänge vorstellen, indem dabei der Sympathicus, direkt gereizt, eine Dilatatorinnervation hervorruft, deren Wirkung die gleichzeitig durch Vermittelung der Hirnrinde erfolgende Sphincterhemmung noch verstärkt.

Die Untersuchungen B u m kes haben uns nun gezeigt, daß auch bei Individuen, bei denen die Lichtreflexbahn ungestört ist, die auf psychische, sensorische und sensible Reize normalerweise eintretenden Irisbewegungen fehlen können, und zwar fand er dieses Symptom hauptsächlich bei der Dementia praecox. Er machte dabei auch die Beobachtung, daß in manchen Fällen die Reaktion auf sensible Reize noch bestand oder wiederkehrte, während die Erweiterung auf psychische und sensorische Reize, wie auch die Pupillenunruhe dauernd verschwunden war. Er sagt: ,Wir dürfen somit feststellen, daß die Psychoreflexe und die durch das Wechselspiel der psychischen Vorgänge bedingte ,Pupillenunruhe' bei der Dementia praecox auf der Höhe der Krankheit stets fehlen, daß ferner dieses Symptom den anderen katatonischen Zeichen oft, aber nicht immer, längere Zeit vorangeht und, wo es einmal vorhanden ist, nicht wieder verschwindet; und daß endlich die reflektorische Erweiterung auf sensible Reize zuweilen länger erhalten bleibt als wie die Psychoreflexe und gelegentlich in der Remission wiederkehren kann.

Diese Symptome haben also mit allen anderen katatonischen Zeichen das gemein, daß sie nicht in jedem Falle vorhanden zu sein brauchen; immerhin sind sie so häufig und vor allem oft schon so früh zu konstatieren, daß ihnen ein gewisser diagnostischer Wert $\mathrm{m}$. E. heute zuerkannt werden muß."

Zu ähnlichen Schlüssen wie Bumke kam Hübner; auch er hob hervor, daß die Reaktionen auf sensible Reize am längsten erhalten zu sein pflegen. Dieser Autor vermißte bei $75 \%$ der von ihm untersuchten Fälle von Dementia praecox die Erweiterungsreaktionen, bei $17 \%$ waren sie nicht sicher festzustellen oder es zeigte sich nur bei sensibler Reizung noch eine Irisbewegung, und bei nur $8 \%$ waren sie gut erhalten. $\mathrm{B} \mathrm{u} \mathrm{m} \mathrm{ke}$ nahm in $69 \%$ der Fälle von Jugendirresein Fehlen und in $31 \%$ Herabsetzung der genannten Reaktionen an, bzw. waren bei der letzten Gruppe 
nur noch die sensiblen Reize von einer Wirkung auf die Pupille gefolgt. Beide Forscher fanden auch bei einzelnen Imbezillen und Idioten Herabsetzung bzw. Fehlen der Erweiterungsreaktionen.

Eine Verminderung der Reaktion auf sensorische und sensible Reize stellte Moebi us ${ }^{1}$ ) bei alten Leuten fest. Auch wir sahen bei der senilen Demenz und bei arteriosklerotischen Verblödungsprozessen auf sensible, sensorische und psychische Reize häufig kaum mehr eine Erweiterung der Pupillen eintreten. Moebi us glaubte als Ursache für die Pupillenenge der Greise und die Verminderung der genannten Reaktionen eine Herabsetzung der Sympathicusinnervation annehmen zu sollen, indem er ausführt, daß bei alten Leuten infolge der Verminderung der allgemeinen Erregbarkeit dem pupillenerweiternden Zentrum weniger starke Reize zugeführt würden. Nach unseren heutigen Anschauungen über das Wesen der pupillenerweiternden Vorgänge können wir Moebi us nur mehr teilweise beipflichten, da wir den Hauptanteil am Zustandekommen dieser Reaktionen der hemmenden Wirkung der Hirnrinde zuerkennen müssen. Bei den Untersuchungen von Moebius zeigte sich auch wieder ein Unterschied in der sensorischen und sensiblen Reaktion, indem letztere länger erhalten blieb bzw. stärker war als erstere. Hübner, der ebenfalls senil demente Kranke untersuchte, kam zu denselben Resultaten wie Moebius; er fand bei ungefähr der Hälfte seiner Versuchspersonen Herabsetzung der psychischen Reaktion neben erhaltener sensibler; bei zwei Kranken fehlten alle Erweiterungsreaktionen, zwei weitere ließen nur noch die sensible Reaktion erkennen.

Bumke sagt bei der Besprechung der Symptome des Fehlens der Erweiterungsreaktionen bei der Dementia praecox: „Auf der anderen Seite wird ihre Bedeutung für die Diagnose der jugendlichen Verblödungsprozesse dadurch erhöht, daß sie bei anderen Krankheiten nicht vorzukommen scheinen. Gewiß verschwinden auch bei der progressiven Paralyse die Psychoreflexe, aber doch erst gleichzeitig mit dem Lichtreflex. Dann kommen, wie wiederholt hervorgehoben wurde - ganz selten - im epileptischen Dämmerzustande und bei anderen sehr erregten Kranken Zustände vor, in denen die durch lebhafte psychische Vorgänge maximal dilatierte Pupille einer stärkeren Erweiterung nicht mehr fähig ist. Ich habe das wiederholt bei einer schwer geängstigten melancholischen Kranken gesehen, glaube aber heute die daraus resultierende diagnostische Schwierigkeit überwinden zu können. Derartige Angstpupillen reagieren auch auf Helligkeitssteigerungen nicht ganz so gut wie andere, die Reizschwellen für den Lichtreflex liegen bei ihnen höher als bei Gesunden und erst recht höher als bei Katatonikern."

Dem ersten Teil dieser Aufstellungen $\mathrm{Bu} \mathrm{mkes,} \mathrm{in} \mathrm{dem} \mathrm{er} \mathrm{annimmt,}$

1) Moebius, Notiz über das Verhalten der Pupille bei alten Leuten. Centralbl. f. Nervenheilk. 1883, 337. 
daß die Erweiterungsreaktionen bei der Paralyse nur dann verschwinden, wenn die Lichtreaktion aufgehoben ist, kann ich nicht beipflichten. Bei meinen Untersuchungen stellte sich die unzweifelhafte Tatsache heraus, daß bei der Paralyse die Pupillenerweiterung auf sensorische und psychische Reize häufig schon fehlte, ehe noch eine deutliche Einschränkung der Lichtreaktion oder ein Fehlen derselben feststellbar war, sehr viel seltener war dies bei der Reaktion auf sensible Reize zu beobachten, diese war sogar in manchen Fällen noch erhalten, wenn auch stark verringert, nachdem die Lichtreaktion bereits erloschen war.

Daß man Gefahr laufen kann, unter Umständen fälschlicherweise ein Fehlen der Erweiterungsreaktionen anzunehmen bei Kranken, deren Pupillen maximal erweitert sind, habe ich schon weiter oben betont. Wenn auch der einfache Angstaffekt im allgemeinen keine derartige pupillenerweiternde Wirkung ausübt, daß ein starker Hautreiz, lautes Anrufen der Versuchsperson oder dgl. nicht doch eine kleine Pupillenbewegung hervorruft, so gibt es zweifellos Fälle, die bei geringer Beleuchtung der Augen kaum noch einen kleinen Saum von Irisgewebe erkennen lassen und bei denen dann psychische Einwirkungen ganz ohne Einfluß auf die Pupillengröße sind. Die Beobachtung Bumkes, daß solche Pupillen schlechter auf Licht reagieren, kann ich bestätigen, indem der Ausschlag bei der Lichtreaktion hinter dem der gesunden Versuchspersonen zurückblieb, offenbar eine Folge assimilierender, dem Dissimilationsprozeß des Lichtreizes im Reflexzentrum entgegenwirkenderVorgänge. Meines Erachtens kann man sich in solchen Fällen dadurch vor groben Irrtümern schützen, daß man die Untersuchung der Erweiterungsreaktionen unter Anwendung einer stärkeren Belichtung vornimmt. Dadurch wird der Tonus des Sphincters so weit verstärkt, daß zu seiner vollständigen Hemmung der Angstaffekt allein nicht ausreicht, so daß ein hinzugefügter Momentanreiz seine Wirkung an der Pupille äußern kann.

Soviel ich es nach meinen eigenen Untersuchungen (siehe auch weiter unten) zu beurteilen vermag und aus den Darstellungen anderer Autoren hervorgeht, kommt eine starke Herabsetzung oder ein Fehlen der Erweiterungsreaktionen bei verschiedenartigen Krankheitsformen vor, die aber alle das gemein haben, daß ihr Endausgang ein Verblödungszustand ist. In einem Erklärungsversuch, den $\mathrm{Bumke}$ für die katatonischen Pupillenstörungen gibt, sagt er: „Nahe liegt es ja und ich habe das deshalb schon in meiner früheren Mitteilung hervorgehoben, für das Fehlen einer von psychischen Vorgängen abhängigen Erscheinung eine erhebliche quantitative Herabsetzung eben dieser Vorgänge verantwortlich zu machen, eine Annahme, die bei katatonischen Stuporzuständen ohne weiteres berechtigt erscheint. Aber auch für die hebephrenischen und die paranoiden Formen würde diese Voraussetzung zutreffen, ist doch 
gerade die Affektlosigkeit, die gemütliche Stumpfheit das Symptom, das der oft rein äußerlichen Erregung dieser Kranken ein charakteristisches Gepräge gibt."

Ich habe des öfteren Gelegenheit gehabt, Kranke, die mit Sicherheit an manisch-depressivem Irresein litten und Zustandsbilder des manischen oder depressiven Stupors darboten, zu untersuchen und vermißte in keinem der Fälle die psychischen Pupillenreaktionen. Ebensowenig konnte ich mich von dem dauernden Fehlen dieser Irisbewegungen bei anderen Geisteskrankheiten überzeugen, die nicht durch dauernde organische oder wahrscheinlich organische (Dementia praecox) Veränderungen des Hirngewebes veranlaßt waren. Meines Erachtens haben wir daher in dem Symptom der fehlenden Pupillenunruhe und des Wegfalls der psychischen Erweiterungsreaktionen einen Ausdruck dauernder, wahrscheinlich organischer Veränderungen des Gehirns vor uns, deren Sitz wohl in seiner Rinde zu suchen sein wird. Wenn ich demnach auch nicht zugeben kann, daß die Ansicht Bumkes, nach der die Pupillenreaktionen auf psychische Reize ohne gleichzeitige Störung der Lichtreaktion nur bei der Dementia praecox und der Imbezillität dauernd fehlen können, zu Recht besteht, so gebührt diesem Forscher doch das große Verdienst, zuerst darauf aufmerksam gemacht zu haben, daß sich durch die Beobachtung des Pupillenspiels beim psychischen Geschehen tiefe Einblicke in die Funktionsfähigkeit des Gehirns tun lassen. Die Entdeckung Bumkes, daß bei gewissen Gehirnkrankheiten, über deren anatomische Ursachen wir zurzeit so gut wie nichts sicher wissen, typische Veränderungen der Pupillenbewegungen bestehen können, dürfte für die Diagnostik sowohl, wie noch mehr für die Forschung nach dem Wesen dieser Krankheiten von vielleicht ebenso weittragender Bedeutung werden, wie die Feststellungen Argyll Robertsons, als er die reflektorische Pupillenstarre von anderen Pupillenstörungen abtrennte.

Wohl sind einerseits die Schwierigkeiten, diese Symptome sicher festzustellen, noch ziemlich große, sie erfordern nicht nur Geduld und Beobachtungsgabe des Untersuchers, sondern auch optische Hilfsmittel, und bedarf es andererseits noch großer Versuchsreihen und Beobachtungen bei den verschiedensten Krankheitsbildern, bevor wir zu einer endgültigen Festlegung der Bedeutung dieser Ausfallserscheinungen kommen, aber ich bin überzeugt, daß es gelingen wird, auch hier die Spreu vom Weizen zu sondern und daß wir unter Einhaltung genügender Vorsichtsmaßregeln in ihnen ein wertvolles Kriterium für organisch bedingte Veränderungen der Hirnsubstanz erwarten dürfen.

Verstärkung der Erweiterungsreaktionen. Wie ich schon oben hervorhob, ist es zwar nicht leicht, ein einigermaßen sicheres vergleichsweises Urteil über die Veränderungen der Stärke der Reaktionen auf 
psychischen Reiz zu erhalten, da sich dieses einstweilen noch allein auf der subjektiven Schätzung des Untersuchers aufbaut. Wenn man jedoch sehr viele derartige Beobachtungen macht, so fallen gewisse Unterschiede der Reaktionsart in so deutlicher Weise auf, daß man wohl berechtigt sein kann, dabei von Abweichungen von der Norm, von Verringerung der Ausschläge sowohl, wie von besonders deutlichem oder schnellem Eintreten der Irisbewegungen zu sprechen. Auffallend große Ausschläge sah ich zuerst bei epileptischen Kranken, sowohl auf sensible, wie auf Schreckreize. Nachdem sich mein Urteil durch viele Untersuchungen geschärft hatte, fand ich auch noch bei anderen Krankheiten, so bei der Hysterie, in gewissen Phasen des manisch-depressiven Irreseins und endlich auch bei psychopathischen Individuen eine deutliche Steigerung dieser Reaktionen. Eine unter meiner Leitung von Linde ${ }^{1}$ ) durchgeführte Untersuchung einer größeren Anzahl epileptischer, hysterischer Kranker und Psychopathen bestätigte meine Vermutung, daß sich in vielen Fällen eine besonders ausgiebige, sensible und psychische Reaktion würde feststellen lassen. Bei den genannten Krankheitsformen traten die Erweiterungsreaktionen vielfach sehr rasch auf und die Ausschläge der Iris waren entschieden größer als bei dem normalen Durchschnitt. Den exakten Nachweis für die Tatsächlichkeit dieser subjektiven Feststellungen hoffe ich erbringen zu können, sobald es mir gelungen sein wird, meinem Apparat zur Pupillenkinematographie einen völlig geräuschlosen Gang zu verschaffen.

Die Erklärung dieser Erscheinung dürfte dann nicht schwer sein, besonders auch deshalb nicht, weil Linde fand, daß die Lichtreaktionsbewegung bei denselben Krankheiten vielfach ebenfalls schneller ablief als in der Norm. Wir haben hier offenbar den Ausdruck einer allgemein gesteigerten Empfindlichkeit der nervösen Apparate vor uns, die sich ja auch in dem sonstigen Verhalten derartiger Kranker meist deutlich zeigt. Die von anderen gemachte Beobachtung, daß die Pupillen bei den genannten Erkrankungen hie und da schlechter bzw. langsamer auf Licht reagieren als gewöhnlich, wird unsere Überlegungen nicht stören, da ein derartiges Verhalten sich leicht aus einem Uberwiegen der Hemmungsreize gegenüber den anderen erklären läßt, wie dies auch die dabei beobachtete starke Mydriasis kundtut. Ist die corticale Hemmung des Lichtreflexes eine vollständige, so sehen wir die weiter oben besprochene Pupillenstarre vor uns, bei der wir einen Reizzustand von Hirnrindenelementen als Ursache annehmen. Wir können uns daher nicht wundern, daß sowohl bei Epileptischen wie auch bei Hysterischen im Anfall absolute Pupillenstarre vorkommt, bei der die Iris weder auf Licht noch auf sensible und psychische Reize sich verändert. Nicht sehr selten konnte

1) Linde, M., Pupillenuntersuchungen an Epileptischen, Hysterischen und Psychopathischen. Kraepelins Psychol. Arb. 5, 209. 1907. 
ich eine Steigerung der Erweiterungsreaktionen auch im Beginn der Dementia praecox bei akuten katatonischen Erregungen beobachten. Vielleicht haben wir es dabei mit der Lähmung verausgehenden Reizerscheinungen $\mathrm{zu}$ tun.

Es liegt nun sehr nahe, den Versuch zu machen, ob die mit Wahrscheinlichkeit als Äußerung einer vermehrten Reizbarkeit des Zentralnervensystems aufzufassende Steigerung der Erweiterungsreaktionen durch die gewöhnlichen Sedativa, z. B. Brom, in ähnlicher Weise beeinflußt werden, wie ich dies für die Kniesehnenreflexe nachwies. Eine exakte derartige Untersuchung ist meiner Ansicht nach jedoch auch nicht eher möglich, bis eine einwandfreie, geräuschlose, photographische Aufnahme der Pupillenbewegungen bei psychischen Reizen gelingt, so daß ich einstweilen von solchen Versuchen Abstand nahm.

\section{Veränderungen der Pupillenweite und Pupillenform.}

Bei unseren Besprechungen der Untersuchungsergebnisse beim gesunden Menschen stellten wir eine gewisse Normalbreite für die Größe des Pupillendiameters bei verschiedener Stärke der Belichtung fest. Größere Abweichungen von den dort aufgestellten Mittelwerten werden wir als pathologische Erscheinungen auffassen müssen und nach einer Störung im nervösen Apparat suchen, die zur Erklärung der gefundenen Veränderungen dienen kann.

Seit wir die Wirkungen psychischer Einflüsse auf die Irisinnervation genauer kennen gelernt haben, seit wir darauf aufmerksam wurden, daß psychische Erregungen sich auch in einer Mydriasis äußerlich sichtbar machen können, erscheint uns die Tatsache, daß die Pupillen Geisteskranker vielfach weiter sind als die gesunder, nicht ,nervöser" Menschen, im allgemeinen erklärlich. Wir dürfen wohl annehmen, daß bei den meisten psychischen und nervösen Erkrankungen, wenn nicht dauernd, so doch wenigstens im Beginn des Leidens eine Steigerung der nervösen Reizbarkeit besteht, die dann unter Umständen eine erhebliche Vergrößerung der Pupillen hervorruft.

Eine abnorme Weite der Pupillen kann nun, wie wir gesehen haben, nicht nur Folgeerscheinung einer gesteigerten Erregbarkeit der auf die Pupillenzentren wirkenden Elemente des Zentralnervensystems sein, vielmehr wird dieselbe Erscheinung vielfach durch Unterbrechungen der Pupillenverengerungsbahnen hervorgerufen. Wir werden demnach zwei versehiedene Formen der Mydrasis bzw. Miosis mit Rücksicht auf ihre Entstehungsursache unterscheiden müssen, je nachdem diese Veränderungen der Pupillenweite als Reizerscheinung (gesteigerte nervöse Erregbarkeit) oder als Lähmungserscheinung (Unterbrechung der Verengerungsbahn, herabgesetzte Erregbarkeit) zu deuten sind. 
Untersuchen wir die Pupillen desselben gesunden Menschen unter genau denselben äußeren Bedingungen an verschiedenen Tagen, so finden wir keineswegs immer dieselbe Weite der Pupillen, vielmehr zählt es zu den Seltenheiten, wenn wir nicht Abweichungen finden, die vielfach bis $1,0 \mathrm{~mm}$ und darüber betragen. Diese Feststellung ist überaus leicht erklärlich, wenn wir berücksichtigen, daß die Pupillengröße die Resultante der Wirkung der verschiedenartigsten Nerveineinflüsse ist. Wie diese Ursache der beständigen kleinen Irisschwankungen, der Pupillenunruhe, sind, so veranlassen sie auch länger dauernde Veränderungen der Pupillenweite, wenn die eine oder andere Innervation das Ubergewicht bekommt, sei es nun durch Einwirkungen des Stoffwechsels oder durch psychische Vorgänge. Wollen wir eine Normalbreite für die bei einer bestimmten Kategorie von Personen vorkommende Pupillenweite bestimmen, so tun wir demnach gut, unsere Versuche bei derselben Person mehrmals zu wiederholen und dann das Mittel der hierbei gefundenen Werte als Pupillenweite zu nehmen.

In der Fig. 43 habe ich die Ergebnisse eines größeren Teiles meiner Pupillenuntersuchungen, soweit es sich um Feststellung der Pupillenweite handelte, dargestellt. In der ersten senkrechten Kolumne trug ich die Pupillenweite, die bei einer beiderseitigen Beleuchtung der Augen mit einem 6 MK. starken Licht bei den einzelnen Kategorien, Gesunden und Kranken, gefunden wurde, ein, und zwar im Prozentverhältnis der für die einzelnen Größen anfallenden Personen. In der zweiten Kolumne wurden in gleicher Weise die Pupillenweiten bei beiderseitiger Bestrahlung der Augen mit einem ca. $276 \mathrm{MK}$. starken Licht eingetragen. In der dritten endlich finden wir die Größe der nach einer beiderseitigen Steigerung der Belichtung von ca. 6 auf ca. 276 MK. eintretenden Pupillenverengerung verzeichnet.

Diese Tabelle gründet sich auf die Untersuchung von 84 gesunden Personen, 126 Kranken, die, soweit man von Sicherheit in der klinischen Diagnostik unter Berücksichtigung des Krankheitsverlaufs reden kann, sicher an Dementia praecox litten, 120 epileptischen, hysterischen oder psychopathischen Personen, 112 Alkoholisten und 163 Paralytikern. Zu diesen statistischen Aufstellungen wurden die unter meiner Leitung von Linde bei Hysterischen, Epileptischen und Psychopathen (70 Fälle) und von Neussell'1) bei chronischen Alkoholisten (63 Fälle) durchgeführten Untersuchungen mit verwendet, indem ich sie durch meine eigenen Meßresultate ergänzte. Durch Pfeile wurde die für die Norm gefundene Mitte der Werte angedeutet, so daß sich Abweichungen davon bei den verschiedenen Krankheiten deutlich zeigen.

1) Neusell, L., Das Verhalten der Pupillen bei Alkoholismus. Kraepelins Psychol. Arb. 5, 408. 1908. 
Nach diesen Aufstellungen können wir als mittlere Pupillengröße beim Gesunden (Licht beiderseits ca. $6 \mathrm{MK}$. stark) 4,6-5,5 mm annehmen, die Weite der Pupillen schwankt zwischen 3,6 und 6,5 mm. Bei beiderseitigem Lichteinfall von ca. $276 \mathrm{MK}$. Stärke hatten die meisten Personen Pupillen von $2,6-3,5 \mathrm{~mm}$, bei den übrigen fanden sich Werte von $2,1-4,5 \mathrm{~mm}$. Die Pupille verkleinerte sich bei Verstärkung des Lichtes von ca. 6 auf $276 \mathrm{MK}$. meist um 1,1-2,0 mm, manche Personen wiesen stärkere Reaktionen, bis zu $3,0 \mathrm{~mm}$ Pupillenverengerung auf.

\begin{tabular}{|c|c|c|c|c|}
\hline$\%$ & $\begin{array}{c}\text { Pupillenweite } \\
\text { (beiders. Belichung (ca O Mk)) }\end{array}$ & $\begin{array}{c}\text { Pupillenweite } \\
\text { (beiders. Belichtung (ca } 278 \mathrm{Mk}) \text { ) }\end{array}$ & $\mid$\begin{tabular}{c|} 
Pupillenverengerung \\
hrieiders. Lichtreiz (ca $270 \mathrm{Mk})$
\end{tabular} & \\
\hline . & & & & \multirow{3}{*}{ Norm } \\
\hline & & & & \\
\hline & $26-50-245$ & & 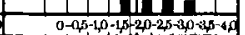 & \\
\hline 50 & & & & \multirow{4}{*}{$\begin{array}{c}\text { Dementia } \\
\text { praecox }\end{array}$} \\
\hline $\begin{array}{l}40 \\
30\end{array}$ & & & & \\
\hline & & & & \\
\hline & 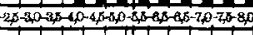 & $202-23-8$. & 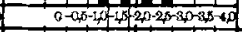 & \\
\hline 50 & 70 & & & \multirow{4}{*}{$\begin{array}{l}\text { Epilepsie } \\
\text { Hysterie } \\
\text { Psychopathie }\end{array}$} \\
\hline . & & & & \\
\hline & & & & \\
\hline & 10 & & Hat & \\
\hline 50 & & - & & \multirow{4}{*}{$\begin{array}{c}\text { Alkoholismus } \\
\text { chron. }\end{array}$} \\
\hline 40 & & & 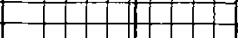 & \\
\hline & & & +1 & \\
\hline & 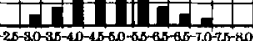 & 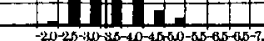 & $\ln ^{2}$ & \\
\hline 50 & & 1 & -1111 & \multirow{4}{*}{ Paralyse } \\
\hline & & & & \\
\hline $\begin{array}{l}30 \\
20\end{array}$ & & & & \\
\hline & $\frac{1}{4}$ & $20-25-1$ & $\theta$ & \\
\hline
\end{tabular}

Fig. 43 .

Vergleichen wir mit diesen Befunden die bei der nächsten Gruppe, der Dementia praecox, erhobenen, so finden wir bei schwacher Beleuchtung der Augen keine sehr wesentlichen Abweichungen; nur ein kleiner Teil der Kranken zeigte Vergrößerung des Pupillendiameters bis zu $8,0 \mathrm{~mm}$. Größere Abweichungen finden wir bei Anwendung stärkeren Lichtes. Die Pupillenweite blieb bei den meisten Versuchspersonen weiter als bei den Gesunden, nur wenige wiesen die bei letzteren meist vorkommende Enge von 2,6-3,5 mm auf, die Mehrzahl zeigte Pupillen von $3,1-4,5 \mathrm{~mm}$ Weite, bei manchen betrug sie gar 6,5 $\mathrm{mm}$. Die Erklärung für diese Erscheinung gibt uns die nebenstehende Aufzeichnung der Reaktionsbreite. Die Pupillen der an Dementia praecox Erkrankten 
reagierten vielfach nicht so ausgiebig auf Lichteinfall wie die der Gesunden. Wir haben weiter oben schon erwähnt, daß die Pupillen bei der Dementia praecox oft sehr weit sind und als Ursache hierfür eine stärkere Hemmung des Sphinctertonus infolge gesteigerter Reizbarkeit der diese vermittelnden, nervösen Elemente angenommen. Ich muß hier bemerken, daß es sich bei meinen Fällen vielfach um akute Erkrankungen, Anfangsstadien der Dementia praecox handelte, die auch in ihrem sonstigen Verhalten eine deutliche Steigerung der nervösen Reizbarkeit erkennen ließen. Diese zeigten dann, wie das wohl allgemein für die ,gespannten Katatoniker" bekannt ist, weite Pupillen bei Tageslicht. Die Verdunkelung (Herabsetzung der Lichtzufuhr auf 6 MK.) verstärkte diese Pupillenerweiterung nicht wesentlich, sie war also offenbar der Ausdruck einer verminderten, gehemmten Lichtreaktion. Diese Kranken ließen unter geeigneten Versuchsbedingungen (mittelstarke Beleuchtung von 25-30 MK.) die Reaktionen auf psychische und besonders sensible Reize nicht, wenigstens nicht völlig, vermissen. Nach alledem dürfte die Ursache für die bei Tageslicht abnorm weit erscheinenden Pupillen akut an Dementia praecox Erkrankter in einem Reizzustand der den Lichtreflex hemmenden Organe zu suchen sein. Verschwindet dieser im Verlauf der Krankheit, so macht er offenbar meist einer Lähmung Platz, die Pupillen werden enger und dann fehlen die Reaktionen auf psychische und sensible Reize.

In der nächsten Reihe sind die bei der Epilepsie, Hysterie und Psychopathie erhobenen Befunde zusammengefaßt. Man wird nach der Berechtigung einer derartigen Summierung fragen. Bei den Untersuchungen stellte sich heraus, daß betreffs der Pupillenweiten und Irisbewegungen bei diesen drei Krankheitsformen kein wesentlicher Unterschied zu finden war, ein Ergebnis, das nicht allzu auffallend ist, wenn wir bedenken, daß bei den genannten Krankheiten eines der hervorragendsten allgemeinen Merkmale die Steigerung der nervösen Reizbarkeit ist. Diese drückt sich auch deutlich in den dargestellten Pupillenbefunden aus. Zunächst ist die Pupillenweite bei schwacher Beleuchtung meist größer als in der Norm, sie bleibt auch bei Steigerung der Lichtstärke größer. Dieser Befund könnte auffallend erscheinen, wenn wir die dritte Kolumne betrachten und sehen, daß der Ausschlag bei der Belichtung im allgemeinen größer ist als bei den Gesunden. Dafür gibt uns aber ein leicht zu beobachtender Vorgang die Erklärung. Untersuchen wir Kranke der genannten Gruppe, so sehen wir bei der Belichtung zwar eine sehr starke, dabei rasche Verengerung der Pupillen eintreten, warten wir jedoch einige Zeit und lassen die Netzhaut sich adaptieren, so geht die Verengerung sehr stark zurück, viel stärker als beim Gesunden. Wir werden nicht fehlgehen, wenn wir als Ursache hierfür, wie auch für die abnorme Weite der Pupillen bei den genannten Krankheiten eine Steigerung der 
nervösen Reizbarkeit und dadurch bedingte, bald eintretende, starke Hemmung des Lichtreflexes annehmen, womit auch die Tatsache in Einklang steht, daß die auf psychische und sensible Reize eintretende Pupillenerweiterung bei den Untersuchten vielfach stärker war als in der Norm.

Die chronischen Alkoholisten zeigten bei schwacher Beleuchtung durchschnittlich engere Pupillen als die Gesunden; bei Einfall starken Lichtes gleichen sich diese Unterschiede ziemlich aus. Wollte man nun schließen, daß dementsprechend die Reaktionen auf Lichteinfall bei dieser Krankheitsform herabgesetzt seien, so überzeugt uns die Darstellung der hierbei gefundenen, zum Teil sehr hohen Werte von der Irrigkeit dieser Meinung. Der scheinbare Widerspruch der Aufstellungen erklärt sich dadurch, daß die weiten Pupillen der Alkoholisten ausnehmend gut auf Licht reagierten, während die bei schwachem Licht schon auffallend engen bei Lichtverstärkung nur wenig reagierten. Wir müssen daher bei diesen Kranken zwei Kategorien unterscheiden; die einen zeigen enge, wenig gut auf Licht reagierende, die anderen weite, bei Lichtzuwachs auffallend ausgiebig sich verengernde Pupillen. Auf diese Gruppenbildung werde ich weiter unten noch zurückkommen. Bei dem Alkoholismus chron. müssen wir offenbar, ähnlich wie bei der Dementia praecox, zwischen solchen Individuen, deren Gehirn durch die chronische Vergiftung so weit gelitten hat, daß Lähmungen, Herabsetzung der Erregbarkeit, geringere Grade von Demenz eingetreten sind, und solchen, die noch die Zeichen der akuteren Vergiftung, Reizerscheinungen darbieten, unterscheiden. Die ersteren haben dann infolge der verminderten sensiblen und psychischen Reizbarkeit und damit einhergehenden geringeren Hemmung des Lichtreflexes, zum Teil auch infolge direkter Schädigung der die Lichtreaktion vermittelnden Elemente engere, schlechter reagierende Pupillen, die anderen, wie die Epileptiker und Psychopathen, weite, sehr gut reagierende Pupillen. Ob diese letztere Eigenschaft allerdings allein auf Rechnung des Alkoholgenusses zu setzen ist, erscheint mir sehr fraglich, da wir bedenken müssen, daß der chronische Alkoholist vielfach von Hause aus schon ein minderwertiger, psychopathischer Mensch war.

In der letzten Reihe finden wir die bei der Paralyse erhobenen Befunde dargestellt. Die Pupillenweite war bei diesen Kranken bei Einfall schwachen Lichtes meist geringer als in der Norm, bei starker Beleuchtung dagegen häufig größer. Die Lichtreaktionsbewegung fehlte bei einem großen Teil derselben ganz, bei den anderen war sie meist sehr viel geringer als bei den Gesunden. Der letztgenannte Umstand erklärt die Tatsache, daß die Pupillen bei geringer Beleuchtung durchschnittlich enger, bei starker zum größeren Teil weiter sind als in der Norm. Die ganz weiten, mydriatischen Pupillen waren, wie unsere 
früheren Darlegungen schon zeigten, meist absolut starr, die ganz engen, miotischen zeigten reflektorische Starre, so daß die Grenzwerte für die Weite der Paralytikerpupillen, sowohl bei schwacher wie bei starker Belichtung, ziemlich gleich groß sind. Jedenfalls zeigen die Tabellen, daß eine Miosis bei der Paralyse nicht so häufig ist, wie man sie wohl anzunehmen gewohnt ist, daß dagegen eine starke Mydriasis bei dieser Erkrankung keine seltene Erscheinung ist.

In unserer Tabelle spiegelt sich deutlich die bekannte Erscheinung wieder, daß die Pupillen Geisteskranker vielfach weiter sind als die gesunder Personen, besonders bei heller Beleuchtung. Unsere Darlegungen zeigten aber auch, daß diese Erweiterung der Pupillen sehr verschiedenartige Ursachen haben kann. Die Beobachtung, daß ein Mensch abnorm weite Pupillen hat, kann uns allerdings vermuten lassen, daß sein Nervensystem irgendwie erkrankt ist, sie läßt jedoch keine Schlüsse auf die Art der Erkrankung zu. Erst der Vergleich der Pupillenweiten bei verschieden starker Belichtung der Augen, im Zusammenhalt mit dem Ausfall der Lichtreaktion, offenbart uns die Ursache der Vergrößerung der Pupillen. Hat ein Mensch sehr enge Pupillen, so können wir daraus nicht eher auf eine nervöse Erkrankung schließen, bis wir uns von dem Verhalten der Pupillen nach Verdunkelung der Augen überzeugt haben. Bleiben sie auch dann eng, so handelt es sich wohl zumeist um eine Erkrankung an Tabes, seltener Paralyse oder senile Demenz, oder wir haben ein Zeichen von Vergiftung mit Morphium, Opium, Nikotin, Alkohol, Brom usw. vor uns.

Erweiterung der Pupillen tritt nun auch noch bei Zuständen auf, die mit Geistes- oder Nervenkrankheiten nicht in direkter Verbindung stehen. Beim Asthma, bei drohender Erstickung (Chloroformnarkose), bei Endzuständen der Lungentuberkulose wurde Erweiterung der Pupillen beobachtet und dürfte als eine Intoxikationserscheinung aufzufassen sein. Bei starken Chokwirkungen, bei den Geburtswehen usw. findet ebenfalls häufig eine Erweiterung der Pupillen statt, die dann in die Reihe der auf psychische bzw. sensible Reize folgenden Erweiterunsreaktionen zu stellen ist.

Bei Nervenkranken finden wir häufig eine mehr oder weniger starke Pupillenungleichheit, eine Anisokorie. Früher glaubte man diese Erscheinung als ein bedeutsames Zeichen, besonders für eine organische Erkrankung des Zentralnervensystems, ansehen zu sollen, bis umfangreiche, statistische Arbeiten zeigten, daß eine Anisokorie bei den verschiedenartigsten nervösen Störungen vorkommen kann und geringe Grade derselben auch bei ganz gesunden Leuten beobachtet werden. Bei der Feinheit, mit der die Iris auf alle möglichen Reize reagiert, kann es nicht verwunderlich erscheinen, daß sich geringe Unterschiede in der Pupillenweite beider Augen, die doch die Resultante der verschieden- 
artigsten, nervösen Vorgänge ist, leicht einstellen, da wir anderenfalls eine sonst kaum zur Beobachtung kommende, genaue Utbereinstimmung der Reaktionen auf beiden Körperhälften voraussetzen müßten. Will man eine Pupillenungleichheit mit Sicherheit feststellen, so muß man die entsprechenden Messungen mehrmals wiederholen, da kleine Verschiebungen der Werte um $0,1-0,3 \mathrm{~mm}$ in kurzen $Z$ wischenräumen, in der Zeit, die verfließt, bis man eine Messung der Pupille vorgenommen hat, vorkommen, wodurch man irrtümlich zu der Annahme einer Anisokorie gelangen kann. Ich habe nur dann eine Pupillenungleichheit als bedeutsam aufgefaßt, wenn die Differenz der Pupillendurchmesser beider Augen mindestens $0,5 \mathrm{~mm}$ betrug. Unter dieser Voraussetzung fand ich bei Gesunden in ca. 3\%, bei der Dementia praecox in ca. $4 \%$, beim Alkoholismus in $8 \%$, bei der Epilepsie, Hysterie und Psychopathie in $20 \%$, bei der Paralyse in $26 \%$ und bei der Hirnlues in $40 \%$ der Fälle eine Pupillenungleichheit. Bei den Gesunden und den Kranken, die an Dementia praecox, Alkoholismus, Epilepsie, Hysterie oder Psychopathie litten, dürfte die Anisokorie im wesentlichen durch verschieden starke Innervation der den Sphincter hemmenden Elemente infolge von verschiedenartiger Anlage der beiden Hirnhemisphären oder erworbenen halbseitigen Störungen veranlaßt sein, während bei der Paralyse und Lues cerebri hauptsächlich Störungen in den Lichtreflexbahnen als Ursache für die Pupillendifferenz zu betrachten sind. Häufig kennzeichnet sich ein durch die letztgenannten Veränderungen bewirkter Größenunterschied der beiderseitigen Pupillen dudurch, daß derselbe verschwindet, wenn man die Beleuchtungsstärke ändert, worauf ich schon weiter oben, bei der Besprechung der reflektorischen Lichtstarre, hinwies.

Untersuchen wir Menschen mit Anisokorie häufiger, so finden wir zwar im allgemeinen immer wieder dieselbe Pupille größer als die andere, vielfach zeigt sich jedoch zunächst $\mathrm{z}$. B. die rechte, bei einer späteren Untersuchung dagegen die linke größer. Diesen Wechsel der Pupillengröße bezeichnet man als ,,springende Mydriasis", ein Ausdruck, der schlecht gewählt erscheint, da auf keinem der beiden Augen eine Mydriasis zu bestehen braucht und auch nicht immer die Innervation der weiteren Pupille gestört ist ${ }^{1-7}$ ). Das genannte Phänomen beobachtete

1) Mikloszewski, Alternierende Ungleichheit der Pupillen. Neurol. Centralbl. $1900,879$.

2) König, W., Utber ,springende Pupillen“" in einem Falle von cerebraler Kinderlähmung, nebst einigen Bemerkungen ïber die prognostische Bedeutung der ,springenden Pupillen" bei normaler Lichtreaktion. Deutsche Zeitschr. f, Nervenheilk. 15, 122.1899.

3) Riegel, W., Uther die springende Mydriasis. Deutsche Zeitschr. f. Nervenheilk. It, 169 . 1900 .

4) Piltz, J., Experimentell erzeugter reciproker Wechsel der Pupillendifferenz bei der progressiven Paralyse. Neurol. Centralbl. 1900, 434. 
ich nicht selten bei der Paralyse, aber fast noch häufiger bei der Epilepsie und Hysterie. Es erübrigt sich wohl, näher auf die Ursachen desselben einzugehen, die in dem verschiedenartigen Zusammenwirken von Erregung und Hemmung der Irisinnervation beruhen.

Besonders bei organischen Nervenleiden finden wir manchmal die Pupille nicht mehr kreisrund, sondern entweder zackig gerändert oder oval verzogen ${ }^{1}$ ). Solche entrundete Pupillen werden erfahrungsgemä $B$ später oft lichtstarr, wodurch die Unregelmäßigkeiten des Irissaumes eine gewisse diagnostische Bedeutung gewinnen, die allerdings nicht überschätzt werden darf. Ich kenne Leute, die schon jahrelang entrundete, im übrigen gut reagierende Pupillen zeigen, bei denen sich aber bisher keine Anzeichen irgendeiner nervösen oder psychischen Erkrankung einstellten. Braunstein und Piltz gelang es, künstlich Entrundung der Pupille durch isolierte Reizung einzelner Ciliarnerven zu erzeugen.

Vorübergehende Formveränderungen wurden unter anderen von Karplus bei der Hysterie und von Westphal $\left.{ }^{2}\right)^{3}$ ) bei Katatonischen beobachtet. Die Pupillen waren zugleich völlig oder fast ganz absolut starr. In einem von Karpl us mitgeteilten Falle reagierten die maximal weiten Pupillen nach dem hysterischen Anfall auf Licht sehr träge, und bei intensiver Beleuchtung nahm die vorher kreisrunde Pupille die Gestalt einer liegenden Ellipse an. Westphal beobachtete in einigen Fällen bei der Katatonie vorübergehende Veränderungen der Form an Pupillen, die zu anderer Zeit gut auf Licht und Konvergenz reagierten. Er sagt: „Dies normale Verhalten wechselte in ganz unregelmäßiger Weise mit Zuständen ab, in denen die Form der Pupillen und die Lichtreaktion sehr auffallende Veränderungen erlitt." "Sie bestanden zunächst in einer Formveränderung der Pupillen, die ihre kreisrunde Gestalt verloren, um eine querovale Form anzunehmen. Die Gestalt dieser liegenden Ovale war bei verschiedenen Untersuchungen eine wech-

5) GeBner, C., Ưber die springende Mydriasis. Münch. med. Wochenschr. 1901,429 .

6) Schaumann, O., Ủber die Häufigkeit und klinische Bedeutung der Pupillendifferenz nebst einigen speziellen Bemerkungen über die sog. ,,springende Mydriasis“. Zeitschr. f. klin. Medizin 49, 61. 1903.

7) Bielschowsky, A., Ein Beitrag zur Kenntnis der Pupillenphänomene. Klin. Monatsbl. f. Augenheilk. 41, 308. 1908.

1) Piltz, J., U̇ber den diagnostischen Wert der Unregelmäßigkeiten des Pupillenrandes bei den sog. organischen Nervenkrankheiten. Neurol. Centralbl.1903.

2) Westphal, A., Über ein im katatonischen Stupor beobachtetes Pupillenphänomen sowie Bemerkungen über die Pupillenstarre bei Hysterie. Deutsche med. Wochenschr. 1907.

3) Derselbe, Weitere Beobachtungen über im katatonischen Stupor beobachtete Pupillenphänomene nebst einem Erklärungsversuch der „katatonischen Pupillenstarre". Deutsche med. Wochenschr. 1909. 
selnde." „Stets waren die Umgrenzungen der von der Pupille gebildeten Ovale abgerundet; eckige, zackige Pupillarformen konnte ich niemals beobachten." „Die verzogenen, nicht mehr kreisrunden Pupillen reagierten auf Lichteinfall träge, bei stärkerer Entrundung wurde die Lichtreaktion eine minimale, bestand nur in einer gerade noch wahrnehmbaren Zusammenziehung des Irissaumes, während die quergestellte ovale Pupille häufig auch bei stärkster Beleuchtung lichtstarr erschien." Diese Erscheinungen traten manchmal nur einseitig auf, dann fehlte die konsensuelle Lichtreaktion auf dem betreffenden Auge, während die runde Pupille des anderen ungestörte Lichtreaktion darbot.

Die Erklärung dieser Störungen der Pupilleninnervation ist nicht leicht. Westphal sucht sie in Beziehung zu den übrigen bei katatonischen Kranken zur Beobachtung kommenden Spannungszuständen in der Körpermuskulatur zu setzen; davon weiter unten noch bei der speziellen Besprechung der Pupillensymptome der Dementia praecox. Am wahrscheinlichsten dürfte sich die Sache so verhalten, daß die in der Hirnrinde liegenden, die Hemmung der Sphincterinnervation vermittelnden Zellelemente in gewissen Stadien der Katatonie nur teilweise erkrankt, gereizt sind, so daß die dadurch erfolgende Hemmung sowohl einseitig, wie auch dort nur in der Bewegung einzelner Bündel der Irismuskulatur äußerlich sichtbar wird und ähnlich wie die Reizung einzelner Ciliarnerven verzogene Pupillen erzeugt. Die Beobachtung, daß die Lichtreaktion der betroffenen Augen im allgemeinen dabei herabgesetzt ist, spricht dafür, daß die übrigen Hemmungselemente zwar nicht so stark wie die vorhin gemeinten, aber doch noch in geringem Maße eine erhöhte Reizbarkeit zeigen. Der Wechsel der Pupillenform, d. h. die Veränderung der Stellung des Ovals fände dann vielleicht eine Erklärung in einem Wechsel von Erregung und darauffolgender Erschöpfung der betreffenden Rindenelemente. Danach wäre die Beobachtung dieser, wie es scheint, seltenen Pupillenerscheinungen - ich hatte bisher nie Gelegenheit, dieselben zu sehen - von weittragendster Bedeutung für die Auffassung des Wesens der Katatonie, indem sie uns darauf hinweisen muß, daß sich im Verlauf dieser Erkrankung organische Veränderungen in der Hirnrinde entwickeln, die zunächst Reizsymptome äußerlich sichtbar werden lassen, als Vorläufer späterer Lähmungserscheinungen.

\section{Pupillenstörungen bei versehiedenen Giftwirkungen und bei einigen Erkrankungen des Zentralnervensystems.}

Nachdem wir die unter physiologischen Bedingungen zu beobachtenden Pupillenerscheinungen besprochen und versucht haben, eine Darstellung der vorkommenden Störungen dieser Vorgänge zu geben, 
sollen im folgenden noch die Pupillenveränderungen bei bestimmten Giftwirkungen und einigen Erkrankungen des Zentralnervensystems in zusammenfassender Weise beschrieben werden. Wenn ich selbst auch nur vereinzelte Versuche über Giftwirkungen auf die Irisbewegungen anstellte, so glaubte ich auf eine Darstellung derselben doch schon der Vollständigkeit halber nicht verzichten zu sollen. Bei der Besprechung der Pupillenstörungen bei Erkrankungen des Zentralnervensystems werde ich nichts wesentlich Neues, das nicht schon in dem Voraufgegangenen dargestellt wäre, bringen, ich hielt es jedoch für zweckentsprechend, nachdem meine Darstellungen bisher nur unter dem Gesichtspunkte der Frage nach Art und Lokalisation der Störungen geschahen, in Kürze noch zusammenzustellen, welche Pupillenbefunde bei einzelnen $\mathrm{Er}$ krankungen des Nervensystems häufiger oder nur gelegentlich zu erwarten und für die Diagnostik der einen oder anderen Krankheit wichtig sind.

\section{Pupillenstörungen bei verschiedenen Giftwirkungen.}

Wir kennen eine ganze Anzahl von chemischen Mitteln, die imstande sind, eine Veränderung der Pupillenweite hervorzurufen oder die Bewegungserscheinungen der Iris zu verändern, zu beschleuigen, zu verlangsamen. Zum Teil wenden wir diese Substanzen häufig zu diagnostischen und therapeutischen Zwecken an, zum Teil treten die Pupillensymptome als Äußerungen von Vergiftungen in Erscheinung, sei es, daß dem Körper von außen Gifte zugeführt werden, sei es, daß sich im Organismus selbst Stoffe bilden, die eine Veränderung der Pupille und der Irisbewegungen verursachen.

\section{Pupillenreagenzien.}

Mydriatica. Unter den Medikamenten, die wir als Pupillenreagenzien benutzen, ist das Atropin das älteste und bestbekannte Mydriaticum. Schon im Jahre 1693 machte der Botaniker Johannes Ray darauf aufmerksam, daß in der Wurzel der Tollkirsche eine Substanz enthalten sei, die, in den menschlichen Organismus gebracht, eine Erweiterung des Sehlochs veranlasse. Die chemische Analyse ergab dann später, daß ein in der Belladonna enthaltenes Alkaloid, das Atropin, die pupillenerweiternde Fähigkeit besitzt. Wir verwenden meist dessen schwefelsaures Salz in $1 / 2-2$ proz. Lösung. Träufeln wir von dieser etwas ins Auge, so erweitert sich nach einigen Minuten die Pupille und wird nach ca. 10 Minuten fast maximal weit, zugleich absolut starr; nach 1-2 Stunden tritt noch eine Akkomodationslähmung hinzu, so daß wir einen Zustand wie bei der Ophthalmoplegia interna vor uns haben. Je nach der Stärke der verwendeten Lösung und der Empfind- 
lichkeit der Versuchsperson dauert die Störung 1-10 oder noch mehr Tage an.

Früher war man der Ansicht, daß der Irismuskel durch das Atropin gelähmt werde. Seit den Untersuchungen von Bernstein, Dogiel und besonders von $\mathrm{Schultz}^{1}$ ) kann es jedoch keinem Zweifel mehr unterliegen, daß die Atropinmydriasis durch eine Lähmung der Endigungen der Nn. ciliares breves veranlaßt ist. Die Nerven des Dilatators werden durch das Gift nicht affiziert. Der beim Atropingebrauch übrigbleibende, kleine Irissaum kann durch Reizung des Halssympathicus noch verkleinert bzw. zum Verschwinden gebracht werden. Umgekehrt entfaltet Atropin seine Wirkung auch noch an der durch Entfernung des Ganglion ciliare oder Durchschneidung des Sympaticus erweiterten Pupille. Die Wirkung des Homatropins ist der des Atropins ganz ähnlich, nur wird dabei die Akkommodation weniger stark mitbetroffen und die Wirkung verschwindet früher, nach 8-24 Stunden.

Energischer noch als Atropin wirkt das Scopolamin (Hyoscin), das sich bei subcutaner Anwendung durch sehr lange Dauer seiner Wirkung (bis 14 Tage und darüber) auszeichnet. Da das Hyosein bei Aufregungszuständen häufig als Sedativum zur Anwendung kommt, ist die Tatsache seiner langen Nachwirkung auf die Iris wohl zu beachten, damit man sich vor Fehlschlüssen bei der Pupillenuntersuchung schütze.

Ein weiteres Mydriaticum kennen wir im Cocain. Dieses Mittel erweitert die Pupille dadurch, daß es einen Reizzustand des Dilatators veranlaßt; es greift also an einer ganz anderen Stelle an als das Atropin und verwandte Substanzen, läßt aber ebenfalls den Muskel völlig unberührt. Die schwächeren Lösungen des salzsauren Salzes dieses Alkaloids $(2-3 \%)$ bringen nach 5-20 Minuten eine Erweiterung der Pupillen hervor, die nach kürzerer Zeit, 6-20 Stunden, wieder verschwindet. Die Iris bleibt dabei beweglich, die Pupille reagiert auf Lichteinfall und bei der Konvergenz vielfach ausgiebiger als ohne Cocaineinfluß. Die sensiblen und psychischen Reaktionen sind verstärkt, desgleichen ist die Pupillenunruhe lebhafter. Nehmen wir aber sehr starke Cocainlösungen, so tritt eine maximale Mydriasis mit absoluter Pupillenstarre auf, da nun auch, wie beim Atropin, die kurzen Ciliarnerven gelähmt werden.

Miotica. Unter den Mitteln, deren Instillation ins Auge eine Pupillenverengerung hervorruft, sind das Eserin (Physostigmin) und das Pilocarpin die wesentlichsten und gebräuchlichsten. Das Eserin zeigt der Atropinwirkung ganz entgegengesetzte Folgeerscheinungen. Dieses Mittel reizt die Endigungen der kurzen Ciliarnerven und führt dadurch

1) Schultz, P., ṫher die Wirkungsweise der Mydriaca und Miotica. Arch. f. Anat. u. Physiol. 1898, 47. 
eine Sphincterkontraktion und einen Akkommodationskrampf herbei. Seine Wirkung $(1 / 2-2 \%$ Lösung des salizylsauren Salzes) tritt sehr rasch in ca. 1-2 Minuten nach dem Einträufeln ein und erreicht in $1 / 2-1$ Stunde ihren stärksten Grad, um nach $1-1 \frac{1}{2}$ Tagen wieder zu verschwinden. Durch das Physostigmin wird die Reaktionsfähigkeit der Iris zwar nicht aufgehoben, aber naturgemäß stark eingeschränkt. Das Pilocarpin hat eine ganz ähnliche Wirkung.

\section{Pupillenveränderungen durch dem Körper zugeführte Gifte.}

Bei der Besprechung der Pupillenreagentien handelte es sich um Giftstoffe, die, direkt ins Auge gebracht, eine Wirkung auf die Pupilleninnervation zeigen; außerdem gibt es nun noch eine Reihe von chemischen Mitteln, die gewissermaßen indirekt die Irisbewegungen beeinflussen, indem sie, in den Körper aufgenommen oder dort entstanden, eine Veränderung der nervösen Reizbarkeit hervorrufen und dadurch auch eine Wirkung auf die die Irismuskulatur versorgenden Nerven äußern. Zunächst wollen wir einige wichtige Stoffe besprechen, die, in den Körper aufgenommen, Pupillenstörungen zeitigen können.

Alkohol. Eines der ,gebräuchlichsten" Gifte stellt der Alkohol dar. Die Bezeichnung des Alkohols, des ,Volksnährmittels", als Gift bedarf zunächst einer Erklärung. Die Giftigkeit einer Substanz ist bekanntlich keineswegs eine ihr immanente Eigenschaft, wie Aggregatzustand oder Dichte, sondern nur eine zufällige, bei ihrer Einwirkung auf gewisse Lebewesen hervortretende Reaktion, indem das Gift eine bestimmte, außerhalb der Norm liegende, chemische Veränderung in dem vergifteten Organismus hervorbringt. Aus der gesetzten Veränderung folgt dann die funktionelle Störung. Es gibt nun Stoffe, die in jeder Menge, auch der kleinsten, geeignet sind, den menschlichen Körper zu schädigen, bei anderen hingegen bedarf es einer gewissen Stärke der Dosis, bis der Organismus dadurch in seinen Funktionen gestört wird. Zudem ist die Empfindlichkeit für die Einwirkungen chemischer Mittel bei den Einzelindividuen sehr verschieden. Im gewöhnlichen Sprachgebrauch bezeichnen wir bekanntlich nur die chemischen Stoffe, von denen kleine Mengen schon genügen, Funktionsschädigungen des menschlichen Organismus hervorzurufen, als Gifte, und der Umgang mit solchen Stoffen ist durch gesetzliche Bestimmungen fest geregelt. $\mathrm{Zu}$ dieser Kategorie der Gifte gehört nun freilich der Alkohol nicht, und es wird keinem Staatsanwalt einfallen, den Veranstalter eines Sektgelages zur Verantwortung zu ziehen, trotzdem der $\S 229$ des deutschen Strafgesetzbuches lautet: „Wer einem anderen Gifte oder solche Stoffe beibringt, welche die Gesundheit zu zerstören geeignet sind..." wird bestraft. Der Alkohol ist aber dennoch in wissenschaftlichem Sinne als 
Gift zu bezeichnen, da er, in größeren Quantitäten genossen, bei jedem Menschen vorübergehende oder auch dauernde Schädigungen von Körperfunktionen nach sich zieht und ganz kleine Mengen desselben schon geeignet sind, bei Personen mit wenig widerstandsfähigem Nervensystem starke Störungen hervorzurufen. In dem Moment, wo eine solche schädigende Einwirkung nachweisbar ist, wird der Alkohol für den betreffenden Organismus zum Gift. Wollen wir daher die Wirkung des Alkohols auf die Irisinnervation studieren, so müssen wir unterscheiden: zwischen den Folgeerscheinungen kleiner und großer der Versuchsperson zugeführter Mengen und ferner nach Möglichkeit die körperlichen Qualitäten und auch die Größe der Versuchspersonen mit in Betracht ziehen. Nur so wird sich feststellen lassen, wann und in welcher Erscheinungsform sich eine Alkoholvergiftung an der Pupille der Versuchsperson äußert.

Untersuchungen über die Pupillenreaktionen im Rauschzustande besitzen wir von $G$ udden ${ }^{1}$ ) und $\mathrm{Cramer}^{2}$ ). Letzterer fand die Pupillenreaktionen sonst normaler Personen im Alkoholrausch nicht verändert. Bei geistig minderwertigen und alkoholintoleranten Individuen dagegen war die Reaktion auf Lichteinfall im Rausch vielfach träge. Gudden stellte fest, daß eine ganze Anzahl sinnlos Betrunkener fast keine Lichtreaktion der Pupillen mehr erkennen ließ, bei anderen war sie sehr träge. Nachdem die Berauschten ausgeschlafen hatten, stellten sich die normalen Reaktionen der Pupillen wieder ein; der Lichtreflex kehrte mit dem Wiedererwachen des Bewußtseins zurück. Manche der Untersuchten ließen allerdings noch längere Zeit eine Herabsetzung der Lichtreaktionen erkennen, während bei anderen die Reaktionsbewegungen der Iris am Tage nach dem Rausch auffallend stürmisch abliefen und sich hie und da hippusartige Schwankungen fanden.

Hübner ${ }^{3}$ ) stellte Versuche mit Studenten an, die wohl als chronische Alkoholisten aufzufassen waren. Nach Genuß von 6-8 Flaschen Bier fand sich bei dreien eine erhebliche Steigerung des Lichtreflexes und der Reaktionen auf psychische und schmerzhafte Reize, bei den übrigen war ebenfalls eine Vermehrung der Reizbarkeit an den Irisbewegungen zu bemerken, wenn auch nicht so deutlich wie bei den Erstgenannten. Vog $t^{4}$ ) verabreichte $\mathbf{4 0}$ geistig minderwertigen Personen (Idioten und Degenerierten) je $30 \mathrm{ccm}$ Rum oder Arrak in Gestalt von Grog und

1) Gudden, H., Die Pupillenreaktion bei Rauschzuständen und ihre forensische Bedeutung. Neurol. Centralbl. 1900, 1096.

2) Cramer, A., Über die forensische Bedeutung des normalen und pathologischen Rausches. Monatsschr. f. Psychiatrie 13, 36. 1903.

3) Hübner, A. H., Untersuchungen über die Erweiterung der Pupillen auf psychische und schmerzhafte Reize. Allgem. Zeitschr. f. Psychol. 1905, 616.

4) Vogt, H., Über die Wirkung des Alkohols auf die Veränderungen der Pupillenreaktion. Neurol. Centralbl. 1904. 586.

z. f. d. g. Neur. u. Psych. O. II. 
fand bei einem Drittel der Fälle Veränderungen der Pupillenreaktionen (Trägheit, Ungleichheit der Reaktion). Diesen Störungen ging meist eine Trübung des Bewußtseins parallel.

Es ist mir nicht bekannt, ob bisher systematische Untersuchungen der Alkoholwirkung auf die Pupillenreaktionen beim Normalen gemacht wurden, d. h., ob versucht wurde, etwaige Veränderungen dieser Bewegungen nach verschieden starken Alkoholgaben in verschiedenen Zeitabschnitten nach der Aufnahme des Mittels festzustellen. Die Untersuchungen Cramers an betrunkenen Studenten usw. können uns natürlich nur ein ganz oberflächliches Bild der Alkoholwirkung auf die Pupille geben; aus ihnen scheint jedoch das eine hervorzugehen, daß Fehlen der Lichtreaktion nicht zu den Erscheinungen des Rausches an sich, $d$. h. beim sonst gesunden Menschen gehört. Das Material, welches Gudden zu seinen Untersuchungen diente, ist ein recht verschiedenartiges. Es wurden wahllos alle in sinnlos betrunkenem Zustand ins Krankenhaus eingelieferten Personen untersucht, darunter befanden sich natürlich. neben sonst gesunden Personen, viele chronische Alkoholisten, Epileptiker, Hysterische, Psychopathen usw.; dazu waren die aufgenommenen Alkoholmengen nach Qualität und Quantität naturgemäß äußerst verschieden. Diese Untersuchungen können uns demnach nur das eine sagen, daß sich bei gewissen Individuen im Rausch auch an den Pupillen Erscheinungen zeigen, die auf eine schwere akute Schädigung des Gehirns zurückzuführen und in eine gewisse Parallele zum Bewußtseinszustand zu setzen sind. Daraus ergibt sich die praktische, von Gudden gezogene Nutzanwendung, daß man bei Rauschzuständen nicht versäumen soll, die Lichtreaktion der Pupillen zu prüfen, da ihr Fehlen in forensischen Fällen als ein wertvolles Beweismittel für den Nachweis eines sog. pathologischen Rauschzustandes dienen kann. Vogt zeigte, daß das Nervensystem psychisch minderwertiger Personen auch dadurch seine geringe Widerstandsfähigkeit gegen Alkohol offenkundig werden läßt, daß nach Aufnahme mittlerer Mengen dieses Mittels deutliche Störungen der Irisinnervation eintreten.

Ich machte nun den Versuch, beim gesunden Menschen die Wirkung kleinerer und größerer Alkoholmengen auf die Pupilleninnervation festzustellen. Nach Gaben von $20 \mathrm{ccm}$ Alkohol (in Gestalt von Kognak) konnte ich bei 5 Versuchspersonen keine deutlichen Veränderungen bemerken; die Pupillenweite war zwar bei zweien um 0,3 bzw. $0,5 \mathrm{~mm}$ vergrößert, bei schwacher Beleuchtung ( $1 / 4$ Stunde nach Aufnahme des Alkohols), doch dürfte diese Feststellung uns noch nicht zu besonderen Schlüssen berechtigen, da auch normalerweise bei verschiedenen Messungen derartige Größenunterschiede zur Beobachtung kommen. Die übrigen Versuchspersonen ließen keine Veränderung der Pupillenweite erkennen. Die Irisausschläge bei der Belichtung und bei psychischen 
und sensiblen Reizen unterschieden sich nicht von den beim Versuch ohne Alkohol beobachteten. Die Pupillenunruhe schien bei 3 Versuchspersonen, darunter die beiden obengenannten, verstärkt. Nach Zufuhr von $40 \mathrm{ccm}$ Alkohol geschahen die Lichtreaktionsbewegungen bei 4 Versuchspersonen auffallend prompt, die Differenz der Pupillenweite bei geringer und starker Belichtung war größer, um $0,2-0,8 \mathrm{~mm}$, die Reaktionszeit (Latenz und Kontraktionszeit) dagegen unverändert, so daß die mittlere Geschwindigkeit der Lichtreaktionsbewegung vergrößert erschien. Nach subjektivem Urteil liefen auch die Erweiterungsbewegungen bei sensiblen und psychischen Reizen schneller ab als unter normalen Bedingungen; die Pupillenunruhe war bei allen Versuchspersonen vermehrt. Nach diesen Beobachtungen führten meine Versuche zu dem nämlichen Resultat wie die Hübners, und ich erwähne sie deshalb. $\mathrm{Zu}$ einer exakten Prüfung der Alkoholwirkung bedarf es jedoch genauerer und von dem subjektiven Ermessen unabhängiger Untersuchungen, zu denen nur die geräuschlose, photographische Registrierung der Pupillenbewegungen herangezogen werden kann.

Ein vorläufiger Erklärungsversuch der geschilderten Erscheinungen nach mittleren Alkoholgaben dürfte eine Steigerung der Reflexerregbarkeit als ihre Ursache annehmen lassen. Beim Gesunden bedarf es offenbar sehr viel größerer Mengen, einer schweren Vergiftung, bis die Reizerscheinungen durch Lähmungswirkungen ersetzt werden, während nach den oben besprochenen Beobachtungen an psychisch minderwertigen oder durch chronischen Alkoholmißbrauch geschädigten Individuen solche Lähmungserscheinungen früher auftreten. Wenn ich hier die von den oben genannten Autoren beobachtete Pupillenstarre bzw. träge Lichtreaktion der Pupille als Lähmungserscheinung bezeichne, so folge ich dabei der Ansicht dieser Beobachter. Diese Pupillenerscheinungen könnten jedoch auch ganz anders verursacht sein. Sie könnten Äußerungen einer Hirnrindenreizung darstellen, die in ähnlicher Weise durch das Alkoholgift hervorgerufen wäre, wie die Pupillenstarre bei der Epilepsie möglicherweise durch die Hirnninde reizende Stoffwechselgifte gezeitigt wird. Vielleicht ist für die Annahme einer Reizwirkung auch der Umstand zu verwerten, daß bei sehr vielen der Guddenschen Fälle zur Zeit der Pupillenuntersuchung die Reizerscheinungen auf den übrigen Körpergebieten im Vordergrund standen; die Kranken waren ungebärdig, gestikulierten heftig, schimpften usw. Jedenfalls scheint mir eine einwandfreie Erklärung der Pupillenerscheinungen nach Alkoholgenuß und im Rausch noch nicht möglich, einige Klarheit könnten vielleicht systematisch durchgeführte Untersuchungen an einer größeren Reihe von Versuchspersonen mittels der photographischen Pupillenmeßmethode im Verein mit anderen psychologischen Versuchen bringen. 
Die Pupillenstörungen beim chronischen Alkoholismus sollen weiter unten getrennt besprochen werden, da sie vielfach nicht als direkte Folge der Alkoholaufnahme zu betrachten sind und andere individuelle Momente eine große Rolle dabei spielen.

Nicotin. Ein weiteres Genußgift, dessen Gebrauch zu Pupillenstörungen führen kann, ist das Nicotin. Dieses Gift gehört physiologisch zu der Pilocarpingruppe, und seine Wirkungen auf die Iris sind ähnlich denen, welche dieses Mittel erzeugt. Bringt man Nicotin in den Augenbindehautsack, so tritt nach einer kurz dauernden Pupillenerweiterung eine Miosis auf; denselben Vorgang beobachtet man bei der allgemeinen Nicotinvergiftung. Bei der chronischen Vergiftung soll sich sogar reflektorische Pupillenstarre entwickeln können, doch liegen hierüber noch zu wenig einwandfreie Beobachtungen vor. Das Atropin hat eine dem Nicotin völlig antagonistische Wirkung und beseitigt daher die Nicotinmiosis völlig.

Morphium. Opium. Schon auf geringe Dosen von Morphium oder Opium tritt beim Menschen eine Verengerung der Pupille ein, die auch noch bestehen bleibt, wenn die sonstigen Wirkungen dieser Mittel, wenigstens bei der groben Beobachtung, nicht mehr nachweisbar sind. Der chronische Morphiumgebrauch führt zu einer dauernden Miosis und gleichzeitigen Herabsetzung der Pupillenreaktionen. Bei Zeitmessungen der Pupillenbewegungen auf Lichteinfall fand ich bei Morphinisten weder die Reflex- noch die Kontraktionszeit der Irismuskulatur gegen die Norm verändert, während die Größe der Reaktionsbewegung verkleinert, mithin also auch die mittlere Geschwindigkeit dieses Vorganges vermindert war. Bei der Entziehungskur weicht die Miosis bekanntlich bald einer Mydriasis; auch jetzt waren die Reflex- und Kontraktionszeiten nicht verändert, die mittlere Geschwindigkeit der Bewegung jedoch erhöht. In keinem Falle von Morphinismus vermißte ich die Reaktionen auf psychische, sensorische oder sensible Reize; während der Entziehungskur waren sie vielfach sehr deutlich, stärker wohl als in der Norm zu beobachten.

Außer den vorgenannten kennen wir noch eine ganze Reihe von Giften, deren Aufnahme in den menschlichen Organismus zu Störungen der Irisbewegungen führen kann, doch würde ihre Besprechung hier zu weit führen. Ich verweise daher auf die diesbezüglichen Zusammenstellungen von Uhthoff') und von Albrand und Schroeder ${ }^{2}$ ); die Tabellen der letztgenannten Autoren sind im wesentlichen auch in der Pupillenlehre von Bach wiedergegeben.

1) Uhthoff, Die Augenveränderungen bei Vergiftungen und Erkrankungen des Nervensystems und des Gehirns. Handb. d. ges. Augenheilk. v. Saemisch 11. 1904 .

2) Albrand, W., u. Schroeder, Ch., Das Verhalten der Pupille im Tode. Halle a. S. 1905 . 


\section{Beeinflussung der Pupille durch im mensehlichen Organismus er- zeugte Gifte.}

Zum Schlusse unserer Betrachtungen über die Veränderungen der Pupille und der Irisbewegungen durch Giftwirkungen möchte ich nicht unterlassen, kurz einige Pupillenstörungen zu streifen, deren Ursache vielleicht in einer Autointoxikation zu suchen ist, für deren Zustandekommen wir möglicherweise Giftstoffe verantwortlich machen können, die durch Erkrankung oder fehlerhafte Anlage einzelner Organe des Körpers in diesem entstehen oder als Abfallprodukte im Blutstrom kreisen.

Im Jahre 1899 machte Lewandowsky $y^{1}$ ) darauf aufmerksam, da/3 nach intravenöser Injektion von Adrenalin neben anderen Erscheinungen am Auge Erweiterung der Pupille eintritt. Bekanntlich ist das Adrenalin die wirksame Substanz des Extraktes der Nebennieren und seine Wirkung nach den Untersuchungen Langleys, Elliots und anderer vollkommenen in Parallele zu stellen mit dem Effekt einer Sympathicusreizung.

Ein Utberschuß von Adrenalinproduktion und Erguß in die Blutbahn müßte demnach zu einer Pupillenerweiterung führen und es liegt vielleicht da, wo wir zugleich neben einer Mydriasis dauernde Blutdrucksteigerung beobachten, eine derartige oder ähnliche Giftwirkung vor. Diese Vermutung mag zurzeit sehr gewagt erscheinen, doch sollte man meines Erachtens einerseits keine nachweisbare, wenn auch noch so geringfügige Störung nervöser Vorgänge unbeachtet lassen, besonders bei Krankheiten, die wenige für uns erkennbare, körperliche Symptome bieten - ich denke dabei hauptsächlich an das manisch-depressive Irresein - und andererseits dürften ursächliche Momente für diese Erkrankungen noch am ehesten in Veränderungen des Stoffwechsels der Betroffenen zu suchen sein, sei es, daß sie durch eine mangelhafte Organanlage oder durch erworbene Organveränderungen verursacht sind.

In seiner Arbeit über die Pupillenstörungen bei Geistes- und Nervenkrankheiten widmet Bumke dem Verhalten der Pupille in der Erschöpfung einen besonderen Abschnitt. Er geht dabei von der bekannten klinischen Beobachtung aus, daß in vielen Erschöpfungszuständen, bei hochgradiger Müdigkeit, im Hungerzustande und ebenso bei anämischen Kranken die Pupillen oft auffallend weit sind. Er machte selbst die Beobachtung, daß häufig abstinierende Geisteskranke, die zur Zeit ihrer Aufnahme in der Anstalt maximale Mydriasis zeigten, nach der künstlichen Ernährung in einigen Tagen normale Weite der Pupillen erkennen ließen.

1) Lewandowsky, M, L̀ber die Wirkungen des Nebennierenextraktes auf die glatten Muskeln, im besonderen die des Auges. Arch. f. Anat. u. Physiol. (Physiol. Abt.) 1899, 360. 
Bumke stellte daraufhin an dem Pflegepersonal der psychiatrischen Klinik Versuche über den Einfluß der Ermüdung auf die Irisinnervation an, indem er bei den zur Nachtwache verwendeten Pflegern die $\mathrm{Pu}$ pillen abwechselnd nach durchschlafener und nach durchwachter Nacht untersuchte. Er fand, daß die Pupillen aller Versuchspersonen am Morgen nach durchwachter Nacht größer waren als zur gleichen Zeit an anderen Tagen und am Abend des Tages zuvor. Die Reaktion auf Lichteinfall und bei der Konvergenz war nicht nachweisbar verändert, die Empfindlichkeit der Iris gegenüber sensiblen Reizen dagegen gesteigert und die Pupillenunruhe vermehrt. Bei der Prüfung des ,galvanischen Lichtreflexes" stellte sich heraus, daß die Lichtempfindlichkeit erhöht war, die galvanische Reflexempfindlichkeit hingegen vermindert erschien. B u mke schreibt: „Eine völlig befriedigende Erklärung dieser ganz verschiedenen Beeinflußung von Licht- und Reflexempfindlichkeit durch die Ermüdung ist zurzeit wohl noch nicht möglich, wir müssen uns begnügen festzustellen, daß dieselben Momente, welche die subcortical verlaufenden Reflexbahnen (möglich wäre ja auch eine Ermüdung des Sphincter iridis, die anzunehmen aber doch eigentlich kein Grund vorliegt), in ihrer Leitungsfähigkeit schädigen, die Erregbarkeit gewisser corticaler Zentren zu erhöhen vermögen und dürfen dabei noch einmal daran erinnern, daß auch die sensible Erweiterung, Psychoreflexe und Pupillenunruhe, alles ebenfalls von der Hirnrinde abhängige Reaktionen, durch die gleichen Faktoren gesteigert worden waren."

Ich machte die gleichen Versuche wie Bumke und fand ebenfalls, daß die Pupille nach durchwachter Nacht vergrößert war und die Reaktionen auf psychische und sensible Reize verstärkt erschienen. Die Reaktionszeiten bei der Verengerung auf Lichteinfall waren nicht wesentlich verändert. Auffallend war eine schnelle Ermüdbarkeit, d. h. die Pupille wurde sehr bald wieder weiter, der Effekt der Belichtung ließ bald nach. Die Messungen waren erschwert durch dauerndes, lebhaftes Schwanken des Irissaumes.

Demnach sprechen auch meine Versuchsresultate für eine Veränderung der Reizbarkeit der die Iris versorgenden Nervenelemente. Meines Erachtens dürften sich die beobachteten Erscheinungen auf eine gemeinsame Ursache mit gleichlautender Veränderung der nervösen Reizbarkeit zurückführen lassen. Es liegt zunächst kein Anlaß vor, wie auch Bumke richtig hervorhebt, eine Ermüdung des Sphincter iridis anzunehmen, da dieser Muskel ja in den wenig erleuchteten Schlafräumen kaum sehr angestrengt werden kann. Nehmen wir dagegen eine Steigerung der Reizbarkeit der Hirnrindenelemente an, so erklären sich alle bisher festgestellten Tatsachen ungezwungen. Die Steigerung der Reaktionen auf psychische und sensible Reize, ferner auch die Herabsetzung der galvanischen Reflexempfindlichkeit erscheint be- 
greiflich, wenn wir bedenken, daß die gesteigerte Reizbarkeit der antagonistisch wirkenden Hirnrinde zu Hemmungserscheinungen der Spincterinnervation führen muß, so daß stärkere Reize notwendig werden, um eine Pupillenverengerung hervorzurufen; umgekehrt genügen dann geringere Anstöße, um eine Erweiterung zu veranlassen. Die Steigerung der galvanischen Lichtempfindlichkeit beim Ermüdeten wird keine Änderung unserer Anschauung bedingen, da auch sie ungezwungen als Ausdruck einer gesteigerten Reizbarkeit der nervösen Organe aufgefaßt werden kann.

Die Ermüdungserscheinungen kommen nun bekanntlich durch eine Anhäufung von Stoffwechselprodukten, namentlich von Produkten unvollkommener Oxydation zustande, sie sind also gleichbedeutend mit einer Vergiftung. Mithin müssen wir die bei der Ermüdung und in der Erschöpfung auftretenden Pupillenerscheinungen mit zu den durch Intoxikation veranlaßten zählen. Gönnt man dem Organismus Zeit zur Erholung, so verschwinden die Pupillenerscheinungen wieder, wie ich mich bei meinen Versuchspersonen überzeugen konnte. Nach ungefähr 6stündigem Schlaf war die Erweiterung verschwunden und die Auslösung der psychischen Reflexe nicht mehr erleichtert. Ist jedoch die Selbststeuerung des Stoffwechsels gestört, tritt z. B. nach starken Anstrengungen nicht die physiologischerweise zu erwartende Ruhe, der Schlaf, ein, so gelingt es dem Organismus nicht, die ihn schädigenden Abfallstoffe auszuspülen, und nun kommt es zu einer Steigerung der nervösen Reizbarkeit und zugleich zu den oben genannten Pupillenstörungen, die sich wohl allmählich noch verstärken und zu länger dauernden Symptomen werden können. Hierhin dürften die Pupillenerscheinungen, Erweiterung, Verstärkung der psychischen Reaktionen, manchmal verbynden mit träger Lichtreaktion zu zählen sein, die wir bei Zuständen starker Erschöpfung, nach länger dauernder Nahrungsverweigerung usf. sehen.

\section{Veränderungen der Pupille und der Irisbewegungen bei verschiedenen Erkrankungen des Zentralnervensystems.}

\section{Paralyse.}

Bei der progressiven Paralyse treffen wir bekanntlich sehr häufig Pupillenstörungen an, und wir besitzen eine ganze Reihe von Arbeiten, in denen diese Erscheinungen genaue Berücksichtigung fanden. Leider wurde bei vielen der früheren Untersuchungen nicht streng zwischen der reflektorischen und absoluten Pupillenstarre unterschieden, vielmehr nur festgestellt, ob die Lichtreaktion erhalten, ob sie geschwächt oder erloschen war, ohne bestimmten Hinweis darauf, ob die Konvergenzreaktion dabei völlig intakt war. Ich gebe zunächst eine Zusammen- 
stellung einiger Statistiken, die von verschiedenen Forschern an gröBerem Krankenmaterial gewonnen wurden und füge meine eigene bei, indem ich dabei zunächst auch nicht zwischen reflektorischer und absoluter Pupillenstarre unterscheide.

\begin{tabular}{|c|c|c|c|c|}
\hline & $\begin{array}{c}\text { Anzahl } \\
\text { der Fälle }\end{array}$ & $\begin{array}{c}\text { Fehlen der } \\
\text { Lichtreaktion } \\
\%\end{array}$ & $\begin{array}{c}\text { Träge } \\
\text { Lichtreaktion } \\
\% \\
\end{array}$ & $\begin{array}{c}\text { Gute } \\
\text { Lichtreaktion } \\
\% \\
\end{array}$ \\
\hline Gudden $\left.^{1}\right) \ldots .$. & 1326 & 41 & 36 & 23 \\
\hline Moeli ${ }^{2}$ ) . . . . & 500 & 47 & 24 & 28 \\
\hline Thomsen $^{3}$ ) ... & 366 & 47 & 22 & 31 \\
\hline Retzlaff ${ }^{4}$ ).... & 255 & 49 & 28 & 23 \\
\hline Joffroy $)^{5}$. & 227 & 55 & 20 & 25 \\
\hline Hirschl $\left.{ }^{6}\right)$ & 200 & 50 & 27 & 23. \\
\hline Wollenberg ${ }^{7}$ ). . & 178 & 50 & 30 & 20 \\
\hline Siemerling ${ }^{8}$ )... & 151 & 50 & 14 & 36 \\
\hline A. Westphal $\left.{ }^{9}\right)$.. & 148 & 50 & 26 & 24 \\
\hline$W^{r}$ eiler $\left.{ }^{10}\right) \ldots$ & 550 & 42 & 40 & 18 \\
\hline Durchschnitt bei . . & 4101 & 48 & 27 & 25 \\
\hline
\end{tabular}

Aus der Tabelle ergibt sich mit guter Utbereinstimmung das Resultat, daß bei der Paralyse in ca. der Hälfte der Fälle die Lichtreaktion der Pupille erloschen war, in einem weiteren Viertel war sie als träge, un-

1) Gudden, H., Zur Ätiologie und Symptomatologie der progressiven Paralyse. Arch. f. Psych. 26, 430. 1894.

2) Moeli, Uber die reflektorische Pupillenstarre bei der progressiven Paralyse. Arch. f. Psych. 18, 1. 1887.

3) Thomsen, Zur diagnostischen Bedeutung der Pupillenphänomene, speziell der reflektorischen Pupillenstarre, bei Geisteskranken. Charité-Ann. 11, 339. 1886.

4) Retzlaff, K., Die diagnostische Bedeutung der Pupillenstarre und der Pupillenträgheit für die Erkennung von Nerven- und Geisteskrankheiten. J. D. Berlin 1907. 1904.

5) Joffroy, Des signes oculaires dans la paralysie générale. Arch. de Neurol.

6) Hirschl, Die Ätiologie der progressiven Paralyse. Jahrb. f. Psych. 14, 321. 1896.

7) Wollenberg, Statistisches und Klinisches zur Kenntnis der paralytischen Geistesstörung beim weiblichen Geschlecht. Arch. f. Psych. 26, 472. 1894.

8) Siemerling, Statistisches und Klinisches zur Lehre von der progressiven Paralyse der Frauen. Charité-Ann. 13, 384. 1888.

9) Westphal, A., Ätiologisches und Symptomatologisches zur Lehre von der progressiven Paralyse der Frauen. Charité-Ann. 1893.

10) Weiler, K., Pupillenuntersuchungen bei Geisteskranken. Neurol. Centralblatt 1906,475 . 
ausgiebig zu bezeichnen und nur ungefähr ein Viertel der Kranken ließ keine deutliche Störung der Lichtreaktion erkennen. Um nun ein annähernd genaues Urteil über die Häufigkeit der reinen reflektorischen Lichtstarre zu bekommen, unterzog ich meine an 550 Fällen gemachten Beobachtungen einer kritischen Sichtung, indem ich eine Trennung in dem Sinne vornahm, daß alle Fälle, die bei völlig intakter Konvergenzreaktion ein Fehlen oder eine starke Einschränkung der Lichtreaktion erkennen ließen, als solche mit reflektorischer Lichtstarre zusammengefaßt wurden. Diejenigen, bei denen beide Reaktionen fehlten, oder sich stark eingeschränkt erwiesen, wurden zur Gruppe der absoluten Starre genommen, so daß als gut reagierende nur die Pupillen bezeichnet wurden, die ganz normale Licht- und Konvergenzreaktionen darboten.

Unter diesen Gesichtspunkten verteilten sich die Pupillenbefunde so, daß $43 \%$ der Fälle reflektorische Starre und $41 \%$ absolute Starre zeigten, so daß nur $16 \%$ normale Pupillenreaktionen erkennen ließen.

Vergleichen wir damit die Resultate unserer genauen Messungen bei 163 Paralytikern, so fanden wir bei 57\% der Untersuchten eine vollkommene oder unvollkommene reflektorische Starre, bei $34 \%$ ließ sich eine vollkommene oder unvollkommene absolute Starre feststellen, nur $9 \%$ der Kranken zeigten ganz normale Reaktionen.

Zur Erklärung der Differenz dieser Resultate möge folgendes dienen. Einerseits geschahen die Beobachtungen der erwähnten 550 Kranken unter wesentlich ungünstigeren Bedingungen als die der letztgenannten, sie wurden nur mit einer einfachen Handlampe gemacht, und andererseits dürften unter diesen "Paralytikern" auch noch manche Kranke sein, bei denen wir heute diese Diagnose nicht mehr stellen würden, die vielmehr entweder als Fälle von cerebraler Lues aufzufassen wären, oder als Arteriosklerotiker, Alkoholisten usw. Die Verschiebung der Diagnose in dem Sinne, daß manche der Kranken wohl an Hirnlues litten, würde wahrscheinlich eine Verminderung der Prozentzahl der absoluten Starre mit sich bringen, die Ausschaltung der anderen nicht paralytischen und nicht luetischen Kranken den Satz der normal reagierenden Pupillen herabsetzen. Wesentlichere Bedeutung hat jedoch die verfeinerte Untersuchungsmethodik, mit deren Hilfe es gelang, auch feinere, der groben Untersuchung entgehende Störungen aufzudecken.

Die Frage, ob die reflektorische Lichtstarre als ein spezifisch tabisches Symptom bei der Paralyse zu betrachten ist, beantworten manche Autoren bejahend. Prüfen wir daraufhin unsere Fälle, zunächst die 550 grob untersuchten, so läßt sich folgende Tabelle aufstellen: 


\begin{tabular}{|c|c|c|c|}
\hline \multirow{2}{*}{ Falle mit: } & \multicolumn{3}{|c|}{ Reflexe } \\
\hline & normal & gesteigert & fehlen \\
\hline reflektorischer Starre & $18 \%$ & $50 \%$ & $32 \%$ \\
\hline absoluter Starre & $13 \%$ & $52 \%$ & $35 \%$ \\
\hline normalen Reaktionen & $22 \%$ & $66 \%$ & $12 \%$ \\
\hline
\end{tabular}

Als fehlend wurden die Kniesehnenreflexe auch dann bezeichnet, wenn sich nur noch eine minimale Quadricepszuckung auslösen ließ (bei öfterer Untersuchung). Nach dieser Aufstellung wäre kein wesentlicher Unterschied der Reflexveränderungen bei den Fällen mit reflektorischer gegenüber denen mit absoluter Pupillenstarre vorhanden.

Betrachten wir die 163 genau untersuchten Fälle ebenfalls unter diesem Gesichtspunkte, so kommen wir zu folgenden Feststellungen:

\begin{tabular}{|c|c|c|c|}
\hline \multirow{2}{*}{ Falle mit: } & \multicolumn{3}{|c|}{ Reflexe } \\
\hline & normal & gesteigert & fehlen \\
\hline reflektorischer Starre . . . & $25 \%$ & $60 \%$ & $15 \%$ \\
\hline absoluter Starre . . . . . . & $12 \%$ & $69 \%$ & $19 \%$ \\
\hline normalen Reaktionen & $34 \%$ & $56 \%$ & $10 \%$ \\
\hline
\end{tabular}

Auch diese Tabelle zeigt deutlich, daß im Verhalten der Kniesehnenreflexe bei der absoluten und reflektorischen Pupillenstarre kein durchgreifender Unterschied besteht.

Wir können demnach nicht behaupten, daß die reflektorische Starre vorwiegend bei der tabischen Form der Paralyse zur Beobachtung kommt. Allerdings muß ich einschränkend noch den Umstand erwähnen, daß bei der häufigen relativen Enge der Paralytikerpupillen die Schätzung der Konvergenzreaktion nicht immer leicht und genügend sicher geschieht, und daß sich unsere Zahlen auch dann verschieben, wenn wir nur die Fälle mit vollständiger absoluter oder vollständiger reflektorischer Starre, nicht aber die, bei denen die Reaktionen in dem einen oder anderen Sinne zwar verringert aber doch noch auszulösen sind, zu unseren Berechnungen verwerten. Bei dieser Auswahl zeigten nur $13 \%$ der Fälle mit absoluter Starre, dagegen $36 \%$ der Kranken mit reflektorischer Lichtstarre ein Fehlen der Kniesehnenreflexe.

Jedenfalls finden wir bei der überwiegenden Mehrzahl der Paralytiker $(54 \%)$ eine Steigerung der Sehnenreflexe. Diese Erhöhung der Reflexerregbarkeit kann nun durch sehr verschiedenartige Veränderungen des Nervensystems bedingt, in ihrem Wesen verchieden sein. Zunächst 
finden wir bekanntlich eine Steigerung der Sehnenreflexe bei Erkrankungen der Seitenstränge, der spastischen Spinallähmung, ferner kann aber auch ein Wegfall der cerebralen Hemmung eine starke Reflexsteigerung hervorrufen, ohne daß im Rückenmark selbst Veränderungen der Reflexzentren oder der Reflexbahnen vorliegen. Bei Untersuchungen, die ich mittelst einer genauen graphischen Methode über das Kniesehnenphänomen bei Erkrankungen des Zentralnervensystems anstellte ${ }^{1}$ ), zeigte sich an der Form der gewonnenen Kurven dieser Unterschied sehr deutlich. Leider wurden die Fälle, welche zur Pupillenuntersuchung kamen, nur zum geringen Teil mit dieser Methode untersucht, da dieselbe erst später ausgearbeitet wurde, so daß wir kein exaktes Urteil über das Wesen der beobachteten Reflexsteigerung haben. So weit ich jedoch nach dem Resultate gelegentlicher Versuche vermute, kombiniert sich eine Reflexsteigerung infolge von Seitenstrangerkrankung häufiger mit absoluter Pupillenstarre, während die bei der reflektorischen Starre auftretende eher Folge eines Wegfalles der cerebralen Hemmung sein dürfte. Utber diese Vermutungen kommen wir zurzeit nicht hinaus, und es wird Aufgabe systematischer Untersuchung eines größeren Paralytikermaterials mittelst genauer Pupillenund Kniereflexuntersuchungsmethoden sein, um über diese Frage ins reine $\mathrm{zu}$ kommen.

Im Anschluß hieran wollen wir eine weitere bei der Paralyse vorkommende Folgeerscheinung des Wegfalls cerebraler Hemmung besprechen, den Ausfall der Reaktionen auf psychische und sensible Reize. Wie wir bei unseren früheren Darlegungen bemerkt haben, fehlten diese nicht selten auch bei Paralytikern, die noch Lichtreaktion erkennen ließen, während bei der Lichtstarre die Erweiterung auf psychische und sensorische Reize regelmäßig ausblieb und die Reaktion auf sensible Reize selten und dann auch nur in geringem Umfang er halten war. Bei den 163 Paralytikern waren die psychischen Reflexe nur in $23 \%$ der Fälle, die noch eine deutliche Lichtreaktion erkennen ließen, erhalten. Die Reaktion auf sensible Reize war seltener aufgehoben, immerhin jedoch bei $46 \%$ der Kranken mit erhaltener oder nur eingeschränkter Lichtreaktion, sie war dagegen bei $14 \%$ der Fälle mit Lichtstarre noch nachweisbar.

Neben diesen für die Paralyse wichtigsten Pupillensymptomen finden sich häufig noch andere Veränderungen der Pupillen und der Irisbewegungen bei dieser Krankheit, so vor allem die Pupillenungleichheit. Sie war des öfteren Gegenstand statistischer Untersuchungen und es wurde meist bei ca. 40-60\% der Paralytiker eine Anisokorie beobachtet. Ich fand unter meinen 550 Fällen bei ca. 42\% Pupillen-

1) Weiler, K., Untersuchung des Kniesehnenreflexes beim Menschen. Zeitschr. f. d. ges. Neurol. u. Psychiatrie. Orig. 1, 118. 1910. 
ungleichheit, bei den genau untersuchten 163 in $27 \%$ der Fälle gröbere Unterschiede in der Größe beider Pupillen.

Die Erscheinung der sog. springenden Mydriasis kommt bei der Paralyse nicht selten zur Beobachtung, sie ist jedoch keineswegs ein für diese Krankheit charakteristisches Symptom ebensowenig, wie der Hippus, der auch hie und da, besonders beim paralytischen Anfall sich zeigt.

Außer der vollkommenen oder unvollkommenen reflektorischen Starre kommen naturgemäß bei der Paralyse auch alle jene Pupillen veränderungen vor, die wir weiter oben als Vorläufer der reflektorischen Lichtstarre bezeichneten, verlangsamtes Eintreten der Reaktion, schnelles Nachlassen des Sphinctertonus und Fehlen der sekundären Reaktion. Fuchs konnte bei der Tabes und bei der Paralyse mittelst seiner photographischen Methode nachweisen, daß die mittlere Geschwindigkeit der Lichtreflexbewegung fast stets stark herabgesetzt war. Ich fand bei 21 paralytischen Kranken die Reflexzeit (d. h. Latenz- plus Kontraktionszeit der Iris) nicht wesentlich verlängert, dagegen deutliche Herabsetzung der mittleren Geschwindigkeit und bei einigen Fällen auch Verlängerung der Latenzzeit.

Bei einem großen Prozentsatz (84\%) der Kranken mit nur eingeschränkter oder guter Lichtreaktion fiel der Umstand auf, daß die sekundäre Reaktion fehlte, d. h. daß die Iris auf den stärkeren Reiz nicht lebhafter reagierte, als auf den, der genügte, sie in Bewegung zu versetzen.

Wir dürfen demnach als wesentliche, bei der Paralyse vorkommende Pupillenstörungen die vollkommene und unvollkommene, reflektorische und absolute Pupillenstarre mit ihren Vorläufern, dem verlangsamten Ablauf der Irisbewegungen, dem schnellen Nachlassen des Iristonus, dem Fehlen der sekundären Reaktion, ferner die Anisokorie und das Fehlen der Reaktionen bei psychischen, sensorischen oder sensiblen Reizen, annehmen.

Der praktische Wert dieser Symptome ist für die einzelnen sehr verschieden groß. Finden wir bei einem Menschen mit psychischen Störungen eine reine reflektorische Pupillenstarre, während wir zugleich ausschließen können, daß es sich um einen der seltenen Fälle von Tabespsychose handelt, d. h. jener Erkrankung, bei der zu einer bestehenden Tabes noch bestimmte psychische Störungen, Sinnestäuschungen usw. hinzugetreten sind, so können wir fast mit absoluter Sicherheit die Diagnose ,progressive Paralyse“ stellen, da die Fälle, in denen sich mit einer Tabes eine andere Psychose verbindet, äußerst selten sind. Findet sich dagegen eine absolute Pupillenstarre, so wissen wir nur, daß es sich höchst wahrscheinlich um eine Erkrankung 
des Zentralnervensystems auf der Basis einer früher erworbenen Lues handelt.

Fast den gleichen Wert wie die Feststellung der reflektorischen Starre hat nach meinen bisherigen Untersuchungen das Fehlen der sekundären Reaktion, deren Nachweis allerdings nur unter Zuhilfenahme genauer Messungen gelingt. Wichtig kann endlich die Feststellung des Fehlens der Irisbewegungen auf psychische, sensorische oder sensible Reize werden in Fällen von beginnender Paralyse, bei denen die Pupillen noch keine wesentliche Veränderung der Lichtreaktion erkennen lassen und die im allgemeinen ein der Neurasthenie oder Psychopathie ähnliches Krankheitsbild darbieten, während das Bestehen einer Dementia praecox auszuschließen ist. Die Feststellung, daß die genannten Reflexe fehlen, kann uns dann insofern vor einer Fehldiagnose schützen, als diese Erscheinungen bei der Psychopathie ganz im Gegensatz zur Paralyse besonders deutlich zu sein pflegen.

\section{Syphilis des Zentralnervensystems.}

Während Lähmungen der äußeren Augenmuskeln oft schon im ersten Stadium der Erkrankung an Hirnlues auftreten, beobachtet man Innervationsstörungen der inneren Augenmuskeln meist erst lange Zeit nach der luetischen Infektion. Am häufigsten handelt es sich dabei um eine absolute Pupillenstarre, veranlaßt durch eine Schädigung der zentrifugalen Pupillenfasern. Nach den neuesten Untersuchungen von Wilbrand, Sänger ${ }^{1}$ ) und Nonne ${ }^{2}$ ) ist der Sitz der Störung viel häufiger im Oculomotoriusstamm als in dem den Sphincter innervierenden Teil des Oculomotoriuskerns zu suchen.

Von 48 an Hirnlues Erkrankten, die ich genau untersuchte, wiesen 5 eine vollständige, 16 eine unvollständige absolute Pupillenstarre auf, es zeigten also ca. $44 \%$ der Fälle zentrifugale Pupillenstörungen. Diese Erscheinung war bei einem Drittel der Kranken nur einseitig ausgebildet.

Eine absolute Pupillenstarre beobachtete ich des öfteren auch bei Kindern, die von paralytischen Vätern bzw. Müttern abstammten und die meist außer der Pupillenstörung keine Zeichen einer Erkrankung des Nervensystems darboten. Bei allen ergab die von Herrn Dr. Pla ut ausgeführte Untersuchung des Blutserums einen positiven Ausfall der Wassermannschen Luesreaktion. Ob hier die Pupillensymptome als Vorläufer schwerer syphilitischer oder metasyphilitischer Veränderungen des Nervensystems zu betrachten sind, läßt sich naturgemäß erst nach länger dauernder Beobachtung der Fälle entscheiden. Jedenfalls werden

1) Wilbrand u. Saenger, Die Neurologie des Auges. Wiesbaden.

2) Nonne, M., Syphilis und Nervensystem. Berlin 1909. 
wir auch dann, wenn sich neben dem Pupillenbefunde zunächst keine deutlichen Zeichen psychischer Störung finden lassen, unsere Prognose sehr vorsichtig stellen und zunächst eine antisyphilitische Behandlung vornehmen. Finden wir neben der Pupillenstörung noch erworbene Veränderungen der Psyche, so handelt es sich wohl immer um eine beginnende Erkrankung an Paralyse oder seltener an Hirnlues. Von zwei Kindern, die von denselben luetischen Eltern stammten und die beide einen positiven Ausfall der Wassermannschen Luesreaktion im Blut zeigten, wurde das eine, bei dem sich zunächst neben einer leichten Abnahme der intellektuellen Leistungsfähigkeit nur eine doppelseitige absolute Pupillenstarre feststellen ließ, nach einiger Zeit paralytisch und ging an dieser Krankheit zugrunde.

Unter den von mir untersuchten Fällen von Hirnlues fand sich bei dreien eine einseitige, bei einem eine doppelseitige Ophthalmoplegia interna; die Pupillen waren dabei mydriatisch. Die Ursache dieser Augenmuskelstörung ist bekanntlich sehr häufig in einer syphilitischen Erkrankung zu suchen, so konnte Alexander ${ }^{1}$ ) bei 77 Fällen von Ophthalmoplegia interna in $76 \%$ den Nachweis früherer syphilitischer Infektion erbringen.

Seltener als die absolute Starre ist bei den syphilitischen Erkrankungen die Reflextaubheit, als deren Ursache sich meist eine Schädigung des Chiasma oder der Tractus optici durch syphilitische Wucherungen fand, seltener eine Störung im Nervus opticus, veranlaßt durch Gummata oder meningitische Entzündungsprozesse. Vereinzelt führte die Erkrankung des Chiasma oder der Tractus optici zur hemianopischen Reflextaubheit.

Eine Frage von weitgehendster praktischer Bedeutung ist die, ob unter die Folgeerscheinungen der syphilitischen Erkrankung des Nervensystems auch die reflektorische Pupillenstarre einzureihen ist. Alle Autoren sind sich darüber einig, daß die reflektorische Pupillenstarre bei der Hirnlues zu den seltenen Erscheinungen gehört. Fehlen bei einem Menschen sonstige Zeichen einer Erkrankung an Hirnsyphilis, während er eine reflektorische Pupillenstarre zeigt und leichte psychische Störungen, die an sich vielleicht als neurasthenische Beschwerden gedeutet werden könnten, so dürfte es sich zumeist um den Beginn einer paralytischen viel eher, als um eine luetische Erkrankung des Nervensystems handeln. Unter meinen Kranken fanden sich nur zwei, welche neben Zeichen, die auf eine luetische Hirnerkrankung hinwiesen, eine reflektorische Pupillenstarre darboten. Auch hier müssen wir noch die Frage offen lassen, ob dieses Symptom nicht doch ankündigt, daß bei den Betreffenden eine tabische oder paralytische Erkrankung sich vor-

1) Alexander, Syphilis und Auge. Wiesbaden 1899. 
bereitet, da einerseits in nicht allzu seltenen Fällen bei der Paralyse nebenbei auch syphilitische Erkrankungsprozesse ihre Wirkung entfalten und andererseits Fälle bekannt sind, bei denen die reflektorische Pupillenstarre lange Jahre vor dem Ausbruch der paralytischen Erkrankung beobachtet wurde.

Praktisch wird man daher gut daran tun, Individuen, bei denen sich neben einer reinen reflektorischen Pupillenstarre, ohne sonstige Augenmuskellähmungen, leichte erworbene psychische Veränderungen finden, die sich nicht ungezwungen als einem anderen Krankheitsbilde zugehörig erweisen, für beginnende Paralytiker zu halten.

Die luetische Meningitis kann unter Umständen auch Pupillenstörungen zur Folge haben, die sich in einer Mydriasis oder Miosis äußern, verbunden mit Fehlen oder Trägheit des Lichtreflexes, je nachdem größere oder kleinere Partien der Hirnoberfläche von dem Entzündungsprozeß ergriffen sind. Zumeist sind diese Störungen einseitig ausgebildet.

Sehr häufig finden wir bei der Hirnlues Pupillenungleichheit. Bei meinen Kranken bestand eine solche in $44 \%$ der Fälle. Unregelmäßigkeiten des Irisrandes, träge Reaktion und Hippus kamen ebenfalls zur Beobachtung.

Aus dem Vorhergehenden ergibt sich, daß Pupillenstörungen bei der Hirnsyphilis in der mannigfachsten Form vorkommen, sehr selten handelt es sich dabei um reflektorische, am häufigsten um absolute Pupillenstarre. Da die letztere auch bei der Paralyse nicht selten zu finden ist, kann ihre Feststellung uns zur Differenziäldiagnose zwischen Paralyse und Hirnlues kaum etwas nützen, während das Bestehen einer reflektorischen Starre zunächst sehr für eine Erkrankung an Paralyse spricht. Zeigen sich jedoch neben der absoluten Pupillenstarre noch Lähmungserscheinungen anderer Augenmuskeln, so handelt es sich zumeist um eine luetische Hirnkrankheit. Gerade bei dieser finden wir ja bekanntlich besonders häufig Augenmuskelstörungen, unter denen die Oculomotoriuslähmung, seltener die vollständige, meist die unvollständige im Vordergrund steht. So fand Alexander bei 146 Fällen von Augenmuskelstörung auf syphilitischer Basis bei $63 \%$ den Oculomotorius, bei $33,5 \%$ den Abducens und bei $1,5 \%$ den Trochlearis erkrankt.

Nach alledem müssen wir sagen, daß bei der Hirnlues alle möglichen Pupillenveränderungen vorkommenkönnen, vielfach vereint mit anderen Augenmuskelstörungen, daß es dabei einerseits keine für die Krankheit typische Pupillenstörung gibt, während andererseits die reflektorische Pupillenstarre nur sehr selten eine Begleiterscheinung der syphilitischen Hirnerkrankung ist. 


\section{Dementia praecox.}

Utber Veränderungen der Pupillen und ihrer Reaktionen bei der Dementia praecox war weiter nichts bekannt, als daß sich vielfach Anisokorie feststellen ließ und katatonische Kranke häufig erweiterte $\mathrm{Pu}$ pillen zeigten, bis Bumke darauf aufmerksam machte, daß die Reaktionen auf psychische, sensorische und sensible Reize bei einem großen Teil der an dieser Krankheit Leidenden fehlten. Bumke teilt hierüber in seinem Referat: „Neuere Untersuchungen über die diagnostische Bedeutung der Pupillensymptome" 1 ) unter anderen folgendes mit. Bei der Untersuchung von ca. 200 Fällen von Dementia praecox fand er bei ca. $60 \%$ derselben ein Fehlen der psychischen Reflexe. Er schreibt: „Freilich hat sich die Hoffnung, daß wir nunmehr ein verlässiges „Frühsymptom“ besäßen, nicht erfüllt. Gerade in den Anfangsstadien des Leidens, in denen wir diagnostischer Hilfsmittel am dringendsten bedürfen, fehlt auch dieses katatonische Zeichen leider nur zu oft. Wohl aber ist es auf der Höhe der Krankheit in mehr als der Hälfte der Fälle zu finden, und das ist deshalb nicht unwichtig, weil diese Anomalie der willkürlichen Herstellung, der Simulation, nicht zugänglich ist und weil sie, soviel wir bis jetzt wissen, bei anderen Krankheiten, ausgenommen vielleicht einige Fälle von Imbezillität und manche Endstadien anderer Verblödungsprozesse, nicht vorkommt. Daß das Symptom bei je nach der Fassung des Begriffs mehr oder weniger zahlreichen Fällen von sogenannter "Dementia praecox" dauernd fehlt, das beweist gegen seine diagnostische Bedeutung wenigstens so lange nichts, als wir über die wirkliche Zugehörigkeit dieser Fälle zu dieser Krankheitsgruppe nichts auszusagen vermögen."

Inzwischen waren durch $\mathrm{Hüb}$ ner und Verfasser Nachuntersuchungen

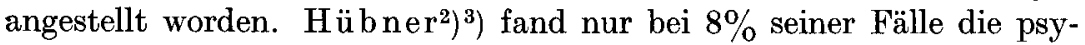
chischen Reaktionen erhalten, bei $75 \%$ fehlten sie und bei den übrigen $17 \%$ waren sie als fraglich zu bezeichnen, bzw. zeigte sich auf sensible Reize allein noch Erweiterung. Aus der letzten Zeit liegen noch Untersuchungen von Sioli ${ }^{4}$ ) über denselben Gegenstand vor, der nur bei einzelnen Fällen von Dementia praecox die psychischen Reaktionen erhalten fand.

1) Münch. med. Wochenschr. 190r. 2313.

2) Hübner, A. H., Untersuchung über die Erweiterung der Pupille auf psychische und schmerzhafte Reize. Münch. med. Wochenschr. 1905, 1170.

3) Derselbe, Untersuchungen über die Erweiterung der Pupillen auf psychische und sensible Reize, nebst einigen allgemeinen Bemerkungen über Pupillenreaktionen. Arch. f. Psych. 41, 1016. 1906.

4) Sioli, F., Ửber die A. Westphalschen Pupillenstörungen bei Katatonie und die Pupillenunruhe und sensible Reaktion bei Dementia praecox. Neurol Centralbl. 1910, Nr. 10. 
Im Gegensatz zu den vorerwähnten Autoren fand $i^{1}{ }^{1}$ ) bei einer Zusammenstellung der Untersuchungsresultate von 85 Kranken, bei denen die Diagnose Dementia praecox gestellt war, nur bei ca. $12 \%$ keine Reaktionen auf psychische Reize, bei weiteren 35\% nur einen geringen Ausschlag, während bei 53\% deutliche Erweiterungsbewegungen der Iris zu sehen waren.

Ich setzte meine Untersuchungen inzwischen fort und kann jetzt über die bei $126 \mathrm{zu}$ dieser Gruppe gehörigen Kranken erhobenen Befunde berichten. Die Untersuchungen erstreckten sich bis ins Jahr 1908 und es wurden jetzt nach Erhebung der Katamnesen alle diagnostisch zweifelhaften Fälle ausgeschaltet. Es blieben von ca. 230 Fällen die genannten 126 übrig, davon gehörten 12 der paranoiden, 35 der hebephrenen und 79 der katatonischen Form der Dementia praecox an. Bei den paranoiden Kranken fehlten die psychischen Reaktionen nur in 2 Fällen, in 4 weiteren waren sie nicht besonders deutlich, die übrigen ließen keine Störung erkennen. Unter den Hebephrenen wiesen 19 keine psychischen Reflexe auf, bei 5 Kranken zeigten sich nur geringe Ausschläge. Bei 24 Katatonischen vermißte ich die Erweiterungsreaktionen und bei weiteren 17 Kranken dieser Gruppe konnte ich nur geringe Irisbewegungen erzielen. Demnach fehlten die psychischen Reaktionen bei ca. $36 \%$ der Untersuchten völlig, bei weiteren $20 \%$ waren sie deutlich vermindert, gut erhalten nur bei $44 \%$. Trennen wir die Fälle, bei denen nur die Reaktionen auf psychische und sensorische Reize ausblieben, von denen, die auch die Erweiterung auf sensible Reize vermissen ließen, so kommen wir zu dem Resultat, daß bei $40 \%$ die psychischen und sensorischen Enwirkungen keine und in weiteren 34\% nur geringfügige Bewegungen der Iris hervorriefen, während die sensible Reaktion nur in den obengenannten $36 \%$ bzw. $20 \%$ vermißt oder vermindert gefunden wurde.

Nach alledem ließen sich also bei meinen Kranken in ca. 74\% der Fälle Störungen der Pupillenbewegungen auf psychische Reize feststellen, in $56 \%$ war zugleich auch die sensible Reaktion gestört. Danach würden meine Untersuchungsresultate im wesentlichen mit den von Bumke, Hübner und Sioli mitgeteilten übereinstimmen," doch glaube ich die Fälle mit eingeschränkter Reaktion nicht so ohne weiteres mitverwenden zu dürfen. Bei meinen an Gesunden angestellten Versuchen zeigten sich keineswegs selten auch nur geringe Ausschläge, besonders bei der Prüfung der Empfindlichkeit für psychische und sensorische Reize, so daß eine Verminderung dieser Reaktionen noch nicht als pathalogisch aufgefaßt werden darf. Andererseits läßt sich jedoch nicht leugnen, daß bei den an Dementia praecox Leidenden verhältnis-

1) Weiler, K., Pupillenuntersuchungen bei Geisteskranken. Zeitschr. f. Psych. 63, 572. 1906.

Z. f. d. g. Neur. u. Psych. O. II. 
mäßig sehr viel häufiger eine Herabsetzung der psychischen Reaktionen gefunden wurde, als bei den Gesunden, so daß es sich dabei wahrscheinlich doch des öfteren um ein beginnendes Erlöschen der Reflexerregbarkeit handelt. Wie dem nun auch sein mag, jedenfalls dürfen wir eine schlechte, unausgiebige psychische Reaktion nicht für gleichbedeutend mit dem völligen Fehlen dieser Pupillenerweiterungsbewegungen halten, so daß wir nur in $40 \%$ der Fälle eine sicher pathologische Veränderung der Reaktionen auf psychische Reize fanden, bei $36 \%$ erstreckte sich die Störung auch auf die sensible Reaktion.

Meine Untersuchungsresultate weichen demnach wesentlich von denen Siolis und Hübners, weniger von denen $\mathrm{Bu} m \mathrm{kes}$ ab. Während Sioli fast bei allen seinen Kranken, Hübner bei $75 \%$ und $\mathrm{Bumke}$ bei ca. $60 \%$ Fehlen der Erweiterungsreaktionen auf psychische Reize feststellen konnte, zeigten von meinen Fällen, wie gesagt, nur $40 \%$ diese Erscheinung.

Suchen wir nach einer Erklärung für den Unterschied der Resultate, so könnte man zunächst die Ursache in der verschiedenen Art der angewandten Untersuchungsmethoden vermuten. Sioli untersuchte unter Zuhilfenahme des Hübnerschen Pupillenapparates, Hübner und Bumke mit der Westienschen Lupe, ich benutzte meinen Apparat. Da alle diese Instrumente gestatten, das Auge der Versuchsperson genügend stark vergrößert zu sehen, kann kaum ein Unterschied in der Sicherheit der Beobachtung entstehen, anders verhält es sich jedoch mit der angewandten Beleuchtung. Während die anderen Autoren das Auge des Untersuchten nur sehr schwach beleuchteten (ca. 7 Meterkerzen), wandte ich sehr viel stärkeres Licht (ca. 25 Meterkerzen) an und zwar, wie ich weiter oben auseinandersetzte, hauptsächlich aus dem Grunde, weil bei geringer Beleuchtung vielfach nur ein ganz schmaler Irissaum übrig bleibt, ein Zeichen dafür, daß der Tonus des Sphincters minimal ist. Da die psychischen Reflexe aber, wie oben ausgeführt, wohl als cerebrale Hemmung des Sphinctertonus gedeutet werden müssen, setzt ihre Auslösbarkeit diesen Tonus voraus. Um vor Fehlschlüssen gesichert zu sein, verstärkte ich von vornherein bei allen meinen Versuchen am Gesunden und Kranken durch stärkere Belichtung den Sphinctertonus, und zwar so weit, daß die von mir angewendeten Reize beim Gesunden immer genügten, eine Hemmung desselben in einer Pupillenerweiterung sichtbar werden zu lassen. Zum Teil, aber wohl doch nur zum geringeren, dürfte daher die Abweichung meiner Resultate in der verschiedenen Untersuchungsmethode beruhen. Wesentlicher als dies scheint mir dagegen die Verschiedenartigkeit des untersuchten Krankenmaterials zu sein. Sioli dienten bei seinen Untersuchungen alte Fälle von Dementia praecox, verblödete Kranke; ein ähnliches Material hatte Hübner, während Bumke häufiger schon 
frischere Fälle beobachtete. Meine Kranken endlich waren meist erst kürzere Zeit erkrankt, d. h. bei ihnen hatte sich die Krankheit erst seit kurzem so weit entwickelt, daß Anstaltspflege notwendig wurde. Wie B u m ke schon hervorhob, scheint der Wegfall der psychischen Reaktionen vielfach erst dann einzutreten, wenn sich schon eine gewisse Demenz eingestellt hat, während in frischen Fällen das Pupillensymptom häufig noch fehlt. Dieser Umstand bedingt wohl im wesentlichen die Abweichung meiner Untersuchungsresultate von denen der genannten Autoren.

Bumke beklagt in seinen Ausführungen, daß seine Hoffnung, in dem Pupillensymptom eine frühzeitig nachweisbare, objektive Krankheitserscheinung der Dementia praecox zu haben, sich nicht erfüllte. Die Berechtigung dieser Klage zeigt zwar auch meine Statistik, doch möchte ich nicht verfehlen, darauf hinzuweisen, daß unter Umständen im Beginn der Erkrankung das Fehlen der psychischen Pupillenreaktion uns allein zeigt, daß diese schwere Krankheit im Entstehen begriffen ist. Ich führe hier auszugsweise die Krankheitsgeschichte eines derartigen Falles an.

Anfang November 1907 wurde eine 21 jährige Krankenpflegerin in die Klinik verbracht. UỦber hereditäre Belastung der Familie konnte nichts in Erfahrung gebracht werden. Die Kranke selbst war früher immer gesund gewesen, litt nie an Krämpfen. Sie lernte gut in der Schule, ging nachher als Zimmermädchen in Dienst, wurde dann Krankenpflegerin. In diesem Beruf war sie seit drei Jahren tätig, hatte viel anstrengenden Nachtdienst. Anfangs fielen bei ihr nur zeitweilige Stimmungsschwankungen auf, leichte depressive Verstimmungen wechselten mit Zeiten, in denen sie auffallend heiter war. Allmählich trat eine Verschlechterung des Zustandes ein; die Kranke fühlte sich sehr müde, war dauernd deprimiert, schrieb an die Angehörigen, es sei am besten, wenn sie auf dem Friedhof läge.

Bei der Aufnahme in die Klinik war sie in einem leichten Depressionszustand. Sie war besonnen, über Ort und Zeit gut orientiert, gab sachgemäß mit leiser Stimme Auskunft. Ihre Auffassung schien erschwert, ihre Antworten erfolgten meist nach langem Besinnen; dabei schien sie leicht ängstlich. Alle ihre Bewegungen geschahen langsam, schlaff. Sich selbst überlassen, saB sie mit bekümmertem Gesichtsausdruck da, nestelte in sonderbarer, unmotivierter Weise an ihrem Haar, zupfte an ihren Strümpfen. Auffallend war eine gewisse dauernde Unruhe in der Gesichtsmuskulatur, Zucken der Mundwinkel, Spitzen der Lippen, Stirnrunzeln, manchmal auch leichtes, unmotiviertes Lächeln. Die Extremitäten waren ebenfalls fast andauernd in Bewegung, sie zupfte mit den Händen an den Kleidern, am Haar, fuhr nach dem Mund usf. Die Beine wurden vorgestreckt; zurückgezogen, sowohl im Sitzen wie auch im Iiegen. Auf die Frage, warum sie das tue, antwortete sie: ,Man muß doch etwas tun, wenn man im Bett liegen muß." Die Bewegungen machten ganz den Eindruck leichter choreatischer Erscheinungen. Intelligenzdefekte waren nicht nachweisbar.

Bei der körperlichen Untersuchung stellte sich die Kranke dar als ein mittelgroßes, kräftig gebautes, gut genährtes Mädchen. Die Haut und die sichtbaren Schleimhäute waren auffallend blaß. Der Conjunctivalreflex und der Würgreflex fehlten. Die Sehnenreflexe waren an den Armen gesteigert, die Kniesehnenreflexo dagegen kaum auslösbar. Es bestand ein leichter Grad von Dermographismus. 
Die Sensibilität war intakt. Katalepsie und Befehlsautomatie fehlten, ebensowenig bestanden negativistische Erscheinungen.

Die Kranke gab noch an, daß sie in letzter Zeit öfter geglaubt habe, man rufe sie mit Namen; wenn sie sich umdrehte, sah sie niemanden. Nachts erschienen ihr schwarze Gestalten, die sie, mit offenen Augen im Bett liegend, drohend auf sich zukommen sah, doch müßten das „,wohl Träume“ gewesen sein. Im übrigen war über Sinnestäuschungen nichts zu erfahren.

Die genaue Pupillenuntersuchung ergah folgendes,

\begin{tabular}{|c|c|c|c|c|c|c|c|c|c|c|c|}
\hline \multirow[t]{2}{*}{ Name } & Alt & Datum & R I & II & $\mathrm{III}$ & iv & L I & II & III & IV & \multirow{2}{*}{$\frac{\text { Konvergenz }}{\mathrm{R}+\mathrm{L}+}$} \\
\hline & 21 & $24 . \mathrm{X} .07$ & 7,3 & 4,5 & 4,0 & 4,5 & 7,3 & 4,5 & 4,0 & 4,5 & \\
\hline & & 30. X. 07 & 7,5 & 4,8 & 3,9 & 4,8 & 7,5 & 4,8 & 3,9 & 4,8 & $\mathrm{R}+\mathrm{L}+$ \\
\hline \multicolumn{2}{|c|}{$\begin{array}{l}\text { Psych. Reaktio- } \\
\text { nen: }\end{array}$} & \multicolumn{10}{|c|}{$\begin{array}{l}\text { Schmerz: R0L } 0 ; \text { Schreck: R0 Lo; } \\
\text { Geistige Arbeit: R } 0 \text { L } 0 \text {. }\end{array}$} \\
\hline \multicolumn{2}{|c|}{ Bemerkungen: } & \multicolumn{10}{|c|}{$\begin{array}{l}\text { Bei der zweiten Untersuchung schien hier und da auf tiefe } \\
\text { Nadelstiche eine minimale Pupillenerweiterung einzutreten. }\end{array}$} \\
\hline
\end{tabular}

Anfangs November 1907 wurde die Kranke auf Wunsch der Angehörigen nach Hause entlassen. Ihr Zustand hatte sich nicht wesentlich geändert. Mit Rücksicht auf den Pupillenbefund wurde die Diagnose „Dementia praecox“ gestellt, jedoch als unsicher bezeichnet.

Anfang Januar 1908 wurde die Kranke neuerdings in die Klinik gebracht, da sie in einen Erregungszustand geraten war. In ihrem körperlichen Zustand hatte sich seit der letzten Beobachtung nichts geändert. Der Pupillenbefund war wie folgt.

\begin{tabular}{|c|c|c|c|c|c|c|c|c|c|c|c|}
\hline Name & Alt & Datum & R I & II & III & IV & $L_{I} \mathbf{I}$ & II & III & IV & Konvergenz \\
\hline & 21 & 13. I. 08 & 6,0 & 4,6 & 3,8 & 4,6 & 6,0 & 4,6 & 3,8 & 4,6 & $\mathrm{R}+\mathrm{L}+$ \\
\hline \multicolumn{2}{|c|}{$\begin{array}{l}\text { Psych. Reaktio- } \\
\text { nen: }\end{array}$} & \multicolumn{10}{|c|}{$\begin{array}{l}\text { Schmerz: R0 L0; Schreck: R0 L 0; } \\
\text { Geistige Arbeit: R0 L } 0 \text {. }\end{array}$} \\
\hline
\end{tabular}

Die Kranke gab an, daß sie seit 14 Tagen wieder Pflegedienst versah. Sie habe viel unter Kopfweh gelitten, sich sehr müde gefühlt. Ihre Stimmung sei nach anfänglicher Besserung wieder schlechter geworden; sie habe viel geweint, da sie merkte, daß sie wieder krank werde. Sie habe sich sehr gehemmt gefühlt, oft das, was sie sagen wollte, nicht herausbringen können. Manchmal habe sie das Gefühl gehabt, als sei sie allen im Wege, als wolle man sich ihrer entledigen. Sinnestäuschungen seien nicht wieder aufgetreten. Am Tage vor ihrer Aufnahme in die Klinik sei sie morgens beim Aufstehen ohnmächtig geworden, habe alles doppelt gesehen und sei sehr sehwindlig gewesen. Im Bett habe sie darauf noch mehrmals Ohnmachtsanwandlungen gehabt, gefürchtet, sie falle aus dem Bett. Als sie hörte, daß sie wieder ins Krankenhaus solle, sei sie erregt geworden.

Die früher aufgefallenen Bewegungsstörungen waren verschwunden; ihr Intellekt zeigte keine Abnahme. In der Klinik beruhigte sich die Kranke bald, beschäftigte sich, war guter Stimmung und zeigte nichts Auffallendes. Ende Januar 1908 wurde sie wieder nach Hause geschickt, mit der Weisung, sich noch 
einige Zeit ruhig zu verhalten. Die Diagnose schwankte zwischen Hysterie und Dementia praecox.

Anfang März desselben Jahres wurde die Kranke aus einem Sanatorium, wo sie sich seit Mitte Februar aufhielt, wieder in die Klinik verwiesen, da sie Neigung zum Zerstören von Gegenständen zeigte, zeitweise halluzinierte und einen ,Suicidversuch" machte. Die Kranke erzählte, daß sie sich im Sanatorium immer beobachtet gefühlt habe; die Leute dort scien ,Spioniere", die Menschen hätten zeitweise doppelte Köpfe gehabt, während die Körper einfach blieben. Man habe sie durch das Schlüsselloch beobachtet, ..ausspioniert". hie und da habe sie auch rufen hören. Um dem Spionieren ein Ende zu machen, habe sie nach einer Wärterin ein Glas geworfen und sich dann mit den Scherben an der Hand verleizt (über Pulsader), jedoch ohne Suicidabsicht.

Die Kranke zeigte jetzt in noch stärkerem Maße als früher die eigentümlichen, manirierten, triebartigen Bewegungen, so machte sie z. B. Anstalten, den Arzt an der Nase zu fassen, hielt aber mitten in der Bewegung inne, fuhr sich dann mit dem Finger an die Lippen; dieselben Bewegungen wiederholte sie häufig hintereinander. Sie zeigte deutliche Echolali und Echopraxie. Bei den Versuchen erklärte sie: ,.Sie ruinieren mir ja meinen ganzen Willen." Sie war dabei nicht imstande, den Antrieben, Bewegungen nachzumachen bzw. Gesprochenes zu wiederbolen, zu widerstehen. Deutliche Intelligenzdefekte waren nicht nachweisbar. Im körperlichen Zustand hatte sich nichts geändert. Der Pupillenbefund war folgender.

\begin{tabular}{c|c|c|c|c|c|c|c|c|c|c|c}
\hline \hline $\begin{array}{c}\text { Name } \\
=\end{array}$ & Alt & Datum & R I & II & III & IV & L I & II & III & IV & Konrergenz \\
\hline & 21 & 5. III. 08 & 5,8 & 4,4 & 3,6 & 4,4 & 5,8 & 4,4 & 3,6 & 4,4 & R- L -
\end{tabular}

Psych. Reaktionen:

Schmerz: R0 L 0; Schreck: R 0 L 0 ; Geistige Arbeit: R $0 \mathrm{~L} 0$.

Mitte März 1908 wurde die Kranke nach Hause abgeholt. Es konnte jetzt kein Zweifel mehr an der Diagnose Dementia praecox bestehen.

In diesem Falle wies zunächst nur der Pupillenbefund darauf hin, daß es sich um eine derartige Erkrankung handeln könne, während das psychische Zustandsbild eher im Sinne einer psychogenen Störung, einer Hysterie, zu deuten war. Der Fall zeigt deutlich, wie wertvoll unter Umständen die Untersuchung der psychischen Reflexe auch zu Beginn der Dementia praecox sein kann.

Meines Erachtens darf man das Bumkesche Symptom in seiner vollen Ausbildung als geradezu pathognomonisch für diese Krankheitsform erachten, wenn eine sonstige organische Hirnkrankheit ausgeschlossen werden kann. Jedenfalls konnte ich bisher weder bei Gesunden, noch bei Psychopathen, Hysterischen, Epileptischen, Alkoholisten und Manisch-depressiven jemals ein Erloschensein der psychischen Reflexe feststellen.

Ob das Symptom bei fortgeschrittenen Fällen von Dementia praecox regelmäßig auftritt, entzieht sich meiner Beurteilung. Nach den Untersuchungen Siolis und Hübners scheint ja nur ein geringer Prozentsatz übrig zu bleiben, bei dem diese Störung dauernd fehlt, doch dürfte 
der Wert des Symptoms auch dann, wenn es bei einer größeren Anzahl von Kranken im Verblödungsstadium vermißt würde, nicht wesentlich vermindert erscheinen, ebenso wenig wie der diagnostische Wert der Pupillenstarre bei der Paralyse deshalb geringer wird, weil nicht alle Paralytiker dies Symptom aufweisen. Alte Fälle von Dementia praecox standen mir nur selten zur Verfügung; bemerkenswert scheint mir jedoch die Beobachtung, daß sich bei Kranken mit schon jahrelang bestehender paranoider Demenz nur sehr selten ein Fehlen der psychischen Reflexe nachweisen ließ. Vielleicht deutet auch dieser Umstand, wie mancher andere, darauf hin, daß zwischen dieser und den anderen Formen der Dementia praecox doch ein wesentlicher Unterschied besteht, daß es sich möglicherweise um zwei ganz andersartige Krankheitsprozesse handelt.

Bei keinem der von mir Untersuchten sah ich die einmal verschwundenen, psychischen Reflexe bei gelegentlicher Nachuntersuchung wieder auslösbar, trotzdem sich das Zustandsbild manchmal wesentlich verändert hatte und keineswegs immer in dem Sinne, daß der betreffende Kranke stumpfer, gleichgültiger war als bei der früheren Untersuchung; manche waren vielmehr erregter.

Die Pupillenweite war bei der Dementia praecox vielfach größer als bei den Gesunden, die weitesten Pupillen fand ich bei den ,,gespannten" Katatonikern. Bei diesen Kranken zeigte sich oft auch die Lichtreaktion beeinträchtigt, indem der Irisausschlag geringer war als bei den Gesunden. Bei Zeitmessungen fand ich keine wesentlichen Abweichungen der absoluten Zahlen gegenüber der Norm, die mittlere Geschwindigkeit der Irisbewegung war jedoch verlangsamt. Eine Erklärung dieser Erscheinungen ließe sich am einfachsten wohl in der Annahme einer verstärkten Hemmung des Lichtreflexes, ausgelöst durch Reizung der Hirnrinde, finden. Gerade bei diesen sogenannten „gespannten“"Kranken läuft man übrigens leicht Gefahr, fälschlicherweise ein Fehlen der psychischen Reflexe anzunehmen, da offenbar hier von vornherein eine starke Hemmung des Sphinctertonus statthat. Untersucht man bei geringer Beleuchtung, so scheinen die Reaktionen auf psychische Reize zu fehlen, verstärkt man jedoch das Licht, so lassen sie sich häufig noch auslösen.

In seltenen Fällen zeigt sich bei der Dementia praecox das von A. Westphall) als „katatonische Pupillenstarre“ beschriebene Phänomen, bei dem vorher normal reagierende Pupillen unter Veränderung ihrer Form, sie nehmen querovale Gestalt an, absolut starr werden. Nach kürzerer oder längerer Zeit verschwindet das Symptom, um regellos wiederzukehren. Während ich bei meinen Untersuchungen bisher

1) Westphal, A., UUber ein im katatonischen Stupor beobachtetes Pupillenphänomen usw. Deutsche med. Wochenschr. 1907. 
keine entsprechenden Beobachtungen machen konnte, beschrieb Sioli in seiner vorerwähnten Arbeit 5 Fälle von Katatonie, bei denen das Westphalsche Symptom deutlich zu sehen war.

Als Störungen der Pupillenreaktionen lernten wir also bei der vorliegenden Krankheitsgruppe einerseits solche vorübergehender Natur kennen, Einschränkung der Lichtreaktion, die sich in seltenen Fällen zur absoluten Starre steigerte, andererseits fanden sich dauernde Veränderungen der Irisinnervation, indem eingroßer Prozentsatzder Untersuchten die Reaktionen auf psychische, sensorische und sensible Reize vermissen ließ. Die Pupillen waren vielfach weiter als in der Norm, vorübergehend zeigten sich auch Veränderungen der Form (ovale Pupillen).

\section{Maniseh-depressives Irresein.}

Genauere Untersuchungen über die Pupillenverhältnisse bei Manischen und Melancholischen stellte meines Wissens nur Fuchs an, während von anderen Autoren gelegentlich bemerkt wird, daß manische Kranke öfter weitere Pupillen mit teils besonders schneller, teils unausgiebiger Lichtreaktion zeigten; andere wieder sahen auch miotische $\mathrm{Pu}$ pillen bei dieser Krankheit. F u chs berichtet über einen Fall von Manie, 6 Fälle von Melancholie, einen der letzteren bezeichnet er als präsenile Melancholie, so daß es zweifelhaft erscheinen darf, ob er zur Krankheitsform des manisch-depressiven Irreseins gehört. Er fand die Reaktionen im allgemeinen etwas verlangsamt.

Ich untersuchte Kranke, die an manisch-depressivem Irresein litten, nicht systematisch, d. h. nicht wahllos, sondern hauptsächlich nur solche Fälle, bei denen die Diagnose zunächst nicht ganz sicher erschien. Es handelte sich meist um Stuporfälle oder Kranke, bei denen neben einem manischen oder depressiven Symptomkomplex eigentümliche paranoide Wahnbildungen bestanden. Ich kann im ganzen über 56 Fälle berichten. Die Pupillenweite war sehr wechselnd, miotische Pupillen fand ich nie, dagegen vielfach mydriatische. Die Lichtreaktion, auch die sekundäre, war bei allen Kranken gut auslösbar, bei den Fällen mit starker Mydriasis war der Irisausschlag manchmal etwas geringer als in der Norm; die Reaktionszeiten waren dabei nicht wesentlich verändert.

Hauptsächlich interessierte natürlich das Verhalten der psychischen Reflexe. Bei keinem meiner Fälle vermißte ich diese ganz, bei ungefähr $10 \%$ derselben waren sie nicht besonders ausgiebig, und zwar handelte es sich dabei nur um ältere Kranke mit paranoiden Symptomen. Im manischen oder depressiven Stupor dagegen waren die sensiblen, wie 
auch die psychischen Reaktionen deutlich und ausgiebig zu sehen. Demnach dürften wir in dem B u m k eschen Pupillensymptom ein brauchbares Hilfsmittel zur Differenzialdiagnose des verschiedenen Wesens von Stuporfällen besitzen, das um so wertvoller erscheint, als diese Unterscheidung bekanntlich meist mit großen Schwierigkeiten verknüpft ist. Meines Erachtens sind wir berechtigt, stuporöse Kranke, die bei genauer, wiederholter Prüfung keine psychischen Reaktionen erkennen lassen und die nicht an einer anderen organischen Hirnkrankheit leiden, als sicher der Dementia-praecox-Gruppe zugehörig zu betrachten.

Das wesentliche Ergebnis der Untersuchungen an manisch - depressiven Kranken besteht also darin, daß die Erweiterungsreaktionen dabei nie vermißt werden.

\section{Psychopathie, Hysterie und Epilepsie.}

Wenn ich die bei diesen drei Krankheitsformen gewonnenen Untersuchungsergebnisse hier im Zusammenhang bespreche, so geschieht das deshalb, weil sich herausstellte, da $ß$ sich in den Pupillenverhältnissen dieser Kranken untereinander keine wesentlichen Unterschiede feststellen ließen, abgesehen von den in den hysterischen bzw. epileptischen Anfällen beobachteten Störungen.

Wie aus der weiter oben dargestellten Tabelle (Fig. 43) deutlich hervorgeht, war die Pupillenweite sowohl bei schwacher wie bei starker Beleuchtung der Augen durchschnittlich größer als beim Gesunden, desgleichen der Irisausschlag bei der Lichtreflexbewegung. Die Reaktionen auf psychische und sensible Reize, sowie die Pupillenunruhe waren meist verstärkt.

Alle diese Erscheinungen lassen sich ungezwungen als Ausdruck gesteigerter nervöser Reizbarkeit erklären, die bekanntlich allen diesen drei Krankheitsformen eigentümlich ist. Vorwiegend äußert sich diese erhöhte Empfindlichkeit des Nervensystems in der den Sphinctertonus hemmenden Wirkung der Rindenelemente. Wenn auch die Lichtreaktion sehr ausgiebig und schnell zu erfolgen pflegt - die Untersuchungen Lindes ${ }^{1}$ ) ergaben eine Verkürzung der Reaktionszeiten und erhöhte mittlere Geschwindigkeit der Irisbewegungen so geht die starke Pupillenverengerung doch bald, früher als in der Norm, zurück. Diese Erscheinung könnte ja allerdings in einer stärkeren Ermüdbarkeit der den Reflex vermittelnden Elemente begründet sein, wahrscheinlich verhält sich jedoch die Sache so, daß die erregende Wirkung des Lichteinfalls sofort von einer hemmenden Innervation seitens der Hirnrinde gefolgt ist, die gewissermaßen als

1) Linde, M., Pupillenuntersuchungen an Epileptischen, Hysterischen und Psychopathischen. Kraepelins psychol. Arb. 5, 210. 1907. 
eine Verstärkung der normalen sekundären Erweiterung (siehe unter Physiologie der Lichtreflexbewegung) betrachtet werden kann. Die Pupille wird daher bald wieder weiter und bleibt, nach Adaptation an den Lichtreiz, weiter als in der Norm. Gerade diese abnorm starke Reizbarkeit erschwert bei den Psychopathen, weniger bei den Epileptischen, am meisten bei den Hysterischen, die Feststellung der psychischen Reaktionen, so paradox es auch klingen mag, daß gerade die Reflexbewegung, deren vermittelnde Elemente so leicht erregbar sein sollen, schwer auszulösen ist. Die dauernde Hemmung der Lichtreflexe ist aber bei diesen Kranken vielfach so stark, daß bei Anwendung geringer Beleuchtung nur noch ein ganz schmaler Irissaum übrig bleibt. Damit ist dann auch die Wirkungsmöglichkeit der Rindenhemmung erschöpft, und wir erzielen durch Reize keine stärkere Pupillenerweiterung. Steigern wir jedoch den Spinctertonus durch vermehrte Belichtung, so lassen sich die psychischen Reflexe leicht und sogar meist deutlicher als in der Norm auslösen. Das Innervationsgleichgewicht der Lichtwirkung und der psychischen Reize ist hier offenbar viel labiler als in der Norm und bei den geringsten Anlässen gewinnt die hemmende Gewalt der Rindeninnervation das Ubergewicht.

Die Tatsache, daß die Pupillenbewegungen bei den vorliegenden Krankheitsgruppen meist vergrößert und beschleunigt sind, ist insofern von größerer Bedeutung, als sie uns in manchen Fällen die Differentialdiagnose gegenüber anderen Erkrankungen des Nervensystems erleichtern kann. So wird z. B. im Zweifelsfall eine gesteigerte Empfindlichkeit der Iris für psychische Einflüsse eher für eine der genannten Krankheiten als für Dementia praecox oder eine andere organisch bedingte Gehirnkrankheit sprechen. Desgleichen werden wir bei einem Menschen mit neurasthenischen Beschwerden zunächst keine Bedenken haben, die Diagnose Neurasthenie oder Psychopathie zu stellen, wenn die Pupillenbewegungen besonders deutlich zu sehen sind, während wir bei deutlich nachweisbarer Einschränkung der Reaktionen unsere Prognose mit großer Vorsicht stellen müssen. Das Fehlen der psychischen Reflexe oder der Lichtreaktion wird uns veranlassen, nach weiteren Zeichen einer organischen Hirnerkrankung zu suchen.

Außer den erwähnten Pupillenveränderungen fand sich bei einem großen Prozentsatz unserer Kranken (20\%) Anisokorie; (untersucht wurden 120 Fälle).

Fuchs fand bei seinen Messungen die Geschwindigkeit der Reaktionsbewegungen bei der Epilepsie ebenfalls vergrößert, desgleichen bei der Neurasthenie. Die von ihm bei Hysterischen gefundenen Werte für die mittlere Geschwindigkeit der Pupillenreaktionen ,bewegten sich dagegen unter den sonstigen Durchschnittszahlen, und es wäre demzufolge als Typus der hysterischen Pupillenreaktion eine langsamere, 
trägere Reaktion anzusehen, als z. B. bei Neurasthenie oder Epilepsie besteht". Im Gegensatz zu Fuchs, der nur wenige Fälle untersuchte, konnten wir einen Unterschied in der Reaktionsweise bei diesen Krankheiten nicht feststellen. Im übrigen decken sich die Resultate dieses Forschers auch insofern mit den unseren, als er meist erweiterte Pupillen und vermehrte Pupillenunruhe dabei beobachtete.

Während früher allgemein die Anschauung galt, daß zu den differentialdiagnostisch wichtigsten Symptomen des epileptischen Anfalls die Pupillenstarre gezählt werden müsse, in der Annahme, daß es im hysterischen Anfall nie zu einer Aufhebung des Lichtreflexes komme, kann nach den neueren Forschungsergebnissen kein Zweifel mehr an der Irrtümlichkeit dieser Auffassung bestehen. Die Mitteilungen von Westphal, Karplus, Hoche, Bumke u. a. mußten uns leider überzeugen, daß dieses bis dahin für stichhaltig angenommene Kriterium des epileptischen Anfalls nicht mehr als solches betrachtet werden darf. Es handelte sich bei den beobachteten Störungen immer um absolute Pupillenstarre, die meist mit Mydriasis, in seltenen Fällen bei Hysterischen mit Miosis verknüpft war. Im übrigen verweise ich auf die bei der Besprechung der absoluten Pupillenstarre hierüber gemachten Erörterungen. Noch besonders bemerkenswert ist der Umstand, daß die Pupillen bei der hysterischen, ähnlich wie bei der katatonischen Starre, manchmal eine ovale, verzerrte Gestalt annehmen. Absolute Stäre der Pupillen wurde auch in epileptischen Dämmerzuständen beobachtet; ich selbst beobachtete eine kurz vorübergehende in der Absence.

Wir konnten als gemeinsame Eigenschaften der Pupillen bei der Epilepsie, Hysterie und Psychopathie Vergrößerung ihres Durchmessers und der Reaktionsbewegungen, verbunden mit Beschleunigung ihres Ablaufs feststellen. Die psychischen Reflexe waren zumeist verstärkt, die Pupillenunruhe erschien vermehrt. Die Pupillenstarre im epileptischen Anfalle ist eine absolute, sieko $m \mathrm{mt}$ a uch in Dä $m$ merzuständen und bei Absencen vor. Auch im hysterischen Anfall kann es zu absoluter Starre der Pupille mit Mydriasis oder auch Miosis kommen. Die Pupillen sind dabei manchmal verzogen, oval.

\section{Chronischer Alkoholismus.}

Wir besitzen eine ganze Reihe von Arbeiten, die sich mit den Pupillenstörungen bei chronischen Alkoholisten beschäftigen und denen zum Teil ein sehr großes Untersuchungsmaterial zur Grundlage diente. 
Die ersten größeren Untersuchungen wurden von Thomsen $\left.{ }^{1}\right)^{2}$ ), Siemerling ${ }^{3}$ ), Moeli ${ }^{4}$ ) und Uhthoff ${ }^{5}$ ) angestellt. Das übereinstimmende Ergebnis dieser Arbeiten war die Feststellung der Tatsache, daß Pupillenstörungen bei Alkoholisten nicht gerade sehr häufig, nur bei ca. $6 \%$ der Fälle, zu finden waren. Vereinzelt zeigte sich eine isolierte reflektorische Lichtstarre, die meist aber nur vorübergehend bestand. Moeli hielt es auf Grund sehr umfassender Versuche für sehr zweifelhaft, ob eine vollständige oder länger dauernde Lichtstarre wirklich als eine durch den Alkoholmißbrauch entstandene Störung aufzufassen sei. Vorübergehende Lichtstarre dagegen kommt zweifellos, wenn auch sehr selten, vor, Uh th off sah sie in $1 \%$ seiner Fälle. Die häufigste, bei chronischen Alkoholisten beobachtete Pupillenstörung ist die unvollständige oder vollständige absolute Starre. Diese bildet sich ebenfalls manchmal zurück und dann kann zeitweise die Konvergenzreaktion besser auslösbar sein als die Lichtreaktion und dadurch das Bild einer unvollständigen reflektorischen Starre sich darbieten. Eine Herabsetzung, Einschränkung der Lichtreaktion stellte Uhthoff bei 2,5\% seiner (1000) Fälle fest.

Bei der Durchsicht von 900 Krankheitsgeschichten, die über Personen mit rein alkoholischen Störungen (Lues sicher ausgeschlossen) - chronischer Alkoholismus, Delirium, Alkoholwahnsinn, Korssakowsche Psychose - in der psychiatrischen Klinik in München geführt waren, fand ich bei nur $6 \%$ der Fälle die Lichtreaktion als träge bezeichnet, bei keinem fehlte sie vollständig. Neussel16) berichtet in seiner, unter meiner Leitung angefertigten Arbeit über 63 mit meiner Methode genau untersuchte Fälle und kommt zu dem Schlusse, daß sich die Lichtreaktion bei dem weitaus größeren Teil derselben ausgiebiger erwies als beim Gesunden; nur bei etwa $3 \%$ fand er eine Einschränkung. Im übrigen zeigten sich keine wesentlichen Abweichungen von der Norm. Ich selbst untersuchte noch 49 Alkoholkranke, so daß unser vergleichbares Untersuchungsmaterial 112 Personen umfaßt. Das Gesamtresultat unserer Beobachtungen läßt sich dahin zusammenfassen, daß

1) Thomsen, Zur Pathologie und pathologischen Anatomie der akuten kompletten (alkoholischen) Augenmuskellähmung (Polioencephalitis acuta superior Wernicke). Arch. f. Psych. 19, 185. 1890.

2) Derselbe, Zur Klinik und pathologischen Anatomie der multiplen Alkoholneuritis. Arch. f. Psych. 21, 806. 1890.

s) Siemerling, Statistische und klinische Mitteilungen ïber Alkoholismus usw. Charité-Ann. 16, 373. 1891.

4) Moeli, Weitere Mitteilungen ïber die Pupillenreaktion Geisteskranker. Berl. klin. Wochenschr. 1897, 373.

5) Uhthoff, Untersuchungen über den Einfluß des chronischen Alkoholismus auf das menschliche Sehorgan. v. Graefes Arch. f. Ophthalmol. 32, 95. 1886.

6) NeuBel, L., Das Verhalten der Pupillen bei Alkoholismus. Kraepelins psychol. Arbeiten 5, 408. 1908. 
zunächst die Pupillenweite der Alkoholisten durchschnittlich etwas hinter der Norm zurückblieb. Andere wiesen wiederum sehr weite Pupillen auf, die auch sehr ausgiebig auf Lichteinfall reagierten, während bei den engeren Pupillen der pupillomotorische Erfolg des Lichtreizes manchmal geringer war als beim Gesunden. Ca. $8 \%$ der Fälle zeigten leichtere Grade von Anisokorie. Die Reaktionszeit hielt sich meist in der normalen Breite, manchmal war sie verkürzt, bei einigen wenigen schien sie verlängert.

Vergleichen wir hiermit die Ergebnisse der Messungen, die Fuchs bei Alkoholikern anstellte, so finden sich einige Abweichungen. Dieser Autor fand die Pupillenweite nicht wesentlich von der Norm verschieden, dagegen die mittlere Geschwindigkeit der Reaktionsbewegung verlangsamt. Bei einigen, es handelt sich um Fälle, die zeitweise auch an epileptischen Anfällen litten, war sie dagegen erhöht. Fuchs kommt zu der Anschauung, daß sich die Trägheit der Pupillenreaktion proportional zur Schwere des Zustandsbildes zu verhalten scheine. Bei der Durchsicht seiner Tabellen zeigt sich, daß die absolute Dauer der Pupillenreaktionen bei seinen Alkoholisten nicht größer, vielfach sogar kleiner ist als in der Norm; daß die Verlangsamung der Geschwindigkeit der Reaktionsbewegung daher nur durch den geringeren Ausschlag derselben zustande kommt. Seine Messungen decken sich demnach mit den Ergebnissen unserer Feststellungen der Reaktionszeiten im wesentlichen. Mir scheint es nun sehr fraglich, ob wir überhaupt sehr viel Wert auf die Berechnung der mittleren Geschwindigkeit der Pupillenbewegungen legen dürfen, da einerseits die von der Iris zurückgelegten Wege sehr klein und die Reaktionszeiten relativ groß sind, wodurch kleine Veränderungen der Größe der Irisbewegung den Wert der mittleren Geschwindigkeit sehr stark ändern und andererseits Versuche zeigten, daß die Ausschläge der Iris sich bei verschiedenen Versuchen bei demselben Individuum ungleich groß erwiesen, während die Reaktionszeiten dabei fast ganz unverändert blieben. Die absolute Dauer der Bewegungen dürfte daher für ihre Beurteilung maßgebender sein, als die dabei entwickelte Geschwindigkeit. Jedenfalls zeigten sich die Reaktionszeiten sowohl bei unseren Messungen, wie bei denen von Fuchs vielfach verkürzt, selten verlängert.

Für die alkoholischen Veränderungen der Pupillenreaktionen finden wir in der Literatur die verschiedenartigsten Ursachen angegeben. Die beobachteten Lähmungserscheinungen können sowohl durch Stammwie auch Kernaffektionen veranlaßt sein. Eine Entzündung der Sehnerven wird bekanntlich nicht selten durch den chronischen Alkoholmißbrauch erzeugt und kann zur Reflextaubheit der Retina führen. $\mathrm{Ob}$ die zentrifugalen Pupillenstörungen ebenfalls häufiger einer Neuritis des Oculomotorius oder der Ciliarnerven ihre Entstehung verdanken, 
mag zweifelhaft sein, jedoch ist die Berechtigung dieser Annahme im Hinblick auf die sonst häufig im Gefolge des chronischen Alkoholismus auftretende Polyneuritis nicht ganz unwahrscheinlich. Rai $\operatorname{man}^{1}{ }^{1}$ ) vertritt dagegen die Anschaung, da $\beta$ die auf alkoholischer Basis entstandenen Augenmuskellähmungen durch Kernläsionen veranlaßt seien, da er bei der anatomischen Untersuchung derartiger Fälle meist Blutungen und Gefäßveränderungen im Mittelhirn, in der Gegend der Augenmuskelkerne fand. Allerdings waren die Nervenkerne nur selten degeneriert. Die Nerven der gelähmten Augenmuskeln waren meist normal oder nur unbedeutend affiziert. Die von Raiman $n$ gefundenen Tatsachen genügen, wie er selbst zugibt, zunächst noch nicht, für alle alkoholischen Augenmuskellähmungen mehr oder weniger ausgeprägte Kernstörungen als Ursache anzunehmen, während bei der Polioencephalitis haemorrhagica superior ausnahmslos Kernläsionen die Pupillenerscheinungen veranlassen.

Wie aus meinen Darlegungen hervorging, fanden sich bei unseren Alkoholisten nur selten deutlichere Störungen der Pupilleninnervation. Als Ursache hierfür dürfen wir vielleicht die Tatsache heranziehen, daß der Alkoholismus in Bayern von dem der meisten anderen deutschen Länder insofern verschieden ist, als es sich dabei viel mehr um Bierals um Wein- oder Schnapsgenuß handelt. Die alkoholischen Störungen sind offenbar sehr verschiedenartig, je nach der Art der genossenen Alkoholika. So entspricht denn auch der bekannten Tatsache, daß Alkoholdelirien meist oder ausschließlich nur nach voraufgegangenem Schnapsmißbrauch auftreten, die geringe Zahl der in München jährlich zur Beobachtung kommenden Deliranten (ca. 30). Sehr selten sind hier auch Erkrankungen an Korssakowscher Psychose (jährlich kaum 8 Fälle), während im übrigen durchschnittlich jährlich über 300 Individuen infolge Alkoholmißbrauchs für längere oder kürzere Zeit Aufnahme in der Klinik finden müssen.

$\mathrm{Ob}$ die von uns gefundenen Veränderungen der Pupillenreaktionen lediglich auf Kosten des Alkoholmißbrauches zu setzen sind, erscheint mir fraglich. Die Annahme, daß die bei einem Teil der Fälle beobachtete Verkürzung der Reflexzeit in einer Steigerung der nervösen Reizbarkeit, die wir auch beim Alkoholexperiment eintreten sahen, begründet sei, hat ja manches für sich. Wir dürfen jedoch den Umstand nicht vergessen, daß unter den chronischen Alkoholisten sehr häufig, vielleicht in der Mehrzahl, von Haus aus minderwertige, psychopathische Menschen sind, so daß die erwähnten Pupillenerscheinungen auch schon, wie bei anderen nichttrinkenden Psychopathen, bestanden haben können, bevor noch eine spezifisch-alkoholische Schädigung Platz griff. Die

1) Raimann, Zur Lehre von der alkoholischen Augenmuskellähmung. Jahrb. f. Psychiat. u. Neurol. 20, 36. 1901. 
andere Gruppe der Kranken, die träge unausgiebige Reaktionen erkennen ließen, zeigte zum Teil arteriosklerotische Veränderungen, doch erscheint es unwahrscheinlich, diese als ursächliches Moment für die Pupillenstörungen anzusehen, vielmehr dürften hier neuritische Erkrankungen, vielleicht auch leichte Kernläsionen, eine Rolle spielen jedenfalls ist unser Krankenmaterial nicht geeignet, in der Frage nach den Entstehungsursachen der alkoholischen Pupillenstörungen mehr Klarheit zu verschaffen.

$\mathrm{Nach}$ den in der Literatur niedergelegten Befunden und auf Grund unserer Untersuchungen treten nur bei einer geringen Prozentzahl der Alkoholkranken Pupillenstörungen auf. Meist handelt es sich dabei um absolute Starre, Reflextaubheit oder Trägheit der Lichtreaktion, die manchmal auch sehr wenig ausgiebig erscheint. Eine rein alkoholisch bedingte, dauernde, reflektorische Pupillenstarre scheint nicht vorzukommen. 